\title{
COMPACTING BIOMASS AND MUNICIPAL SOLID WASTES TO FORM AN UPGRADED FUEL
}

Final Technical Report*

Period covered: 12/01/98-05/31/00

By

Henry Liu and Yadong Li

Capsule Pipeline Research Center

College of Engineering

University of Missouri-Columbia

Columbia, Missouri 65211-2200

November 2000

DOE Award No. DE-AC26-98FT

* The Quarterly Report for the period April 1 to May 31, 2000 is incorporated herein. 


\section{DISCLAIMER}

This research project, entitled "Compacting Biomass and Municipal Solid Waste to Form an Upgraded Fuel," was sponsored by the Solid Fuels \& Feedstocks Grand Challenge Program, National Energy Technology Laboratory (NETL), U.S. Department of Energy (DOE), under Contract DE-AC26-98FT40155. Any opinion expressed in this report is that of the contractor and not necessarily that of the U.S. Department of Energy. 


\section{ACKNOWLEDGMENT}

This project was sponsored by the Solid Fuels \& Feedstocks Grand Challenge Program, National Energy Technology Laboratory (NETL), U.S. Department of Energy (DOE). The authors appreciates the sponsorship of the project by DOE, and the valuable comments and suggestions of Mr. Carl Maronde, the DOE Project Monitor, during the course of the project. The authors would also like to acknowledge the donation of materials, services, and/or consultations provided by the following persons and corresponding institutions or companies:

- LaBeme Brondel, Missouri Department of Natural Resources, Division of Energy

- Gregg Coffin, University Missouri-Columbia Power Plant

- Stephen Foster, Foster Brothers Wood Products, Inc.

- Robert Gillette, Donald Gabelsberger, and Melanie Green, Central Electric Power Cooperative

- Ted Gundlach, Gundlach Machine Company

- Ed Kramer, American Pulverizer Campany

- Lowell Patterson, Dennis Pendergrass, and Richard Wieman, City of Columbia Public Works

Allen Thompson, Department of Biological \& Agricultural Engineering, University of Missouri-Columbia

The P.I. of this project was Henry Liu, Professor of Civil and Environmental Engineering and Director of Capsule Pipeline Research Center, University of Missouri-Columbia. Other senior investigators included William J. Burkett, Senior Research Associate, CPRC; Bruce Cutter, Associate Professor of Forestry; Rex Gish, Manager, Engineering Laboratory; Yadong Li, Research Assistant Professor of Capsule Pipeline Research Center; Yuyi Lin, Associate Professor of Mechanical and Aerospace Engineering; Thomas Marrero, Professor of Chemical Engineering (ChE); Terry Maynard, Business Manager, CPRC; and Carla Roberts, Senior Secretary, CPRC. Yadong Li served as the Technical Manager and Terry Maynard served as the Business Manager of the project.

Graduate Research Assistants include: Rusheng Hu, Jonathan Wenzel, and Ou Zhang. Undergraduate Research Participants include Jamie Graham, Jamie Kiesler, Meng-Yaw Kueh, Shyue-Lee Lo, and Amy Morgan. 
Biomass waste materials exist in large quantity in every city and in numerous industrial plants such as wood processing plants and waste paper collection centers. Through minimum processing, such waste materials can be turned into a solid fuel for combustion at existing coalfired power plants. Use of such biomass fuel reduces the amount of coal used, and hence reduces the greenhouse effect and global warming, while at the same time it reduces the use of land for landfill and the associated problems. The carbon-dioxide resulting from burning biomass fuel is recycled through plant growth and hence does not contribute to global warming. Biomass fuel also contains little sulfur and hence does not contribute to acid rain problem. Notwithstanding the environmental desirability of using biomass waste materials, not much of them are used currently due to the need to densify the waste materials and the high cost of conventional methods of densification such as pelletizing and briquetting. The purpose of this project was to test a unique new method of biomass densification developed from recent research in coal log pipeline (CLP). The new method can produce large agglomerates of biomass materials called "biomass logs" which are more than 100 times larger and 30\% denser than conventional "pellets" or "briquettes." The Phase I project was to perform extensive laboratory tests and an economic analysis to determine the technical and economic feasibility of the biomass log fuel (BLF).

A variety of biomass waste materials, including wood processing residues such as sawdust, mulch and chips of various types of wood, combustibles that are found in municipal solid waste stream such as paper, plastics and textiles, energy crops including willows and switch grass, and yard waste including tree trimmings, fallen leaves, and lawn grass, were tested by using this new compaction technology developed at Capsule Pipeline Research Center (CPRC), University of Missouri-Columbia (MU). The compaction conditions, including compaction pressure, pressure holding time, back pressure, moisture content, particle size and shape, piston and mold geometry and roughness, and binder for the materials were studied and optimized. The properties of the compacted products-biomass logs-were evaluated in terms of physical, mechanical, and combustion characteristics. An economic analysis of this technology for anticipated future commercial operations was performed.

It was found that the compaction pressure and the moisture content of the biomass materials are critical for producing high-quality biomass logs. For most biomass materials, dense and strong logs can be produced under room temperature without binder and at a pressure of 70 $\mathrm{MPa}(10,000 \mathrm{psi})$, approximately. A few types of the materials tested such as sawdust and grass need a minimum pressure of $100 \mathrm{MPa}(15,000 \mathrm{psi})$ in order to produce good logs. The appropriate moisture range for compacting waste paper into good logs is $5-20 \%$, and the optimum moisture is in the neighborhood of $13 \%$. For the woody materials and yard waste, the appropriate moisture range is narrower: $5-13 \%$, and the optimum is $8-9 \%$.

The compacted logs have a dry density of 0.8 to $1.0 \mathrm{~g} / \mathrm{cm}^{3}$, corresponding to a wet density of 0.9 to $1.1 \mathrm{~g} / \mathrm{cm}^{3}$, approximately. The logs have high strength and high resistance to impact and abrasion, but are feeble to water and hence need to be protected from water or rain. They also have good long-term performance under normal environmental conditions, and can be stored for a long time without significant deterioration. Such high-density and high-strength logs not only facilitate handling, transportation, and storage, but also increase the energy content of biomass per unit volume. After being transported to power plants and crushed, the biomass logs can be co-fired with coal to generate electricity. 
A cost model for biomass fuel production based on this technology was developed. The model uses life-cycle cost analysis with a net-cash-flow approach. The model was used to determine the unit cost of the biomass log fuel (BLF) in \$/ton (dollars per ton). The production cost of the biomass logs, including a $15 \%$ above-inflation return on investment, was found to be between $\$ 5.5$ and $\$ 8$ per ton for plants having capacities between 675,000 and 135,000 tons per year. If the return rate is increased to $20 \%$ and $25 \%$, the corresponding unit production costs will be $\$ 6.3$ to $\$ 9.1$ and $\$ 7.1$ to $\$ 10.1$ per ton. This BLF process appears to be more economical than other conventional densification processes, and it produces a denser and stronger fuel that is easier to transport and handle. Analysis of the transportation cost of the densified biomass logs showed that barge is the most cost-effective, followed by rail and then truck. Pneumatic capsule pipeline (PCP) and hydraulic capsule pipeline (HCP) are not economical compared to truck for transporting biomass logs due to the relatively small volume of BLF that needs to be transported to each power plant. The unit cost of biomass logs handling at power plants, including crushing and storage, is only about $\$ 0.53 /$ ton.

Based on this study, it can be concluded that the BLF technology is both technically and economically feasible, and it appears to be rather promising for use at conventional coal-fired power plants for co-firing with coal. It should be further developed so that it can be used commercially. Additional R\&D needed to bring the BLF technology to the marketplace include: testing the mass production of biomass logs, testing the freezing/thawing, transportation and handling of the mass produced biomass logs, testing the handling (storage and crushing) and burning the biomass $\log$ fuel at existing coal-fired power plant in different types of commonlyused boilers such as stoker, fluidized-bed, cyclone and pulverized-coal types, designing a multimold biomass-log manufacturing machine, and prepare a manual of practice for the BLF process including manufacturing, transportation, handling and combustion of this environmentally desirable new fuel. Such R\&D should be included in a Phase II project. 


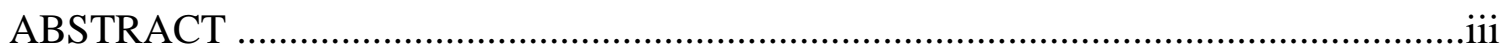

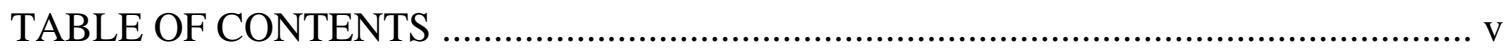

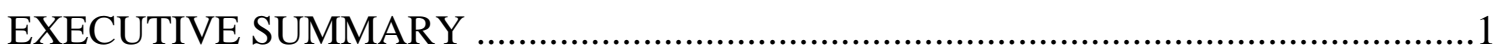

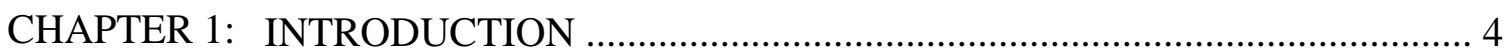

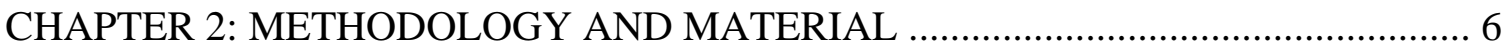

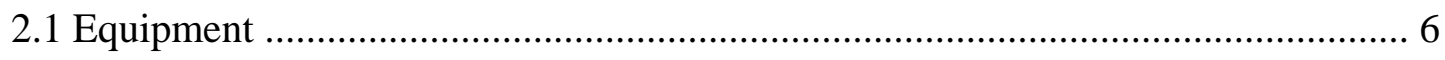

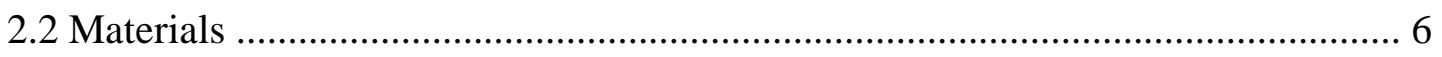

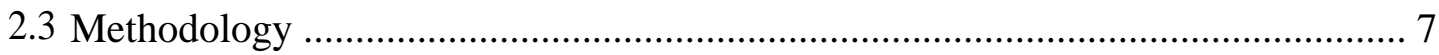

2.3.1 Optimization of compaction conditions ........................................................... 7

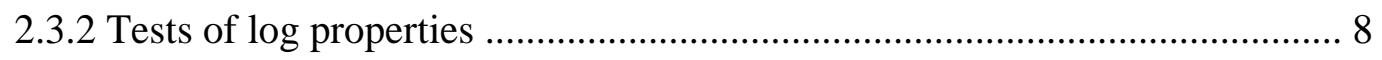

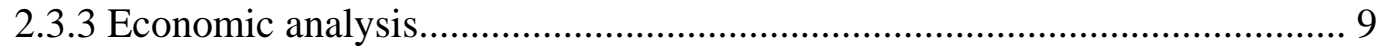

CHAPTER 3: RESULTS AND DISCUSSION......................................................13

3.1 Compaction of Municipal Solid Wastes ……………............................................13

3.1.1 Effect of pressure on individual types of papers ........................................ 13

3.1.2 Effect of pressure and holding time on mixed paper ..................................13

3.1.3 Effect of moisture content and pressure on mixed paper............................. 13

3.1.4 Effect of particle size and shape on compaction of paper............................. 14

3.1.5 Long-term performance of the logs............................................................. 14

3.1.6 Compaction of mixture of paper and plastics ........................................... 15

3.1.7 Compaction of typical combustibles in municipal solid waste .................... 16

3.2 Compaction of Woody Materials ....................................................................... 16

3.2.1 Effect of pressure and holding time .........................................................17

3.2.2 Effect of moisture content....................................................................... 18

3.2.3 Effect of particle size and shape.............................................................. 18

3.2.4 Long-term performance of the logs...................................................... 19

3.3 Compaction of Yard Waste .............................................................................. 20

3.3.1 Effect of moisture content ………………………................................ 20 
3.3.2 Effect of compaction pressure ................................................................... 20

3.3.3 Long-term performance of the logs............................................................ 21

3.3.4 Effect of particle size on quality of grass logs ........................................... 21

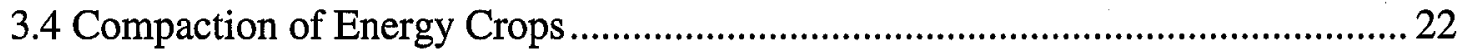

3.5 Comparison between Small and Large Logs........................................................ 22

3.6 Effect of Mold and Piston Conditions.................................................................... 23

3.6.1 Mold and piston shapes ............................................................................... 23

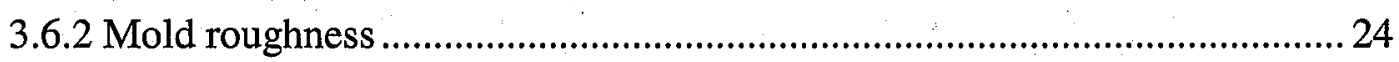

3.7 Effect of Back Pressure ......................................................................................... 24

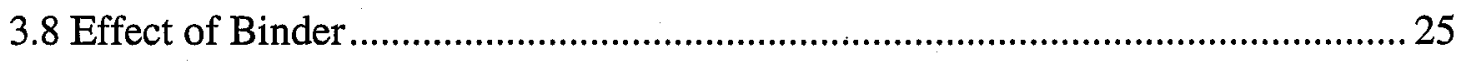

3.9 Effect of Zeta Potential ................................................................................... 25

3.10 Water Expulsion during Compaction.................................................................. 26

3.11 Volume Reduction through Compaction........................................................... 26

3.12 Water/Rain Resistance of the Biomass Logs ...................................................... 27

3.13 Combustion Characteristics of the Biomass Logs................................................. 27

3.14 Economics of Production and Use of Biomass Logs as Fuel............................... 28

3.14.1 Unit production cost ................................................................................... 28

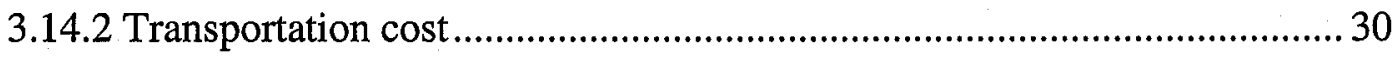

3.14.3 Power plant handling cost .............................................................................. 31

3.14.4 BLF delivered cost .................................................................................. 31

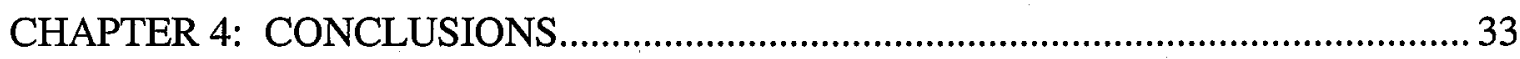

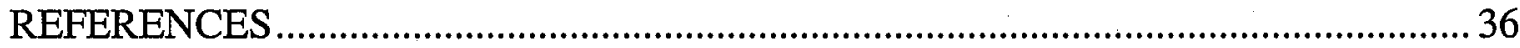

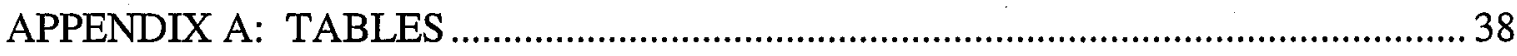

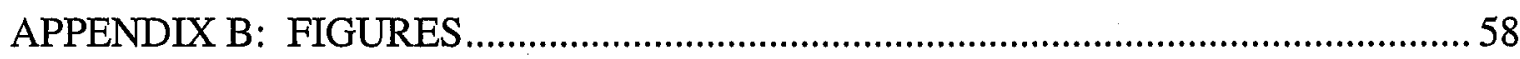

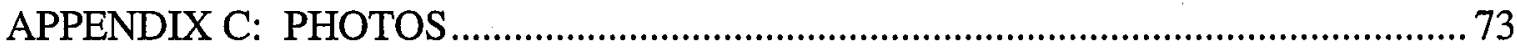




\section{EXECUTIVE SUMMARY}

Biomass is a substantial renewable energy resource that can be used as a fuel for power generation. Biomass is also referred to as a "green energy" resource because it is carbon-neutral and produces virtually no sulfur emissions. Co-firing biomass with coal in existing coal-fired power plants has emerged to be an attractive and low-cost option for generating "green power" and reducing green-house gas and acid gas emissions. However, the uneven, fluffy and/or bulky nature of biomass materials often makes it difficult and costly to handle, store, and transport. It is also difficult for the raw biomass materials to be fed and burned effectively in boilers. Densification of biomass materials can not only improve their handling and combustion properties, but also significantly reduce transportation and storage costs.

In this study, a new compaction technology developed at Capsule Pipeline Research Center (CPRC), University of Missouri-Columbia (UMC) was tested for producing densified high-quality biofuel from biomass waste materials. The objectives of this Phase I project were: (1) to find the optimum compaction and process conditions for producing high-quality densified fuel logs ${ }^{*}$ from various biomass waste materials by conducting extensive laboratory tests; (2) to assess the properties of the logs compacted in terms of the combustion characteristics, impactand wear-resistance, and water absorption, and (3) to conduct economic analysis of this technology for anticipated future commercial use. A small compaction machine which produces 48.5-mm (1.91-inch)-diameter laboratory-size biomass logs and a large compaction machine which produces $137-\mathrm{mm}$ (5.4-inch)-diameter commercial-size biomass logs were used in this study. The large machine, designed by CPRC personnel, has unique capabilities including highpressure and high-speed compaction, back-pressure control during ejection of logs from mold, special mold geometry, etc.

A variety of biomass waste materials, including sawdust, mulch and chips of various types of wood, combustibles such as paper, plastics and textiles that are found in municipal solid waste stream, energy crops (willows and switch grass), and yard waste including tree trimmings, fallen leaves, and lawn grass, were tested using this compaction technology. The compaction conditions, including compaction pressure, pressure holding time, back pressure, moisture content, particle size and shape, piston and mold geometry and roughness, as well as binder for enhanced agglomeration were studied and optimized. The properties of the compacted products biomass logs-were evaluated in terms of physical, mechanical, and combustion characteristics.

It was found that the compaction pressure and the moisture content of the biomass materials are critical for producing high-quality biomass logs. For most biomass materials, dense and strong logs can be produced under room temperature without binder and at a pressure of 70 $\mathrm{MPa}(10,000 \mathrm{psi})$, approximately. A few of the materials tested such as sawdust and grass need a minimum pressure of $100 \mathrm{MPa}(15,000 \mathrm{psi})$ in order to produce good logs. The appropriate moisture range for compacting waste paper into good logs is 5-20\%, and the optimum moisture is in the neighborhood of $13 \%$. For the woody materials and yard waste, the appropriate moisture range is narrower: $5-13 \%$, and the optimum is $8-9 \%$.

\footnotetext{
"In this report and in related literature, the term "logs" means solid cylinders much larger in size than "pellets" or

"briquettes." Larger than 5-inch-diameter biomass logs are envisioned for commercial use.
} 
The effects of particle size and shape on log quality vary with different biomass materials. For shredded paper, the size and shape have little effect on the quality of the logs compacted. But for woody materials, particle size has some effect and particle shape has remarkable effect on the log quality. Woody materials in the form of mulch produce strongest logs, sawdust the second, and chips the last. For grass (lawn grass and switch grass), grinding into fine particles can help produce slightly denser logs, but it adversely affects the impact resistance and abrasion resistance of the logs. Therefore, except for wood in the form of chips, all different particle sizes and shapes can produce good logs as long as the raw material can be fed into the mold efficiently. Note that wood chips are not waste materials and hence should not be considered as a material source for producing biomass logs.

The pressure holding time has a significant effect on the quality of the biomass logs compacted only at low compaction pressure. At the optimum compaction pressure (70-100 MPa or 10,000-15,000 psi for most of the biomass materials), a 10-second holding time is more than adequate. Since longer holding time means a decreased production rate of biomass logs for each compaction machine, it is more efficient to adjust pressure and moisture conditions to improve the log quality than to increase the holding time.

The effect of mold exit geometry and piston end shape on the quality of the biomass logs is significant in certain cases and insignificant in other cases. The roughness of the mold has some effect on compacted log quality - smoother mold makes denser logs. Smoother molds also use less energy for compaction and hence are more economical.

The back pressure, which the large compaction machine at CPRC has the capability to control, can significantly improve the integrity and increase the density of the logs made of dry paper and leaves; its effect on wet and more ductile biomass logs is insignificant. For waste paper and leaves, a back pressure of $0.7 \mathrm{MPa}(100 \mathrm{psi})$ or even smaller is sufficient to improve the log quality.

The compacted logs have a dry density of 0.8 to $1.0 \mathrm{~g} / \mathrm{cm}^{3}$, which corresponds to a wet density of $0.9-1.1 \mathrm{~g} / \mathrm{cm}^{3}$ approximately. They are highly resistant to impact and abrasion, but feeble to water and hence need to be protected from water or rain. The logs also have good longterm performance under normal environmental conditions, and can be stored for a long time without significant deterioration. Such high-density and high-strength logs not only facilitate handling, transportation, and storage, but also increase the energy content of biomass per unit volume. After being transported to power plants and crushed, the biomass logs can be co-fired with coal to generate electricity. The biomass log fuel (BLF) made of waste paper has an average heating value of $16.5 \mathrm{MJ} / \mathrm{kg}(7,100 \mathrm{Btu} / \mathrm{lb})$. For logs made of a mixture of paper and plastics, the heating values will be higher because plastics usually have more than twice the heating value of paper. The logs made of woody materials and yard waste materials have an average heating value of $20.0 \mathrm{MJ} / \mathrm{kg}(8,500 \mathrm{Btu} / \mathrm{lb})$.

A cost model for biomass log fuel (BLF) production based on this technology was developed. The model uses life-cycle cost analysis coupled with a net-cash-flow approach. The model was used to determine the unit cost of the BLF in \$/ton (dollars per ton) including a return on investment. The production cost of the BLF, including a $15 \%$ above-inflation return of investment, was found to be between $\$ 5.5$ and $\$ 8$ per ton for plants having capacities between 675,000 and 135,000 tons per year, respectively. If the return rate is increased to $20 \%$ or $25 \%$, the unit production cost will be $\$ 6.3$ to $\$ 9.1$ or $\$ 7.1$ to $\$ 10.1$ per ton respectively. This process 
appears to be more economical than other conventional densification processes including pelletizing, briquetting, and extrusion, which usually cost over $\$ 10$ per ton, and it produces a denser and strong fuel. Analysis of the transportation cost of the densified biomass logs showed that barge is the most cost-effective, followed by rail and then truck. Pneumatic capsule pipeline (PCP) and hydraulic capsule pipeline (HCP) are not cost-effective compared to truck for transporting BLF due to its relatively small volume (less than 1 million tons per year) needed at each power plant. The unit cost of biomass logs handling at power plants, including crushing and storage, is only about $\$ 0.53 /$ ton. It is concluded that even without consideration of the tipping fees avoided at landfills, the BLF is economical for distances up to about 50 miles in today's market. Its economical range can be extended to distances much beyond 100 miles if the tipping fee is considered.

Notwithstanding the promising findings of this project, further study is needed before the BLF can be used commercially. The study should include: (1) testing mass production of biomass $\operatorname{logs}$ in order to find out quality control and other potential problems that cannot be found in the Phase I study; (2) testing the transportation (by truck), handling, and storage of mass produced logs; (3) test-burning the mass-produced biomass logs with coal at existing coal-fired power plants in various types of conventionally used boilers; (4) designing a multi-mold biomass compactor for mass production of biomass logs in commercial applications; (5) preparing a manual of practice on the entire process of BLF manufacturing, transport, storage, handling and combustion at power plants; (6) conducting an economic analysis similar to the one performed under Phase I, except that more accurate cost data found from the Phase II study will be used. 


\section{CHAPTER 1. INTRODUCTION}

Biomass and the combustibles in municipal solid waste have been recognized to be substantial renewable and "green energy" resources. Compared to fossil fuels, biomass fuel recycles greenhouse gases such as $\mathrm{CO}_{2}$ and $\mathrm{NO}_{\mathrm{x}}$, and hence it does not contribute to increased $\mathrm{CO}_{2}$ and $\mathrm{NO}_{\mathrm{x}}$ in the atmosphere and the resultant global warming. Furthermore, biomass contains little sulfur and hence reduces $\mathrm{SO}_{2}$ emissions from coal-fired power plants, thereby reducing the acid rain problem. Consequently, co-firing biomass in existing coal-fired boilers has emerged as an attractive and low-cost method for generating green power. However, the bulky, loose, fluffy, dusty, and uneven characteristics of the biomass materials make them difficult to handle, transport, store, feed, and burn efficiently and economically. Densification of the materials not only improves the handling, transportation, and storage properties, but also increases the energy density of the fuel so that the densified biomass fuel can be more compatible with coal when co-fired with coal in power plants. This explains why in most of the limited existing commercial applications of biomass fuel, biomass materials are first compressed into pellets before they are burned at power plants.

Conventional processes for biomass densification can be classified into three types $[1,2]^{*}$ : extrusion, pelletizing, and roll briquetting. In an extruder, the raw material is conveyed and compressed either by a screw or a piston (plunger) through a die to form compacts of cylindrical or other shapes. A pelletizer consists of a hard, perforated steel die and one or two rollers. By rotating the die and/or the rollers, the feedstock is forced through the perforations to form densified pellets. In a briquetting roller press, the feedstock falls in between two rollers rotating in opposite directions and is compacted into pillow-shaped briquettes. Briquetting biomass usually requires binder. Roller-and-die pelletizer is the most widely used machine type in wood pelletizing today [1]. Most producers use preheating of the biomass to form stable and dense pellets or briquettes $[2,3]$. A study showed that preheating biomass could significantly increase the throughput of the pelletizing machine so as to reduce the energy requirement per unit mass of the biomass pellets formed [4]. The moisture content of the biomass materials in the pelletizing process needs to be accurately controlled in order to produce high-quality pellets. For instance, to make fuel pellets from municipal solid waste (mainly waste paper), the moisture must be controlled at $(16 \pm 2 \%)$ [5].

The Capsule Pipeline Research Center (CPRC) at the University of Missouri-Columbia has developed a high-pressure, piston-in-mold (punch-in-die) compaction process during the past decade for coal logs compaction. The process is unique in that by using a pressure higher than that used in pelletization and extrusion, by using a back-pressure during ejection of compacts from molds, and by using special mold exit shape, high-quality biomass logs can be produced without binder and without heat. Also, the product (logs) is much larger in size than pellets or briquettes and hence cost less to mass produce. This project was intended to study the technical and economic feasibility of producing biomass $\log$ fuel (BLF) as a low-cost, highly densified biomass fuel for co-firing with coal in conventional existing coal-fired power plants. The project was designed for implementation in two stages. Phase 1, preliminary study, involved extensive laboratory tests and an economic analysis. Phase II is proof-of-concept study under real-world conditions such as mass production of BLF and power plant test-burns. This report describes

\footnotetext{
* Numbers in [ ] correspond to corresponding items in REFERENCES on page 36.
} 
only the result of the Phase I study. Phase II has not yet been funded or carried out. The objectives of Phase I Project were: (1) to find the optimum compaction conditions for various biomass and waste materials; (2) to assess key properties of the biomass logs compacted including combustion characteristics, impact- and wear-resistance, water absorption, etc.; and (3) to evaluate the economics of production, transportation, and power-plant handling of the biomass logs. The following chapters present details of the methodology, materials, testings, analyses and findings of the Phase I project. 


\section{CHAPTER 2. METHODOLOGY AND MATERIALS}

This chapter presents the materials, equipment, methodologies and procedures used in the experiments and analyses in the phase I Project. Results of the study will be reported in CHAPTER 3-RESULTS AND DISCUSSION.

\subsection{Equipment}

Two compaction machines-a small one and a large one-were used in this study for fabricating the biomass logs. The small compaction machine consists of a hydraulic press (Baldwin Locomotive Works, Inc.), a cylindrical mold (die) with 48.5-mm (1.91-inch) inner diameter and 300-mm (12-inch) length, and an upper piston (punch) and a lower piston having a diameter slightly (less than $1 \mathrm{~mm}$ ) smaller than the inner diameter of the mold. Driven by the hydraulic press, both pistons move up and down in the mold to compact the biomass material fed into the mold. The maximum load of the hydraulic press is $267 \mathrm{kN}(60,000 \mathrm{lbs})$. Therefore, the maximum compaction pressure that can be generated in the 1.91-inch-diameter mold is $145 \mathrm{MPa}$ $(20,940$ psi). During operation, the biomass material is fed into the top of the mold with the lower piston already in the mold. Then the upper piston is advanced into the mold and the compaction force is applied. The compaction speed can be controlled, having a minimum of 30 seconds to reach $138 \mathrm{MPa}(20,000 \mathrm{psi})$. The commonly used compaction speed in this study was approximately $2 \mathrm{MPa}$ per second. At this speed, about 70 seconds were needed to reach the highest compaction pressure in the tests $(138 \mathrm{MPa})$. The machine is also equipped with a computerized data acquisition system so that the pressure and displacement of the pistons can be monitored during compaction and ejection of the biomass log. This compaction machine is shown in Photo 2-1.

The large machine was designed by CPRC personnel and manufactured by Gundlach Machine Company in 1998 for coal log compaction. This machine, as shown in Photo 2-2, uses a single mold with an upper and a lower piston, and a hydraulic press that can generate a maximum of $2,230 \mathrm{kN}$ (250 tons) of force. The inner diameter of the mold is $137 \mathrm{~mm}(5.4$ inches). Therefore the maximum pressure that can be reached in the mold is $150 \mathrm{MPa}(21,800$ psi). This machine is highly automated by using a PLC (Programmable Logic Controller). The machine can perform either single-ended or double-ended compaction. The compaction speed is fast: the highest pressure can be reached in 3 seconds. This machine is also featured with a backpressure control, which means during ejection of logs a controlled pressure can be maintained on the withdrawing piston, preventing tension to develop in the logs during ejection, and hence preventing cracks and capping. Note that capping is the loss of a lens-shaped layer on the top of the $\log$ upon ejection of the log from mold, a phenomenon often found in coal log compaction when back pressure is not used or incorrectly applied.

\subsection{Materials}

The materials tested in this study can be categorized into the following four groups:

(1) Municipal solid wastes. This includes five types of papers-corrugated-board, newsprint, office paper, commercial printings (magazines, brochures, and advertisements), and non-corrugated box board-which make up over $70 \%$ of all the paper products in ordinary municipal solid waste streams. Waste plastics of five 
different resins in the form of film (e.g., bags and wrappings) and hard products (e.g., plastic bottles) as well as textiles and wood were also tested.

(2) Woody materials. This includes wood and bark of oak, walnut, pine, and cottonwood in the forms of sawdust, mulch, and chips. Oak and walnut are typical hardwood, pine is a softwood, and cottonwood is classified as a soft hardwood.

(3) Yard waste. This includes hardwood and softwood tree trimmings, fallen leaves, lawn grass clippings, and some tree fruits such as pine cones.

(4) Energy crops. Two types of energy crops were studied - switchgrass and willows.

Table 2-1 lists all the materials tested, including a brief description of each material and its source.

\subsection{Methodology}

\subsubsection{Optimization of compaction conditions}

The compaction conditions of all the biomass materials were optimized through the examination of the effects of various factors as follows:

(1) Effect of compaction pressure. The compaction pressure (or simply "pressure") means the ultimate peak pressure applied during the compaction process. Four different pressures $-34,69,102$ and $138 \mathrm{MPa}^{*}(5,000,10,000,15,000$ and 20,000 psi) - were used to examine the pressure effect.

(2) Effect of pressure holding time. The pressure holding time means the time over which the peak pressure is applied before the pressure is released. The effect of a pressure holding times from zero to 120 seconds was studied for one typical biomass material (oak sawdust), and a 10-second holding time was used for most of the biomass materials tested.

(3) Effect of moisture content. The effect of moisture content on the compaction of biomass logs was studied for all the different materials tested and the appropriate moisture range and the optimum moisture were determined for the compaction of each material.

(4) Effect of particle size and particle shape. The effects of particle size and shape on the properties of the compacted logs were extensively studied for most of the materials. The different particle sizes and shapes were achieved by using different sieves and/or shredding methods.

(5) Effect of mold and piston conditions. These conditions include the geometry of the mold and the pistons and the roughness of the mold. In addition to the straight mold and flat-end piston, a 48.5-mm-diameter mold with $1^{\circ}$ tapered exit and a piston with convex end were used to study the effect of mold and piston geometry, and a rough mold and a smooth mold were used to study the effect of mold roughness.

(6) Effect of back pressure. The back-pressure control capability of the large compaction machine was used to study this effect. Back pressure means during ejection of logs a controlled pressure can be maintained on the withdrawing piston, preventing logs from developing cracks and capping. Effects of back pressures ranging from 0.7 to 10 $\mathrm{MPa}$ (100 to $1500 \mathrm{psi}$ ) were tested for different biomass materials.

\footnotetext{
* $1 \mathrm{MPa}$ is equal to $145 \mathrm{psi}$. Therefore, $34,69,102$, and $138 \mathrm{MPa}$ are equivalent to $5,000,10,000,15,000$, and 20,000 psi respectively.
} 
(7) Effect of binder. Orimulsion, a petroleum byproduct, was used as binder to test the improvement on biomass logs made of certain materials. The effect of Orimulsion addition of up to $6 \%$ by weight was tested.

(8) Effect of zeta-potential control. For some biomass materials which were found to have high zeta potential and were difficult to be compacted into strong logs, a reagent that can neutralize or nullify the zeta potential was added to examine the improvement on log properties.

(9) Effect of the size of compaction machine and logs. The quality of biomass logs produced by the small machine and the large machine was compared to examine the effects of the compaction machine and the size of the logs.

\subsubsection{Tests of log properties}

The quality of the biomass logs compacted was evaluated based on the following properties tested:

(1) Density. Since the moisture of the biomass logs changes with time and humidity of the environment, the dry density is used to express this property of the logs. Except in some special cases, the densities of the logs were measured 2 minutes after the logs were ejected from the mold. The 2-minute density was chosen because most of the logs underwent expansion after ejection and most rapid expansion occurred within the first 2 minutes.

(2) Compressive strength. The compressive strength was tested according to ASTM Standard Method C39-96 [6]. This test was limited to certain logs which had a length to diameter ratio greater than 1.5. Since all the logs underwent significant plastic deformation or yield (usually shortened longitudinally) before the final failure occurred in this test, only limited measurements of compressive strength were taken.

(3) Splitting tensile strength. The splitting tensile strength was tested according to ASTM Standard Method C 496-96 [7]. This test was only performed for certain logs made of sawdust, because logs made of other materials did not break along the axial direction in the tests. Instead, the circular cross sections of the logs were squeezed into elliptic ones, making the results not meaningful.

(4) Impact resistance. The impact resistance of the logs was tested by adapting the ASTM Standard Method D 440-86 for drop test for coal [8]. The logs were dropped twice from $1.83 \mathrm{~m}(6 \mathrm{ft})$ onto a concrete floor. Logs made of paper rarely broke during the drop tests, therefore, percent weight loss after two drops was used to express or compare their impact resistance. However, logs made of other materials often break, an impact resistance index (IRI) introduced by Richards [9] was used to evaluate the impact resistance of the logs. The $\mathbb{R I}$ is calculated from $I R I=(100 \times N) / n$, where $N$ is the number of drops, and $n$ is the total number of pieces after $N$ drops. Because two drops were used as standard, the number of drops $N$ in the above equation is always 2 , and maximum value of IRI is 200 . Thus, the IRI for paper logs would be always 200 because the paper logs rarely broke in the drop test. It should be mentioned that some logs upon hitting the concrete floor broke into pieces of various sizes ranging from large pieces to fine particles. When the number of pieces was counted in a test, the small pieces that weigh less than $5 \%$ of the initial weight of the log was not included in the calculation of the IRI. After the first drop, all the 
pieces that weigh less than $5 \%$ of the original weight of the log were not collected and not used for the second drop.

(5) Abrasion resistance. The abrasion resistance of the logs was tested by using a procedure adapted from the ASTM Standard Method D 441-86 for tumbler test of coal [10]. In this test, three logs with a diameter of $48.5 \mathrm{~mm}$ and length of approximately $50 \mathrm{~mm}$ were placed in a porcelain jar. The jar was rotated at $60 \mathrm{rpm}$ for 40 minutes. The total number of revolutions during a test is approximately 2400 . The weight of each log before and after tumbling was measured and the weight loss was calculated as an indicator of the abrasion resistance.

(6) Water and rain resistance. The water resistance of the logs was tested by immersing the logs in water under room temperature and observing the water absorption of the logs. The rain resistance was tested using the Rain Simulation Tower of the Department of Biological and Agricultural Engineering at the University of MissouriColumbia. The logs were put in the rain for different periods of time to test their durability to rain.

(7) Long-term performance. The long-term performance of biomass log compacted was observed by monitoring the changes of dimensions, density, moisture, impact resistance and abrasion resistance of the logs placed in open air in the laboratory.

(8) Combustion characteristics. The combustion characteristics including higher heating value*, volatile matter, fixed carbon, and ash content of the materials were tested to assess the combustion property of the fuel logs made of the materials. The heating values were measured with an Automatic Calorimeter (LECO Corporation, Model AC-300, System 789-500), and the volatile matter, fixed carbon, and ash content were obtained using a Proximate Analyzer (LECO Corporation, Model MAC-400, System 785-700).

It should be noted that except for cases in which the long-term performance of the logs was studied, the test items 2 through 6 stated above were all conducted 24 hours after the logs were made and stored in air-tight bags.

\subsubsection{Economic analysis}

The cost analysis involves analyzing the biomass log fuel (BLF) production cost, transportation cost, and handling cost at power plants. A cost model using a life-cycle analysis and a net-cash-flow approach was constructed for the calculation of the unit cost of production, power plant handling, and transportation by pipeline. The transportation costs by truck, barge, and rail were obtained by reviewing, analyzing and using applicable cost information found in the literature, and through consultation with transportation agencies or companies. Details of the cost analysis are given in a separate report entitled "Economic Analysis of Compacting and Transporting Biomass Logs for Co-firing with Coal in Power Plants" [11]. A brief description of the cost model is provided here. Results for different scenarios can be found in Section 3.14 of Chapter 3.

The life-cycle cost is performed over the estimated economic life of the system, $N$ years. The net-cash-flow approach is used which considers all the revenues (incomes) of a project as

\footnotetext{
* The higher heating value is calculated from the quantity of heat emitted per unit weight of material during the combustion, assuming the water (contained in the material or generated from hydrogen in the combustion) is condensed.
} 
positive cash flow, and all costs (expenditures) as negative cash flow. During the life cycle (economic life) of the system, each cash flow is treated as a discrete payment (outlay of cash). Costs paid at the beginning of the project are the initial costs, and those paid subsequently are treated as annual costs (outlays). For simplicity, it is assumed that all the capital costs are encumbered at the beginning of the project. So, the capital cost and initial cost are treated as the same thing. All annual costs are assumed to be paid at the end of each year-the end-of-year convention.

The unit price, $U$ (i.e., the price charged to customers for manufacturing, or transporting, or power-plant handling each ton of biomass in $\$ / \mathbf{T}$ ) is calculated based on the need to generate a certain above-inflation rate of return. To achieve this return rate, the after-tax cash flow equations for each year are first developed, treating the unit price as a variable with respect to time (years). These equations include the following:

The after-tax cash flow $(A T C F)$ for any year $n(n=1,2,3 \ldots N)$ is:

$$
A T C F_{n}=B T C F_{n}-T_{n}
$$

where $B T C F_{n}$ is the before-tax cash flow for year $n$, and $T_{n}$ is the corporate income tax that must be paid during year $n$.

The quantity $B T C F_{n}$ is determined from:

$$
B T C F_{n}=R_{n}-C_{n}
$$

where $R_{n}$ is the revenue for year $n$, and $C_{n}$ is the cost for year $n$.

The corporate income tax of year $n, T_{n}$, in Eq. 1 is calculated from

$$
T_{n}=\left(B T C F_{n}-d_{n}\right) t
$$

where $d_{n}$ is the depreciation of year $\mathrm{n}$ which must be determined from the tax code, and $t$ is the rate of corporate income tax, assumed to be $37 \%$ in this analysis. For simplicity, a "straight-line" or uniform depreciation over 20 years is used. Therefore,

$$
d_{n}=d=\frac{C_{c}}{N_{d}}=\frac{C_{c}}{20}
$$

where $C_{c}$ is the capital cost, and $N_{d}$ is the years of depreciation. The value of $N_{d}$ must conform to government tax code. Note that when $N_{d}$ (say, 20 years) is less than $N$ (say, 30 years), Eq. 4 is valid only for the first $N_{d}$ years. Thereafter, there will be no more depreciation and $d_{n}=0$ (zero) for the remaining years of the project's economic life.

Combining Eqs. 1, 2, and 3 yields

$$
A T C F_{n}=(1-t)\left(R_{n}-C_{n}\right)+t d_{n}
$$

The present value of $A T C F_{n}$ is denoted as $A T C F_{n p}$. It can be calculated from

$$
A T C F_{n p}=\frac{A T C F_{n}}{(1+\delta)^{n}}=\frac{(1-t)\left(R_{n}-C_{n}\right)+t d_{n}}{(1+\delta)^{n}}
$$

The quantity $\delta$ in Eq. 6 is the inflation-adjusted discount rate which should be calculated from

$$
\delta=r+I+r I
$$


in which $r$ is the above-inflation return rate, and $I$ is the inflation rate.

The revenue $R_{n}$ in Eq. 6 is to be determined for each year in such a manner that the sum of the present value of $A T C F_{n}$ over the $N$ years is zero, namely,

$$
\sum_{n=0}^{N} A T C F_{n p}=0
$$

where $n=0,1,2,3, \ldots N$. Equation 8 can be rewritten as

$$
\left[\sum_{n=1}^{N} \frac{(1-t)\left(R_{n}-C_{n}\right)+t d_{n}}{(1+\delta)^{\mathrm{n}}}\right]-C_{c}=0
$$

The revenue is assumed to be $R_{n}$ for year $n$, and it escalates at the rate of $e_{r}$. Therefore,

$$
R_{n}=\left(1+e_{r}\right)^{n-1} R_{I} \quad(n=1,2,3, \ldots N)
$$

Assuming that the throughput of the system is $Q(\mathrm{~T} / \mathrm{yr})$, the revenue generated each year becomes

$$
R_{n}=Q U_{n}
$$

where $U_{n}$ is the price charged to the customer for manufacturing or transporting or handling unit weight of the biomass logs, hereafter referred to simply as the "unit price."

Substituting Eq. 11 into Eq. 10 yields

$$
R_{n}=\left(1+e_{r}\right)^{n-1} U_{l} Q
$$

Equation 12 can now be substituted into Eq. 9 to yield

$$
\left\{\sum_{n=1}^{N} \frac{(1-t)\left[\left(1+e_{r}\right)^{n-1} U_{I} Q-C_{n}\right]+t d_{n}}{(1+\delta)^{\mathrm{n}}}\right\}-C_{c}=0
$$

Realizing that both $Q$ and $U_{1}$ in Eq. 13 are constant and do not vary with $n$, they can be factored out of the equation to yield

$$
U_{1}=\frac{\sum_{n=1}^{N} \frac{(1-t) C_{n}-t d_{n}}{(1+\delta)^{n}}+C_{c}}{Q \sum_{n=1}^{N} \frac{(1-t)\left(1+e_{r}\right)^{n-1}}{(1+\delta)^{n}}}
$$

This equation can be used to determine the unit price for the first year. The unit price for any year $n$ can be obtained from

$$
U_{n}=\left(1+e_{r}\right)^{n-1} U_{1}
$$

The annual $\operatorname{cost} C_{n}$ in Eq. 14 is to be determined from

$$
C_{n}=\left(1+e_{c}\right)^{n-1} C_{1} \quad(n=1,2,3, \ldots N)
$$

where $C_{I}$ is the annual cost for the first year, and $e_{c}$ is cost escalation rate which is assumed to be the same as the general inflation rate $I$. 
The present value of the annual cost, $C_{o}$, is determined from the present annual cost of various items including energy, fuel, salaries and wages, property tax, insurance, and other operations/maintenance costs, namely,

$$
C_{o}=C_{e}+C_{f}+C_{s}+C_{p}+C_{i}+C_{o / m}
$$

where $C_{e}$ is the energy cost, $C_{f}$ is the fuel cost, $C_{s}$ is the cost of salary and wages, $C_{p}$ is the property tax cost, $C_{i}$ is insurance cost, and $C_{o / m}$ is other operation/maintenance costs-all firstyear costs based on current values. Note that corporate income tax is not included here since it has already been included before by using $t$ in previous equations.

The property tax, $C_{p}$, and the insurance cost, $C_{i}$, for the present year are calculated from

$$
\text { and } \begin{aligned}
C_{p} & =e_{p} C_{c} \\
C_{i} & =e_{i} C_{c}
\end{aligned}
$$

where $e_{p}$ and $e_{i}$ are respectively the property tax rate and the insurance rate.

This cost model and approach are used to calculate the biomass log production cost, transportation cost by pipeline, and power plant handling cost. More details about the cost model is discussed in a separate report [11]. The detailed assumptions for each scenario and the results are presented in Section 3.14 of Chapter 3. 


\section{CHAPTER 3. RESULTS AND DISCUSSION}

\subsection{Compaction of Municipal Solid Wastes}

Waste paper, plastics, wood, and textiles, which are the major combustibles in the municipal solid waste (MSW) stream, were tested both separately and in combination. The waste paper studied included five types-corrugated-board, newsprint, office paper, commercial printings (magazines, brochures, and advertisements), and non-corrugated box board. Together they make up over $70 \%$ of all the paper products in ordinary MSW streams [12]. Waste plastics of five different resins including HDPE, LDPE, PP, PET and PS, in the forms of film, hard, and foamed products, were also tested. These five types of resins make up $78 \%$ of the total plastics found in MSW [12]. The textiles tested included mainly cloth made of polyester and cotton. The waste wood in the MSW consisted of used furniture, lumber, and pallets.

\subsubsection{Effect of pressure on individual types of papers}

The effect of pressure on the integrity and the density of the logs made from five individual types of papers was tested by the small compaction machine. The papers were airdried and had moistures of 5.3,7.5, 4.7, 3.7, and 5.9\%, respectively for the five types mentioned above. The papers were shredded into pieces (flakes) of $6 \mathrm{~mm}$ by $25 \mathrm{~mm}$ using a heavy-duty office paper shredder. The pressure was applied without any holding time. This means that as soon as the compaction pressure has reached the peak value, it is released. The results are summarized in Table 3-1. It can be seen from Table 3-1 that the higher the pressure, the better the quality of the logs is. When the pressure reached $102 \mathrm{MPa}$, all the papers were compacted into good logs with dry density close to or higher than $1 \mathrm{~g} / \mathrm{cm}^{3}$. Corrugated board and office paper were relatively easy to compact into good logs.

\subsubsection{Effect of pressure and holding time on mixed paper}

A mixture of the five types of papers containing equal weight for each was compacted at four different pressures. Three moistures, 5.4\% (air-dried), 17\%, and $24 \%$ were used. At each pressure, the material was compacted both without and with a 10 -second pressure holding time. The dry densities measured 2 minutes after the ejection of the logs were used to verify the differences. The results in Fig. 3-1 indicate that a 10-second holding time increases the density of the logs made under the same pressure. The lower the pressure, the more significant the effect of the holding time is. At the highest pressure used in this study (138 MPa), holding time no longer made any noticeable difference. The effect of holding time was also related to the moisture content. The closer the moisture content is to the optimum (13\% as will be shown in Section 3.1.3), the less effect the holding time has on the log quality.

\subsubsection{Effect of moisture content on mixed paper}

The logs made of mixed paper containing moistures from $5.4 \%$ to $35 \%$ and compacted at $102 \mathrm{MPa}(15,000 \mathrm{psi})$ are shown in Photo 3-1. The density, compressive strength, abrasion resistance, and impact resistance of the logs made at various pressures and moisture contents are shown in Fig. 3-2. Compressive strength results are reported only for the logs produced under $138 \mathrm{MPa}$. The logs made under lower pressures were compressed (shortened significantly along the axis) before the final failure load was reached. Therefore, the compressive strength results 
were not meaningful for such low-pressure logs. It can be seen from Fig. 3-2(a) that the higher the compaction pressure, the higher the density of the logs becomes. Pressure has more effect on the density of the logs containing lower moisture. When the moisture was higher than $17 \%$, it became difficult to make the density of the logs near $1 \mathrm{~g} / \mathrm{cm}^{3}$ even when $138 \mathrm{MPa}$ pressure was employed. Considering the results from compressive strength tests, tumbler tests and drop tests, it can be concluded that the optimum moisture content for compaction of the mixed paper is in the neighborhood of $13 \%$. High quality logs with high density (near $1 \mathrm{~g} / \mathrm{cm}^{3}$ ) and good abrasion and impact resistance properties can be produced when the moisture is in the range between $10 \%$ and $17 \%$ and when compaction pressure is above $69 \mathrm{MPa}$. The appropriate moisture range for producing logs with reasonable quality is from air-dried (5-6\%) to $20 \%$.

\subsubsection{Effect of particle size and shape}

The effect of particle size of paper on compaction was found insignificant as long as the sizes of the particles were small enough to be fed into the mold smoothly. The particle shape effect was studied by using two different shredding methods: shear-type shredding (office paper shredder) and impact-type shredding (hammermill). The particles shredded by the paper shredder had uniform particles ( 6 by $25 \mathrm{~mm}$ ); those shredded by hammermill had non-uniform particle sizes (from dust-like particles to $25-\mathrm{mm}$ pieces) and irregular shape. It was found that the logs made of the paper shredded by the shear-type shredder have slightly higher densities than those made of hammermill-shredded paper - about 1-5\% higher. However the logs made of hammermill-shredded paper had smoother surface and no layers. Over all the effect of particle shape on paper log quality is small. This means that in commercial operations the choice of shredders should depend on practical and economic considerations rather than the ability to produce slightly better logs.

\subsubsection{Long-term performance of the logs}

It is important to know the change of log properties with time during storage and transportation. The logs made of mixed paper with different initial moisture contents and compacted under $138 \mathrm{MPa}$ pressure without holding time were observed for their changes of dimensions, moisture, and density in the open air in the laboratory. The longitudinal expansion (elongation) was used to describe the change of dimensions of the logs. The moisture and density of the logs were obtained by weighing them at the time the dimensions were measured. The results are shown in Fig. 3-3. It can be seen that the most rapid expansion occurred within the first 2 minutes after being ejected from the mold, and the higher the initial moisture content was, the more expansion the logs would undergo. All the logs with added initial moisture reached their expansion peaks within about 24 hours, then they started to shrink, resulting in density increase. The shrinking was apparently caused by the evaporation of moisture as shown in Fig. 3-3(b). After having been stored in open air for 7 days, the moisture contents of all the logs with initial moisture contents from $10 \%$ to $35 \%$ dropped to less than $9 \%$ and reached a steady state. The dimensions and densities of the logs also became steady after 7 days and a final dry density between 0.8 and $1.0 \mathrm{~g} / \mathrm{cm}^{3}$ was achieved for logs with initial moisture contents of $10 \%$ to $20 \%$. The logs with $5.4 \%$ initial moisture were made of paper mixture without added moisture (airdried). Instead of losing moisture and shrinking when stored in open air, they kept expanding slowly for about 10 days, then came to a steady state. This indicates that a small amount of added initial moisture can help make good paper logs and reduce the log expansion over long periods of time. This seems to indicate that the added moisture softens the fibers in the paper so that the 
paper can hold together more tightly after being compacted. However, if too much moisture is added (for instance, if the moisture is higher than 20\%), the paper swells significantly and becomes difficult to be compacted into dense logs. All these logs were monitored for over two months and no further deterioration of quality was observed. Fluctuations of air humidity had little effect on the $\log$ quality. The 2-minute dry density and the steady-state dry density of the paper logs are given in Table 3-2 along with those of the logs made of mixture of paper and plastic for comparison.

\subsubsection{Compaction of mixture of paper and plastics}

It was found that except for foamed polystyrene (PS), all the other plastic products found in MSW cannot be compacted into good logs even at $138 \mathrm{MPa}$ pressure. Since paper and plastic products are the largest components of MSW entering landfills, it will be ideal if the mixture of paper and plastics can be compacted into good logs in which paper plays the role of a binder. Taking paper and plastics discarded in municipal solid waste as $100 \%$, paper accounts for about $72 \%$ and plastics $28 \%$ [12]. Plastic products exist in three forms: hard, foamed, and filmed. Plastic film makes up $28 \%$ of the total plastics in MSW. Of the total film products, low-density polyethylene (LDPE) film makes up $71 \%$ and high-density polyethylene (HDPE) film 15\% [13]. In this test, mixtures of (1) mixed paper (the same material as mentioned in Section 3.1.2, hereafter to be referred to simply as "paper") and LDPE film, (2) paper and HDPE film, and (3) paper and hard plastics (including foamed products), were compacted by the small compaction machine under various pressure and moisture conditions.

Paper and plastic film. Mixture of paper and LDPE film containing 5\%, 10\%, 15\%, and $20 \%$ of LDPE film by dry weight were compacted at pressures of 69,102 , and $138 \mathrm{MPa}$ and at moistures of $5.4 \%$ (air-dried), 15\%, and 20\%. By the same token, mixtures of paper and HDPE film were compacted. The films were cut into approximately squared pieces of about 10 to 15 $\mathrm{mm}$. The expansions of the logs with time in the open air were monitored and results are shown in Fig. 3-4. The expansion of a log made of paper alone under the same pressure and moisture conditions is also plotted in the same graph for comparison. It can be seen clearly that higher film content produced greater expansion of the logs. After about 7 days, the expansions stopped and the logs reached a steady state. The dry densities of the logs measured 2 minutes after the logs were made and at the steady state after 7 days were measured and the results are listed in Table 3-2. Also listed in Table 3-2 are the results of the tumbler and the drop tests of the logs. It can be seen that higher film content produces lower quality logs. The results for logs made of mixture of paper and HDPE film are not listed because they were almost the same as those for paper and LDPE film. Photos of the logs made of paper and LDPE film and paper with HDPE film, at various film contents, are shown in Photo 3-2. Considering the densities and the results of the drop and tumbler tests, the conditions for making good-quality logs are: maximum film content $15 \%$, minimum pressure $69 \mathrm{MPa}$, and maximum moisture content $15 \%$. The maximum moisture is lower than that for paper alone from which good logs can still be produced at $20 \%$ moisture and $69 \mathrm{MPa}$ pressure.

Paper and hard plastics. Mixtures of paper and hard plastic products including foamed products were compacted. The plastics included hard products made of HDPE, PP, PET, and PS, as well as foamed PS products. The typical products made of these types of plastics are given in Table 2-1. The plastics were shredded into approximately square pieces of about 10 to $15 \mathrm{~mm}$ sizes. Equal amount of these materials was used to form the plastic portion in the mixtures. The 
mixtures containing 10,20 , and $30 \%$ plastics by weight on dry basis were compacted at three different pressure, 69, 102, and $138 \mathrm{MPa}$, and at three moistures, 5.4, 15, and 20\%. The expansions with time of the logs with 10,20 , and $30 \%$ hard plastics compacted at $138 \mathrm{MPa}$ and at $15 \%$ moisture are shown in Fig. 3-5. The properties of the logs were tested and results are given in Table 3-3. Unlike the paper-film logs, the logs containing up 30\% hard plastics still had good quality. The expansions of the logs were also smaller than those of the paper-film logs. Photos of the logs containing different amounts of hard plastics compacted at $102 \mathrm{MPa}$ and at $15 \%$ moisture are shown in Photo 3-3. It can be concluded that the conditions for producing good logs from mixture of paper and hard plastics are: maximum plastic content $30 \%$, maximum moisture $15 \%$, and minimum pressure $69 \mathrm{MPa}$.

Paper and mixed plastics. The compaction of a mixture of mixed paper and mixed plastics containing $77 \%$ mixed paper, $6.4 \%$ plastic film, and $16.6 \%$ hard plastics was studied. Of the $6.4 \%$ plastic film, $71 \%$ was LDPE film and $29 \%$ was HDPE film. This mixture represents the typical composition of the paper and plastics in municipal solid waste [12]. Logs were produced at a pressure of $69 \mathrm{MPa}$ and moisture contents between $5.4 \%$ and $20 \%$. The properties tested are listed in Table 3-4. The results show that reasonably good logs can be produced under these conditions. Apparently, these pressure and moisture conditions are the same as those for paper compaction. This reveals that the compaction characteristics of the mixture are dominated by the paper.

\subsubsection{Compaction of typical combustibles in municipal solid waste}

Waste paper, plastics, textiles and wood constitute $94 \%$ of all the combustibles discarded in MSW streams in the U.S. [12]. The averaged proportions of these four types of materials in the MSW are respectively $56 \%, 23.3 \%, 8.2 \%$, and $12.5 \%$. A mixture of the four types of the materials were prepared according to the above proportions and compaction of the mixture was performed at three different pressures, 69, 102, and $138 \mathrm{MPa}$, and three moistures, 6\% (airdried), $15 \%$, and $20 \%$. The paper portion was a mixture of five types of paper as defined in Section 3.1.2. The plastic portion contained $30 \%$ film and $70 \%$ of hard plastics. These plastics were shredded into approximately squared pieces of 10 to $15 \mathrm{~mm}$ in size. The textile portion was mainly cloth (both artificial and cotton), which was cut into 10 to $15 \mathrm{~mm}$ squared pieces. The wood portion was oak wood shredded to pieces less than $15 \mathrm{~mm}$ in size. This test was aimed at finding the optimum compaction conditions of the typical mixture of the combustibles in MSW.

The expansions with time for the logs compacted at 69,102 , and $138 \mathrm{MPa}$ and at $15 \%$ moisture are shown in Fig. 3-6. The tested properties of the logs produced at different pressures and moistures are given in Table 3-5. It can been seen from the table that to make good logs of this mixture, the compaction pressure must be equal or higher than $102 \mathrm{MPa}$, and moisture must be lower than $15 \%$. Photo 3-4 shows the logs made of this material at air-dried moisture (6\%) and three different pressures 69,102 , and $138 \mathrm{MPa}$.

\subsection{Compaction of Woody Materials}

Six types of woody materials - oak, oak bark, walnut, pine, red cedar, and cottonwood, in the forms of sawdust, mulches, and chips, were studied. Oak and walnut are typical hardwoods, pine and red cedar are typical softwoods, and cottonwood is a soft hardwood. The materials were obtained from sawmills in Missouri and were tested while they were fresh, i.e., stored for less than three months. The sawdust was sieved to remove particles larger than $2.36 \mathrm{~mm}$ before use. 
The wood mulches were produced at sawmills by mulchers (tub grinders) from the scraps generated during the process of sawing the debarked timbers into lumbers, and contained no bark. The mulches consisted of sliver particles with top size of $40 \mathrm{~mm}$ in length and $7 \mathrm{~mm}$ in diameter. The chips were produced by chippers from the same scraps and had approximately rectangular particles with top size of $40 \times 30 \times 5 \mathrm{~mm}$. The oak bark used in this study was also in the form of mulches except that it had significantly more small irregular particles. The oak bark mulch was produced by mulchers from the rejects of the debarking process, consisting of about $80 \%$ bark and $20 \%$ sapwood. Photographic views of different forms (sawdust, mulch and chip) of oak and oak bark are shown in Photo 3-5(a). Other types of wood had the similar forms. The materials had 20 to $45 \%$ initial moisture contents. Different moisture contents for the compaction tests were achieved by air drying - spreading the materials on the floor in the laboratory under room temperature and natural venting.

\subsubsection{Effect of pressure and holding time}

The effect of pressure holding time during compaction was studied extensively using oak sawdust at pressure of $103 \mathrm{MPa}$ and at different holding times ranging from zero second to 60 seconds. Figure 3-7 shows the variation of the densities of the logs with the pressure holding time. The logs were made of oak sawdust with $9.7 \%$ moisture content and compacted at 103 MPa pressure. The densities of the logs were measured both 2 minutes and 24 hours after ejection from the mold. It can be seen that longer holding time increased the density of the logs slightly. A 10-second holding time could result in a 5\% increase in log density. When the holding time was longer than 20 seconds, the effect diminished significantly. The two curves in the figure indicate that the initial dry densities (measured at 2 minutes after ejection) of the logs were always higher than the density after 24 hours. This means that the logs have expanded considerably in 24 hours. The two curves in Fig. 3-7 have similar shape. This means that holding time has little effect on the expansion rate of the logs.

Four different compaction pressures without and with a 10 -second pressure holding time were used to study the compaction of all the woody materials. An example of the results for the logs made of oak sawdust at two different moistures is shown in Fig. 3-8. Similar results were obtained for all the other woody materials tested. The curves for all the cases have the same pattern: the density of the logs increased with the compaction pressure. The holding time had more effect at lower pressure than at high pressure. At the highest pressure used in this study $(138 \mathrm{MPa})$, the effect of holding time became negligible. The figure also shows that the sawdust with $8.7 \%$ moisture produced stronger (denser) logs than that with $15 \%$ moisture. The tested physical and mechanical properties of the logs made of different materials under various pressure and moisture conditions are listed in Table 3-6. It can been seen from this table that material type and particle shape/size also have a significant effect on the quality of the compacted logs. With regard to the types of the materials, bark is easier to compact than wood, and hardwood is easier than softwood. Red cedar was found to be the most difficult one to be compacted. The logs made of red cedar mulch had the poorest quality compared to the logs made of other wood mulches. Oak bark is the easiest among the tested materials to be compacted into good logs. At a moisture close to the optimum (8\%) and a pressure of $69 \mathrm{MPa}$, oak bark could be made into logs with dry density close to $1.0 \mathrm{~g} / \mathrm{cm}^{3}$. The logs also had a high impact and abrasion resistance. For the sawdust materials, oak sawdust made the strongest logs, cottonwood sawdust next, and pine sawdust the least. Pine sawdust logs had very low impact resistance even when made at $138 \mathrm{MPa}$ pressure and at moisture content close to the optimum (8\%), although their densities were fairly 
high. But when the pine sawdust was blended with some oak sawdust, the impact resistance of the logs was significantly improved (see the results for Mixed Sawdust in Table 3-6). The effects of particle size and shape are discussed separately in Section 3.2.3.

\subsubsection{Effect of moisture content}

The effect of moisture content on the properties of the logs was studied extensively for both oak sawdust and pine sawdust. Figure 3-9 shows both the dry and wet densities of the logs made at $138 \mathrm{MPa}$ without holding time as a function of the moisture. The density was measured 2 minutes after ejection from the mold. For both materials, when the moisture was higher than $13 \%$, the logs had low densities and were easy to disintegrate when subjected to small handling forces. At about $4 \%$ moisture, logs with the highest dry density were produced. However, the logs with initial moistures equal or less than $4 \%$ could not maintain good quality for a long time. They tended to absorb moisture from the air and expanded significantly, becoming fragile in a few days. Logs made at around $8 \%$ moisture had both high density and good long-term performance. This phenomenon can be seen from Photo 3-6 and Fig. 3-10. Photo 3-6 shows the logs made of oak sawdust and pine sawdust with different initial moistures three after the logs were made and stored in the open air. Fig 3-10 shows the expansion of the logs after 3 days. The longitudinal expansions (elongations) in 3 days were calculated on the basis of the lengths of the logs measured 2 minutes after ejection from the mold and then re-measured 3 days later.

The change of moisture content with time and air humidity were monitored for all these woody materials spread in a layer less than $10 \mathrm{~mm}$ deep in open shallow containers. Figure 3-11 shows the change of the moisture of oak sawdust with time. The results for other three materials reveal the same pattern: the moisture of the materials decreased sharply initially and then reached an equilibrium relative to the moisture in the air after about 3 days. The equilibrium moisture content changed with the air humidity. By plotting the equilibrated moisture as a function of the measured relative humidity of the air, a linear relationship was found for the six materials shown in Fig. 3-12. The squared correlation coefficients for the linear regression lines are all greater than 0.95 , which means excellent correlation. Under the normal humidity condition (relative humidity $50-60 \%$ ), the equilibrium moisture content for all the materials is close to $8 \%$. Logs made at moisture close to the equilibrium moisture do not tend to absorb moisture from the air so that they can maintain good shape over a long time.

Considering both the density and the long-term performance of the logs, moisture of 5$12 \%$ is the appropriate range for producing good quality logs of all the tested sawdust materials. The optimum moisture is in the neighborhood of $8 \%$. This optimum moisture content can be achieved within three days by natural air drying of the feed materials with an initial moisture over $40 \%$.

\subsubsection{Effect of particle size and shape}

The effect of particle size on log properties was studied using oak sawdust sieved into 4 groups of different ranges of particle size: $0-1.0,1.0-2.36,2.36-4.75$, and $4.75-10 \mathrm{~mm}$. Logs were made of these four groups of materials under the same moisture and pressure conditions. A mixture containing equal amounts of sawdust of the four particle size ranges was also prepared, and logs were made. The densities, abrasion resistance, and impact resistance of the logs were tested to examine the effect of particle size. The tested results are shown in Table 3-7. Logs made of materials with both small and large particles had higher densities than those with 
medium particle sizes. The logs with smallest particle size had the highest abrasion resistance and the lowest impact resistance. The logs with the largest particle size had the highest impact resistance and a low abrasion resistance. The logs with particle size in the range $1.0-2.36 \mathrm{~mm}$ had the worst abrasion resistance and low impact resistance. The logs made of the mixture with all particle sizes have the properties close to the average of the logs made of each particle size range. Photo 3-7 gives a visual presentation of the logs made of sawdust with different particle sizes and the resultant forms of the logs after tumbler and drop tests. Generally, particle size has some effect on the properties of the logs, but not as significant as the effect of moisture content and particle shape.

The effect of particle shape was tested by using oak in the form of sawdust, mulch, and chips. It was found that the material in the form of mulch produces the densest and strongest logs, sawdust the second, and chips the last. The long particles of the mulches can hold together strongly by interlocking mechanism, making the logs highly impact resistant and abrasion resistant. The logs made of oak chips had very poor impact and abrasion resistance. Even when compacted at $138 \mathrm{MPa}$ and containing $8.5 \%$ moisture content which is nearly optimum, the logs broke up in drop tests and tumbler tests. The densities of the chip logs were also lower than mulch logs and sawdust logs made under the same conditions. Photo 3-5 shows the photos of the logs made of oak and oak bark in the forms of sawdust, mulch, and chips before and after the drop and tumbler tests, along with the feedstocks from which the logs were made.

\subsubsection{Long-term performance of the logs}

The dimensions, density, moisture content, abrasion resistance, and impact resistance of the logs made of woody materials were monitored over a long time in the open air in the laboratory. The logs were made at different pressures and at approximately-optimum moisture (about $8 \%$ ) as defined in the previous Section. It was found that the air humidity of the environment has significant effect on the long-term performance of the logs made of woody materials. Figure 3-13 shows the expansion of oak sawdust logs made at $8 \%$ moisture and at four different pressures and monitored during February and March 2000. It can be seen that after an initial 7-day expansion, the logs became very stable and no further significant deterioration was observed. The measured density, impact resistance, and abrasion resistance were also very constant over the 60-day monitoring period although there were occasional small fluctuations in log dimensions. It can also be seen from Fig. 3-13 that logs compacted at higher pressure underwent smaller expansion. The same test was conducted during May and June 1999, but the results showed that the logs kept expanding (becoming looser) with time gradually and had significant fluctuations in dimensions. The difference can be seen by including the expansionwith-time curves obtained during the two different periods in one graph-Fig. 3-14. The main difference in the conditions was the atmospheric humidity. When the logs were monitored during May and June 1999, the relative humidity of air in the laboratory was high and unstable, ranged from 60 to $85 \%$ and fluctuated significantly with time. This condition caused fluctuations of the $\log$ moisture content, dimensions, and deterioration of the logs with time. The deterioration can be clearly seen from Curve 1 in Fig. 3-14, which indicates that the logs kept expanding and became looser and looser with time. In contrast, when the logs compacted under the same conditions were monitored during February to March 2000, the logs were very stable after initial 7 days of expansion and no significant deterioration was observed. This can be seen from Curve 2 in Fig. 3-14. The reason was that the air humidity in the laboratory was very low and stable (relative humidity 40 to $50 \%$ ) during this period. It can be concluded that an environment with a 
low and stable humidity is important for biomass logs to maintain good properties over a long time. The conclusion applies to all other woody materials tested except that the logs made of mulch expanded less than those of sawdust and chips.

\subsection{Compaction of Yard Waste}

Yard waste, including tree trimmings, lawn grass clippings, fallen leaves, and fallen fruits from trees such as oak acorns and pine cones, comprises the second largest component of the municipal solid waste stream in the U.S. [12]. Tested in this compaction study were hardwood tree trimmings and softwood tree trimmings, lawn grass clippings, hardwood leaves including hickory leaves, oak leaves, maple leaves, and a mixture of various types of hardwood leaves, pine needles, and pine cone. The hardwood tree trimmings were mainly branches of hardwood trees consisting of wood, bark, and leaves. The softwood tree trimmings consisted of branches of evergreen trees.

\subsubsection{Effect of moisture content}

Similar to the woody materials, the moisture content of the yard waste materials drastically affects the compaction and the quality of the logs. When fresh, all these yard waste materials had a moisture of 40 to $50 \%$. A long-term measurement of the moisture change with time and air humidity was conducted for all these materials dried naturally by the air in a wellventilated laboratory. It was observed that the moistures decreased sharply initially, and then reached an equilibrium relative to the humidity in the air after about 3 days. The equilibrium moisture content varied with the humidity of the laboratory air. By plotting the equilibrated moisture content as a function of the measured relative humidity of the air, a linear relationship was found for all these materials as shown in Fig. 3-15. Under normal conditions in this laboratory, the relative humidity was $40-70 \%$. The equilibrium moistures for leaves and lawn grass were relatively high $(8-13 \%)$, and for tree trimmings were low $(6-11 \%$ for hardwood tree trimmings and 5-9\% for softwood tree trimmings). It was found that the best logs can be produced when the moisture of the materials has reached the equilibrium with the moisture in the air. The higher the moisture content of the material, the looser the compacted logs are. This is due to the fact that these biomass materials swell when absorbing water, making them hard to compact. This phenomenon can be seen from the different densities of the hickory-leaf logs made at two different moistures, as listed in Table 3-8.

It was found that when the moisture content of any of these yard waste materials is higher than $20 \%$, the logs underwent rapid expansion upon ejection from the mold and disintegrated shortly. However, if the moisture content of the materials is too low (lower than equilibrium), the logs absorb moisture from the air and expand until the equilibrium moisture is reached. The expansion causes deterioration of the quality of the logs. Considering both the density and the long-term performance of the logs, the appropriate moisture range for compacting the yard waste materials is $6-13 \%$, and the optimum is about $9 \%$ for leaves and lawn grass, $8 \%$ for hardwood tree trimmings and $7 \%$ for softwood tree trimmings.

\subsubsection{Effect of compaction pressure}

The effect of the compaction pressure on the quality of the logs was studied for the different yard waste materials using four different ultimate compaction pressures $34,69,102$, and $138 \mathrm{MPa}$. Except the hickory leaves with $15.4 \%$ moisture and the lawn grass with $13.5 \%$ 
moisture, which were partially dried in open air, all the other materials were thoroughly dried in open air in the laboratory. Dry density, abrasion resistance, and impact resistance of the logs were measured to evaluate the log quality. The dry densities were measured 2 minutes after the logs were ejected from the mold. Photo 3-8 shows logs made of mixed hardwood leaves, pine needles, pine cones, and lawn grass, along with the raw materials from which the logs were made of. The pressure effect can be clearly seen in those photos.

Table 3-8 summarizes the tested properties of the logs produced at different pressures without holding time. Considering the density, tumbler test result and drop test result of the logs, it can be concluded a pressure of $69 \mathrm{MPa}$ is essential for all the yard waste materials except lawn grass, which is harder to compress so that at least $102 \mathrm{MPa}$ is needed to produce good logs. The tree trimmings make the strongest logs among all these materials. Under the above pressure conditions and air-dried moistures, the logs made of yard waste materials can have a dry density higher than $0.8 \mathrm{~g} / \mathrm{cm}^{3}$

\subsubsection{Long-term performance of the logs}

An over 2-month observation of the quality change of the logs with time showed that the logs made of leaves, pine needles, tree trimmings, and pine cones could maintain good quality for a long time. Most of the logs stopped expansion after 4 or 5 days. The final volume expansions were all within $10 \%$. However, the logs made of lawn grass expanded about $20 \%$. Same as concluded for woody materials, a low and stable humidity is important for biomass logs to maintain good properties over a long time.

\subsubsection{Effect of particle size on quality of grass logs}

Compaction of lawn grass with three different particle sizes was conducted to study the effect of particle size. The feedstocks of different particles included: (1) originally mowed grass with particle length of about 50-100 mm, (2) grass cut into pieces of about $20-25 \mathrm{~mm}$ long, and (3) hammermill-ground grass of which the particle size was less than $3 \mathrm{~mm}$ inch. The impact and abrasion resistances, density, and expansion with time of the logs made of each of the three grass feedstocks with different particle sizes were tested. The logs were made with the small compaction machine under the same compaction conditions, i.e., $102 \mathrm{MPa}$ compaction pressure without holding time and 7.5\% moisture. Figure 3-16 shows the monitored results of the expansions of the logs with time, and Table 3-9 gives the density, impact and abrasion resistance results.

It can be seen from Fig. 3-16 that the smaller the grass particle size was, the less expansion the logs underwent with time. Compared to the logs made of the originally mowed grass, the logs made of the hammermill-ground grass underwent $3.3 \%$ smaller longitudinal expansion (elongation) on the average. The relative humidity had been between 40 and $50 \%$ during the 40-day monitoring period except the $2^{\text {nd }}, 3^{\text {rd }}$, and $4^{\text {th }}$ days when the humidity reached $63 \%$ at the highest. The expansion on these several humid days was also high as can be seen in Fig. 3-16. Note that the logs made of the ground grass were not observed during the same period when the logs of original grass and cut grass were observed. The relative humidity during the period when the logs of the ground grass were observed was low and stable - between 40 and $50 \%$ over the whole period. This is why there was not a sharp increase in expansion for the ground grass logs on the $2^{\text {nd }}$ through $4^{\text {th }}$ days. 
Table 3-9 shows that the density of the logs made of ground grass was only $2.5 \%$ higher than that of the originally mowed grass, but the impact resistance and abrasion resistance were lower. This could be due to the loss of the interlocking mechanism of the ground grass, causing the logs to lose more mass or break easier when subjected to abrasion or impact. Since grinding the grass does not bring significant improvement in log quality and incurs extra production cost, it is not cost-effective to grind the grass before compaction unless it is necessary in practice to facilitate feeding of grass into the mold.

\subsection{Compaction of Energy Crops}

Two types of energy crops were tested: switchgrass and willow. For the switchgrass, both the aged switchgrass and the fresh were tested. The aged one was supplied from a farmer in Iowa, and it had been stored in the open air for over a year and had a golden-yellow color when being tested. It had been cut into short pieces of $15-\mathrm{mm}$ to $30-\mathrm{mm}$ length when received. The aged switchgrass was also ground by hammermill into fine particles with top size of $5 \mathrm{~mm}$ to make logs to compare with those made of unground switchgrass. The fresh switchgrass was obtained from the test field of the Department of Biological and Agricultural Engineering, University of Missouri-Columbia. The grass had grown as tall as 2 to $2.5 \mathrm{~m}$ when it was harvested. The top portion of the grass was still green while the bottom portion had turned into yellow. It was cut into pieces of 30-mm maximum length and dried under room conditions. The willow feedstock contained freshly-harvested stems, branches, and leaves of willows, and shredded into mulch by a tub-grinder.

The results for the compaction of willow mulch are almost the same as those for hardwood tree trimmings as presented in Section 3.3. Therefore, only the results for switchgrass are presented in this section.

The results for the effect of moisture on the compaction of switchgrass showed that the air-dried moisture is the optimum, which is about $9 \%$ under relative humidity of around $50 \%$. Even under this optimum moisture, all the switchgrass feedstocks, including aged, ground aged, and fresh, need a pressure as high as $138 \mathrm{MPa}$ to be compacted into good-standing logs. This means that the particle size and age of the switchgrass do not have significant effect of this material. Table 3-10 gives the measured properties of the logs made of aged switchgrass, ground aged switchgrass, and fresh switch grass at $138 \mathrm{MPa}$ and at various moistures. It can be seen from this table that the mechanical properties of the logs made of ground switchgrass were even worse than those made of the unground material although the densities of the former were slightly higher than the latter. At higher moisture (11.4\%), the logs' abrasion resistance and impact resistance were improved slightly, but the density decreased significantly.

\subsection{Comparison between Small and Large Logs}

A comparison of the quality of the 137-mm-diameter logs with that of the $48.5-\mathrm{mm}$ diameter logs made of the same materials under similar conditions is given in Table 3-11. The large logs were compacted with the large and fast compaction machine and small logs were compacted with the small hydraulic press. It can be seen that there was only slightly (less than $1 \%$ ) difference between the densities of the large and the small logs made of mixed paper at $15 \%$ to $20 \%$ moisture content. Much greater (over 10\%) differences in density existed between the large and the small logs made of mixed paper at 5.4\% (air-dried) moisture. For air-dried oak sawdust and oak mulch the difference in density was 5 to $6 \%$. The small logs generally had 
higher densities. This could be due to the much higher compaction speed of the large machine than that of the small one. Higher compaction speed means shorter compaction time, equivalent to a shorter holding time.

In general, the size of the logs or compaction machine has small effect on the log quality.

\subsection{Effect of Mold and Piston Conditions}

\subsubsection{Mold and piston shapes}

Previous study on coal log compaction conducted at CPRC proved that the exit shape of compaction mold has a strong effect on coal log quality. An exit with a sharp edge causes cracks or microcracks in coal logs due to stress concentration at the edge generated by elastic expansion of the part of the coal log exiting the mold. It was found that a tapered exit or a round-edged exit of the mold could greatly reduce the stress concentration and damage to coal logs [14]. It was also known that a piston having a convex surface reduces the tendency of capping damage to coal logs and hence produces better quality logs than the flat-end piston. In this study, a mold with $1^{\circ}$ taper angle and $25-\mathrm{mm}$ taper length and a piston with convex end were prepared. Four types of biomass materials with different moisture contents were used to produce logs by both the tapered mold and the straight mold to study the effect of mold exit shape. Similarly, the effect of the piston shape was studied for the same materials by comparing the logs made with a convex-end piston and a flat-end piston. Note that the convex piston was used at the exit end of the mold only, where the pressure is released first and capping is likely to develop. The compaction pressure was $102 \mathrm{MPa}$. The densities and the drop test and tumbler test results of the logs were used to compare their quality in order to evaluate the effect of the mold and piston shape.

The results show that the shapes of mold exit had only minor effect on the quality of the biomass logs. A slight difference in log density can only be detected at the third decimal. For oak sawdust, the logs made with the tapered mold had slightly higher $(0.7 \%$ higher) density than those made with the straight mold. The former also had slightly higher abrasion and impact resistances. For oak mulch, the logs made with the tapered mold had slightly higher density (1.4\% higher), but no difference in abrasion and impact resistance was observed. For the mixed paper logs, those made with the tapered mold had slightly lower densities $(0.4 \%$ lower $)$, but no significant difference in abrasion and impact resistance. For the pine sawdust logs, differences in all the tested properties were negligible. Because only one taper angle $\left(1^{\circ}\right)$ was studied, it is quite possible that a larger than $1^{\circ}$ taper angle may be needed to produce significantly better biomass logs. However, this was not pursued in this research because of the relatively minor improvements in log quality anticipated, and the need to pursue other more important factors in this relatively short (18 month) study.

The effect of a convex-end piston on the properties of the logs made of all the tested materials was found negligible compared to the logs made with the flat-end piston.

In conclusion, convex-end piston cannot significantly improve the quality of biomass logs. Therefore, flat-end piston is recommended, which is easier to manufacture. As to the effect of mold exit shape, while the result is inconclusive because only one exit taper angle $\left(1^{\circ}\right)$ was tested, the limited data suggests that at least for mulch and sawdust the tapered mold produces better biomass logs even though the improvement is not as dramatic as for coal logs. Note that coal logs is a brittle elastic material which easily develops cracks when subjected to stress. In 
contrast, biomass materials contain a large amount of fibers and are very ductile. Thus, biomass logs develop less stress and fewer cracks upon exit from mold.

\subsubsection{Mold roughness}

Previous coal log compaction research found that the wall friction of molds can cause a difference in the axial stress transmitted to the bottom piston. For hard and brittle materials such as coal, a smooth or lubricated mold can significantly increase the transmitted force to the bottom piston during compaction and reduce the ejection force during ejection [15]. In this study, two 48.5-mm-diameter molds having different wall roughness were used to investigate the effect of wall roughness on the quality of biomass logs. Both molds were made of stainless steel. The smooth mold has a heat-treated (hardened) and micro-honed wall which had a roughness of 0.38 micron in average amplitude (peak to valley). The rough mold was not heat-treated and had been scratched by materials during past compaction tests. The wall roughness of this mold was measured to be approximately 22 micron in average amplitude. Four types of materials including mixed paper, oak sawdust, oak mulch, and pine sawdust were tested for the effect of mold roughness. Figure 3-17 shows the pressure-versus-displacement curves of the pistons in the two molds during the compaction of mixed paper; similar results were obtained for other three types of materials. In this test, exactly the same amount of material was fed into the two different molds and the same compaction process was followed, so that the only difference in the compaction condition was wall roughness of the molds. The densities of the logs produced by the two molds were measured as shown in Table 3-12. It can be seen from Fig. 3-17 that for all the tested materials, the piston in the smooth mold moved further than in the rough mold under the same pressure. Therefore, the logs in the smooth mold were compacted more. The densities of the logs shown in Table 3-12 reflect the same conclusion - smoother mold makes denser logs. The differences in densities of the logs made by the smooth and rough mold ranged from $0.5 \%$ to $2 \%$ for different materials. Because smoother molds also require less energy to compact, molds for biomass compaction should have smooth interior.

\subsection{Effect of Back Pressure}

The uniquely designed 250-ton large hydraulic press at CPRC has the special feature of back-pressure control. During ejection of logs a controlled pressure can be maintained on the withdrawing piston to prevent logs from expanding and developing cracks and capping while being ejected. Systematic tests of the effect of back pressure with a series of back pressures ranging from 0 to $10 \mathrm{MPa}$ were conducted. The tested materials included air-dried mixed paper (moisture 5.4\%), mixed paper containing 15\% moisture, air-dried oak sawdust, oak mulch, hickory leaves, and maple leaves. The effects of different back-pressures on the integrity and density of the logs of different biomass materials were tested and the results are summarized in Table 3-13. Two examples of the logs compacted with and without back pressure are shown in Photo 3-9. A pressure of $102 \mathrm{MPa}$ was employed for the compaction of all the logs, and no pressure holding time was used.

The results show that for mixed paper and leaves, back pressure did help produce better logs. The logs of these materials compacted without back pressure had relatively loose top, and developed some cracks near the top potion. By "top" we mean the end of the log which comes out of the mold first during ejection. But for sawdust and mulch, the effect of back pressure is insignificant. It can be seen from Table 3-13 that the back pressure did not need to be very high 
to make a difference - a 0.7-MPa (100-psi) back pressure was sufficient to improve the quality of the logs. For logs made of mixed paper, the higher the moisture was, the less effect of back pressure was observed. The back pressure had the most significant effect on the leaf logs. The leaf logs produced without back pressure had large layered cracks, but those with back pressure did not develop any cracks. Compared to the logs made without back pressure, a 0.7-MPa back pressure brought $8 \%, 4.5 \%, 25 \%$, and $12 \%$ increases in the densities of the logs made of airdried mixed paper ( $5.4 \%$ moisture), mixed paper with $15 \%$ moisture, air-dried hickory leaves, and maple leaves, respectively. For logs made of air-dried oak sawdust and oak mulch, a 100-psi back pressure only increased the density by less than $1.5 \%$. Even without back pressure, no capping and cracking occurred with the sawdust logs and the mulch logs.

The results also show that further increasing of the back pressure from $0.7 \mathrm{MPa}$ to 10 $\mathrm{MPa}$ only resulted in minor improvement in the quality of the logs. This indicates that a back pressure of $0.7 \mathrm{MPa}$ can overcome the tensions on the biomass logs induced during ejection, and prevent the logs from capping and cracking. It is expected that with even smaller back pressure, equally good logs can be produced. However, it is hard to adjust to smaller back pressures with the current compaction machine. Machine modifications are required before back pressure smaller than $0.7 \mathrm{MPa}(100 \mathrm{psi})$ can be produced and controlled by this machine. It can be concluded that back pressure improves the quality of biomass logs, and that it is not necessary to use a back pressure greater than $0.7 \mathrm{MPa}$ to make good logs.

\subsection{Effect of Binder}

It was found that logs produced from biomass materials were very feeble to water, and would disintegrate or dissolve within 1 minute after being immersed in water. The Orimulsion, which was successfully used in improving coal log strength and water resistance, was used as a binder to improve the water resistance of the biomass logs. Logs of mixed paper and oak sawdust with up to $6 \%$ Orimulsion were made at $138 \mathrm{MPa}$ pressure and optimum moisture contents. It was found that the logs with binder still disintegrated in water in less than 10 minutes. It was concluded that binders cannot significantly improve the water resistance of biomass logs. The reason for this is that biomass materials are fibrous. The fiber creates capillary effect which soaks water into the fiber. Unless all the fiber elements were coated completely with Orimulsion, the material would soak water and expand significantly. To make the logs water-resistant, either the surface of the whole log or every particle in the log must be coated thoroughly with a waterrepelling binder material such as Orimulsion. This was found to be neither practical nor economical.

\subsection{Effect of Zeta Potential}

It was found that pine sawdust logs have much poorer mechanical properties than the logs made of other types of sawdust materials. It was also found that the zeta potential of pine sawdust is higher than that of the other sawdusts. From experience gained from previous study on compaction of binderless coal logs, the coal log quality can be improved significantly by reducing the zeta potential of the coal. Aluminum chloride and polyethylene oxide (Polyox) were found to be the most effective additives for neutralizing the zeta potential of coal. A small amount of these additives can increase the strength of the coal logs by 50\%. Polyox was chosen in this study to determine its effects in altering the zeta potential and the quality of biomass logs. Different amounts of Ployox were added into pine sawdust to form feedstocks with Polyox 
concentrations ranging from $0 \%$ to $3 \%$. The moisture content of all the feedstocks was adjusted to $9.2 \%$. Logs were made at $138 \mathrm{MPa}$ pressure without holding time, and were tested for density, impact resistance, and abrasion resistance. The results showed that there was little improvement in the log properties when the additive concentration was less than $1 \%$. Significant improvement could be seen only if the additive concentration was as high as $3 \%$. Because each pound of Polyox costs about 5 dollars, it is not economical to use it in commercial applications.

Another problem is mixing. Because good sawdust logs cannot be produced if the moisture content is higher than $12 \%$, the additive must be mixed with sawdust under low moisture condition. It is difficult to dissolve the additive and achieve a uniform distribution when the moisture is low, especially when the additive concentration is low. It is concluded that adjusting zeta potential of the woody material to improve the logs' quality is not practical. It is much more cost-effective to adjust the moisture content or to mix the pine sawdust with other easy-to-compact sawdust (such as oak sawdust) for improving logs quality than to use Polyox or other additives for zeta potential adjustments.

\subsection{Water Expulsion during Compaction}

Tests were conducted to determine whether high moisture in the biomass materials can be expelled (squeezed out) by high-pressure compaction. This test was conducted for mixed paper, pine sawdust, and oak sawdust.

Mixed paper with three different high initial moisture contents was compacted at 138 MPa pressure with holding times from 0 to 60 seconds. The results are shown in Fig. 3-18. It was found that when the initial moisture content was below $30 \%$, water could hardly be squeezed out even though the pressure holding time was as long as 60 seconds. When the initial moisture content was above $30 \%$, some amount of water could be expelled depending on the initial moisture and holding time. But it was difficult to reduce the moisture content to below $30 \%$.

The same tests were conducted for sawdust. Pine sawdust and oak sawdust with initial moisture contents of $42 \%$ and $39 \%$ respectively were compacted at $138 \mathrm{MPa}$ pressure with 60 second holding time. After compaction, the moisture content of pine sawdust became $37 \%$ and that of oak sawdust became $31 \%$. The material could not maintain log shape and broke loose soon after ejection from the mold.

These results indicate that using high pressure to reduce the moisture of the biomass materials for producing good logs is impractical in commercial applications. Biomass materials containing a high amount of moisture should be dried by other methods such as air dry or sun dry.

\subsection{Volume Reduction through Compaction}

The compaction ratio of a material indicates the volume reduction due to compaction. It is calculated from the ratio of the ultimate density of the compact $(\log )$ to the starting density or bulk density of the feedstock. Since there is significant variability in the starting density determined by different researchers under different conditions, the compaction ratios cannot be documented universally. Even for the same material, the starting density changes with the moisture content and the way it is stored and measured. Nevertheless, the compaction ratio is an important parameter in the design and economic analysis of the compaction process. In order to 
facilitate the cost analysis of the production and transportation of the biofuel produced, and to provide the basic parameters for the design of the compaction machine for commercial application, the compaction ratios of most of biomass materials were determined in this project.

A piled bulk density of the materials was used as the initial density to determine the compaction ratios. Piled bulk density is the bulk density of the biomass raw material piled in a box of 300-mm height under the action of gravity without any means of pre-compaction. The material in the box was shaken to a stable volume before the density was measured. The densities of the logs made at $102 \mathrm{MPa}$, which is the pressure necessary for producing good logs from most of the biomass materials, were used as the ultimate density. Table 3-14 gives the piled bulk densities, the ultimate densities obtained at $102 \mathrm{MPa}$, and the compaction ratios of all the tested materials. It shows that the compaction ratio of biomass materials varies greatly for different materials, ranging from 4 for sawdust to as much as 77 for leaves.

\subsection{Water/Rain resistance of the biomass logs}

The water resistance test of the biomass logs showed that all biomass logs were feeble to water. They all disintegrated or dissolved within 1 minute after being immersed in water.

A rain-resistance test of the logs were conducted to evaluate how the logs behave when exposed to rain. A rain intensity of 2.0 inches per hour was used, which represents the 5-year return period of 1-hour duration rainfall in central and eastern United States. Three different exposure times, 1,5 , and 10 minutes, were used to test the durability of the logs in the rain. Logs used in the rain tests are 48.5-mm-diameter logs made of mixed paper, oak sawdust, and oak mulch, compacted at air-dried moistures and at $102 \mathrm{MPa}$ compaction pressure.

Table 3-15 summarizes the rain test results. The properties of the logs were observed or measured at three times: immediately after exposure to rain, 5 minutes after exposure, and 24 hours after exposure. Immediately after the exposure, pictures were taken to shown the physical changes, and the weights of the logs were measured to find the water absorption. Given in Table 3-15 is the water absorption for each log for three exposure times, and their corresponding expansions and state of the logs 5 minutes and 24 hours after the rain tests. Photo 3-10 shows the logs immediately after 1-, 5-, and 10-minute rain exposures.

It can be seen from both Table 3-15 and Photo 3-10 that the sawdust logs were the most vulnerable to rain. Although only being exposed to rain for 1 minute, the sawdust logs expanded by $37 \% 5$ minutes later and disintegrated in 24 hours. The mulch logs were a little more resistant to the rain, but 5 -minute exposure caused the logs to absorb $12 \%$ water and to expand by $36 \%$ five minutes after the exposure; and 24 hours later, the logs disintegrated as well. The paper logs were the most rain-resistant compared to the sawdust logs and mulch logs: 10-minute exposure caused the logs to absorb $20 \%$ water, and the logs did not disintegrate after 24 hours, though they expanded by $74 \%$ and became fragile.

It can be concluded that all the biomass logs are very vulnerable to water and rain and need to be protected from water or rain during storage and transportation.

\subsection{Combustion Characteristics of Biomass Logs}

The combustion characteristics of the compacted logs mainly depend on the properties of the raw materials. The higher heating value, volatile matter, fixed carbon, and ash content of the 
materials were tested to assess the combustion characteristics of the fuel logs made of the materials.

Table 3-16 gives the tested results. Among the waste papers tested, the commercial printing including magazines, advertisement and brochures has the lowest heating value 11.6$12.8 \mathrm{MJ} / \mathrm{kg}(5,000-5,500 \mathrm{Btu} / \mathrm{lb})$ and very high ash content (about $23 \%)$. The office paper also has fairly low heating value $15.1 \mathrm{MJ} / \mathrm{kg}(6,500 \mathrm{Btu} / \mathrm{lb})$ although the ash content is not as high. The newsprint, corrugated board and box board have heating values between $17.4 \mathrm{MJ} / \mathrm{kg}$ and $19.0 \mathrm{MJ} / \mathrm{kg}(7,500$ and $8,150 \mathrm{Btu} / \mathrm{lb})$. The woody materials and yard waste except softwood tree trimmings all have heating values close to or higher than $19.5 \mathrm{MJ} / \mathrm{kg}(8,400 \mathrm{Btu} / \mathrm{lb})$ and low ash content-most of their ash contents are lower than 5\% except lawn grass and leaves which have $11 \%$ and $8 \%$ ash contents respectively. The softwood tree trimmings only has a heating value of $14.3 \mathrm{MJ} / \mathrm{kg}(6,150 \mathrm{Btu} / \mathrm{lb})$ with a very high ash content $(28 \%)$. The heat values of the plastics are the highest among all the tested materials-all higher than $37.2 \mathrm{MJ} / \mathrm{kg}(16,000 \mathrm{Btu} / \mathrm{lb})$ except PET which has a heating value of $23.3 \mathrm{MJ} / \mathrm{kg}(10,000 \mathrm{Btu} / \mathrm{lb})$. The ash contents of the plastics are all lower than $0.5 \%$. Therefore, adding certain amount of waste plastics to waste paper or other biomass materials will make the logs a better fuel.

\subsection{Economics of Production and Use of Biomass Logs as Fuel}

A detailed cost analysis was conducted to determine the unit production cost, unit transportation cost, and unit power plant handling cost of biomass logs for power plant use. The sum of these three unit costs yields the cost of the fuel delivered to the power plants. It is referred to as the "delivered fuel cost" herein. The life-cycle cost analysis model and net-cash-flow approach as indicated in Section 2.3.3 was used for the calculations of the production cost, power plant handling cost, and transportation cost by pipeline. The transportation costs by truck, barge, and rail were obtained by reviewing, analyzing the applicable cost information, from the literature, and from consulting transportation agencies and companies. Only the results and brief descriptions of the methods and assumptions are presented here. Details of the analysis can be found in a separate report submitted to DOE, entitled "Economic Analysis of Compacting and Transporting Biomass Logs for Co-firing with Coal in Power Plants" [11].

\subsubsection{Unit production cost}

For the unit production cost, two cases were investigated. The first is a fixed-location system for a large biomass log production plant located at the waste processing center of a large city. The second case is a truck-mounted portable plant for compacting biomass materials into 50-mm-diameter logs at different wood-processing plants.

\section{Fixed-Location System}

For the fixed-location system, different throughputs ranging from 135,000 tons per year to 675,000 tons per year are used to examine the effect of the plant size. Large rotary presses, each having a production rate of 386 tons/day, are to be used. The itemized and total capital cost and annual cost are summarized in Table 3-17. In the calculation of the unit production price, the following assumptions were used:

(1) The general inflation rate, I, is $3 \%$.

(2) The return rate, $r$, is $15 \%$.

(3) The economic life of the project, N, is 20 years. 
(4) Depreciation of capital is flat (constant) over 20 years $\left(\mathrm{N}_{d}=20\right)$.

(5) The corporate income tax rate, $t$, is $37 \%$

(6) The discount rate, $\delta$, calculated from Eq. 7 in Section 2.3 .3 , is 0.1845 .

(7) Present costs are based on Year 2000 values.

(8) All the cost items are inflated according to the same general inflation rate, I, of $3 \%$.

(9) The revenue escalation rate, $e_{r}$, is the same as the general inflation rate.

(10) The property tax rate is equal to $2 \%$ of the total capital cost.

(11) The annual insurance cost is $0.5 \%$ of the total capital.

(12) The equity is 1.0. This means that all the money invested on the project (the capital cost) comes from the owner; no money is borrowed. Otherwise, interest rate would also enter the calculation.

(13) The specific gravity of the biomass logs is 1.0 , which means that the logs have the same density as water. This refers to the density of the logs with moisture included (i.e., wet density).

(14) All the biomass fuels need protection from rain.

(15) The biomass waste materials at the source are combustible and already separated from the non-combustible solid waste materials. No cost is included for separation of solid wastes into combustible and non-combustible parts.

Based on the cost items in Table 3-17 and the above assumptions, using the cost model as established in Section 2.3.3, the unit production cost or price for the different throughputs were calculated, and results are shown in Fig. 3-19. It can been seen that the unit cost increases as the plant capacity decreases. For the large plant that produces 675,000 tons of logs per year, the unit production cost is only $\$ 5.47$, whereas for the small plant that produces 135,000 tons per year, the unit cost is $\$ 8.16$. It should be noted that these costs are based on a company return rate of $15 \%$ above inflation. The points on both sides of the curves in Fig. 3-19 mark the results of a sensitivity analysis with $25 \%$ variation of capital or annual cost. It can be seen from Fig. 3-19(a) that an increase or decrease of the capital cost by $25 \%$ causes the unit cost to increase or decrease by $10 \%$ approximately. And, an increase or decrease of the annual cost (operation and maintenance cost) causes the unit cost to increase or decrease by $15 \%$ approximately as shown in Fig. 3-19(b).

Under the same conditions, the unit production cost for higher return rates of 20,25, and $30 \%$ was also calculated for different throughputs ranging from 135,000 tons/yr to 675,000 tons/yr. The results as shown in Figure 3-20 indicate that the unit production cost increases with the return rate linearly-a 5\% increase in return rate causes about $10-11 \%$ increase in the unit production cost.

\section{Portable System}

A portable (truck-mounted) system to produce $50-\mathrm{mm}$-diameter logs at the rate of four logs per second has been designed by CPRC [16]. With 4 logs per second, the system can produce logs at the rate of 39.2 tons/day in a 24-hour-continuous operation. The plant is projected to be operational only 300 days per year. In the other 65 days of each year, the plant is either being repaired, maintained, or on the road (being transported from one source to another). Then, the annual production rate of this system is 11,760 tons/yr.

The capital cost and the annual (operation/maintenance) cost of the portable biomass log production system are summarized in Table 3-18. Use the same cost model and the same 
assumptions as for the fixed-location system, the unit production cost was calculated to be as high as $\$ 79 /$ ton. This shows the importance of economy of scale-both the size of logs and the capacity of plant.

\subsubsection{Transportation cost}

The transportation cost analysis was done for truck, train, barge and pipeline. It should be realized that in over $90 \%$ of cases, truck is the only practical means for transporting biomass logs. However, on limited occasions, a railroad or a waterway may exist linking the biomass waste source or site to the power plant where the logs are burned. On such occasions, rail or barge may provide a better (more cost-effective) alternative to truck. Finally, for biomass logs produced at very large fixed-location plants, pipeline transport may be a possibility. Two types of pipeline are considered herein for transporting biomass waste logs. They are pneumatic capsule pipeline (PCP) which is an existing technology used commercially in Japan [17] for transporting limestone and construction materials, and hydraulic capsule pipeline (HCP) which is a new technology that has been studied extensively in the last nine years at the Capsule Pipeline Research Center (CPRC), University of Missouri-Columbia.

Truck transportation cost was analyzed based on two documents: one is a report on biomass supply issued by the Antares Group [18], and the other is a Tennessee study on biomass transportation and site location, published in the Proceedings of BIOENERGY '96 [19].

Rail and barge transportation costs were analyzed based on U.S. Department of Agriculture's weekly publication [20].

The costs for transporting biomass by using pneumatic capsule pipeline (PCP) and hydraulic capsule pipeline (HCP) were also investigated using the same life-cycle cost model as for the biomass production cost analysis. The data for PCP capital cost and annual cost were supplied by the Sumitomo Metal Industries, Ltd., which operates, manufactures and sells commercial PCP systems driven by blowers [17]. For this study, a special PCP was designed and analyzed using the same life-cycle cost model and assumptions as for the biomass log production cost analysis. The throughput was assumed to be 680,000 tons/yr of biomass log fuel (BLF).

Hydraulic capsule pipeline (HCP) uses unwheeled capsules to carry cargoes moving through a water-filled pipeline. The water moving through the pipe provides buoyancy and the lift needed for suspending (levitating) the capsules in the pipe, and provides the thrust to transport the capsules through the pipe. HCP is a new technology studied initially in Canada at the Alberta Research Council in the 1960s and 1970s [21]. Then the interest spread around the world, as demonstrated by research conducted in many nations. The technology was studied extensively at the University of Missouri-Columbia, in the last two decades.

In previous studies, it was found that due to the need of containers to protect the cargoes transported by HCP in a water-filled pipe, and the need for a separate pipeline to return empty capsules, rigid-container-type $\mathrm{HCP}$ can be economical only if the freight throughput and pipe diameter are large (over 1 million tons per year using pipes larger than $300 \mathrm{~mm}$ in diameter) and when the distance is long (over 20 miles) [22]. Since the quantity of biomass that needs to be transported in each case is generally much less than the quantity of coal and grain that needs to be transported, it is quite questionable that HCP can compete with truck, train or barge for transporting biomass. Nonetheless, a preliminary assessment has been conducted herein to determine the economic feasibility of using HCP to transport biomass. The study was done in the 
same manner as for PCP, using similar cost model and assumptions and the same rate of return$15 \%$.

The unit transportation costs (prices) for biomass logs by the above five transportation modes as a function of distance are given in Table 3-19. It can be seen that barge is the most cost-effective, followed by rail (unit train) and then truck. For instance, transporting biomass 500 miles costs only about $\$ 7$ by barge, $\$ 12$ by unit train, and $\$ 85$ by truck. This rules out using truck in places where train or barge can be used. For relatively short distances without connecting railroads or waterways between the BLF fuel production plant and the power plant that burns such fuel, truck is the common solution. The costs of transporting BLF by truck for 50 miles and 100 miles are approximately $\$ 12$ and $\$ 20$, respectively. Even without rail or barge, transporting biomass logs by truck over 100 miles is costly and uneconomical in most cases.

PCP and HCP systems are not cost-effective as compared to truck, train, or barge, except for the cases of very large systems that can transport more than 1 million tons per year. In spite of that, because PCP and HCP are environmentally more friendly and much safer than truck, they may still be preferable in places where truck is not welcome or allowed, or where the pipeline is used to transport not only BLF but also other cargoes so that the combined throughput will be larger than 1 million tons per year.

\subsubsection{Power plant handling cost}

Upon reaching the power plant by trucks or other transportation means, the biomass logs will be crushed immediately to an appropriate size for combustion and then stored for up to 24 hours in a silo before feeding into the boiler. Therefore, the power plant handling cost of the BLF includes crushing and storage. It was analyzed in a way similar to the analysis of the biomass production cost - life-cycle cost model and net-cash-flow approach. It should be realized that when using biomass fuel for co-firing with coal, the amount of coal needed at the power plant is reduced and hence there is a saving or reduction in the cost of coal handling at the plant. Therefore, the net cost of biomass logs to power plant operation is the cost of handling biomass at the plant, minus the saving or reduction in the cost of handling coal at the plant. However, to be conservative, in this study the saving produced from reduced handling of coal at power plant is ignored.

The analysis was done for different throughputs ranging from 135,000 to 675,000 tons/yr, assuming that the capital cost and annually cost are proportional to throughputs. The results show that the crushing and storage cost of biomass logs at the power plant is about $\$ 0.53$ per ton, which is an order of magnitude smaller than the biomass log production cost.

\subsubsection{BLF delivered cost}

The unit cost to a power plant for using biomass log fuel (BLF) at the plant (i.e., the delivered cost) is the sum of the unit production cost, the unit transportation cost and the unit handling cost at the power plant. For a power plant that uses 675,000 tons of BLF a year transported by truck for a distance of 50 miles, the delivered cost is approximately $\$ 5.5+12+$ $\$ 0.53=\$ 18$ per ton which, on a $\$ /$ Btu basis, is approximately $\$ 1$ per million Btu, or about the same as for coal paid by most power plants nowadays in the United States. This means that without considering environmental benefits and without considering avoided tipping fee at the landfill, the BLF is economical in today's market for transportation distances up to about 50 miles. If tipping fee is included which is usually more than $\$ 15$ per ton of the waste dumped, the 
economical transportation distance for BLF will be much longer than 100 miles. Because the sources of large quantity of biomass waste materials are in cities and because power plants are also located near cities, the transportation distance for BLF in most cases will be less than $\mathbf{5 0}$ miles. This means that even without considering the avoided tipping fee, BLF will be economical in most future applications, as soon as the technology is fully developed and ready for commercial use. 


\section{CHAPTER 4. CONCLUSIONS}

Through this study, it was found that most of the common types of biomass materials and combustible components of municipal solid wastes can be compacted into dense and strong fuel logs by using the high-pressure compaction technology developed by the Capsule Pipeline Research Center, University of Missouri-Columbia. With appropriate compaction pressure, moisture, particle size and particle shape, back pressure control and mold exit shape, all the materials studied can be compacted into high quality logs without using any binder or heat. This technology was also found to be attractive economically. Important conclusions are summarized as follows:

(1) The compaction pressure is a key factor in producing high-quality binderless biomass logs. For sawdust materials of various types of wood, a minimum pressure of $100 \mathrm{MPa}$ $(15,000 \mathrm{psi})$ is needed to produce dense and durable logs. For waste paper, mixtures of paper and plastic film, mixtures of paper and hard plastics, wood mulches, and all the yard waste materials except lawn grass, a pressure of $70 \mathrm{MPa}(10,000 \mathrm{psi})$ can produce good logs. For lawn grass and the mixture containing paper, plastic, textiles, and wood found in municipal solid waste, a pressure of $100 \mathrm{MPa}$ is necessary. For switchgrass which is an energy crop, a pressure as high as $138 \mathrm{MPa}(20,000 \mathrm{psi})$ is needed to form good logs.

(2) The moisture content of the materials is as important as the compaction pressure for producing good biomass logs. High moisture is detrimental to the compaction of biomass materials of all types; good logs cannot be formed if the moisture of any biomass material is higher than $20 \%$. For waste paper, good logs can be formed over a fairly wide moisture range: from air-dried moisture (5-6\%) to $20 \%$, and the optimum moisture for compaction of various types of waste paper is in the neighborhood of $13 \%$. For woody materials and yard wastes, the appropriate moisture range is narrower: $5-13 \%$, and the optimum is the air-dried moisture of $8-9 \%$. Logs made at moisture close to the air-dried moisture, i.e., equilibrium moisture, do not tend to absorb moisture from the air so that they can maintain good shape over a long time.

(3) The pressure holding time has a more significant effect on the quality of the biomass logs compacted at lower pressure. With the increase of compaction pressure, the holding time effect diminishes, and when the holding time was longer than 20 seconds, the effect also diminishes significantly. For most of the biomass materials compacted at $100 \mathrm{MPa}$ pressure, a 10-second holding time can result in about $5 \%$ increase in $\log$ density. Since longer holding means less productivity of biomass logs for each compaction machine, the fact that long holding time is not necessary is good news from the machine design standpoint.

(4) The effects of particle size and shape on log quality vary with different biomass materials. For shredded paper, the size and shape have little effect on the quality of the logs compacted. But for woody materials, particle size has some effect and particle shape has remarkable effect on the log quality. Woody materials in the form of mulch produce the strongest logs, sawdust the second, and chips the last. For grass (lawn grass and switch grass), grinding into fine particles can help produce slightly denser logs, but it adversely affects the impact resistance and abrasion resistance of the logs. Therefore, 
except for wood in the form of chips, all different particle sizes and shapes can produce good logs as long as the raw material can be fed into the mold efficiently.

(5) The effect of mold exit geometry on the quality of biomass logs is present but relatively minor. The effect of piston shape is negligible. The roughness of the mold has a definite but relatively minor effect on compacted log quality-smoother mold interior makes denser logs.

(6) The back pressure can improve the integrity and increase the density (by $8-12 \%$ ) of the logs made of dry paper and leaves; its effect on other biomass logs is minor. For waste paper and leaf logs, a back pressure of $0.7 \mathrm{MPa}(100 \mathrm{psi})$ or even smaller is sufficient to improve the log quality.

(7) The 137-mm (5.4-inch)-diameter logs compacted by the large compaction machine with high compaction speed generally have slightly lower density (5-6\% lower) than $48.5-\mathrm{mm}$ (1.91-inch)-diameter logs compacted by the small machine with low compaction speed. This is most likely a compaction time effect rather than a size effect.

(8) The logs compacted under the optimized compaction have a dry density of 0.8 to 1.0 $\mathrm{g} / \mathrm{cm}^{3}$ and a wet density of 0.9 to $1.1 \mathrm{~g} / \mathrm{cm}^{3}$. Such logs are highly resistant to impact and abrasion and easy to handle, store, and transport. The logs also have good long-term performance under normal environmental conditions, and can be stored for a long time without significant deterioration provided that they are not exposed to high moisture or water.

(9) All the biomass logs are feeble to water. They disintegrate within 1 minute after being immersed in water. They also can be significantly damaged after being exposed to a moderate rain for a few minutes. They need to be protected from water and rain during handling, storage, and transportation.

(10) The logs made of waste paper have an average higher heating value of $16.5 \mathrm{MJ} / \mathrm{kg}(7,100$ $\mathrm{Btu} / \mathrm{lb}$ ). For logs made of a mixture of paper and plastics, the heating values will be higher because plastics usually have more than twice the heating values of paper. If the logs contain 15\% plastics, the higher heating value can reach $21 \mathrm{MJ} / \mathrm{kg}(9,000 \mathrm{Btu} / \mathrm{lb})$. The logs made of woody materials and yard waste materials have an average higher heating value of $20.0 \mathrm{MJ} / \mathrm{kg}(8,500 \mathrm{Btu} / \mathrm{lb})$.

(11) The economics of producing biomass logs in large-scale plants was found to be very attractive. The unit production cost is as low as $\$ 5.5$ to $\$ 8.0$ per ton for plants producing 675,000 to 135,000 tons of logs. This cost includes a $15 \%$ above-inflation return rate for the investor. If the return rate is increased to $20 \%$ and $25 \%$, the corresponding unit production costs will be $\$ 6.3$ to $\$ 9.1$ and $\$ 7.1$ to $\$ 10.1$ per ton. The BLF process appears to be more economical than other conventional densification processes including pelletizing, extrusion and briquetting, and produces a denser and stronger (more wearresistant) fuel. Analysis of the transportation cost of the densified biomass logs showed that barge is the most cost-effective, followed by rail and then truck. Pneumatic capsule pipeline ( $\mathrm{PCP}$ ) and hydraulic capsule pipeline (HCP) are not cost effective compared to truck for transporting biomass logs. The fuel transportation costs of all modes (truck, train, barge, pipeline, etc.) depends on distance. Longer distance requires higher 
transportation cost. The unit cost of biomass logs handling at power plants, including crushing and storage, is only about $\$ 0.53 /$ ton.

(12) The delivered price of BLF to be paid by power plants depends on fuel transportation distance. For a distance of 50 miles transported by truck, the delivered price is in the neighborhood of $\$ 18$ per ton or approximately one dollar per million Btu, which is comparable to that paid by most power plants for costs. Therefore, even without considering environmental benefits and avoided landfill tipping cost, the BLF will be economical for distances up to about 100 miles. With or without tipping cost, it is expected that most large BLF manufacturing facilities near cities will be able to produce and sell BLF at a profit (inflation-adjusted return) over $15 \%$.

(13) Further testing is needed on mass production of BLF, power plant test burn in different types of boilers, design of a multi-mold machine for mass production of BLF, and preparation of a manual of practice, before the BLF new technology can be used commercially. They can be done in a Phase II project. 


\section{REFERENCES}

[1] Klass, D. L. (1998). Biomass for Renewable Energy, Fuels, and Chemicals. Academic Press, San Diego

[2] Bhattacharya, S. C., Sett, S., and Shrestha, R. M. (1989). State of the art for biomass densification. Energy Sources; 11: 161-182.

[3] Bhattacharya, S. C. (1993). State-of-the-art of utilizing residues and other types of biomass as an energy source. RERIC International Energy Journal; 15(1): 1-21.

[4] Aqa, S. and Bhattacharya, S. C. (1992). Densification of preheated sawdust for energy conservation. Energy; 17(6): 575-578

[5] Manser, A. G .R. and Keeling A. A. (1996). Practical Handbook of Processing and Recycling Municipal Waste. CRC Press, Boca Raton

[6] ASTM C 39-96 (1998). Standard test method for compressive strength of cylindrical concrete specimens. Annual book of ASTM Standards; Vol. 04.02: 17-21.

[7] ASTM C 496-96 (1998). Standard test method for splitting tensile strength of cylindrical concrete specimens. Annual book of ASTM Standards; Vol. 04.02: 265-268

[8] ASTM D 440-86 (1998). Standard test method of drop shatter test for coal. Annual book of ASTM Standards; Vol. 05.05: 188-191.

[9] Richards, S. R. (1990). Physical testing of fuel briquettes. Fuel Processing Technology; 25: $89-100$.

[10] ASTM D 441-86 (1998). Standard test method of tumbler test for coal. Annual book of ASTM Standards; Vol. 05.05: 192-194.

[11] Liu, H. and Li, Y. (2000). Economic analysis of compacting and transporting biomass logs for co-firing with coal in power plants; CPRC Report No. 2000-1, University of MissouriColumbia

[12] U.S. EPA. (1998). Characterization of Municipal Solid Waste in the United States: 1997 Update. EPA/530-R-98-007. May 1998.

[13] American Plastics Council (1996). Understanding Plastic Film: Its Uses, Benefits and Waste Management Options, December 1996

[14] Liu, H. and Lin, Y. (1997). Effect of exit shape of compaction mold on coal log quality. Powder Technology, 90: 267-271

[15] Li, Y., Liu, H., and Rockabrand, A. (1996). Wall friction and lubrication during compaction of coal logs. Powder Technology, 87: 259-267

[16] Mao, S., Research and Design of a Portable Log Fabrication System. M.S. Thesis, Department of Mechanical \& Aerospace Engineering, January 2000.

[17] Kosugi, S. (1993). A capsule pipeline system for limestone transportation. Proc. of the $7^{\text {th }}$ Int. Sym. on Freight Pipelines, Wollongong, Australia, Institution of engineers, Barton, Australia. 
[18] Antares Group, Inc. (1999). Biomass Residue Supply Curves for the United States (Update), prepared by Antares Group, Inc., Landover, MD for United States Department of Energy's Biomass Power Program and the National Renewable Energy Laboratory (NREL), June 1999.

[19] Noon, C. E., Daly, M. J., Graham, R. L. and Zahn, F. B. (1996). Transportation and Site Location Analysis for Regional Integrated Biomass Assessment, Proc. Of Bioenergy '96, Nashville, Tennessee, Sept. 15-20, 1996, 6 pages.

[20] Hacker, K. and Malone, C. (2000). USDA Grain Transportation Report 2 Transportation and Marketing, Agricultural Marketing Service, United States Department of Agriculture (USDA), January 11, 2000, 8 pages.

[21] Brown, R.A.S. (1987). Capsule Pipeline Research at the Alberta Research Council, 19581978, Journal of Pipelines, 6(1): 75-82.

[22] Wu, J. (1989) Economic Feasibility of Using Hydraulic Capsule Pipelines to Transport Farm Products of the Midwestern States of the United States, M.S. Thesis, Department of Civil Engineering, University of Missouri-Columbia, 1989, 118 pages. 
APENDIX A: TABLES 
Table 2-1. Descriptions of the biomass waste materials and combustibles in municipal solid waste (MSW) studied in this project

\begin{tabular}{|c|c|c|}
\hline Material & Description & Source \\
\hline Oak sawdust ${ }^{\mathrm{a}}$ & $\begin{array}{l}\text { Mixture of white oak and red oak. Oak is the most } \\
\text { important lumber tree in Missouri, and is a typical } \\
\text { hardwood. }\end{array}$ & Missouri sawmills \\
\hline Oak mulch $^{\mathrm{b}}$ & Same & Missouri sawmills \\
\hline $\begin{array}{l}\text { Oak bark } \\
\text { mulch }^{\mathrm{c}}\end{array}$ & Same & Missouri sawmills \\
\hline Pine sawdust & $\begin{array}{l}\text { Shortleaf pine (also called bull pine or yellow } \\
\text { pine), which is the only native pine in Missouri. It } \\
\text { is a softwood. }\end{array}$ & Missouri sawmills \\
\hline $\begin{array}{l}\text { Cottonwood } \\
\text { sawdust }\end{array}$ & $\begin{array}{l}\text { Eastern cottonwood, which is the fastest growing } \\
\text { native tree in Missouri. Cottonwood is often called } \\
\text { soft hard wood because it is soft although falling } \\
\text { in hardwood category. }\end{array}$ & Missouri sawmills \\
\hline $\begin{array}{l}\text { Cottonwood } \\
\text { mulch }\end{array}$ & Same & Missouri sawmills \\
\hline $\begin{array}{l}\text { Red Cedar } \\
\text { Mulch }\end{array}$ & Eastern red cedar or juniper. It is a softwood. & Missouri sawmills \\
\hline $\begin{array}{l}\text { Walnut } \\
\text { sawdust }\end{array}$ & Black walnut. The finest hardwood in the world. & Missouri sawmills \\
\hline $\begin{array}{l}\text { Hardwood tree } \\
\text { trimmings }\end{array}$ & $\begin{array}{l}\text { Branches of the hardwood trees. Shredded by tub } \\
\text { grinder into mulch when obtained. }\end{array}$ & $\begin{array}{l}\text { Columbia mulch } \\
\text { sites }\end{array}$ \\
\hline $\begin{array}{l}\text { Softwood tree } \\
\text { trimmings }\end{array}$ & $\begin{array}{l}\text { Branches of the evergreen trees. Large quantities } \\
\text { are generated during Christmas. }\end{array}$ & $\begin{array}{l}\text { Columbia mulch } \\
\text { sites }\end{array}$ \\
\hline Mixed paper & $\begin{array}{l}\text { Mixture of five types of papers containing equal } \\
\text { weight for each: newsprint, office paper, } \\
\text { corrugated board, commercial printing, box board. }\end{array}$ & $\begin{array}{l}\text { Offices and } \\
\text { houses. }\end{array}$ \\
\hline Hard HDPE $^{\mathrm{d}}$ & $\begin{array}{l}\text { HDPE in hard forms, typically containers such as } \\
\text { milk jugs and soap bottles. }\end{array}$ & $\begin{array}{l}\text { City of Columbia } \\
\text { Landfill }\end{array}$ \\
\hline HDPE film & $\begin{array}{l}\text { HDPE in the form of film, such as grocery sacks } \\
\text { and trash bags. }\end{array}$ & $\begin{array}{l}\text { City of Columbia } \\
\text { Landfill }\end{array}$ \\
\hline LDPE film & $\begin{array}{l}\text { LDPE in the form of film, such as bubble } \\
\text { packaging, grocery sacks and trash bags. }\end{array}$ & $\begin{array}{l}\text { City of Columbia } \\
\text { Landfill }\end{array}$ \\
\hline Hard PP & $\begin{array}{l}\text { PP in hard forms, typically containers such as } \\
\text { microwave meal boxes, storage boxes, and trash } \\
\text { cans. }\end{array}$ & $\begin{array}{l}\text { City of Columbia } \\
\text { Landfill }\end{array}$ \\
\hline Hard PET & PET in hard form, mainly beverage bottles. & $\begin{array}{l}\text { City of Columbia } \\
\text { Landfill }\end{array}$ \\
\hline Hard PS & $\begin{array}{l}\text { PS in hard form such as blister packs, cups, office } \\
\text { equipment, etc. }\end{array}$ & $\begin{array}{l}\text { City of Columbia } \\
\text { Landfill }\end{array}$ \\
\hline
\end{tabular}


Table 2-1 (Continued)

\begin{tabular}{|l|l|l|}
\hline Foamed PS & $\begin{array}{l}\text { Foamed PS products such disposable cups, egg } \\
\text { cartons, and insulation board, etc. }\end{array}$ & $\begin{array}{l}\text { City of Columbia } \\
\text { Landfill }\end{array}$ \\
\hline Textiles & Cloth made of cotton and artificial polyester & $\begin{array}{l}\text { City of Columbia } \\
\text { Landfill }\end{array}$ \\
\hline Waste wood & Used lumber, pallets, and furniture in MSW & $\begin{array}{l}\text { City of Columbia } \\
\text { Landfill }\end{array}$ \\
\hline $\begin{array}{l}\text { Lawn grass } \\
\text { clippings }\end{array}$ & $\begin{array}{l}\text { Collected from lawn mowing fresh. Green, wet, } \\
\text { and soft. }\end{array}$ & Residential house lawns \\
\hline Fallen leaves & $\begin{array}{l}\text { Freshly fallen hardwood leaves collected under } \\
\text { trees }\end{array}$ & $\begin{array}{l}\text { Parks and residential } \\
\text { areas }\end{array}$ \\
\hline Willow & $\begin{array}{l}\text { Willows are planted as a energy crop for its } \\
\text { fast-growing characteristics. }\end{array}$ & $\begin{array}{l}\text { Lakeside in the City of } \\
\text { Columbia }\end{array}$ \\
\hline $\begin{array}{l}\text { Aged } \\
\text { switchgrass }\end{array}$ & $\begin{array}{l}\text { A typical energy crop. Over one-year aged, } \\
\text { golden-yellow colored. }\end{array}$ & Iowa farm \\
\hline $\begin{array}{l}\text { Fresh } \\
\text { switchgrass }\end{array}$ & $\begin{array}{l}\text { Freshly-harvested from a test field of University } \\
\text { of Missouri-Columbia. About 2 meter tall, half } \\
\text { green and half yellow when being harvested. }\end{array}$ & $\begin{array}{l}\text { University of Missouri- } \\
\text { Columbia }\end{array}$ \\
\hline
\end{tabular}

a. All the sawdust mentioned here was generated from sawing of the timbers after debarking, containing no bark.

b. All the wood mulch (except bark mulch) was produced by mulchers (grinders) from the scraps generated in the processes of sawing the debarked timbers into lumbers, containing no bark.

c. The bark mulch was produced by mulchers from bark scraps that were generated from debarking process. It contains about $80 \%$ of bark and $20 \%$ of wood.

d. HDPE - high-density polyethylene; LDPE - low-density polyethylene;

PP - Polypropylene; $\quad$ PET - Polyethylene terephthalate; $\quad$ PS - poly styrene. 


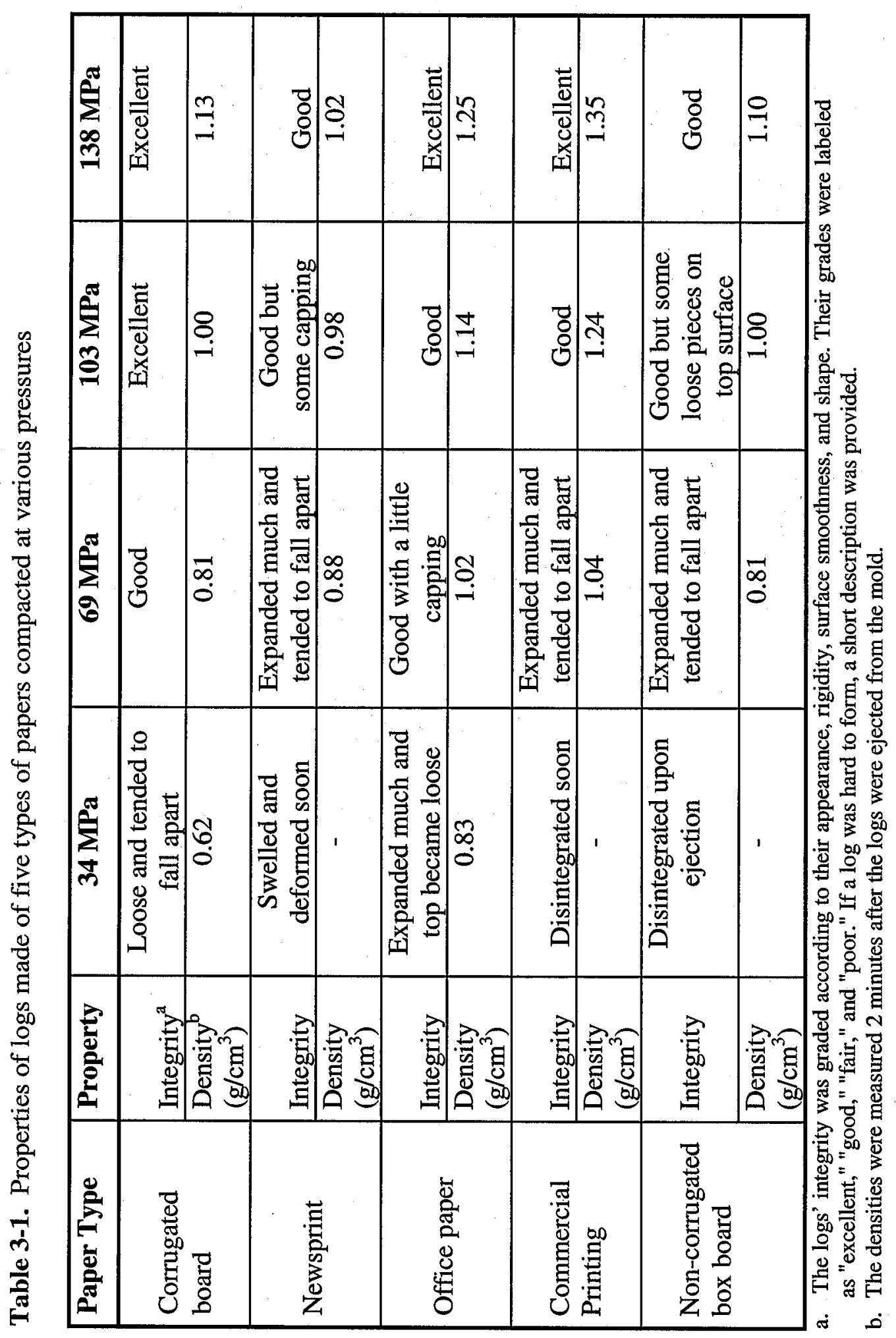




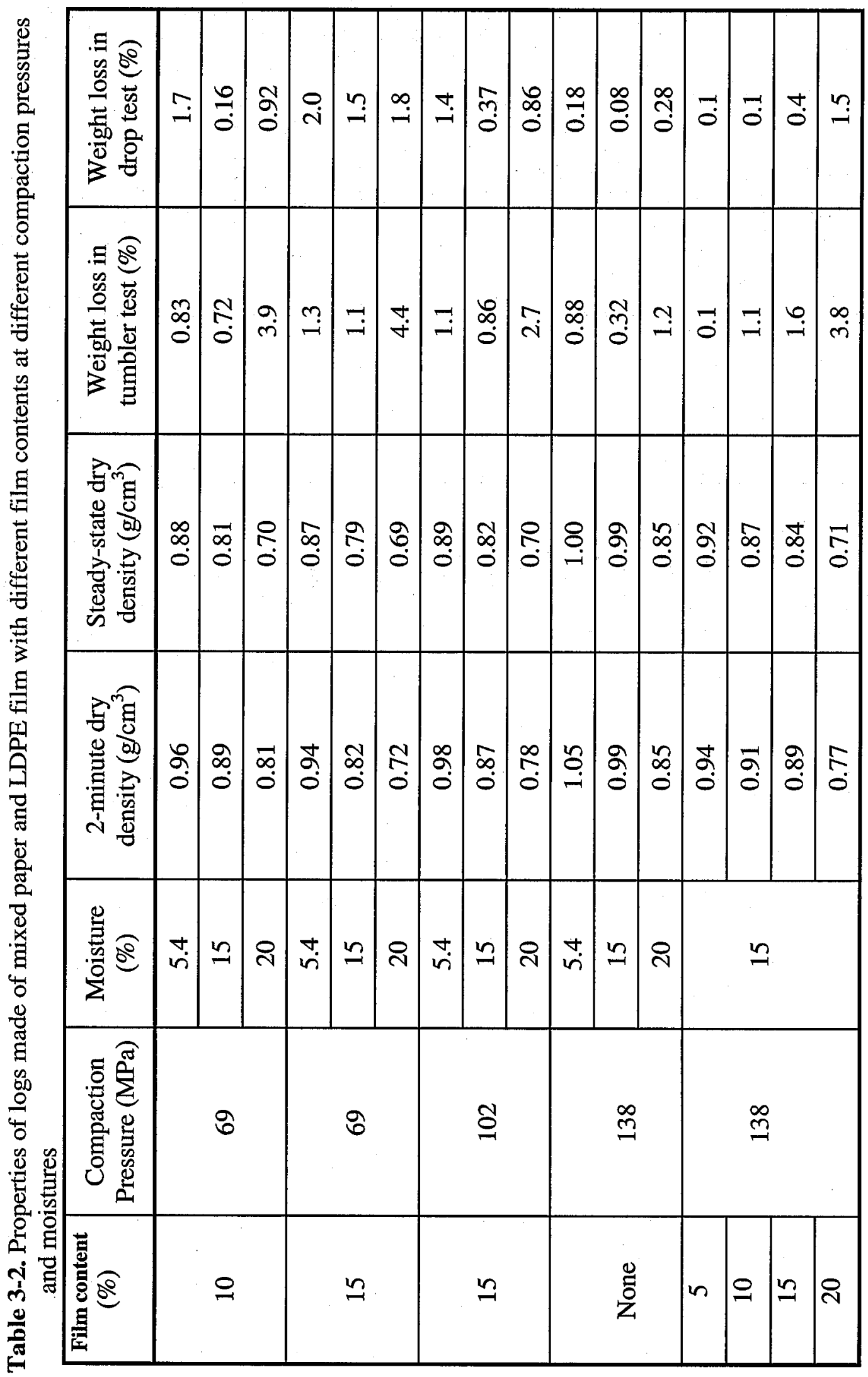




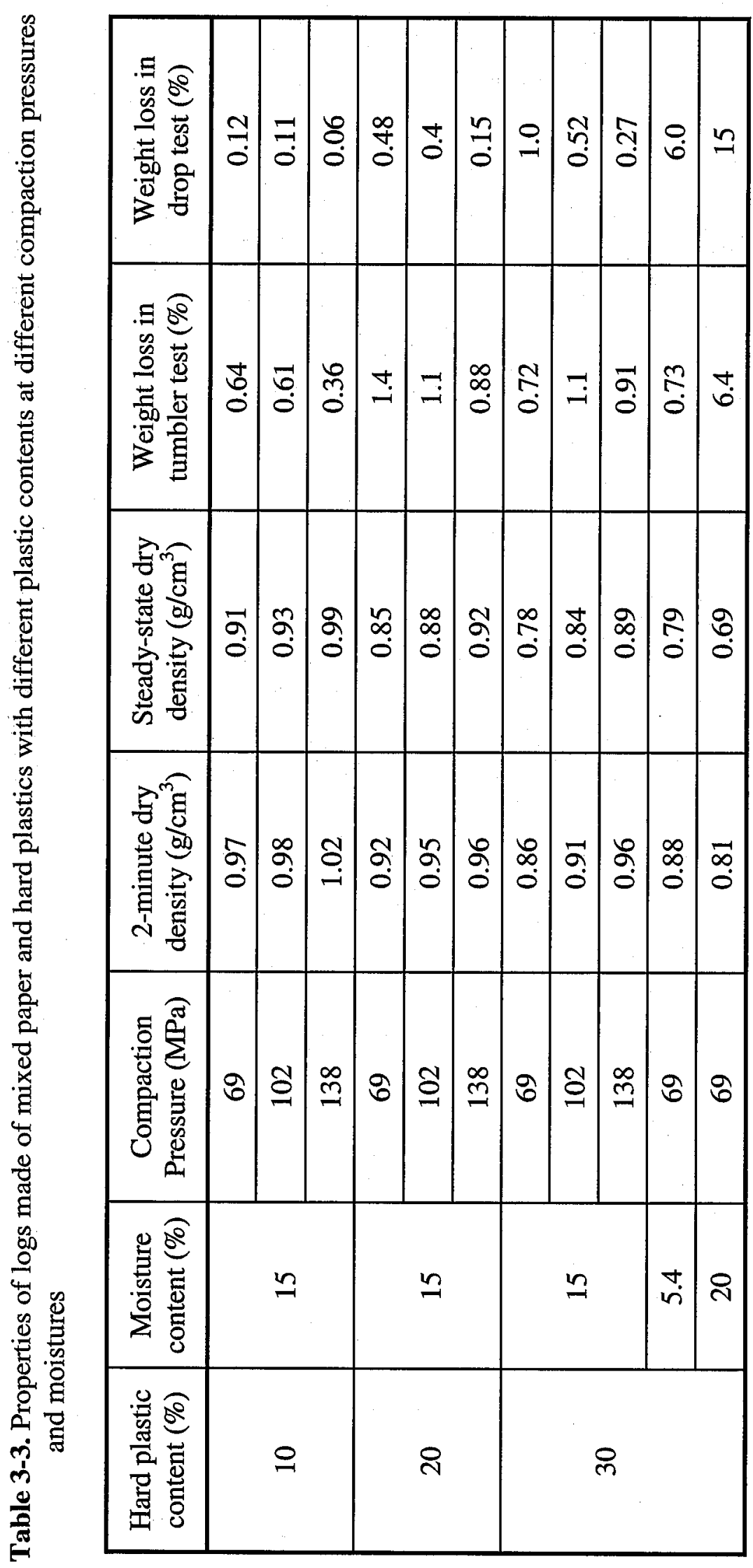




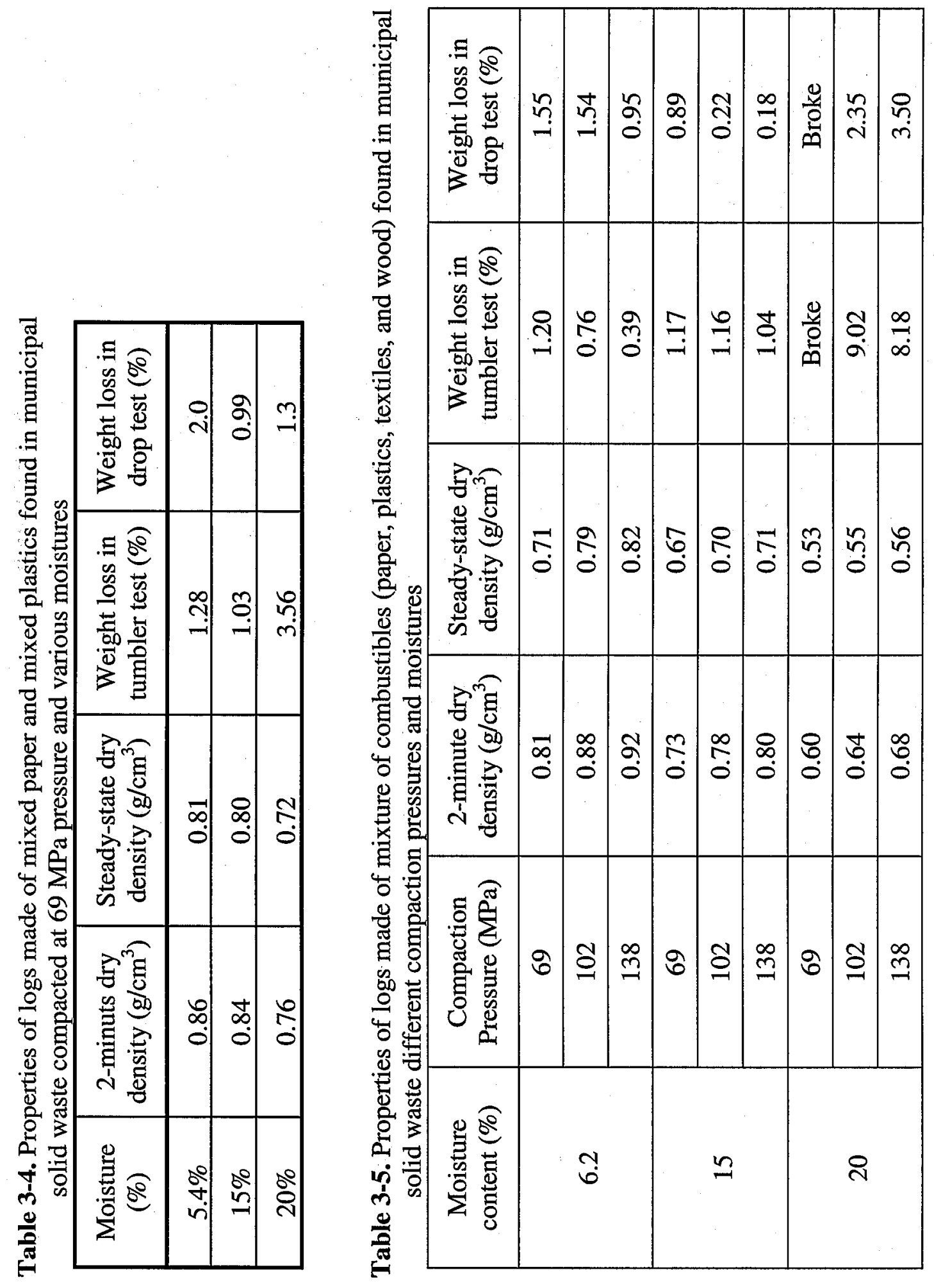




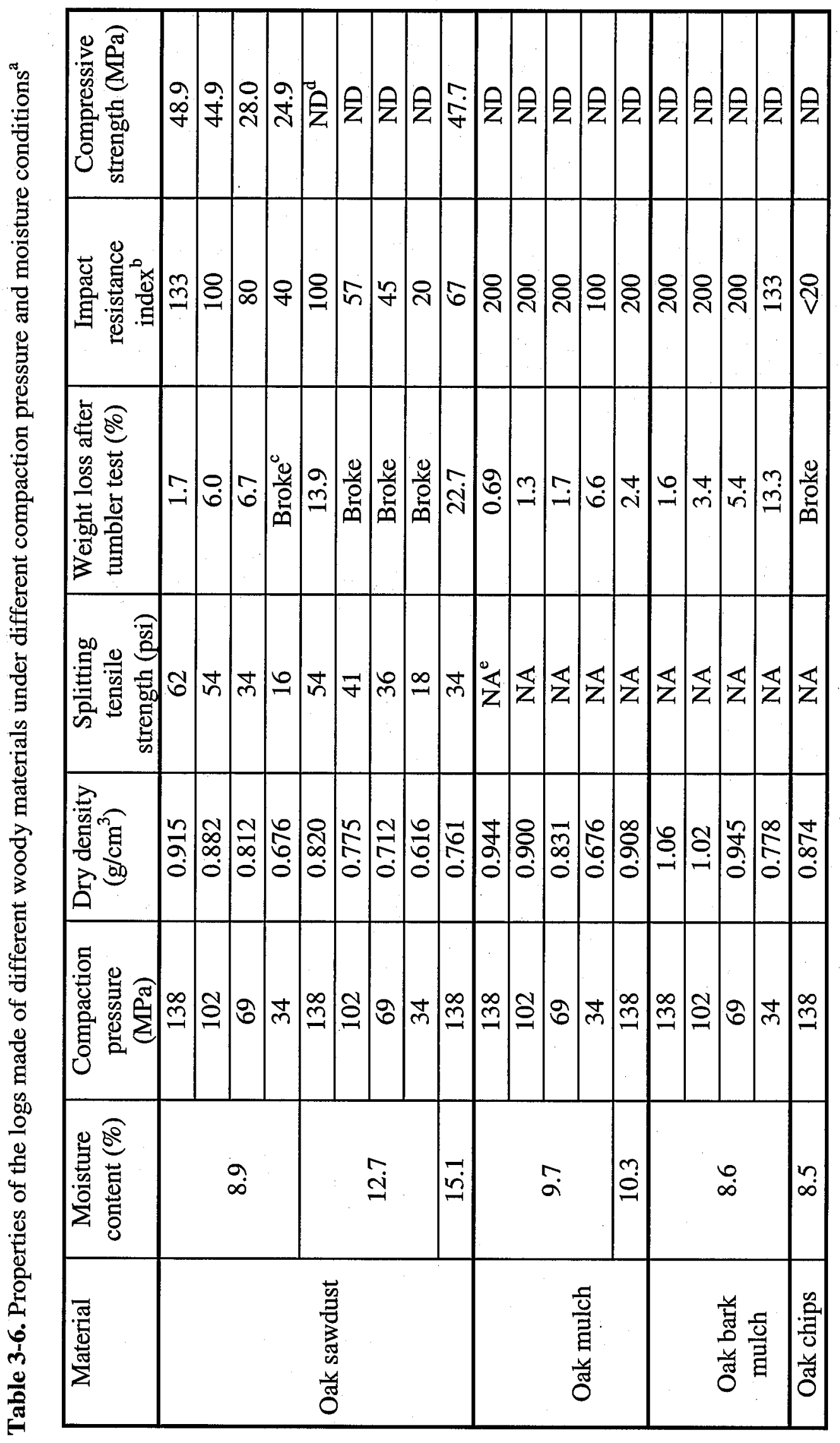




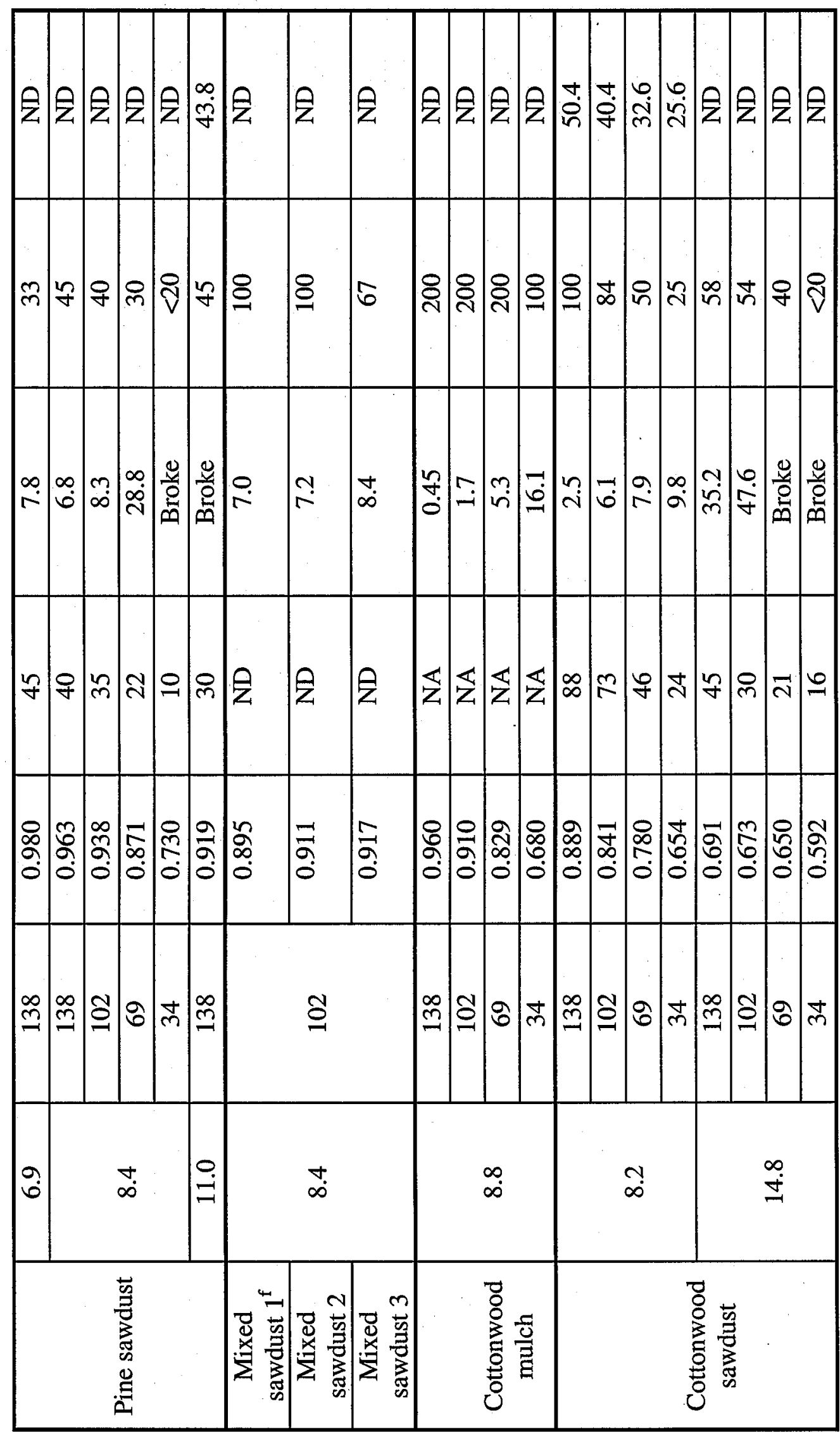




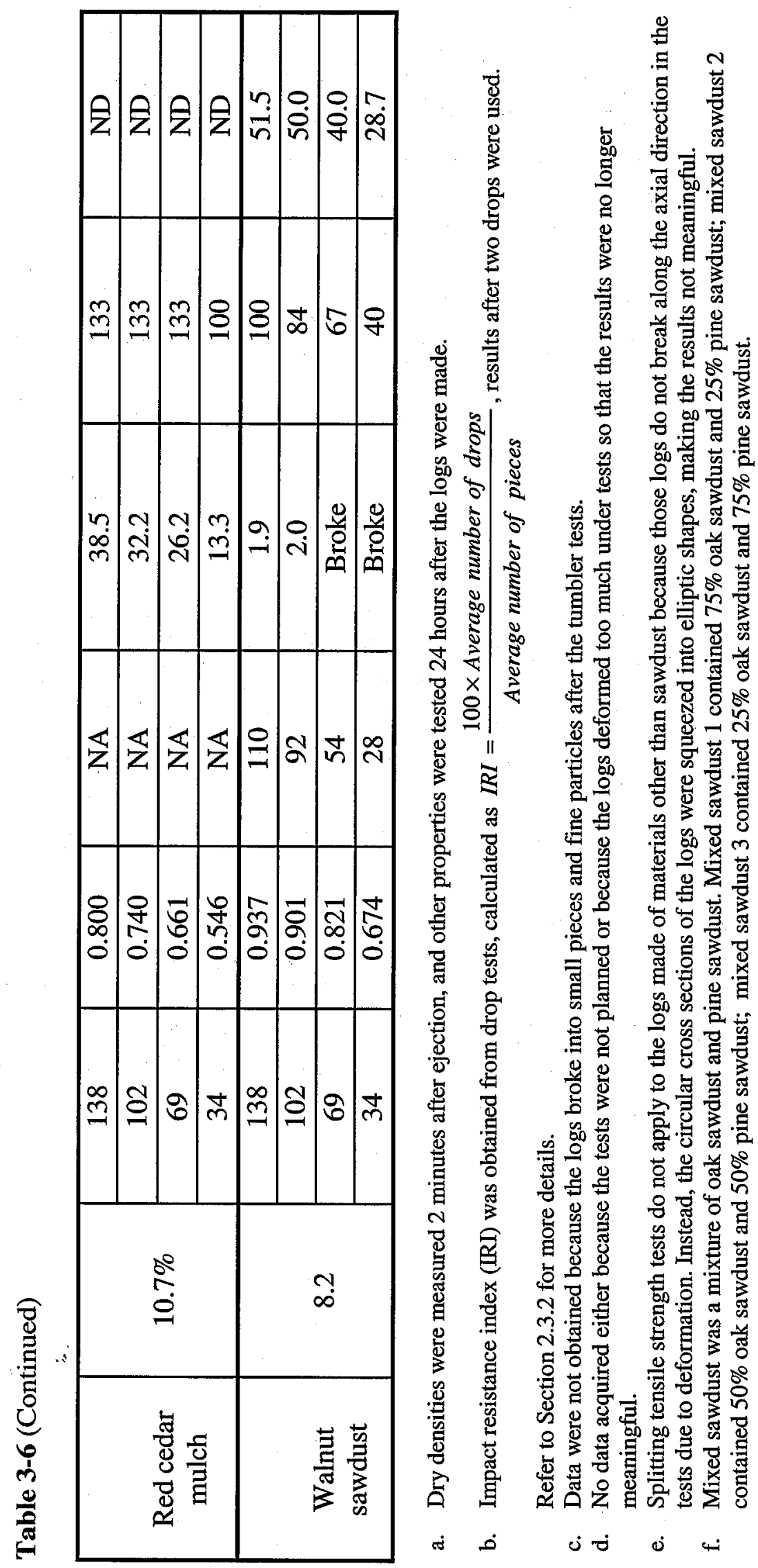


Table 3-7. Effect of particle size on the properties of the logs. The logs were made of oak sawdust at $138 \mathrm{MPa}$ pressure and at $10 \%$ moisture content

\begin{tabular}{|c|c|c|c|}
\hline $\begin{array}{c}\text { Particle size } \\
(\mathrm{mm})\end{array}$ & $\begin{array}{c}\text { Dry density }^{\mathrm{a}} \\
\left(\mathrm{g} / \mathrm{cm}^{3}\right)\end{array}$ & $\begin{array}{c}\text { Weight loss after } \\
\text { tumbler test (\%) }\end{array}$ & $\begin{array}{c}\text { Impact resistance } \\
\text { index }\end{array}$ \\
\hline $0-1.0$ & 0.915 & 0.9 & 100 \\
\hline $1.0-2.36$ & 0.887 & 8.5 & 100 \\
\hline $2.36-4.75$ & 0.880 & 5.5 & 133 \\
\hline $4.75-10$ & 0.911 & 6.5 & 200 \\
\hline $0-10^{\mathrm{b}}$ & 0.907 & 7.5 & 150 \\
\hline
\end{tabular}

a. Densities were measured 2 minutes after the ejection from the mold.

b. Mixture of equal amount of sawdust with the four particle size ranges.

Table 3-8. Properties of logs made of different yard waste materials under different compaction pressure and moisture conditions

\begin{tabular}{|c|c|c|c|c|c|}
\hline Material & $\begin{array}{l}\text { Moisture } \\
\text { content } \\
(\%)\end{array}$ & $\begin{array}{l}\text { Compaction } \\
\text { pressure } \\
\text { (MPa) }\end{array}$ & $\begin{array}{c}\text { 2-minute dry } \\
\text { density } \\
\left(\mathrm{g} / \mathrm{cm}^{3}\right)\end{array}$ & $\begin{array}{l}\text { Weight loss } \\
\text { after tumbler } \\
\text { test }(\%)\end{array}$ & $\begin{array}{l}\text { IRI from } \\
\text { drop test }^{\mathrm{a}}\end{array}$ \\
\hline \multirow{8}{*}{$\begin{array}{c}\text { Hickory } \\
\text { leaves }\end{array}$} & \multirow{4}{*}{15.4} & 138 & 0.764 & 0.41 & 200 \\
\hline & & 103 & 0.739 & 0.42 & 200 \\
\hline & & 69 & 0.714 & 0.09 & 200 \\
\hline & & 34 & 0.622 & 1.97 & 200 \\
\hline & \multirow{4}{*}{10.8} & 138 & 0.887 & 0.41 & 200 \\
\hline & & 103 & 0.859 & 0.59 & 200 \\
\hline & & 69 & 0.801 & 0.61 & 200 \\
\hline & & 34 & 0.658 & 5.28 & 100 \\
\hline \multirow{4}{*}{ Maple leaves } & \multirow{4}{*}{8.9} & 138 & 0.997 & 0.12 & 200 \\
\hline & & 103 & 0.963 & 0.06 & 200 \\
\hline & & 69 & 0.902 & 0.19 & 200 \\
\hline & & 34 & 0.741 & 0.41 & 200 \\
\hline \multirow{4}{*}{ Mixed leaves } & \multirow{4}{*}{8.0} & 138 & 0.980 & 0.09 & 200 \\
\hline & & 103 & 0.923 & 0.17 & 200 \\
\hline & & 69 & 0.849 & 0.40 & 200 \\
\hline & & 34 & 0.669 & 8.57 & 100 \\
\hline \multirow{4}{*}{ Oak leaves } & \multirow{4}{*}{8.6} & 138 & 0.931 & 0.14 & 200 \\
\hline & & 103 & 0.873 & 0.16 & 200 \\
\hline & & 69 & 0.782 & 0.41 & 200 \\
\hline & & 34 & 0.631 & 3.63 & 200 \\
\hline
\end{tabular}




\begin{tabular}{|c|c|c|c|c|c|}
\hline \multirow{4}{*}{ Pine needles } & \multirow{4}{*}{8.9} & 138 & 0.848 & 0.15 & 200 \\
\hline & & 103 & 0.823 & 0.20 & 200 \\
\hline & & 69 & 0.760 & 0.43 & 200 \\
\hline & & 34 & 0.622 & 3.54 & 200 \\
\hline \multirow{4}{*}{ Pine cones } & \multirow{4}{*}{10.0} & 138 & 0.918 & 0.44 & 200 \\
\hline & & 103 & 0.882 & 0.53 & 200 \\
\hline & & 69 & 0.799 & 1.34 & 200 \\
\hline & & 34 & 0.646 & 9.17 & 100 \\
\hline \multirow{8}{*}{ Lawn grass } & \multirow{4}{*}{10.5} & 138 & 0.853 & 0.24 & 200 \\
\hline & & 103 & 0.800 & $\mathrm{NT}^{b}$ & NT \\
\hline & & 69 & 0.738 & NT & $\overline{N T}$ \\
\hline & & 34 & 0.547 & NT & NT \\
\hline & \multirow{4}{*}{13.5} & 138 & 0.754 & 1.61 & 200 \\
\hline & & 103 & 0.742 & NT & NT \\
\hline & & 69 & 0.713 & NT & NT \\
\hline & & 34 & 0.540 & NT & NT \\
\hline \multirow{4}{*}{$\begin{array}{l}\text { Hardwood tree } \\
\text { trimmings }\end{array}$} & \multirow{4}{*}{8.6} & 138 & 0.937 & 0.8 & 200 \\
\hline & & 103 & 0.901 & 3.4 & 200 \\
\hline & & 69 & 0.821 & 5.3 & 100 \\
\hline & & 34 & 0.674 & Broke & 67 \\
\hline \multirow{4}{*}{$\begin{array}{l}\text { Softwood tree } \\
\text { trimmings }\end{array}$} & \multirow{4}{*}{7.8} & 138 & 1.12 & 1.3 & 200 \\
\hline & & 103 & 1.08 & 1.8 & 200 \\
\hline & & 69 & 1.02 & 2.6 & 100 \\
\hline & & 34 & 0.872 & 9.7 & 67 \\
\hline
\end{tabular}

a. IRI is impact resistance index as defined in Section 2.3.2.

b. Not tested. 
Table 3-9. Density, impact and abrasion resistance of logs made of grass with different grass particles. The logs were made at $102 \mathrm{Mpa}$ without holding time. The moisture content of all the grass materials was $7.5 \%$.

\begin{tabular}{|l|c|c|c|}
\hline \multicolumn{1}{|c|}{ Grass type } & $\begin{array}{c}\text { 2-minute dry density } \\
\left(\mathrm{g} / \mathrm{cm}^{3}\right)\end{array}$ & $\begin{array}{c}\text { Weight loss after } \\
\text { tumbler test }(\%)\end{array}$ & IRI of drop test \\
\hline Original & 0.788 & 0.11 & 200 \\
\hline Cut & 0.804 & $\mathrm{NT}^{\mathrm{a}}$ & $\mathrm{NT}$ \\
\hline Ground & 0.808 & 0.58 & 100 \\
\hline
\end{tabular}

a. Not tested.

Table 3-10. Tested properties of the logs made of aged switchgrass (both unground and ground) and fresh switchgrass at $138 \mathrm{MPa}$ without pressure holding time

\begin{tabular}{|c|c|c|c|c|}
\hline Material & $\begin{array}{c}\text { Moisture } \\
\text { content (\%) }\end{array}$ & $\begin{array}{c}\text { Dry density }^{\mathrm{a}} \\
\left(\mathrm{g} / \mathrm{cm}^{3}\right)\end{array}$ & $\begin{array}{c}\text { Weight loss } \\
\text { after tumbler } \\
\text { test }(\%)\end{array}$ & $\begin{array}{c}\text { IRI of drop } \\
\text { tests }^{\mathrm{b}}\end{array}$ \\
\hline Aged unground & 9.8 & 0.82 & 3.0 & 78 \\
\hline Aged unground & 11.4 & 0.76 & 1.7 & 167 \\
\hline Aged ground & 9.4 & 0.86 & 2.3 & 50 \\
\hline Fresh unground & 9.9 & 0.81 & 4.3 & 78 \\
\hline
\end{tabular}

a. Densities were measured 2 minutes after ejection from the mold.

b. IRI is impact resistance index as defined in Section 2.3.2. 
Table 3-11. Comparison of large logs (137-mm diameter) and small logs (48.5-mm diameter) compacted by two different machines under similar compaction conditions ${ }^{*}$

\begin{tabular}{|c|c|c|c|c|}
\hline Material & $\begin{array}{c}\text { Moisture } \\
\text { content }(\%)\end{array}$ & Log size & $\begin{array}{l}\text { 2-minute dry } \\
\text { density }\left(\mathrm{g} / \mathrm{cm}^{3}\right)\end{array}$ & IRI of drop test \\
\hline \multirow{6}{*}{ Mixed paper } & \multirow{2}{*}{5.4} & Large & 0.910 & 200 \\
\hline & & Small & 1.05 & 200 \\
\hline & \multirow{2}{*}{15} & Large & 0.977 & 200 \\
\hline & & Small & 0.977 & 200 \\
\hline & \multirow{2}{*}{20} & Large & 0.852 & 200 \\
\hline & & Small & 0.859 & 200 \\
\hline \multirow{2}{*}{ Oak sawdust } & \multirow{2}{*}{9.5} & Large & 0.826 & 67 \\
\hline & & Small & 0.882 & 100 \\
\hline \multirow{2}{*}{ Oak mulch } & \multirow{2}{*}{8.9} & Large & 0.863 & 167 \\
\hline & & Small & 0.911 & 200 \\
\hline
\end{tabular}

* The large logs were compacted at $112 \mathrm{MPa}$, the values for dry densities and IRI of the small logs are obtained by interpolation for $112 \mathrm{MPa}$ between the values measured for the logs made at $102 \mathrm{MPa}$ and $138 \mathrm{MPa}$.

Table 3-12. Effect of mold roughness on the densities (measured 2 minutes after ejection) of the logs made of different biomass materials at $138 \mathrm{MPa}$

\begin{tabular}{|l|c|c|c|}
\hline Material & $\begin{array}{c}\text { Moisture } \\
(\%)\end{array}$ & Mold type & $\begin{array}{c}\text { 2-minute dry } \\
\text { density }\left(\mathrm{g} / \mathrm{cm}^{3}\right)\end{array}$ \\
\hline \multirow{2}{*}{ Mixed paper } & $5.4 \%$ & Smooth & 0.947 \\
\cline { 3 - 4 } & & Rough & 0.928 \\
\hline \multirow{2}{*}{ Oak sawdust } & \multirow{2}{*}{8.4} & Smooth & 0.953 \\
\cline { 3 - 4 } & & Rough & 0.938 \\
\hline \multirow{2}{*}{ Oak mulch } & \multirow{2}{*}{8.6} & Smooth & 1.147 \\
\hline \multirow{2}{*}{ Pine sawdust } & & Rough & 1.138 \\
\cline { 3 - 4 } & \multirow{2}{*}{7.4} & Smooth & 0.983 \\
\cline { 3 - 4 } & & Rough & 0.979 \\
\hline
\end{tabular}


Table 3-13. Effect of back pressure on the density of biomass logs. All the logs were compacted at $102 \mathrm{MPa}$ without holding time

\begin{tabular}{|c|c|c|c|}
\hline Material & $\begin{array}{c}\text { Moisture } \\
\text { Content (\%) }\end{array}$ & $\begin{array}{c}\text { Back pressure } \\
\text { (MPa) }\end{array}$ & $\begin{array}{l}\text { 2-minute dry } \\
\text { density }\left(\mathrm{g} / \mathrm{cm}^{3}\right)\end{array}$ \\
\hline \multirow{10}{*}{ Mixed paper } & \multirow{5}{*}{5.4} & 0 & 0.851 \\
\hline & & 0.7 & 0.915 \\
\hline & & 2.9 & 0.924 \\
\hline & & 4.8 & 0.928 \\
\hline & & 10.3 & 0.936 \\
\hline & \multirow{5}{*}{15} & 0 & 0.940 \\
\hline & & 0.7 & 0.984 \\
\hline & & 2.9 & 0.987 \\
\hline & & 4.8 & 0.994 \\
\hline & & 10.3 & 0.996 \\
\hline \multirow{5}{*}{ Sawdust } & \multirow{5}{*}{9.3} & 0 & 0.793 \\
\hline & & 0.7 & 0.799 \\
\hline & & 2.9 & 0.810 \\
\hline & & 4.8 & 0.811 \\
\hline & & 10.3 & 0.816 \\
\hline \multirow{5}{*}{ Oak mulch } & \multirow{5}{*}{9.1} & 0 & 0.805 \\
\hline & & 0.7 & 0.817 \\
\hline & & 2.9 & 0.818 \\
\hline & & 4.8 & 0.821 \\
\hline & & 10.3 & 0.827 \\
\hline \multirow{2}{*}{ Hickory leaves } & \multirow{2}{*}{10.3} & 0 & 0.669 \\
\hline & & 0.7 & 0.834 \\
\hline \multirow{2}{*}{ Maple leaves } & \multirow{2}{*}{8.4} & 0 & 0.836 \\
\hline & & 0.7 & 0.940 \\
\hline
\end{tabular}


Table 3-14. Piled bulk densities, log densities, and compaction ratios of the biomass materials. The logs were compacted at $102 \mathrm{MPa}$ without holding time.

\begin{tabular}{|l|c|c|c|c|}
\hline Material & $\begin{array}{c}\text { Moisture } \\
\text { content }(\%)\end{array}$ & $\begin{array}{c}\text { Piled bulk } \\
\text { density }\left(\mathrm{g} / \mathrm{cm}^{3}\right)\end{array}$ & $\begin{array}{c}\text { Log density } \\
\left(\mathrm{g} / \mathrm{cm}^{3}\right)\end{array}$ & $\begin{array}{c}\text { Compaction } \\
\text { ratio }\end{array}$ \\
\hline $\begin{array}{l}\text { Hammermill- } \\
\text { shredded paper }\end{array}$ & $5-6$ & 0.038 & 1.16 & 31 \\
\hline $\begin{array}{l}\text { Paper-shredder- } \\
\text { shredded paper }\end{array}$ & $5-6$ & 0.064 & 1.16 & 18 \\
\hline $\begin{array}{l}\text { Hardwood tree } \\
\text { trimmings }\end{array}$ & $8-9$ & 0.21 & 1.01 & 4.8 \\
\hline Leaves & $8-9$ & 0.013 & 0.96 & 77 \\
\hline Lawn grass & $9-10$ & 0.027 & 0.89 & 33 \\
\hline $\begin{array}{l}\text { Fresh switch } \\
\text { grass }\end{array}$ & $8-9$ & 0.074 & 0.89 & 12 \\
\hline $\begin{array}{l}\text { Age switch } \\
\text { Grass }\end{array}$ & $8-9$ & 0.10 & 0.89 & 9.0 \\
\hline Oak sawdust & $8-9$ & 0.22 & 0.98 & 4.5 \\
\hline Walnut sawdust & $8-9$ & 0.23 & 0.98 & 4.3 \\
\hline Pine sawdust & $8-9$ & 0.23 & 0.91 & 4.0 \\
\hline $\begin{array}{l}\text { Cottonwood } \\
\text { Sawdust }\end{array}$ & $8-9$ & 0.22 & 0.92 & 4.2 \\
\hline Oak mulch & $8-9$ & 0.15 & 1.11 & 7.6 \\
\hline Oak bark mulch & $8-9$ & 0.19 & 1.11 & 5.9 \\
\hline $\begin{array}{l}\text { Cottonwood } \\
\text { mulch }\end{array}$ & $8-9$ & 0.10 & 0.99 & 10 \\
\hline $\begin{array}{l}\text { Red ceder } \\
\text { mulch }\end{array}$ & $9-10$ & 0.10 & 0.82 & 7.9 \\
\hline Oak chips & $8-9$ & 0.21 & 0.95 & 4.5 \\
\hline
\end{tabular}




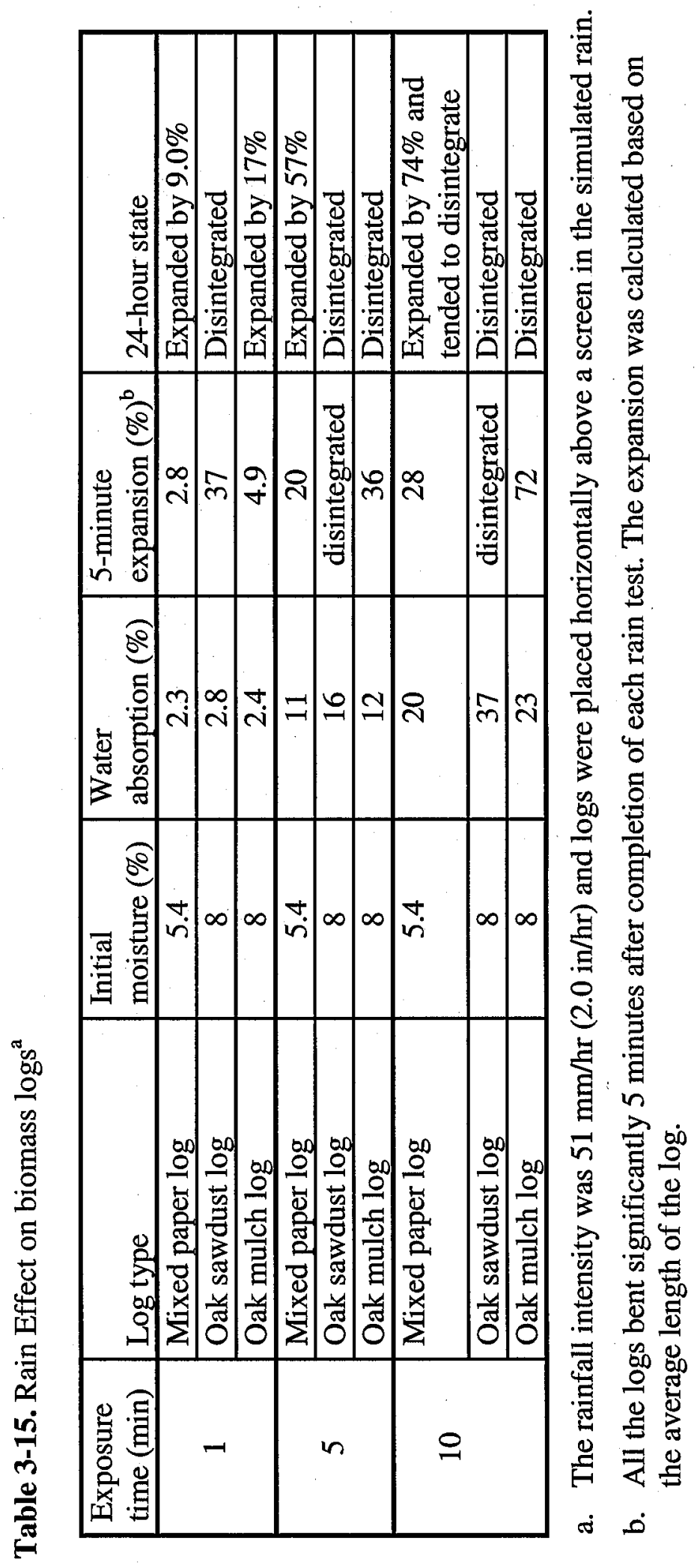


Table 3-16. Combustion characteristics of tested materials (dry basis)

\begin{tabular}{|l|c|c|c|c|}
\hline Material & $\begin{array}{c}\text { HHV }^{\mathrm{a}} \\
\left(\mathbf{B t u}_{\mathbf{l b})}\right.\end{array}$ & $\begin{array}{c}\text { Volatile matter } \\
(\mathbf{\%})\end{array}$ & $\begin{array}{c}\text { Fixed carbon } \\
(\boldsymbol{\%})\end{array}$ & $\begin{array}{c}\text { Ash content } \\
(\boldsymbol{\%})\end{array}$ \\
\hline Office paper & 6500 & 79.87 & 11.35 & 8.79 \\
\hline Newsprint & 8150 & 80.40 & 14.24 & 5.37 \\
\hline Corrugated board & 7420 & 79.77 & 15.47 & 4.77 \\
\hline Magazine & 5550 & 69.74 & 7.40 & 22.87 \\
\hline $\begin{array}{l}\text { Advertisement/ } \\
\text { brochure }\end{array}$ & 4990 & 70.78 & 6.53 & 22.69 \\
\hline Box board & 7630 & 79.02 & 14.70 & 6.29 \\
\hline PS (foamed) $^{\text {PS (hard) }}$ & 17570 & 99.37 & 0.20 & 0.44 \\
\hline PP (hard) & 15770 & 94.86 & 4.65 & 0.50 \\
\hline PET (hard) & 19940 & 99.55 & 0.06 & 0.40 \\
\hline LDPE film & 10010 & 94.72 & 5.28 & 0.01 \\
\hline HDPE film & 19880 & 99.83 & 0.05 & 0.13 \\
\hline Hard HDPE & 19180 & 99.83 & 0.04 & 0.45 \\
\hline Textiles & 8040 & 100 & 0 & 0 \\
\hline $\begin{array}{l}\text { Fresh softwood tree } \\
\text { trimmings }\end{array}$ & 6150 & 58.47 & 13.58 & 27.96 \\
\hline $\begin{array}{l}\text { Fresh hardwood tree } \\
\text { trimmings }\end{array}$ & 8200 & 75.20 & 19.89 & 4.91 \\
\hline Fresh oak sawdust & 8540 & 80.85 & 17.96 & 1.20 \\
\hline Aged oak sawdust & 8490 & 79.27 & 18.18 & 2.56 \\
\hline Fresh oak bark & 7630 & 73.60 & 19.04 & 7.36 \\
\hline Fresh pine sawdust & 8540 & 81.20 & 18.53 & 0.25 \\
\hline $\begin{array}{l}\text { Fresh eastern red } \\
\text { cedar }\end{array}$ & 8390 & 76.19 & 18.85 & 4.97 \\
\hline Fresh cottonwood & 8310 & 81.19 & 17.83 & 0.99 \\
\hline Fresh Walnut & 8330 & 81.25 & 18.29 & 0.46 \\
\hline $\begin{array}{l}\text { Fresh willow } \\
\text { mixture }\end{array}$ & 8560 & 77.52 & 19.79 & 2.70 \\
\hline Aged switch grass & 8160 & 76.12 & 18.56 & 5.32 \\
\hline Fresh switch grass & 8750 & 77.09 & 19.39 & 3.52 \\
\hline Fresh lawn grass & 7890 & 72.74 & 15.93 & 11.33 \\
\hline $\begin{array}{l}\text { Freshly fallen } \\
\text { hardwood leaves }\end{array}$ & 8630 & 69.78 & 22.38 & 7.84 \\
\hline a & & & 17.48 & 3.50 \\
\hline
\end{tabular}
a. $\mathrm{HHV}=$ Higher heating value. $1 \mathrm{Btu} / \mathrm{lb}=2.326 \mathrm{~kJ} / \mathrm{kg}$.
b. See Table 2-1 for definitions of the plastic resins.
c. Fresh $=$ stored in open air less than six months; Aged $=$ stored more than six months.
d. The mixture contained all parts of the trees, including the stems, branches and leaves. 
Table 3-17. Cost items for biomass log production with the fixed-location system having different throughputs

(a) Capital cost $\left(\times 10^{3}\right.$ dollars $)$

\begin{tabular}{|c|c|c|c|c|c|c|c|c|c|c|}
\hline $\mathrm{Q}$ (tons $/ \mathrm{yr})$ & $\mathrm{N}_{\mathrm{cp}}$ & $\mathrm{C}_{\mathrm{cm}}$ & $\mathrm{C}_{\mathrm{bu}}$ & $\mathrm{C}_{\mathrm{md}}$ & $\mathrm{C}_{\mathrm{sr}}$ & $\mathrm{C}_{\mathrm{ms}}$ & $\mathrm{C}_{\mathrm{ls}}$ & $\mathrm{C}_{\mathrm{ss}}$ & $\mathrm{C}_{\mathrm{oe}}$ & Total \\
\hline 675,000 & 7 & 3,500 & 350 & 480 & 723 & 843 & 869 & 43 & 520 & 7,328 \\
\hline 540,000 & 5 & 2,500 & 250 & 384 & 578 & 674 & 695 & 38 & 416 & 5,536 \\
\hline 405,000 & 4 & 2,000 & 200 & 288 & 434 & 506 & 521 & 32 & 312 & 4,293 \\
\hline 270,000 & 3 & 1,500 & 150 & 192 & 289 & 337 & 348 & 25 & 208 & 3,049 \\
\hline 135,000 & 2 & 1,000 & 100 & 96 & 145 & 169 & 174 & 16 & 104 & 1,803 \\
\hline
\end{tabular}

(b) Annual cost $\left(\times 10^{3}\right.$ dollars $)$

\begin{tabular}{|c|c|c|c|c|c|c|c|}
\hline $\mathrm{Q}$ (tons/yr) & $\mathrm{C}_{\mathrm{e}}$ & $\mathrm{C}_{\mathrm{f}}$ & $\mathrm{C}_{\mathrm{w}}$ & $\mathrm{C}_{\mathrm{ws}}$ & $\mathrm{C}_{\mathrm{ps}}$ & $\mathrm{C}_{\mathrm{ti}}$ & Total \\
\hline 675,000 & 521 & 433 & 18 & 660 & 200 & 183 & 2,015 \\
\hline 540,000 & 417 & 346 & 14 & 660 & 160 & 138 & 1,736 \\
\hline 405,000 & 313 & 260 & 11 & 510 & 120 & 107 & 1,321 \\
\hline 270,000 & 208 & 173 & 7 & 510 & 80 & 76 & 1,055 \\
\hline 135,000 & 104 & 87 & 4 & 410 & 40 & 45 & 689 \\
\hline
\end{tabular}

Q - Throughput

$\mathrm{N}_{\mathrm{cp}}$ - Number of compact machines. 7 includes 2 backups; 2 through 5 include 1 backup

$\mathrm{C}_{\mathrm{cm}}$ - Compaction machine cost ( $\$ 500,000$ per machine)

$\mathrm{C}_{\mathrm{bu}}$ - Building cost, proportional to number of compactors

$\mathrm{C}_{\mathrm{md}}$ - Material drying cost, proportional to throughput

$\mathrm{C}_{\mathrm{sr}}$ - Size reduction cost, proportional to throughput

$\mathrm{C}_{\mathrm{ms}}$ - Material storage cost, proportional to throughput

$\mathrm{C}_{\mathrm{ls}}$ - Log storage cost, proportional to throughput

$\mathrm{C}_{\mathrm{ss}}$ - Substation cost, calculated from $C_{s s}=0.67 \mathrm{P}^{0.6}$, where $\mathrm{P}$ is power needed

$\mathrm{C}_{\mathrm{oe}}$ - Other equipment cost, proportional to throughput

$\mathrm{C}_{\mathrm{e}}$ - Electricity cost, proportional to throughput

$\mathrm{C}_{\mathrm{f}}-$ Fuel cost, proportional to throughput

$\mathrm{C}_{\mathrm{w}}$ - Water cost, proportional to throughput

$\mathrm{C}_{\mathrm{sw}}$ - Salary and wage, 12 workers for the first two throughputs, 9 for the third and fourth, and 6 for the last

$\mathrm{C}_{\mathrm{ps}}$ - Parts and supply, proportional to throughput

$\mathrm{C}_{\mathrm{ti}}-$ Property tax and insurance cost, $2.5 \%$ of total capital cost 
Table 3-18. Cost items for biomass log production for the portable system with a throughput of 11,760 tons/yr

(a) Capital cost $\left(\times 10^{3}\right.$ dollars $)$

\begin{tabular}{|c|c|c|c|}
\hline $\mathrm{C}_{\mathrm{ps}}$ & $\mathrm{C}_{\mathrm{sh}}$ & $\mathrm{C}_{\mathrm{ae}}$ & Total $\left(\mathrm{C}_{\mathrm{c}}\right)$ \\
\hline 400 & 2,550 & 200 & 3,150 \\
\hline
\end{tabular}

(b) Anuual cost $\left(\times 10^{3}\right.$ dollars $)$

\begin{tabular}{|c|c|c|c|c|c|c|}
\hline $\mathrm{C}_{\mathrm{e}}$ & $\mathrm{C}_{\mathrm{f}}$ & $\mathrm{C}_{\mathrm{w}}$ & $\mathrm{C}_{\mathrm{sw}}$ & $\mathrm{C}_{\mathrm{m}}$ & $\mathrm{C}_{\mathrm{ti}}$ & Total $\left(\mathrm{C}_{\mathrm{a}}\right)$ \\
\hline 17 & 12 & 1.5 & 90 & 10 & 79 & 210 \\
\hline
\end{tabular}

$\mathrm{C}_{\mathrm{ps}}$ - Cost of the portable system $(\$ 400,000$ including the truck)

$\mathrm{C}_{\mathrm{sh}}$ - Cost of the shelter for storing the biomass material and sheltering the system

$\mathrm{C}_{\mathrm{ae}}$ - Cost of additional equipment at each source

$\mathrm{C}_{\mathrm{e}}$ - Electricity cost

$\mathrm{C}_{\mathrm{f}}-$ Fuel cost

$\mathrm{C}_{\mathrm{w}}$ - Water cost

$\mathrm{C}_{\mathrm{sw}}$ - Salary and wage

$\mathrm{C}_{\mathrm{m}}$ - Maintenance cost

$\mathrm{C}_{\mathrm{t}}$ - Property tax and insurance cost, $2.5 \%$ of total capital cost

Table 3-19. Comparison of unit transportation cost ( $\$$ ton) for biomass logs transported by five different modes

\begin{tabular}{|c|c|c|c|c|c|}
\hline \multirow{2}{*}{$\begin{array}{c}\text { Transportation } \\
\text { distance (mile) }\end{array}$} & Truck & Unit train & Barge & PCP $^{\mathrm{a}}$ & HCP $^{\mathrm{b}}$ \\
\cline { 2 - 6 } & $3.46-3.70$ & $2.82-2.84$ & $2.77-2.78$ & 7.2 & 6.2 \\
\hline 5 & $4.19-4.68$ & $2.87-2.96$ & $2.80-2.82$ & 10.9 & 7.2 \\
\hline 10 & $5.65-6.62$ & $3.00-3.18$ & $2.87-2.91$ & 19.9 & 9.3 \\
\hline 20 & $7.11-8.57$ & $3.14-3.41$ & $2.94-3.00$ & 28.9 & 11.5 \\
\hline 30 & $10.03-12.46$ & $3.41-3.87$ & $3.09-3.18$ & 47.2 & 15.7 \\
\hline 50 & $13.68-17.32$ & $3.74-4.43$ & $3.26-3.41$ & 70.8 & 21.1 \\
\hline 75 & $17.33-22.18$ & $4.08-5.00$ & $3.44-3.63$ & 92.6 & 26.4 \\
\hline 100 & $31.9-41.6$ & $5.43-7.27$ & $4.15-4.53$ & - & - \\
\hline 200 & $75.7-100$ & $9.48-14.08$ & $6.28-7.23$ & - & - \\
\hline 500 & $149-197$ & $16.23-25.43$ & $9.83-11.73$ & - & - \\
\hline 1,000 & &
\end{tabular}

a. The cost for PCP was calculated for a system that transports only 0.68 million tons per year. Larger throughput will be more economical.

b. The cost for HCP was calculated for system that transports 2.0 million tons per year because a throughput smaller than that is not commercially meaningful for HCP. 
APPENDIX B: FIGURES 

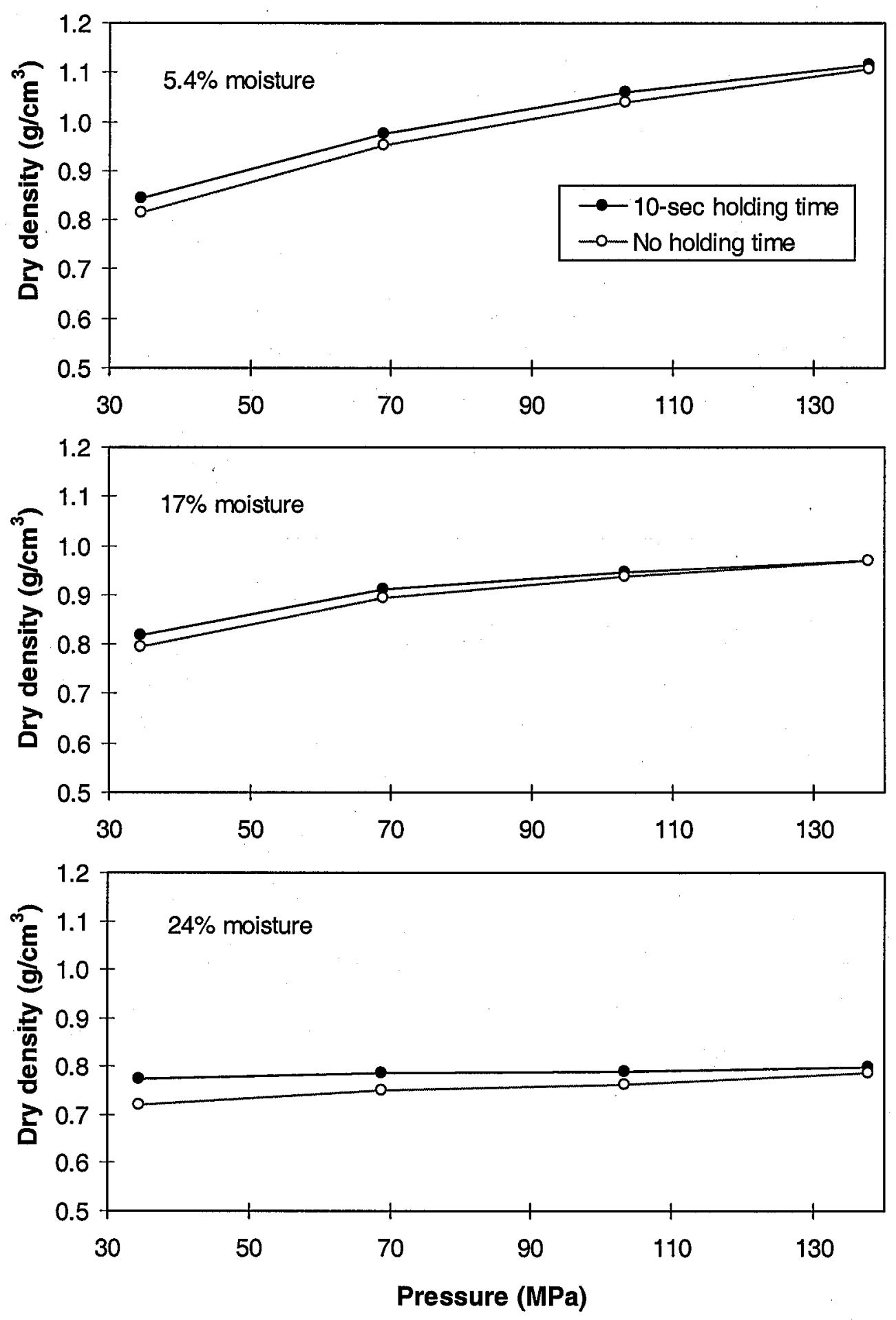

Fig. 3-1. Effects of compaction pressure and holding time on the densities (measured 2 minutes after ejection) of logs made of mixed paper 

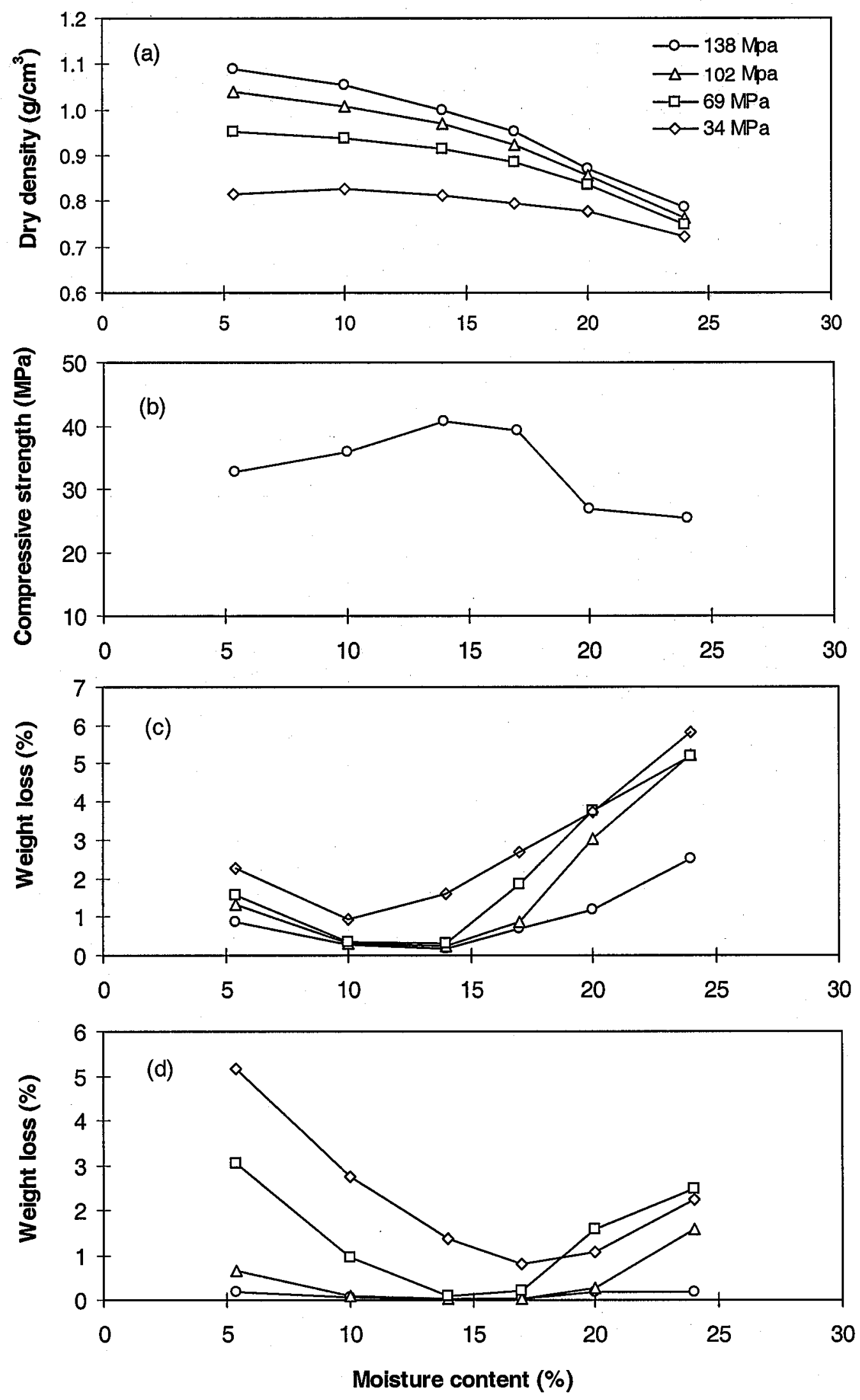

Fig. 3-2. Effects moisture and compaction pressure on properties of logs made of mixed paper:

(a) dry density; (b) compressive strength; (c) tumbler test results; (d) drop test results. 

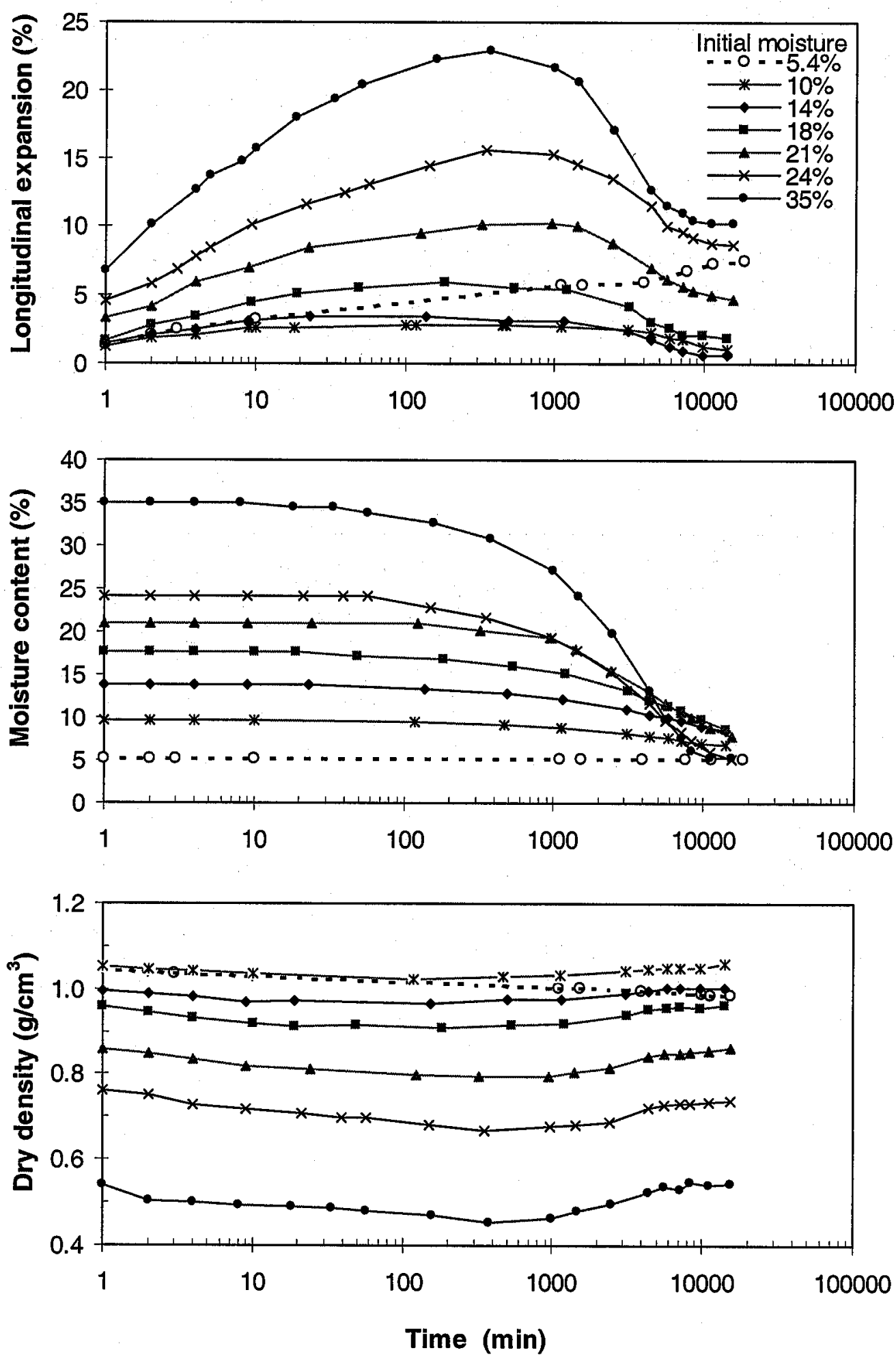

Fig. 3-3. Variation of longitudinal expansion (a), moisture content (b), and dry density (c) of mixed-paper logs with time. All logs were compacted at $138 \mathrm{MPa}$ pressure without holding time, and were exposed to open air under room temperature. 

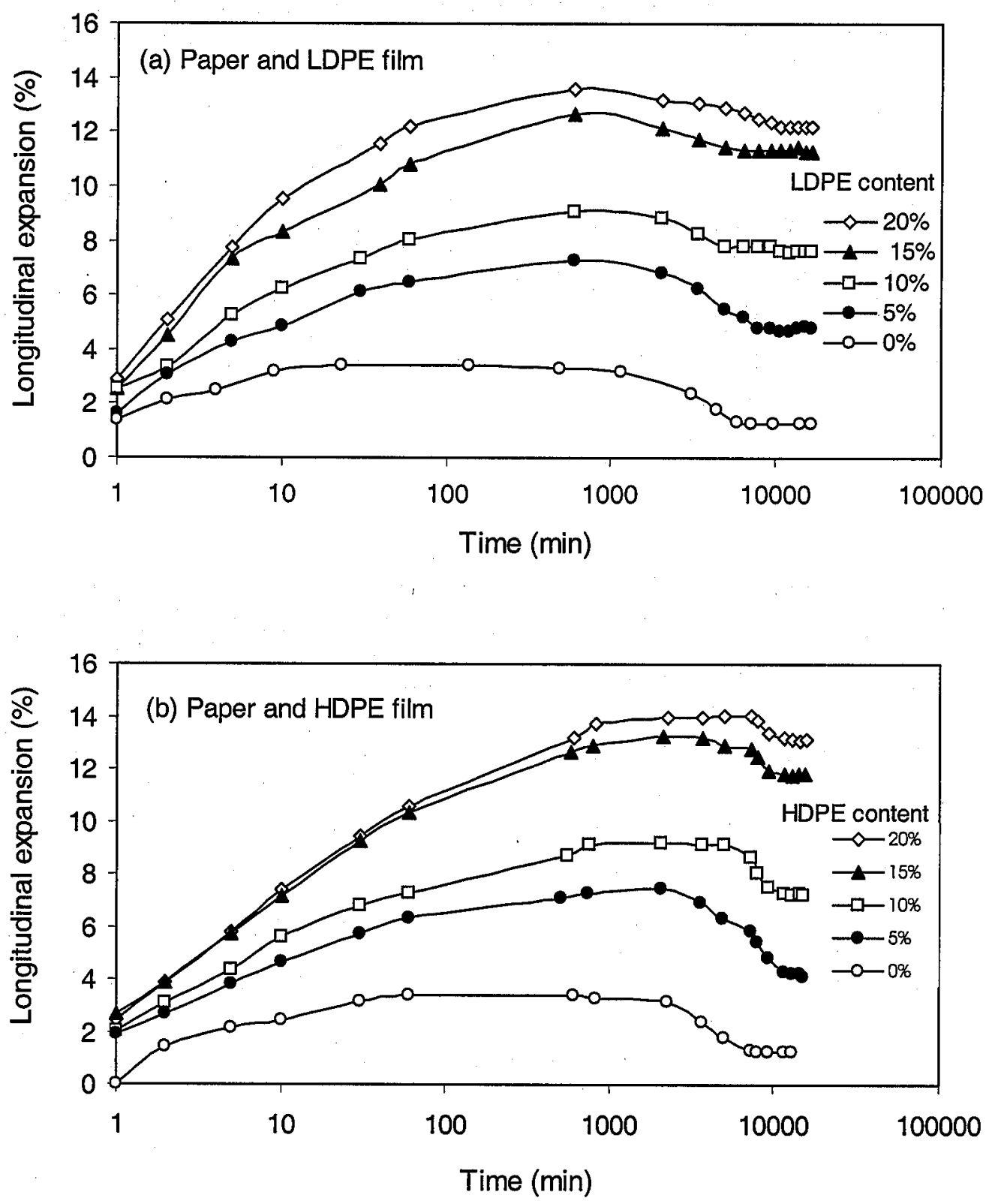

Fig. 3-4. Variation of log length with time in the open air for logs made of mixture of paper and two different plastic films at compaction pressure of $138 \mathrm{MPa}$ 


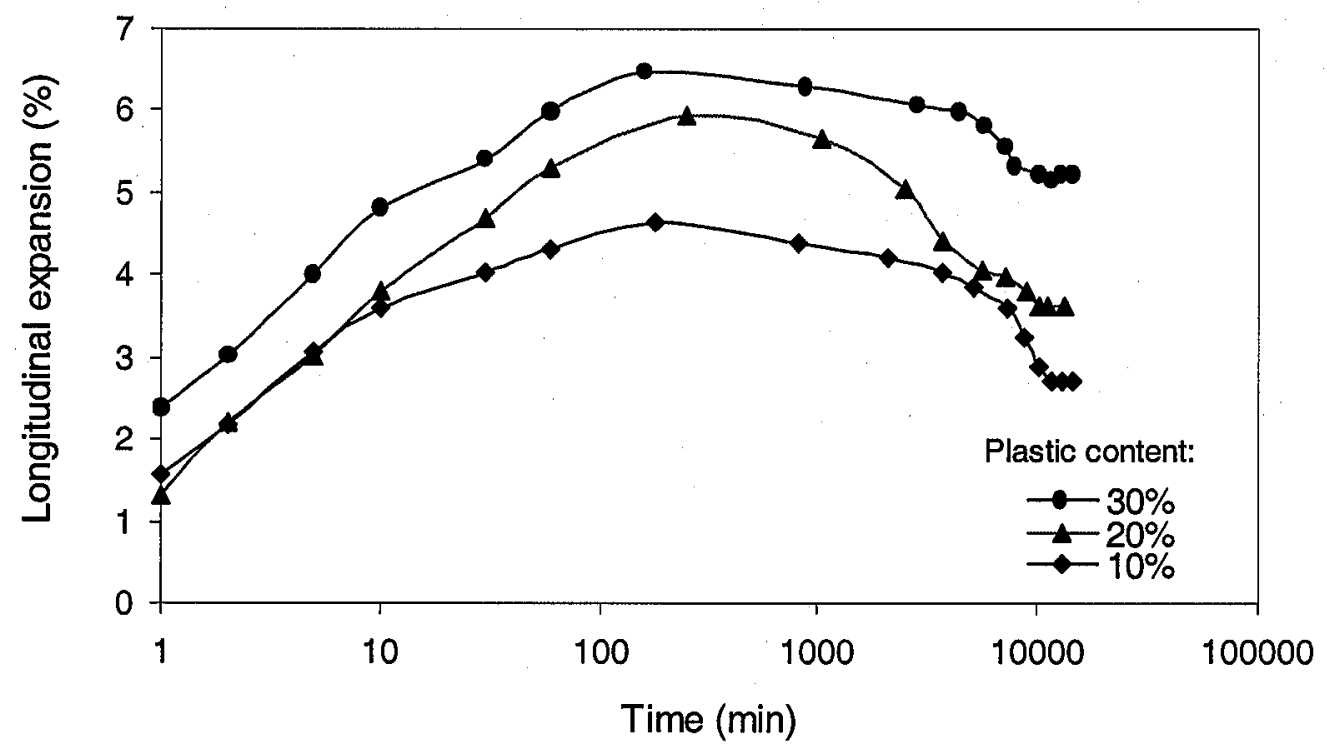

Fig. 3-5. Variation of dimensions with time for logs made of mixture of paper and hard plastics with different plastic contents compacted at $138 \mathrm{MPa}$ and at $15 \%$ moisture

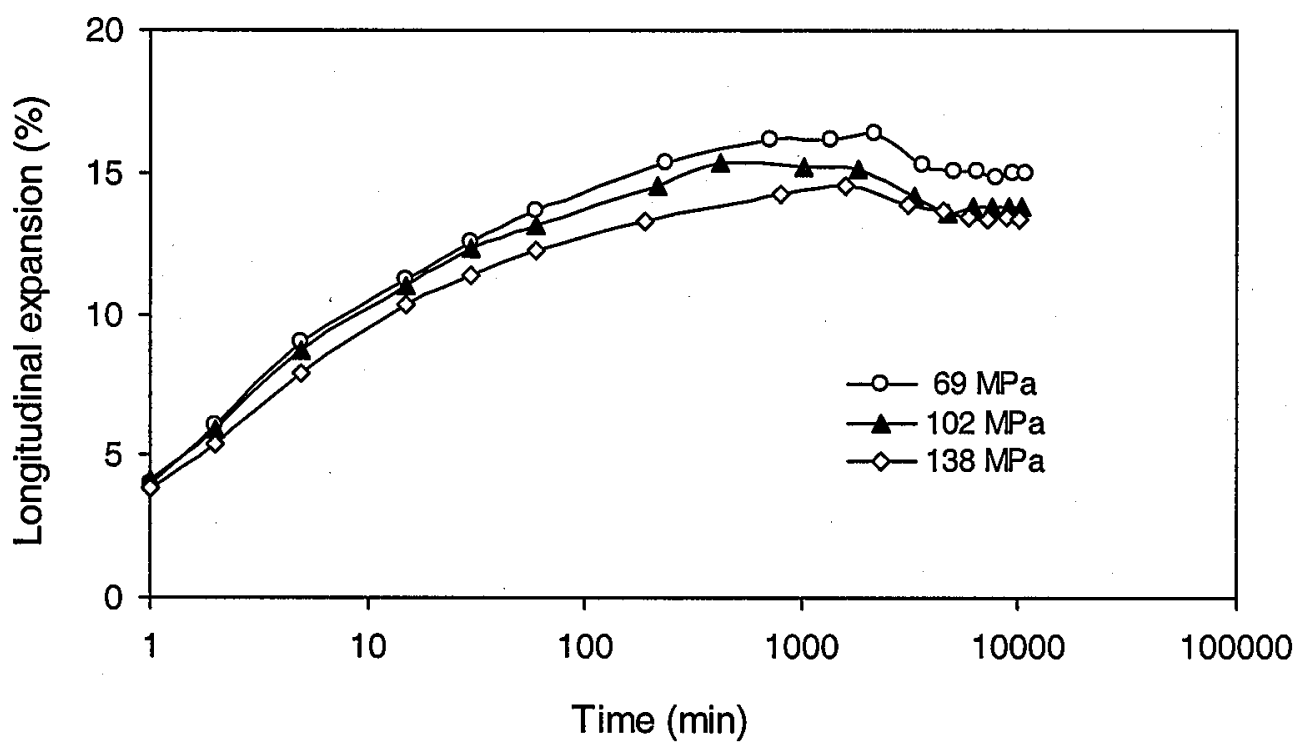

Fig. 3-6. Variation of dimensions of logs made of mixture of four major combustibles (paper, plastics, textile, and wood) in municipal solid waste. The logs were compacted at $15 \%$ moisture and at three different pressures as indicated in the graph. 


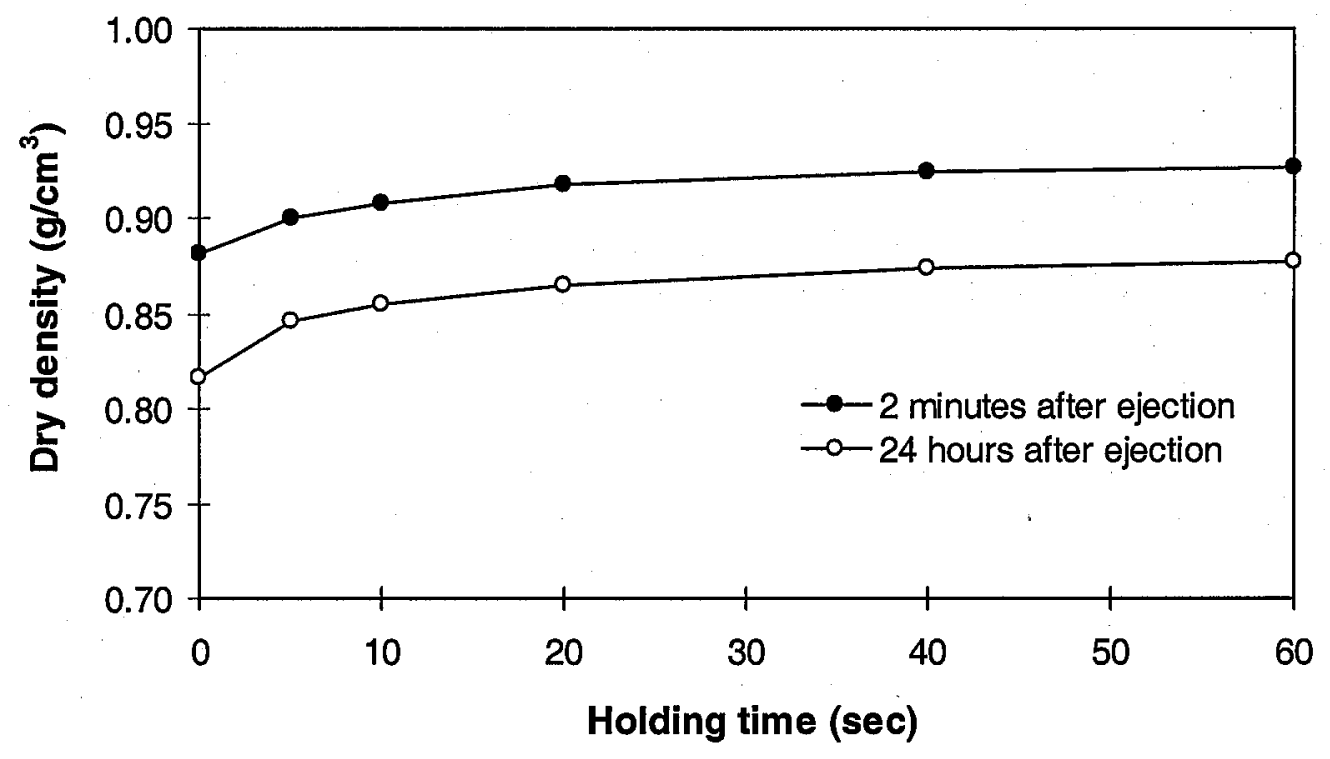

Fig. 3-7. Variation of dry density with pressure holding time for logs made of oak sawdust containing 9.7\% moisture and compacted at $103 \mathrm{MPa}$.

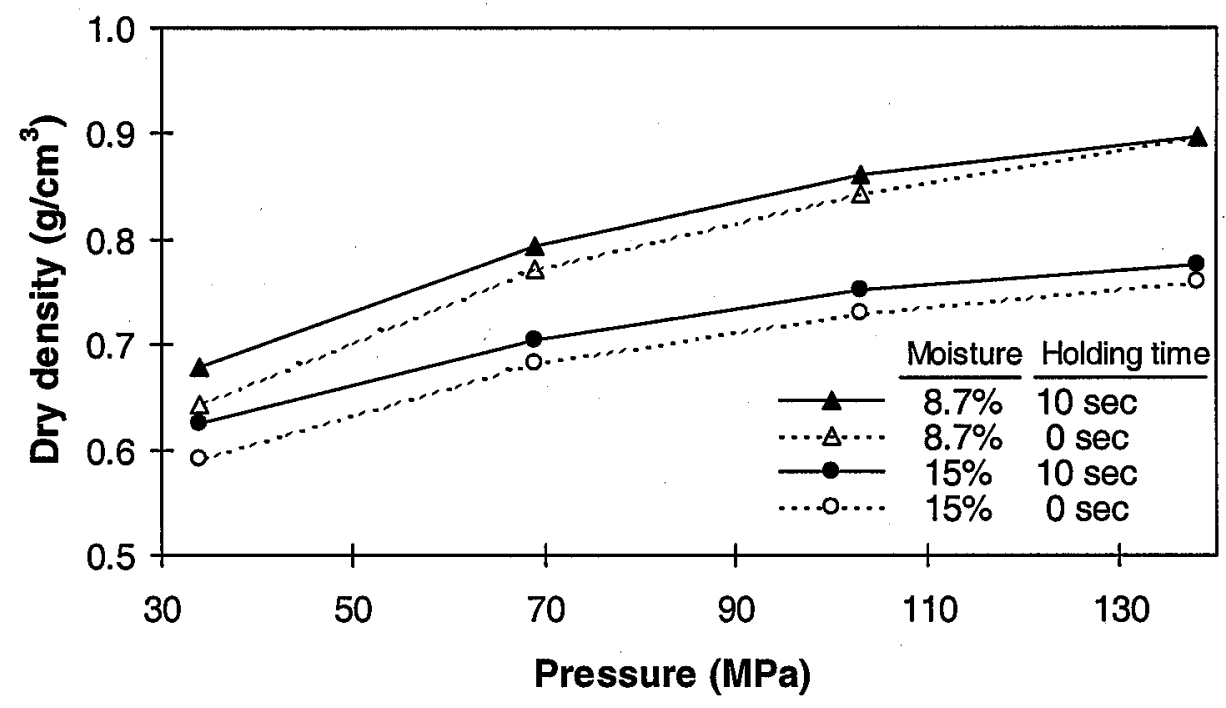

Fig. 3-8. Variation of dry density of logs with compaction pressure, pressure holding time, and moisture for logs made of oak sawdust. 

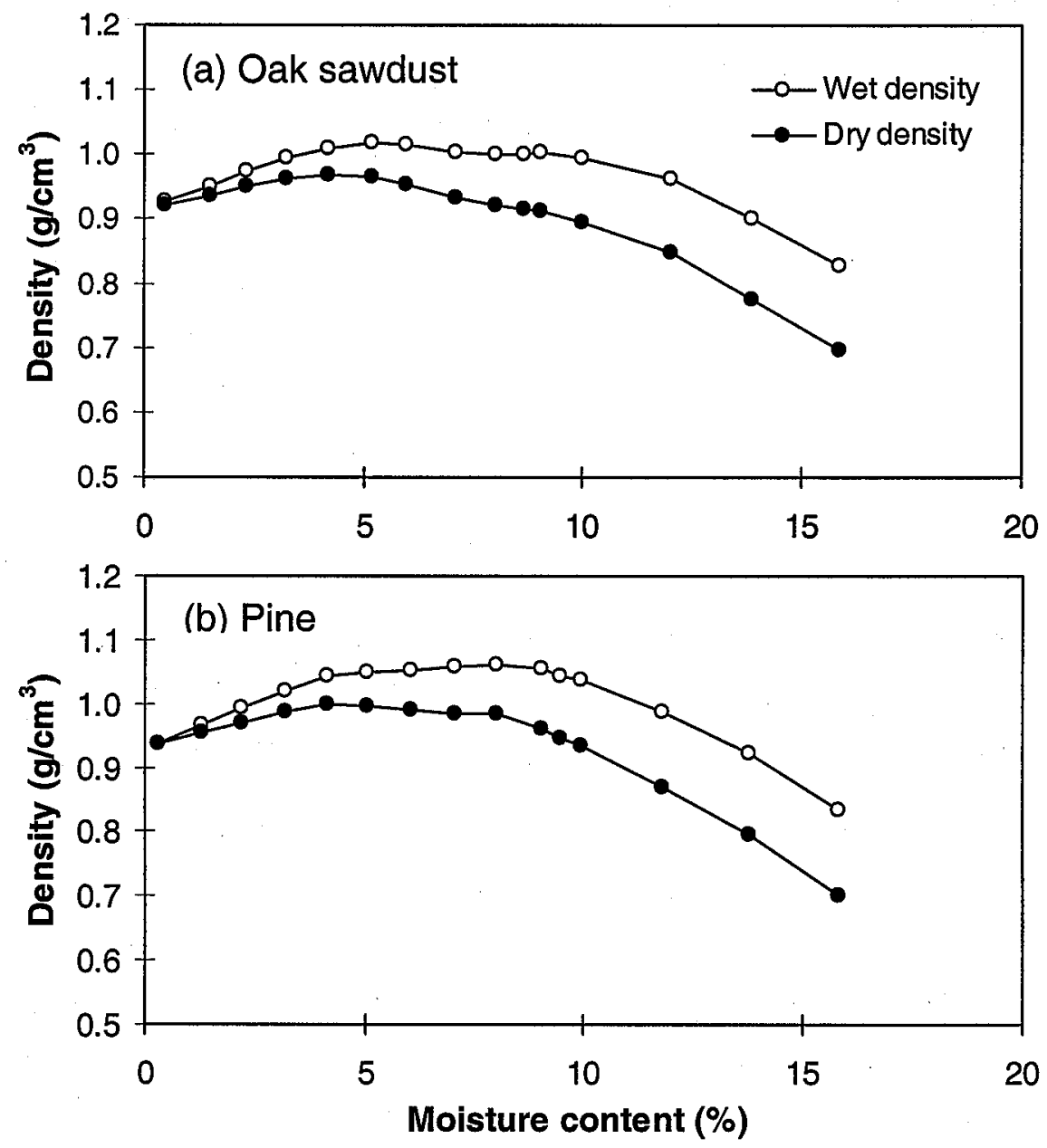

Fig. 3-9. Variation of log density with moisture content for oak sawdust and pine sawdust compacted at $138 \mathrm{MPa}$ pressure without holding time. The densities were measured 2 minutes after ejection. 

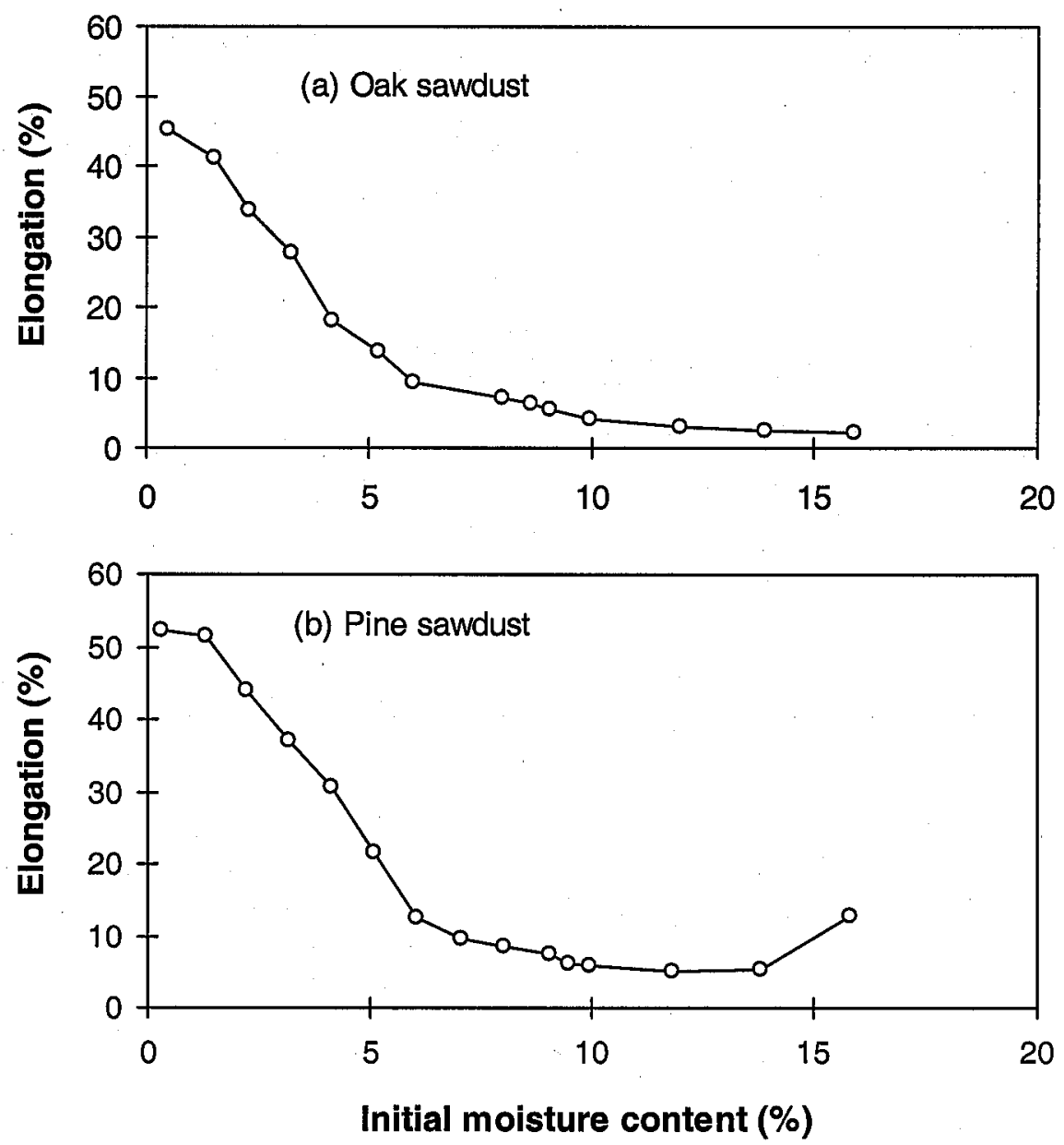

Fig. 3-10. Variation of elongation of logs with initial moisture after 3 days

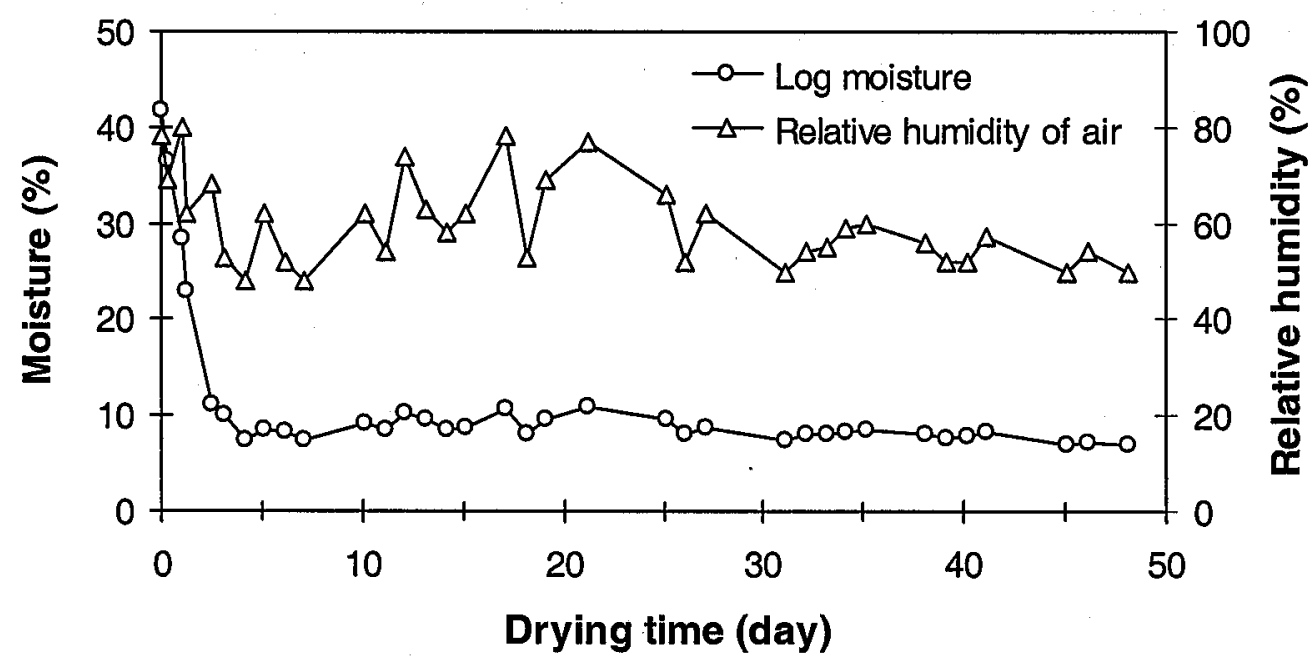

Fig. 3-11. Variation of moisture of oak sawdust with time compared with variation of relative humidity of air with time 


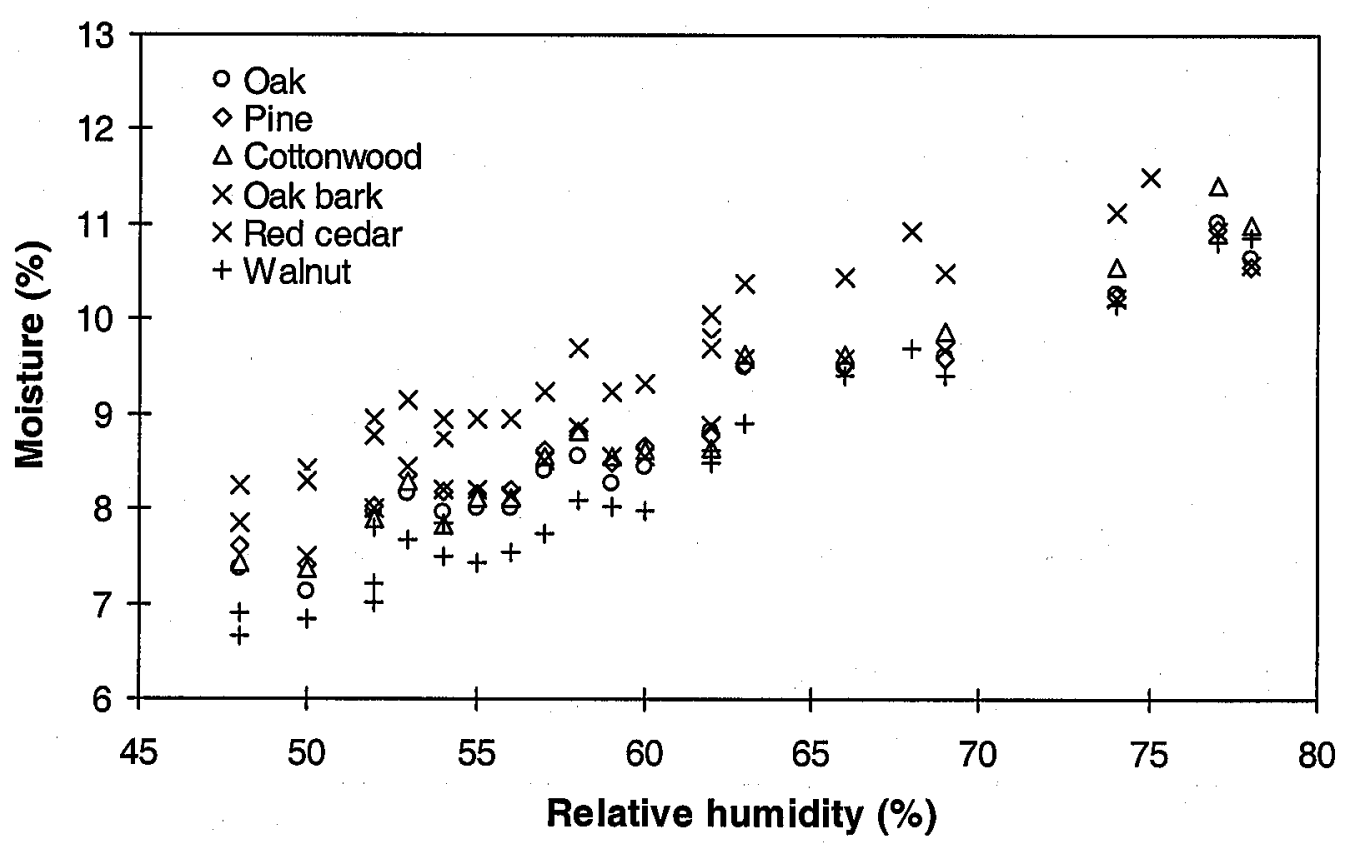

Fig. 3-12. Variation of equilibrium moisture of woody materials with relative humidity of air. The squared correlation coefficients for linear regressions of the date are all greater than 0.95 .

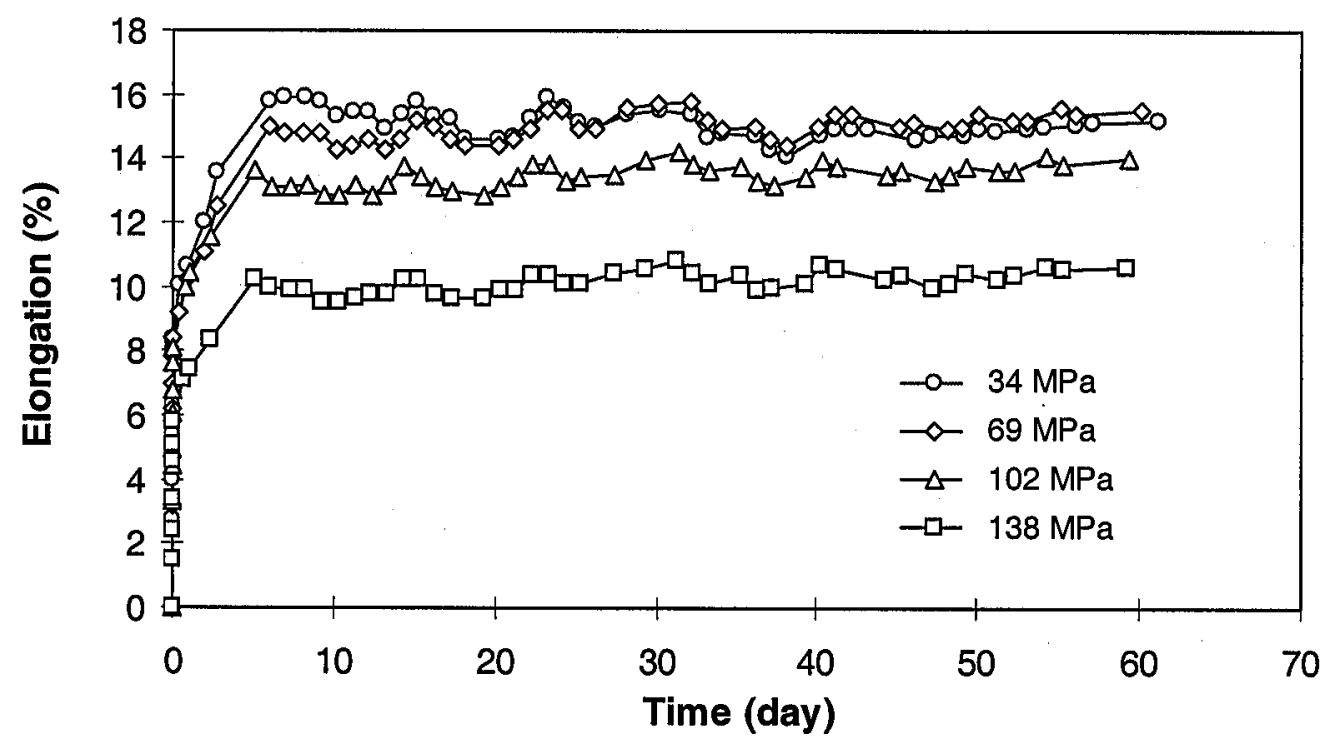

Fig. 3-13. Expansion of logs with time made of air-dried oak sawdust compacted at four different pressures 


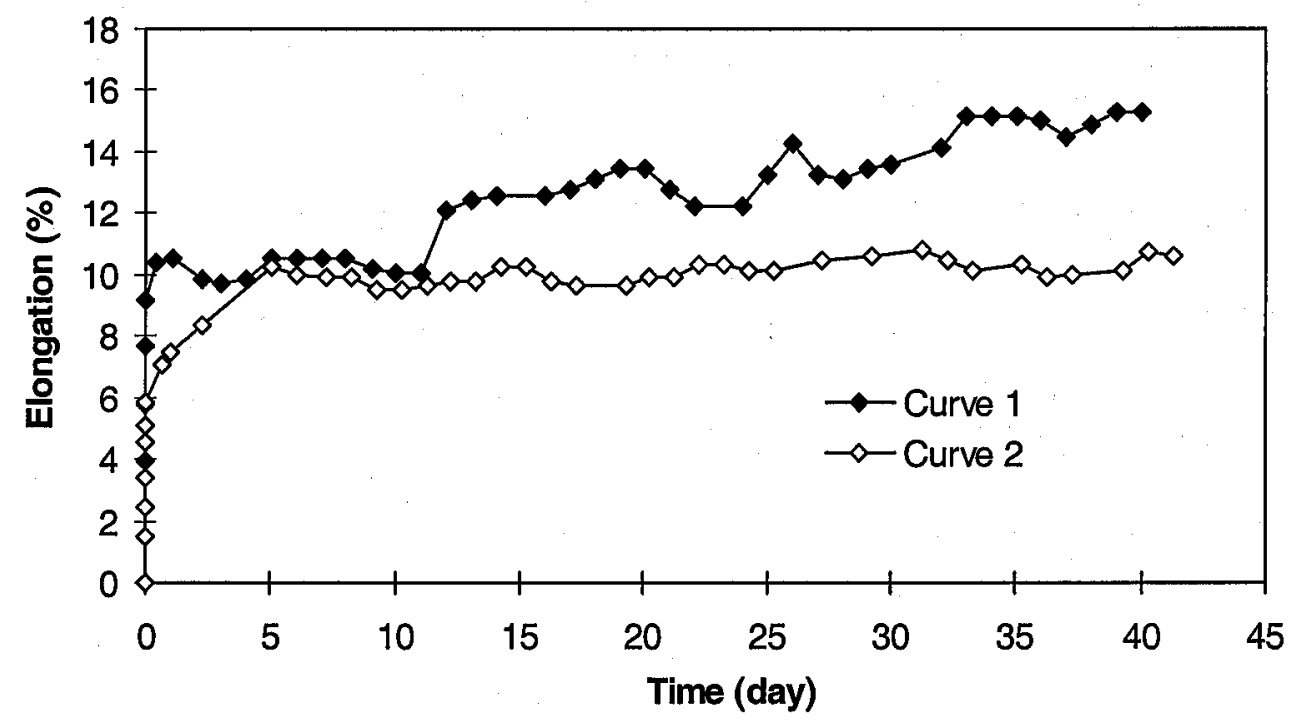

Figure 3-14. Expansions of logs with time observed during two different periods of time. The logs were made of oak sawdust at $138 \mathrm{MPa}$ without holding time and at air-dried moisture (8\%). Curve 1 was obtained during a period when the air humidity was high and changeable (relative humidity $60-85 \%$ ). Curve 2 was obtained during a period when the air humidity was low and fairly stable (relative humidity $40-50 \%$ ).

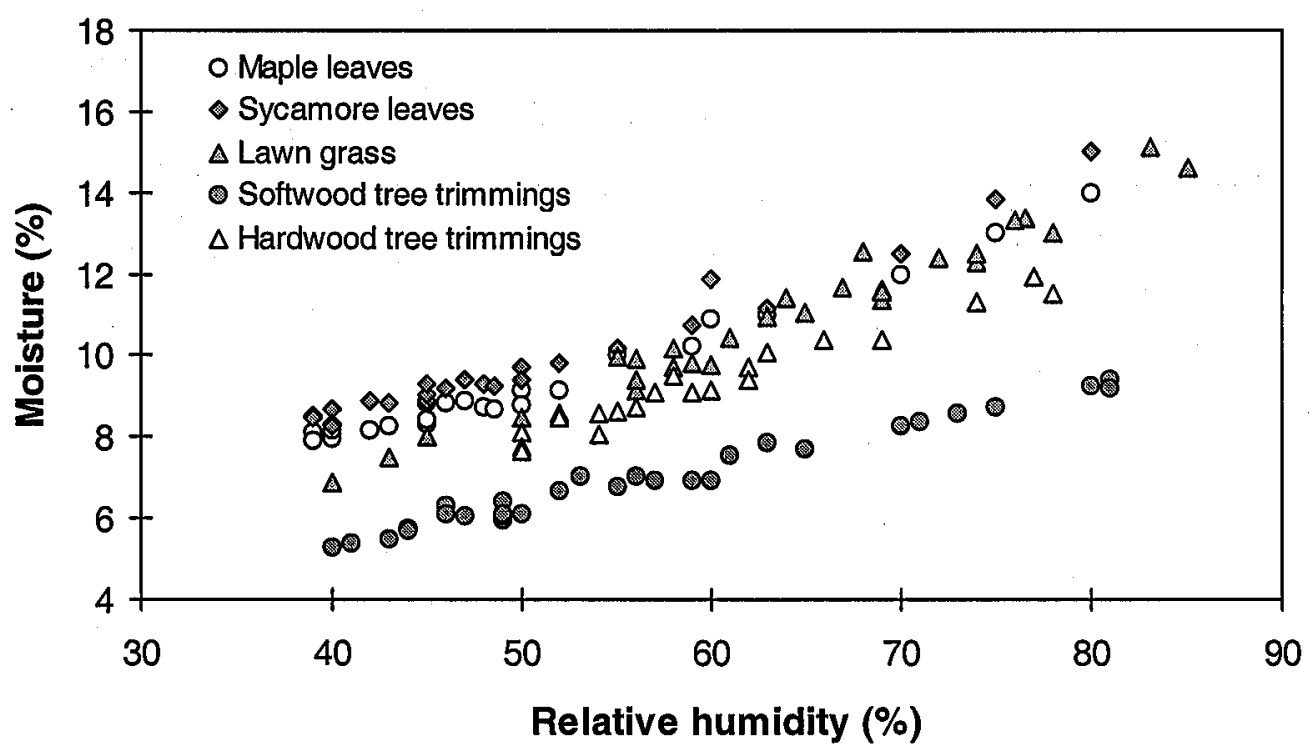

Figure 3-15. Variation of equilibrium moisture of yard waste materials with relative humidity of air. The squared correlation coefficients for linear regressions of the date are all greater than 0.93 


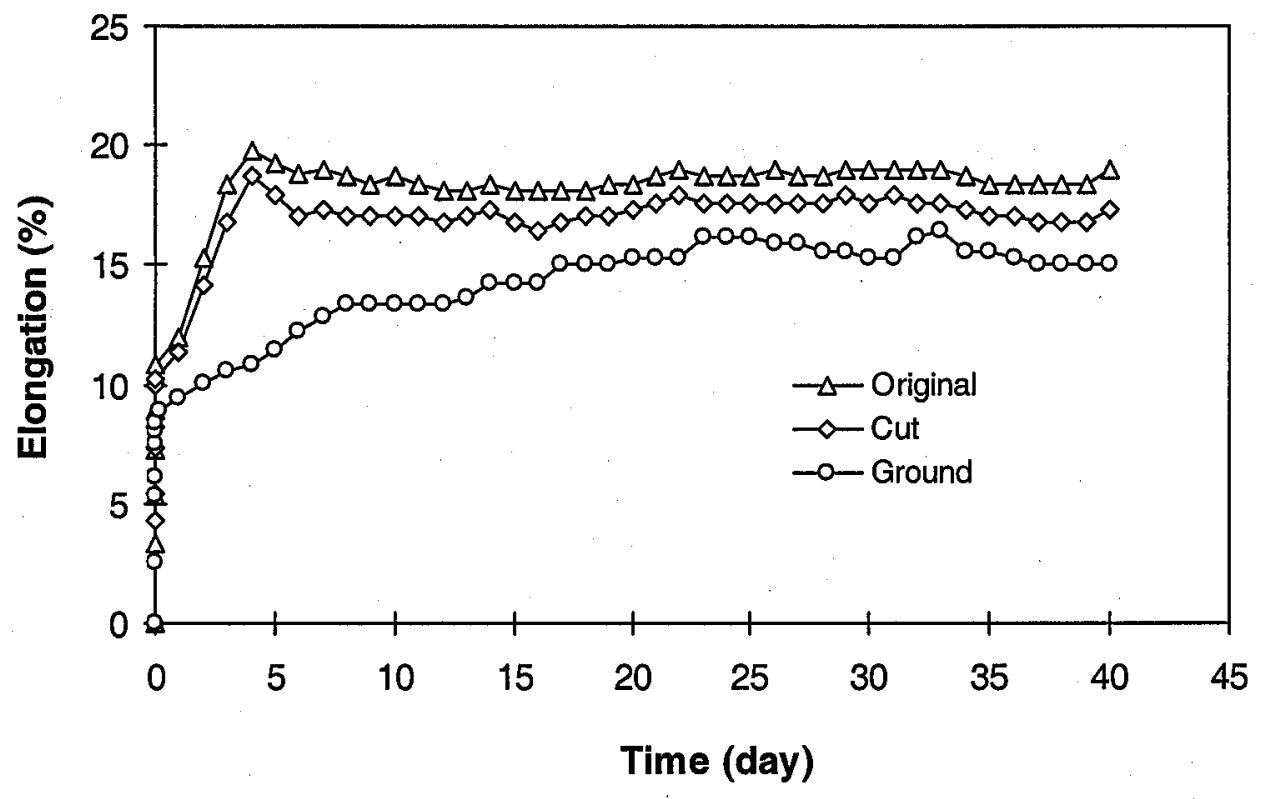

Fig. 3-16. Expansion of logs with time made of lawn grass with different sizes - originally mowed, cut, and hammermillground. The logs were compacted at $102 \mathrm{MPa}$ without holding time.

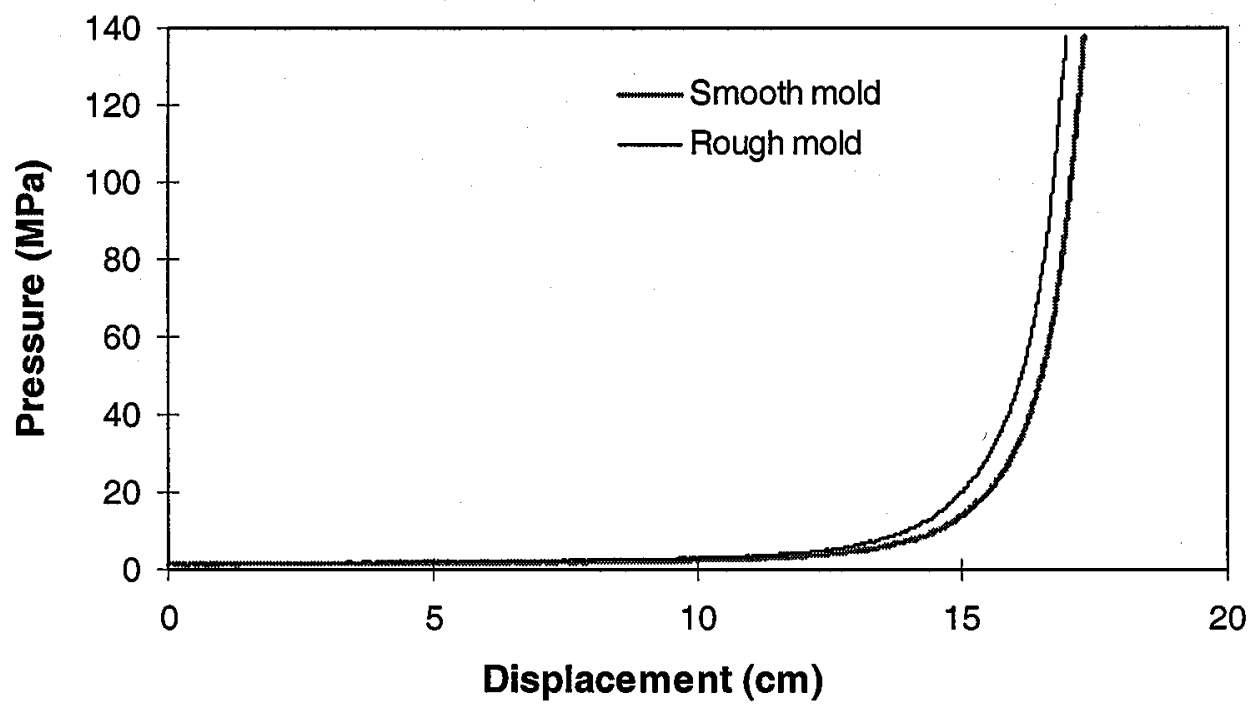

Fig. 3-17. Effect of mold roughness on piston displacement during biomass compaction. The material was room-dried mixed paper (6\%). 


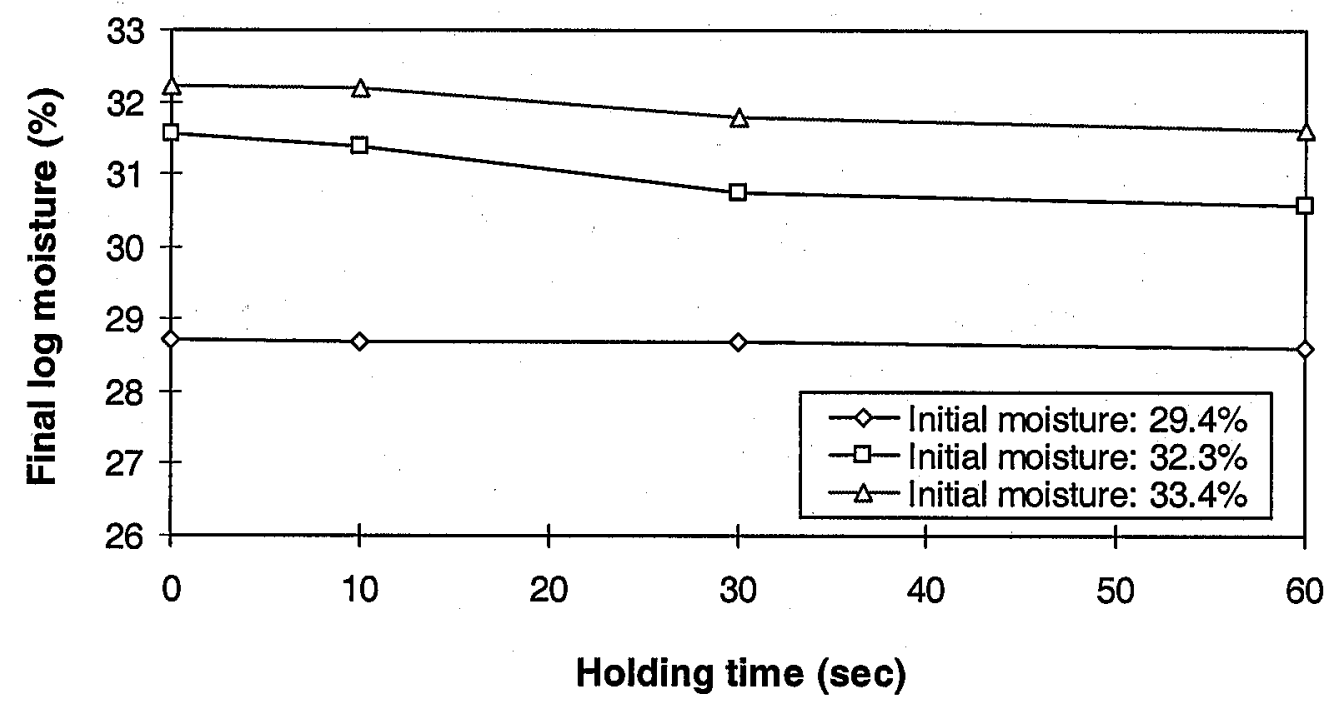

Fig. 3-18. Effect of pressure holding time on the expulsion of moisture in the mixed paper logs compacted at $138 \mathrm{MPa}$ 

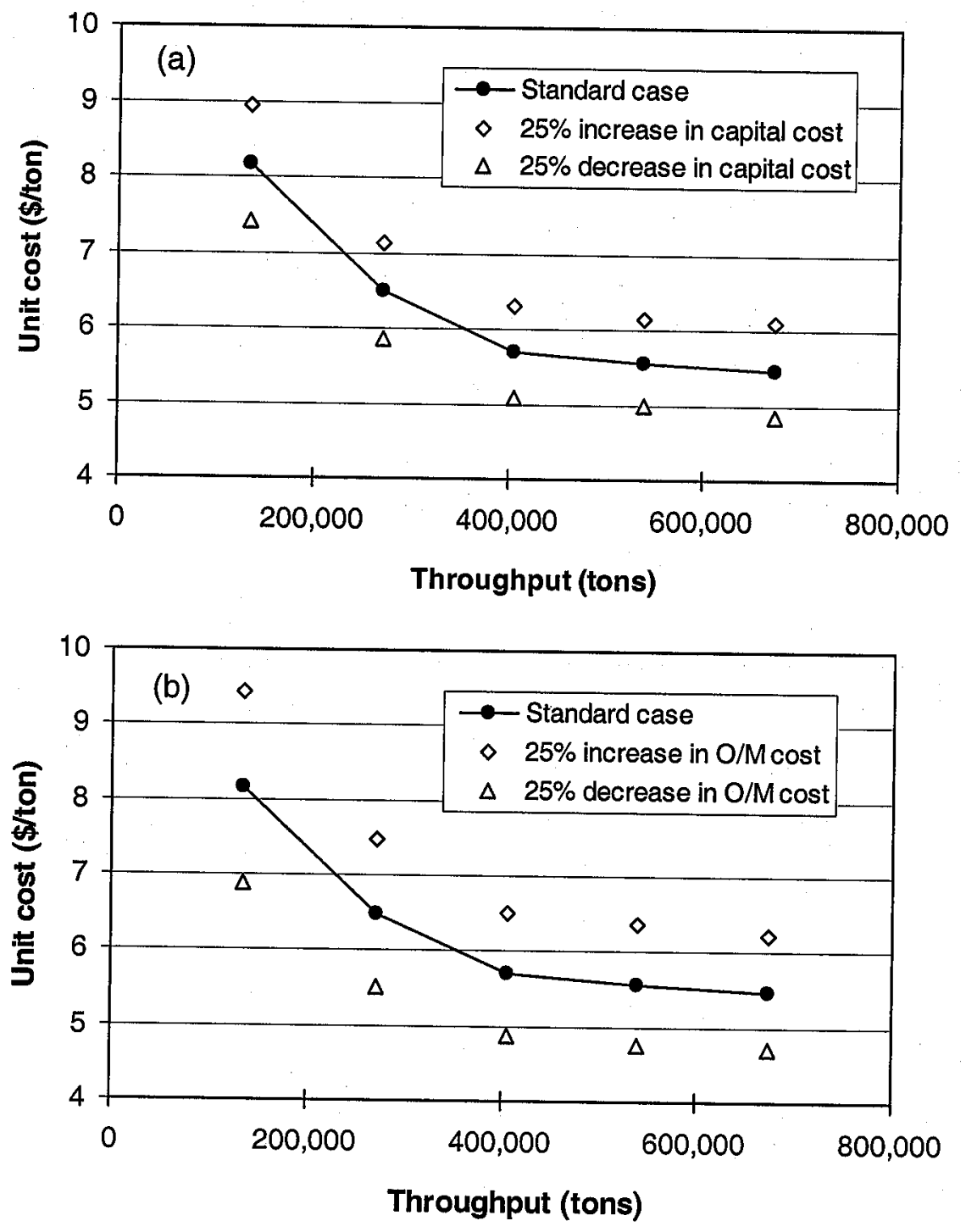

Fig. 3-19. Variation of unit production cost of biomass logs with throughput and sensitivities of the unit cost to capital cost (a) and annual maintenance $(\mathrm{O} / \mathrm{M}) \operatorname{cost}(\mathrm{b})$ 


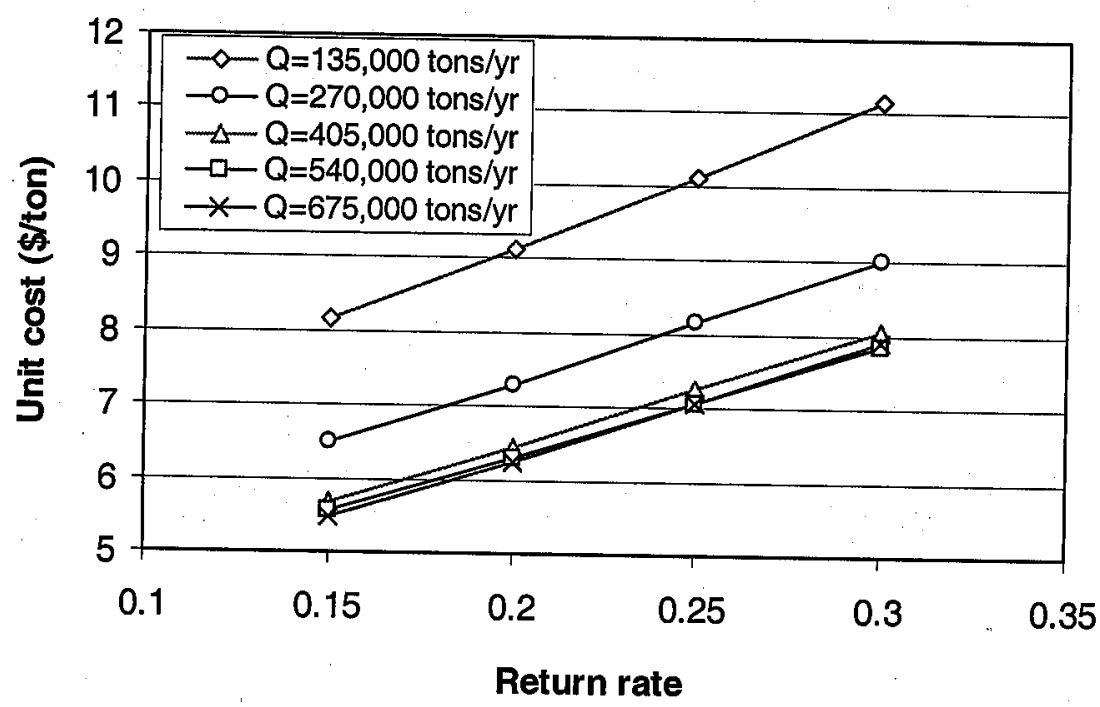

Fig. 3-20. Variation of unit production cost of BLF with company after-tax return rate for different throughputs 
APPENDIX C: PHOTOS 


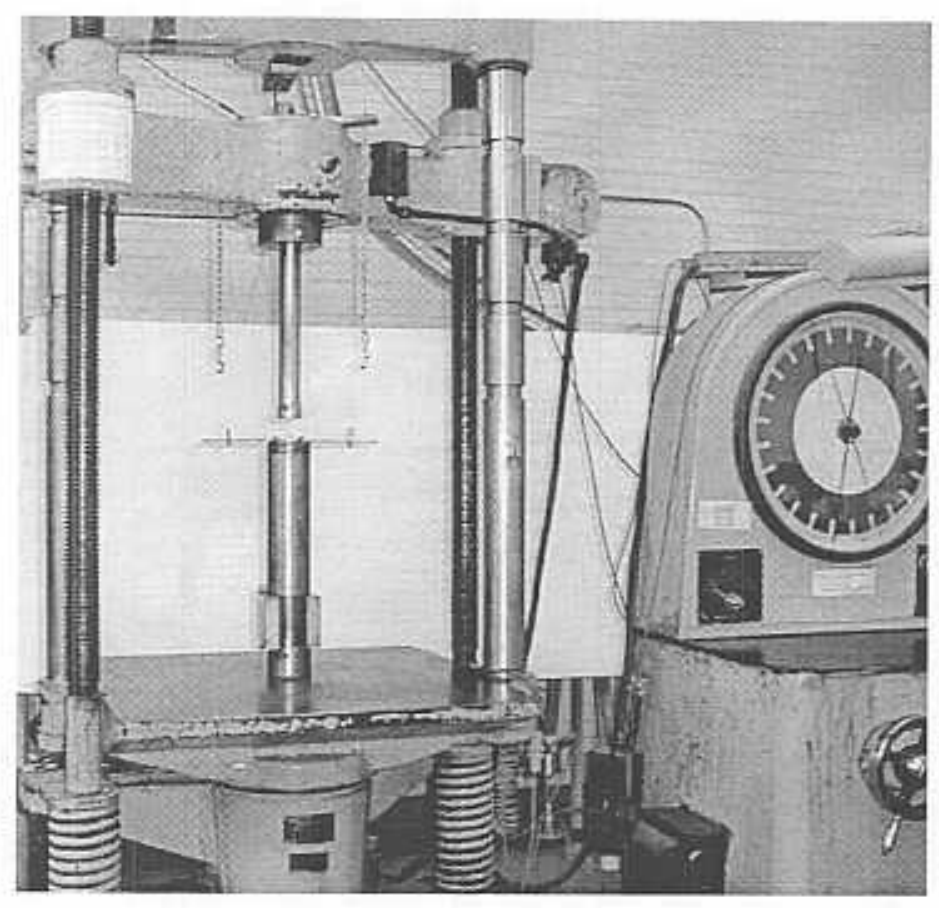

Photo 2-1. Small compaction machine for producing $48.5-\mathrm{mm}$ (1.91-inch)-diameter biomass logs

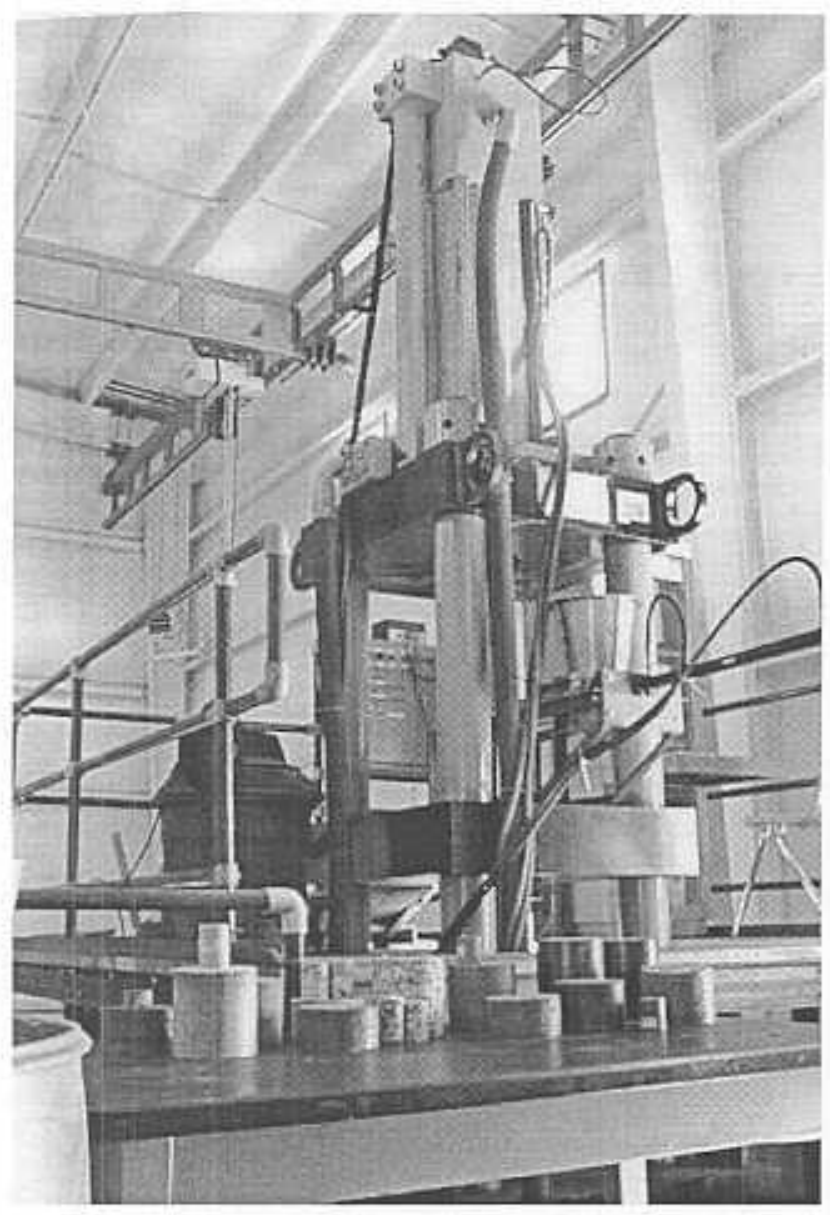

Photo 2-2. Large compaction machine for producing $137-\mathrm{mm}$ (5.4-inch)diameter biomass logs 


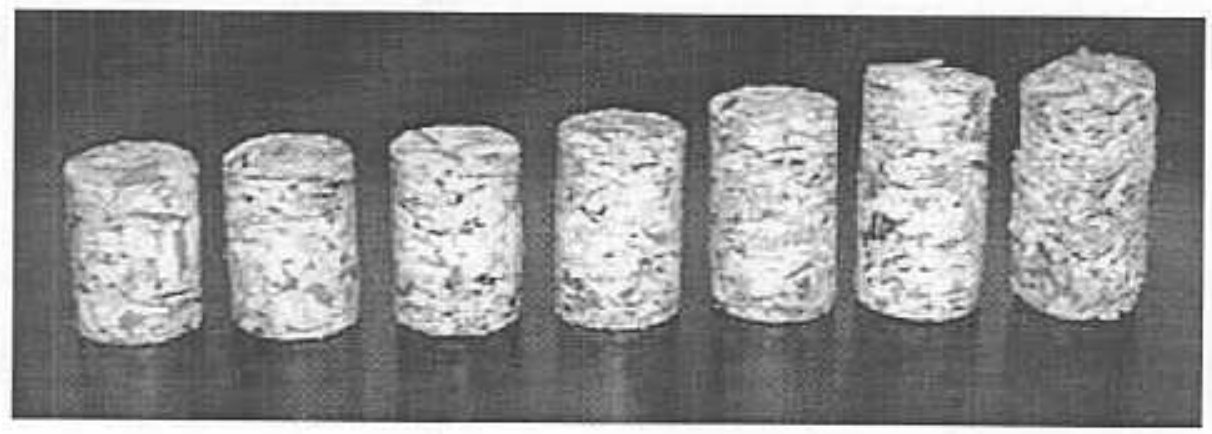

Photo 3-1. Logs made of waste paper with moistures of $5.4 \%$ (leftmost), 10\%, $14 \%, 17 \%, 21 \%, 24 \%$, and $35 \%$ (rightmost) compacted at $102 \mathrm{MPa}$
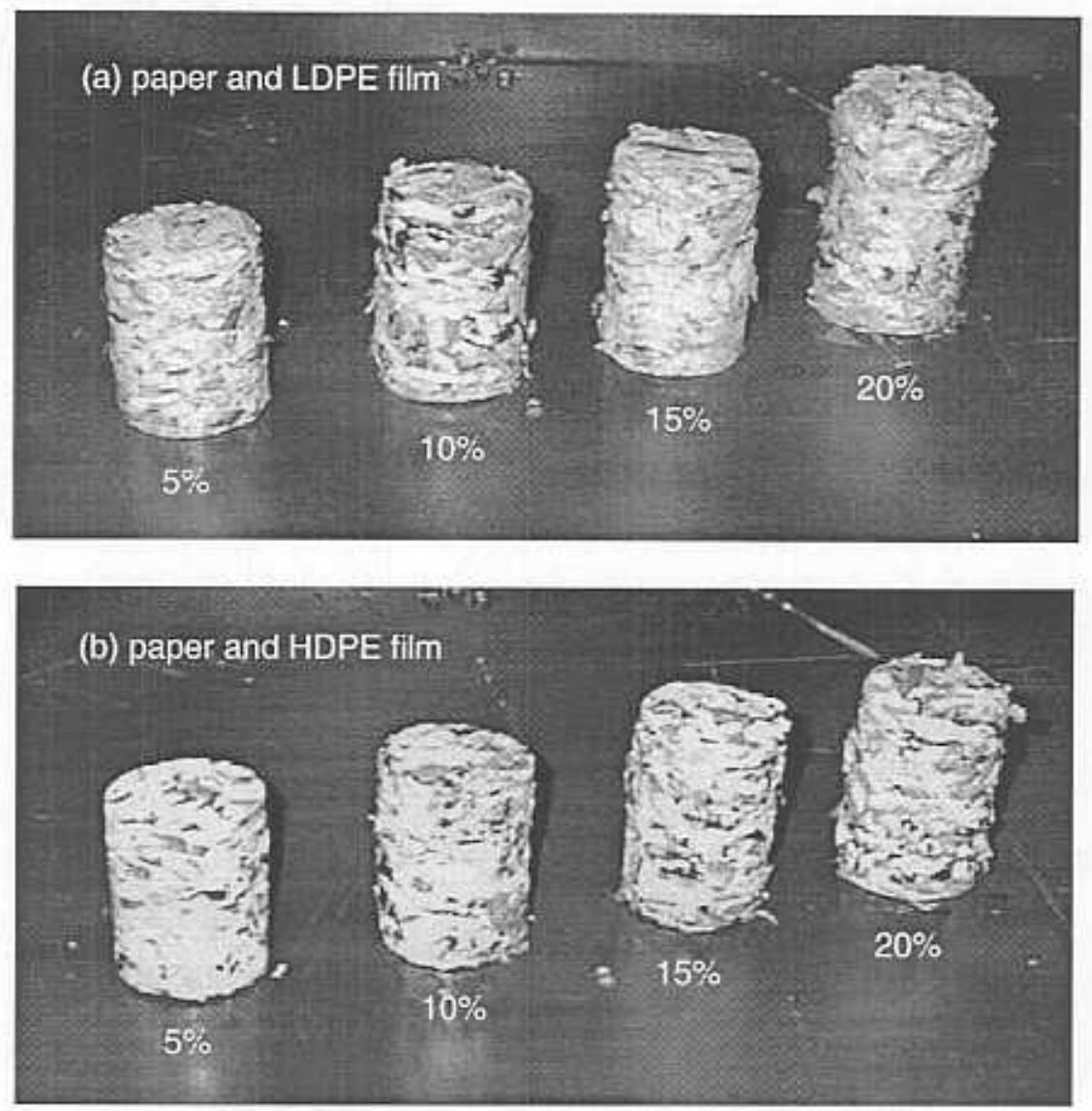

Photo 3-2. Logs made of mixtures of paper and LDPE film and paper and HDPE film with different film contents compacted at $102 \mathrm{MPa}$ and at $15 \%$ moisture 


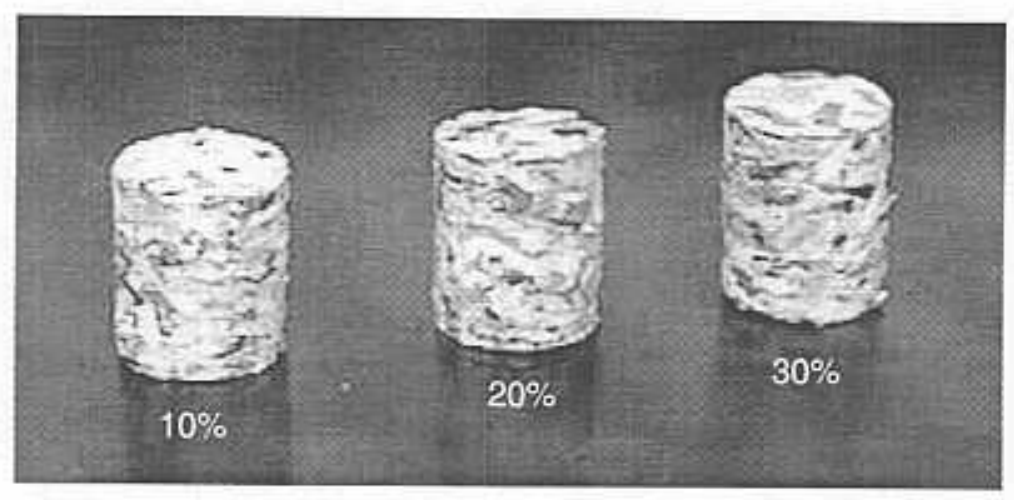

Photo 3-3. Logs made of mixture of paper and hard plastics containing different hard plastic contents compacted at 102 $\mathrm{MPa}$ and at $15 \%$ moisture

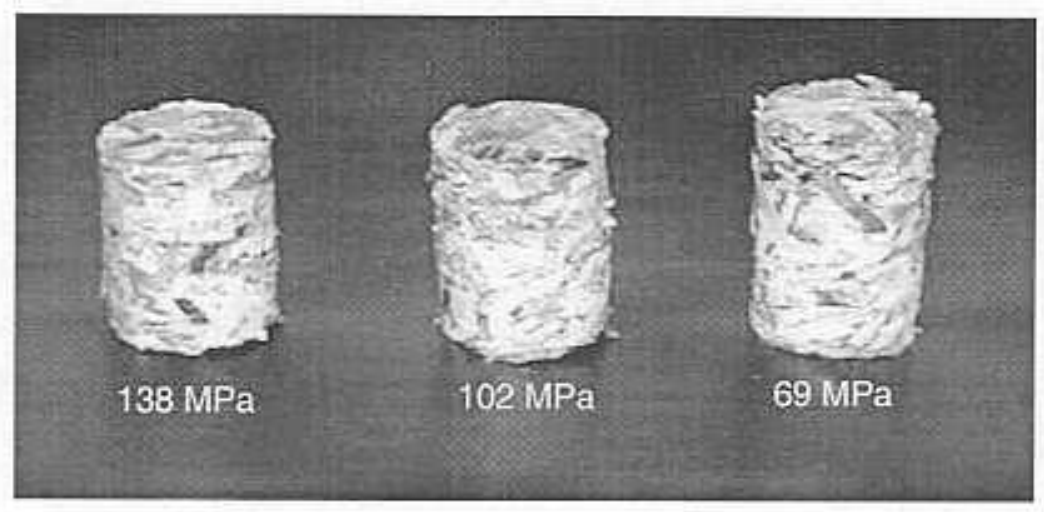

Photo 3-4. Logs made of mixture of air-dried combustibles (paper, plastics, textiles, and wood) at different pressures 

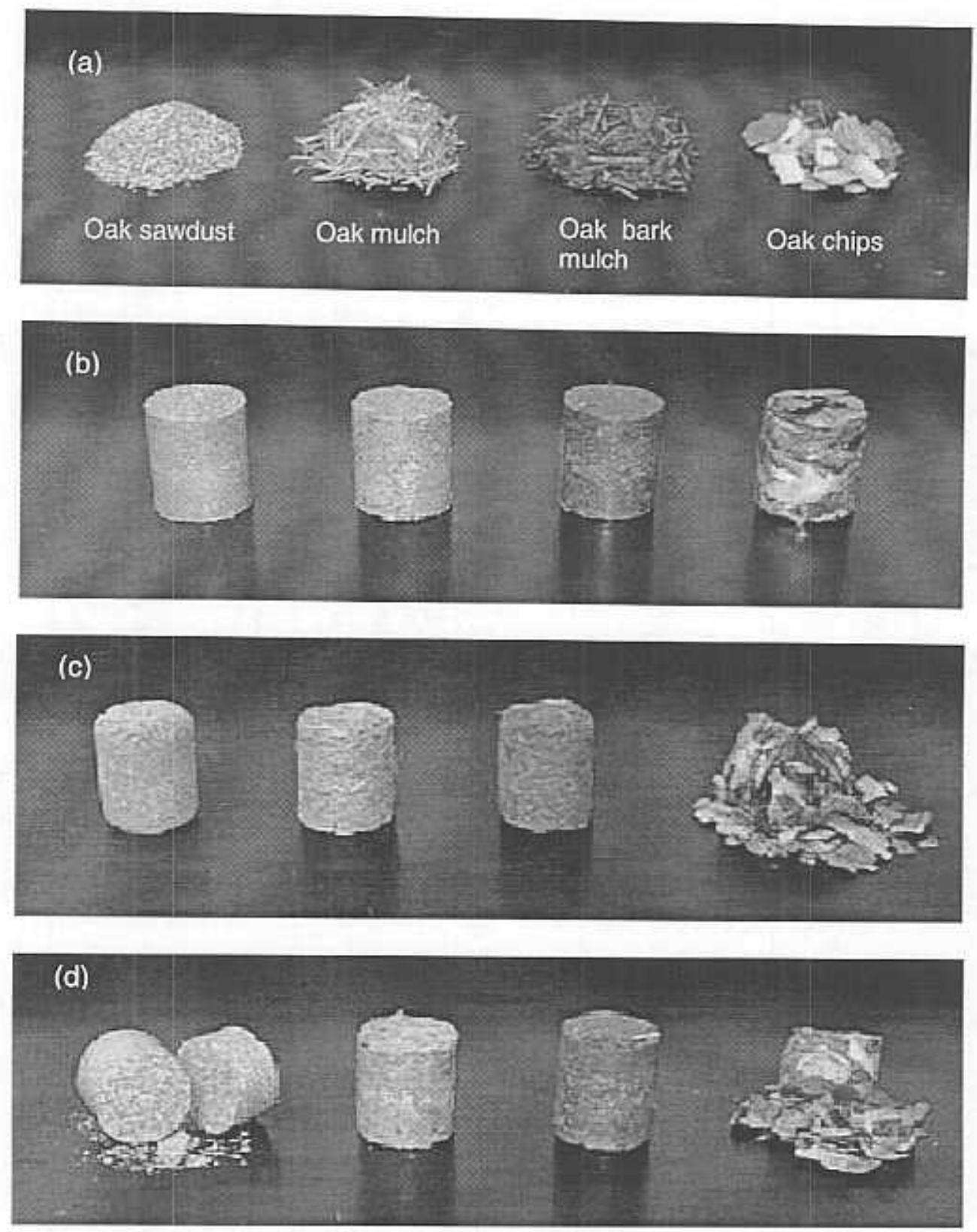

Photo 3-5. Biomass feedstocks in different particle shapes and logs made of these feedstocks. (a) Feedstocks of oak sawdust, oak mulch, oak bark mulch, and oak chips; (b) logs compacted at $138 \mathrm{MPa}$ without holding time; (c) results of tumbler tests of the logs; (d) results of drop tests of the logs. 


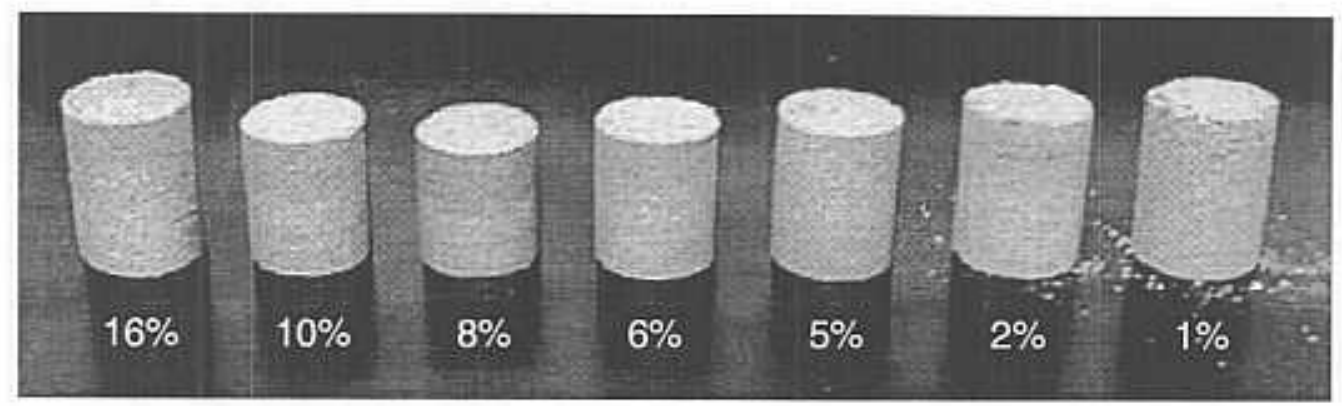

(a) Oak sawdust

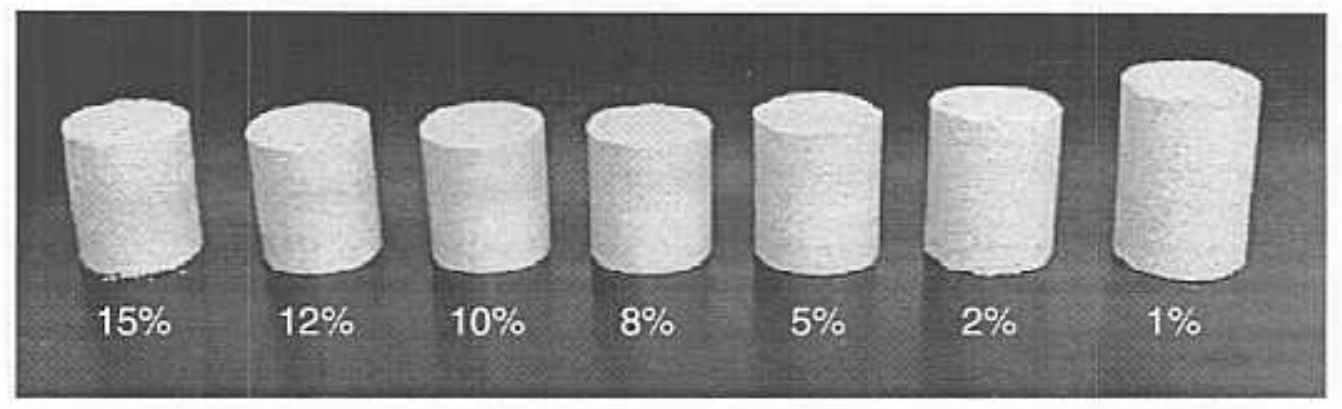

(b) Pine sawdust

Photo 3-6. Oak sawdust logs and pine sawdust logs three days after the logs had been produced. The logs were made at $138 \mathrm{MPa}$ (no holding time) with various moisture contents as indicated underneath each $\log$. 


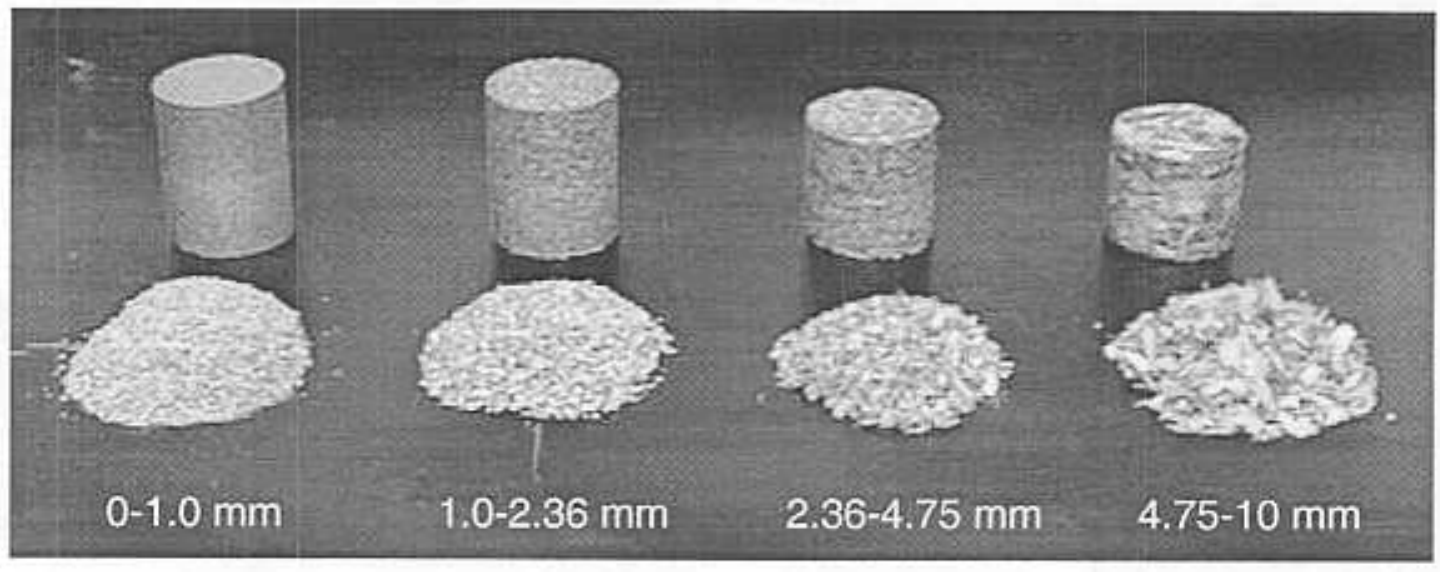

(a) Logs made of oak sawdust with different particle sizes

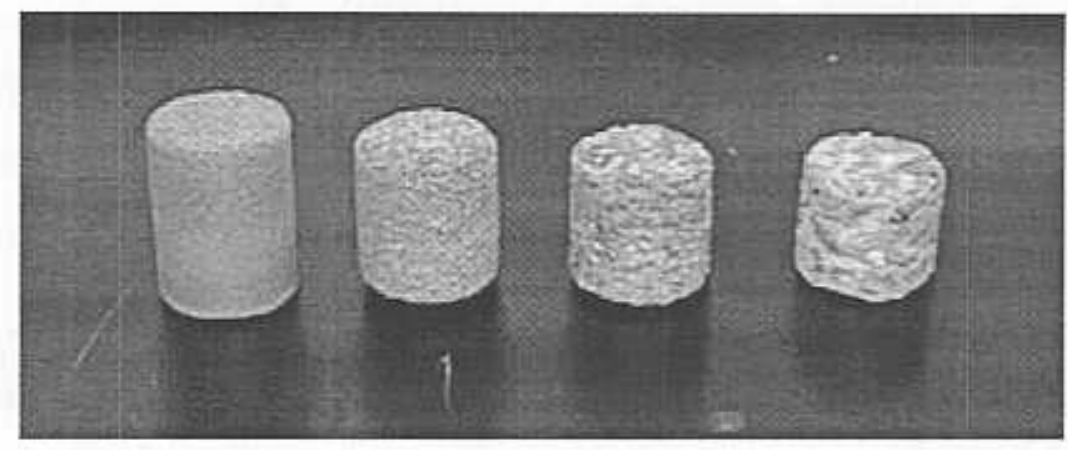

(b) After tumbler test

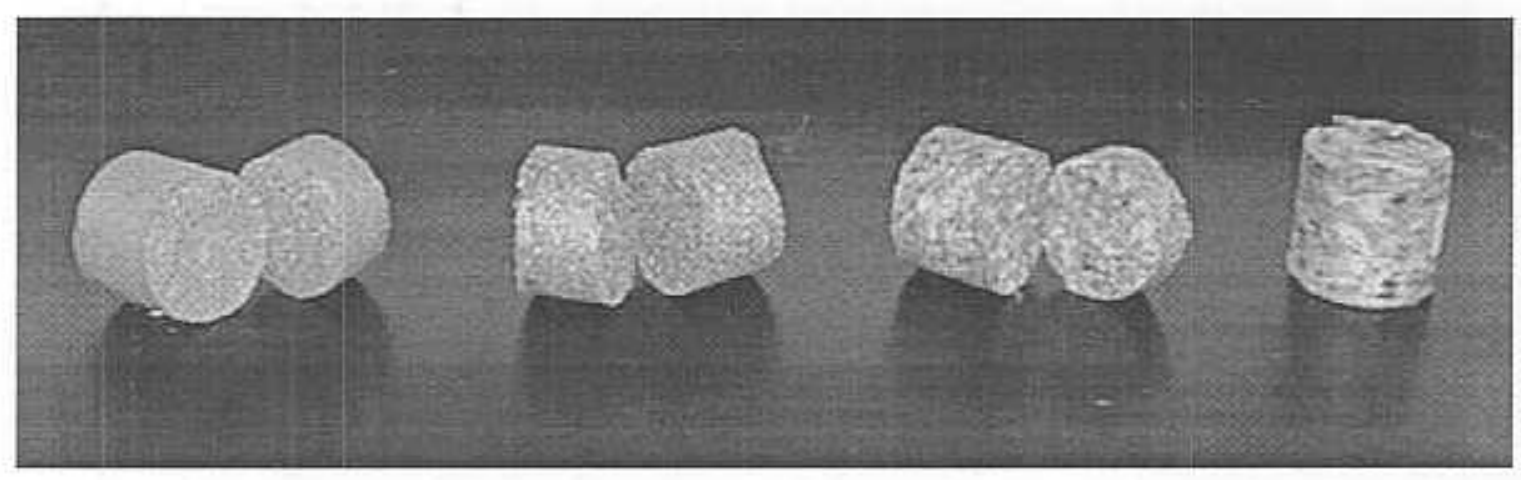

(c) After drop test

Photo 3-7. Effect of particle size of the materials on the properties of the logs. The logs were made under the same moisture $(10 \%)$ and pressure $(138 \mathrm{MPa})$. 

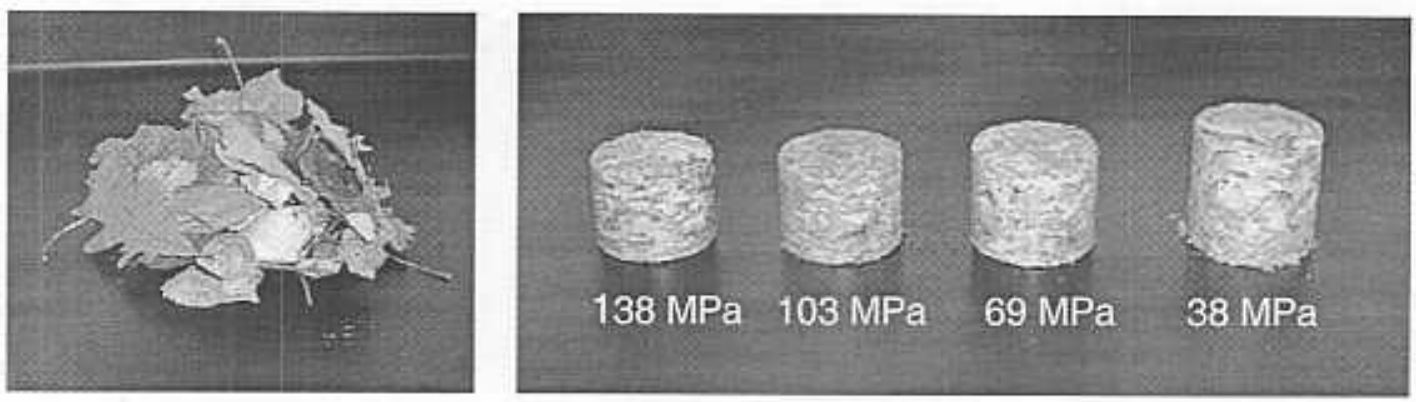

(a) Mixed hardwood leaves, moisture $8.1 \%$
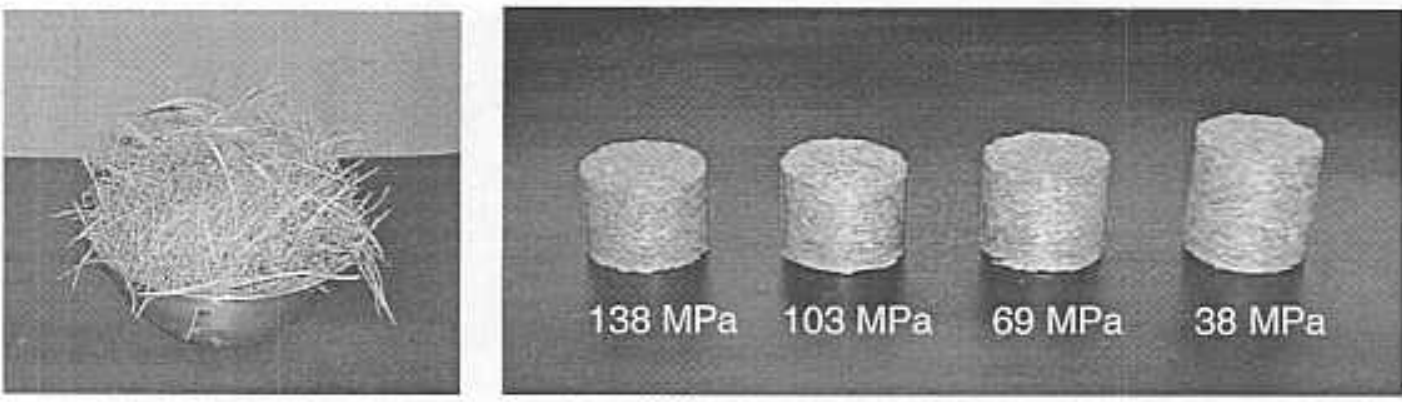

(b) Pine needles, moisture $8.9 \%$
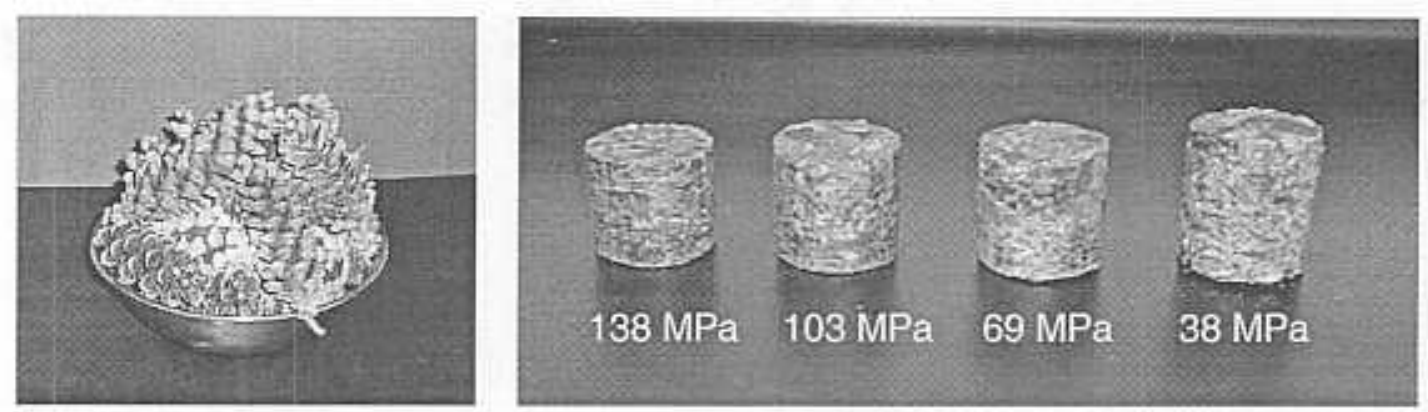

(c) Pine cones, moisture 10\%
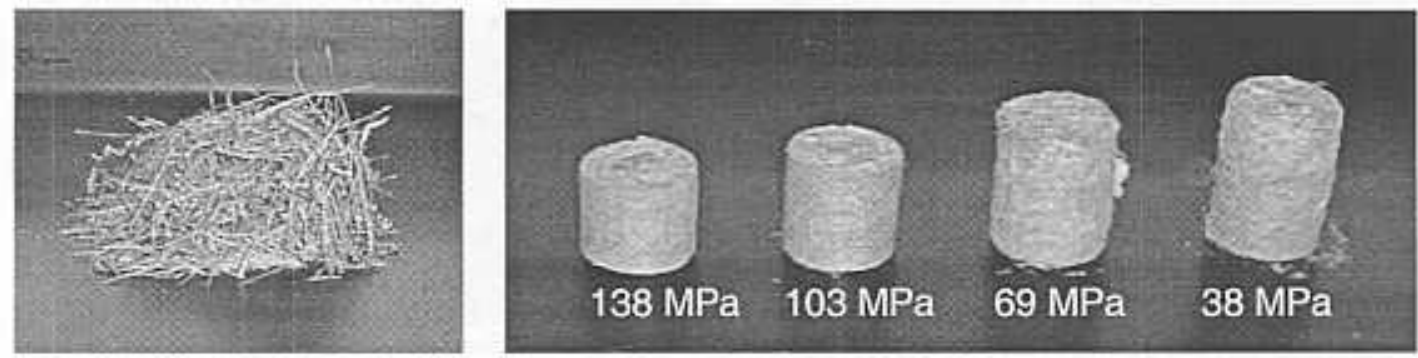

(d) Lawn grass, moisture $10 \%$

Photo 3-8. Raw materials and logs made of the corresponding yard waste materials at four different compaction pressures 


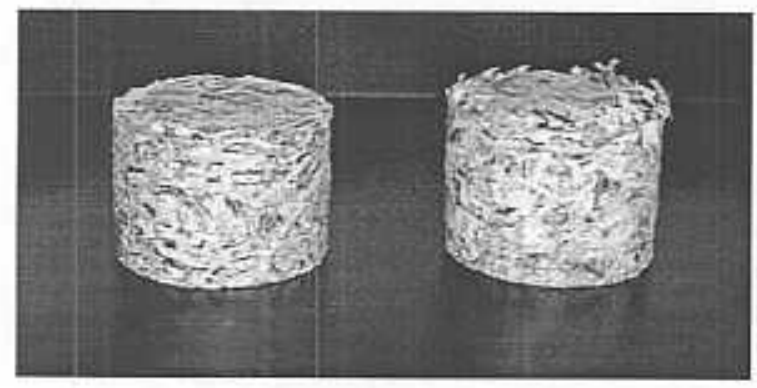

(a) Room-dried mixed paper

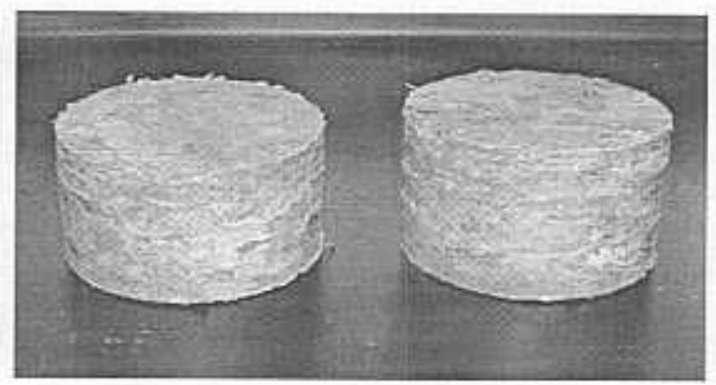

(b) Room-dried maple leaves

Photo 3-9. Effect of back pressure on quality of logs made of mixed paper and leaves. The logs were compacted at $102 \mathrm{MPa}(15,000 \mathrm{psi})$. The logs on the left of each picture were made with $0.7 \mathrm{MPa}(100 \mathrm{psi})$ back pressure, the logs on the right without. 


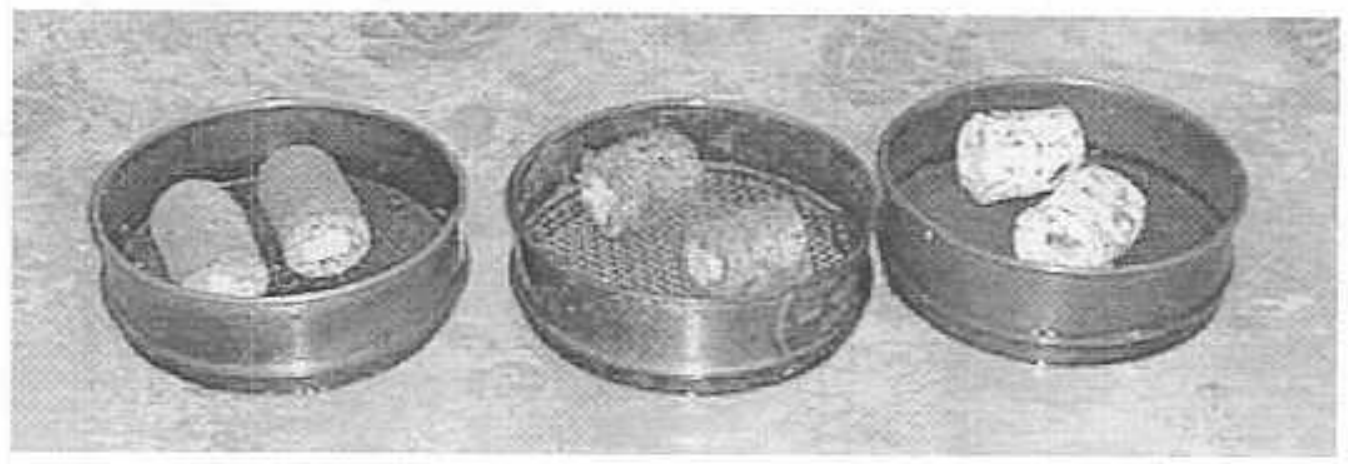

(a) After 1-minute rain test

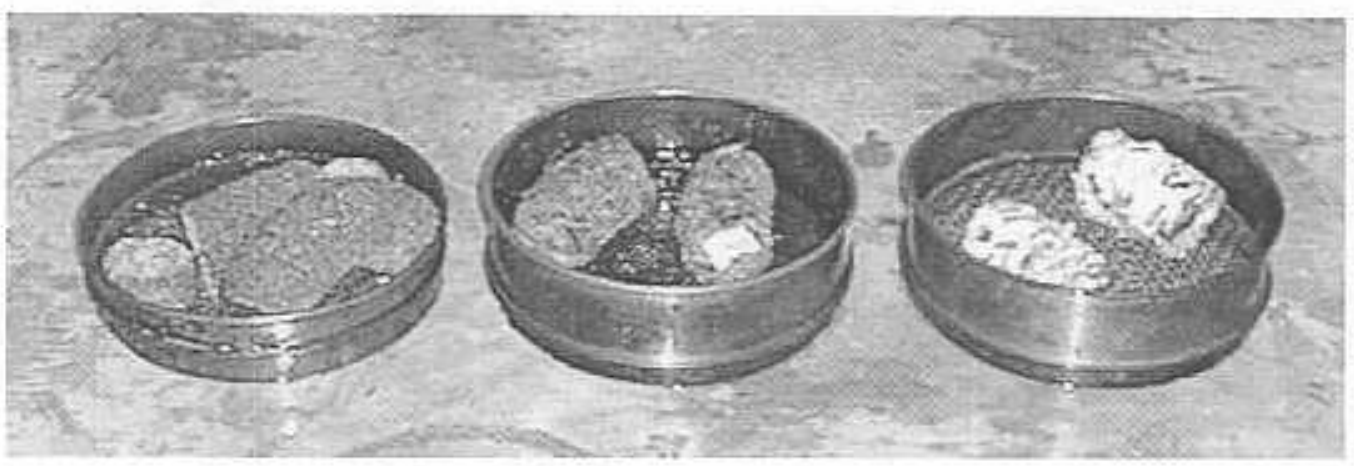

(b) After 5-minute rain test

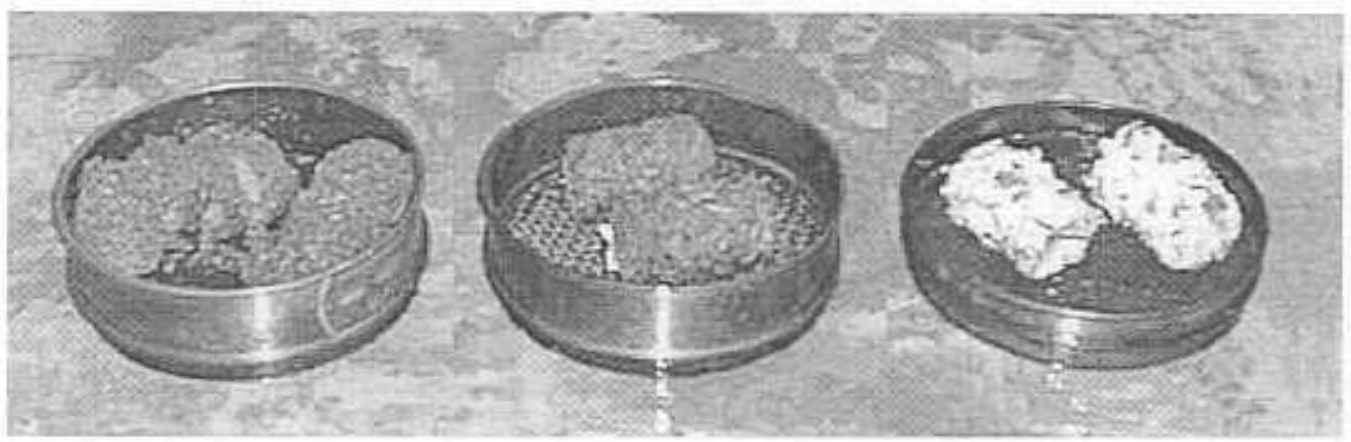

(c) After 10-minute rain test

Photo 3-10. Biomass logs immediately after exposure to $51 \mathrm{~mm} / \mathrm{hr}(2.0$ inch/hr) rain for different intervals. The logs were compacted from oak sawdust (left), oak mulch (middle), and mixed paper (right) at 102 $\mathrm{MPa}$ and at air-dried moistures. 


\title{
Economic Analysis of Compacting and Transporting Biomass Logs for Co-Firing With Coal in Power Plants
}

\author{
Henry Liu and Yadong Li \\ Capsule Pipeline Research Center \\ College of Engineering \\ University of Missouri-Columbia
}
Research Supported by the U.S. Department of Energy's National Energy Technology Laboratory Under Contract No. DE-RA-98FT40155.
Contract Title: "Compacting Biomass and Municipal Solid Wastes to Form an Upgraded Fuel."

November 1, 2000 


\section{Executive Summary}

This study determines the cost-effectiveness of compacting biomass waste materials into logs-large solid cylinders, transporting such logs from the log processing plant to a coal-fired power plant for co-firing with coal, and handling the logs at the plant.

The economic analysis involves both reviewing, analyzing and using applicable cost information and data that exist in the literature, and constructing a cost model using a life-cycle cost analysis and a net-cash-flow approach.

The result shows that for large plants that produce 675,000 tons of 5.4-inch-diameter biomass logs, the unit production cost is as low as $\$ 5.47$ per ton which includes a $15 \%$ aboveinflation, after-tax return. This is much lower than the biomass fuel produced by conventional pelletizing plants and hence is very promising. If by compacting biomass waste into such logs a tipping fee of $\$ 15$ is accredited to the plant and if each ton of such logs is sold for $\$ 10$ (f.o.b.), the plant can earn a profit of $\$ 20$ per ton which generates a return as high as $132 \%$. On the other hand, portable biomass log compaction units that have an annual capacity of only 11,760 tons can produce 2-inch-diameter biomass logs at $\$ 79$ per ton which is not economical. This shows the importance of scale in the cost-effectiveness of biomass log production.

As to biomass log transportation cost, it was found that barge is the most cost-effective, followed by rail (unit train) and then truck. For instance, transporting biomass log fuel (BLF) 500 miles costs only about $\$ 7$ by barge, $\$ 12$ by unit train, and $\$ 85$ by truck. This rules out using truck in places where train or barge can be used.

For relatively short distances without connecting railroads or waterways between the BLF production plant and the power plant that burns the logs, truck is the common solution. The costs of transporting biomass by truck for 50 miles and 100 miles are approximately $\$ 12$ and $\$ 20$, respectively. Even without rail or barge, transporting BLF by truck over 100 miles is costly and uneconomical in most cases.

The costs for transporting biomass by using pneumatic capsule pipeline (PCP) and hydraulic capsule pipeline (HCP) were also investigated. The results show that the unit costs for transporting biomass logs by HCP and PCP systems are higher than those by truck, due to the small tonnage of biomass that needs to be transported in each case. In spite of that, due to safety and environmental considerations, HCP and PCP may still be used in lieu of truck in special cases. Large cities that produce over one million tons of biomass each year may also like to consider HCP or PCP transport due to economy of scale. Research is underway at several organizations to make HCP and PCP more cost effective in the future for transporting biomass and other materials. 
Finally, it was found that the unit cost of biomass handling at power plants, including crushing and storage, is only about 50 cents per ton.

\section{ACKNOWLEDGMENT}

This study is part of a research project sponsored by the Federal Energy Technology Center (FETC), ${ }^{*}$ U.S. Department of Energy (DOE), under the Solid Fuels \& Feedstocks Grand Challenge Program. The DOE Project Monitor is Carl P. Maronde. The P.I. is Henry Liu, Director, Capsule Pipeline Research Center (CPRC), College of Engineering, University of Missouri-Columbia. Dr. Yadong Li served as the Project Manager.

In this report, the cost data on truck, unit train and barge were collected and supplied by Terry Maynard, some equipment cost data were collected and supplied by Bill Burkett, general information on biomass production and transportation costs found from the literature was supplied by Yadong $\mathrm{Li}$, and computer programming of the cost model and computations of the unit costs for various scenarios and PCP was done by both Yadong Li and Xiang Gao. Excellent typing of the report was done by Carla Roberts, Senior Secretary of CPRC. The P.I., Henry Liu, planned and directed the study, and prepared this report with Yadong Li. Excellent comments and suggestions from those who have read and reviewed the first draft, including those from Mr. Carl Maronde of DOE, have been incorporated into this revised report.

Financial support from DOE/FETC (currently DOE/NETL) is appreciated. Any opinion expressed in this report is that of the author and not necessarily that of DOE.

\footnotetext{
"In 2,000, the Federal Energy Technology Center (FETC) has been renamed "National Energy Technology Laboratory (NETL)."
} 
TABLE OF CONTENTS

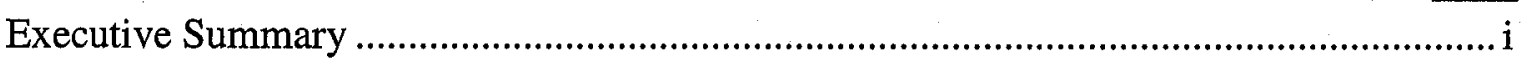

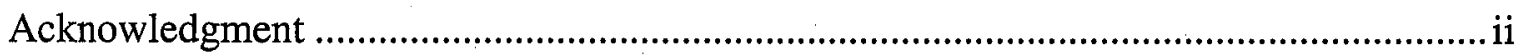

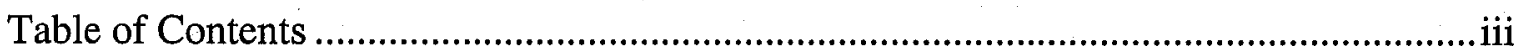

1. INTRODUCTION

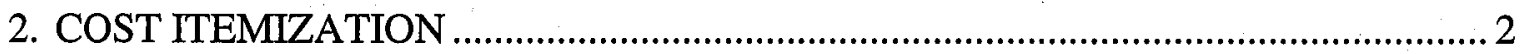

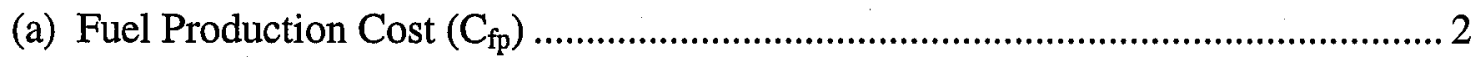

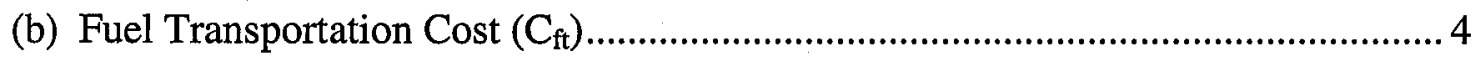

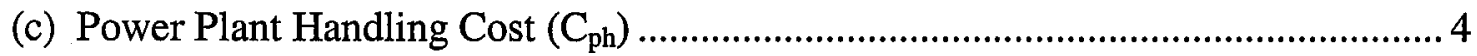

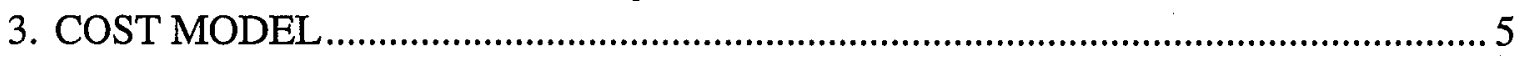

4. COST ASSUMPTIONS AND SCENARIOS ……….......................................... 10

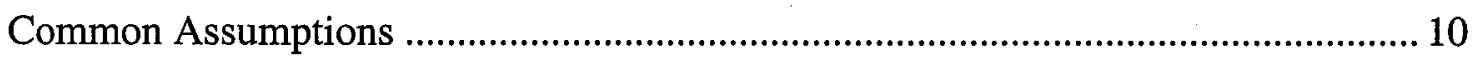

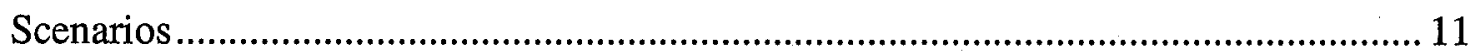

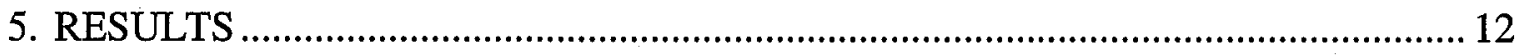

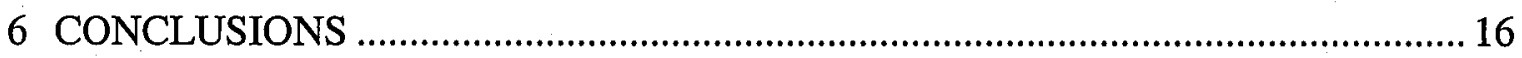

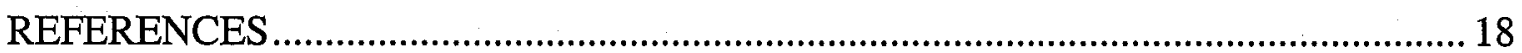

APPENDICES:

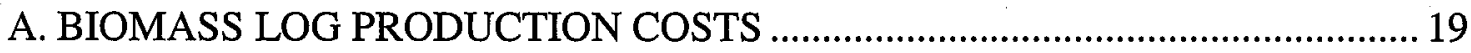

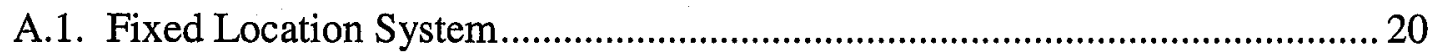

A.2. Portable (Truck Mounted) System ............................................................ 29

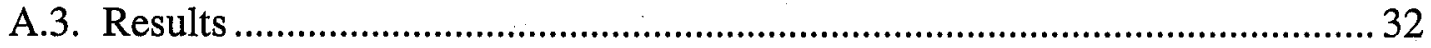

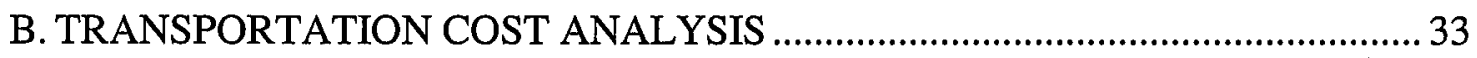

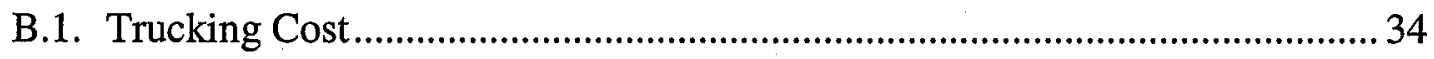

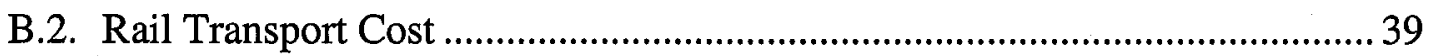

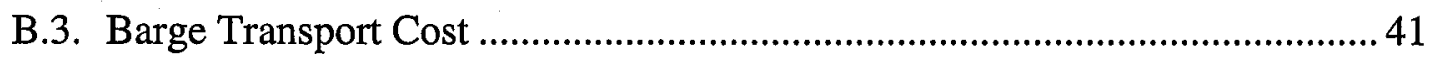

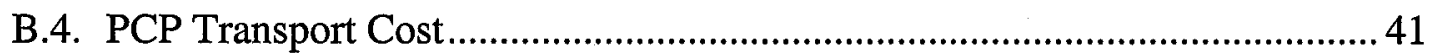

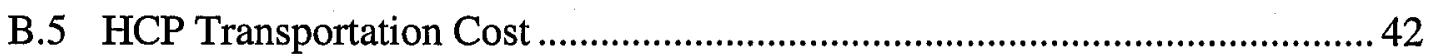

B.6 Comparison between Modes ...................................................................... 44

C. BIOMASS HANDLINGCOST AT POWER PLANTS .......................................47

C.1. Log Storage Facility Cost............................................................................... 47

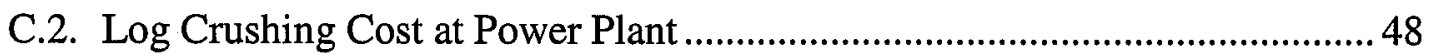

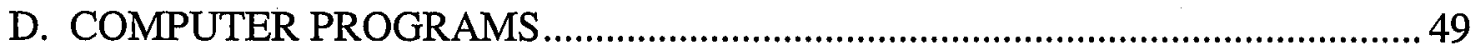

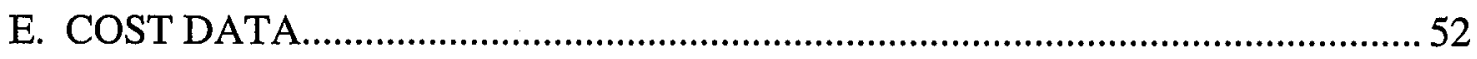




\title{
Economic Analysis of Compacting Biomass Waste Materials Into Logs for Co-Firing With Coal in Power Plants
}

\author{
by Henry Liu and Yadong Li
}

\section{INTRODUCTION}

Wide-spread acceptance and utilization of biomass waste materials, such as waste paper, sawdust, tree trimmings, yard waste and energy crops, for co-firing with coal at power plants depends to a great extent on the cost of the fuel supplied to the power plant--the "delivered cost." This delivered cost, in $\$ /$ ton, is a combination of the fuel production cost and the fuel transportation cost, which must be evaluated separately because they depend on different factors. In mathematical form.

\section{Delivered Fuel Cost $=$ Fuel Production Cost + Fuel Transportation Cost}

The units of all the three terms in Eq. 1 are in $\$ / T$ (dollars per ton).

When the biomass material is compacted at the source and then transported to the power plant, the compaction process affects not only the fuel production cost but also the transportation cost. The transportation cost is affected because the compacted fuel (BLF) is significantly denser than the uncompacted biomass, and so it occupies a much smaller volume and requires fewer trucks or railroad cars to transport the same tonnage. Handling $\mathrm{BLF}$ is also easier and less costly than handling uncompacted biomass in loose form.

Another cost that affects power plant operations, in addition to the delivered fuel cost, is the cost of handling the delivered fuel at the power plant, including crushing of the oversized fuel, and storage of the fuel prior to combustion. However, as it will be shown later, this cost is normally much smaller than the delivered fuel cost.

In this study, it is assumed that the biomass material is compacted at its source or concentration point. This point may be a sawmill or a wood processing plant (for sawdust and mulches), a city solid waste disposal site, processing facility, or transfer station (for yard waste, tree trimmings, and other combustible parts of the municipal solid waste), or a waste paper concentration/processing place (for office paper, newsprint, etc.). After compaction, the biomass is transported by truck, train, barge or pipeline to the power plant. In most cases, 
truck will be the only or the most practical means for transportation. However, in special cases, train, barge or pipeline may be more practical. Train will be a practical option if there is an existing railroad linking the source of the biomass waste material to the power plant. Barge will be a practical option if there is a navigable river, canal or other waterways linking the source to the power plant. Finally, pipeline will be a practical option when very large tonnage (say, over one million tons per year) of biomass waste materials exist at a given source, or in areas where highways are too congested and it is undesirable and costly to use trucks. This limits the use of pipelines to large cities for solid waste transport.

\section{COST ITEMIZATION}

The various cost items involved in fuel production, transportation and handling at power plants are discussed separately as follows:

\section{(a) Fuel Production Cost $\left(\mathbf{C}_{\mathrm{fp}}\right)$}

The items that must be included in the estimation of the fuel production cost include the following:

Raw Material Cost $\left(\mathbf{C}_{\mathbf{r m}}\right)$--This refers to the cost for collecting the raw material, or the money that must be paid to the source supplying the raw material. In most cases, biomass waste materials can be obtained free of charge from the source or supplier who desires to get rid of the material which he (she) cannot find a use or a market for. In other cases, one must pay the source or supplier, or pay the cost for collecting and transporting the raw material to the fuel production facility (compaction plant). Yet, in cases where the owner of the waste material must bring the waste material to a waste disposal site that charges a tipping fee, the owner will be willing to pay the waste collector, and the raw material cost will be negative. This means that the raw material cost can be either zero, positive or negative, depending on individual situations. When the raw material cost is negative, it should be treated as a positive annual income or revenue rather than a negative annual cost. The tipping fee may vary significantly with geographical location and jurisdiction. For instance, in Columbia, Missouri, it is currently $\$ 32$ per ton for industrial waste, and $\$ 16$ per ton for domestic yard waste. In cities on the East Coast, much higher tipping fees are charged. In this study, unless otherwise mentioned, raw material cost is not included in the analysis. 
Fuel Manufacturing Cost $\left(\mathbf{C}_{\mathrm{fm}}\right)-$-Fuel manufacturing at the source or biomass log production plant includes the following costs: (1) size reduction cost which is for crushing or shredding raw materials, (2) drying and storage cost which accounts for the cost of drying and storing the crushed materials at the source, (3) compaction-into-logs cost which is centered on the compaction machine and process, and (4) log storage cost which is for storing biomass logs at the source until they are transported to the power plant. The total fuel manufacturing cost is the sum of these four cost components.

The fuel manufacturing cost is different for different biomass materials, because different biomass materials require somewhat different processing parameters and different equipment. For instance, processing paper waste may require shredding instead of crushing, and it may require pneumatic conveying instead of auger or belt conveying of the shredded material. The shredded paper may also need some kind of pre-compaction densification before it is fed into or as it enters the compactor. Thus, the processing cost for waste paper may be significantly different from the cost of processing leaves or tree trimmings. Also, while most biomass materials require size reduction before it can be compacted to form logs, sawdust requires no size reduction.

In this study, the fuel manufacturing cost will be determined (estimated) for two different types of biomass fuel processing plants: (1) a truck-mounted mobile small plant that can be carried by a flat-bed truck from one source to another, such as from one sawmill to another, and (2) a large plant that is fixed in location such as at the biomass processing or biomass transfer station of a large municipality. The former (i.e., the truck-mounted plant) was designed by Mao [1]. ${ }^{*}$ It includes a rotary press that can produce 2 -inch-diameter biomass logs at the rate of 2 logs per second, and other equipment needed for processing the raw materials and handling the compacted materials--logs or the densified fuel. The latter (the larger fixed plant) is based on a rotary press designed by Xue to produce 5.4-inch-diameter biomass logs at the rate of one log per second [2]. Xue estimated the cost of his machine to be $\$ 263,000$. Using a larger motor, the rotational speed of this machine can be doubled, and the $\log$ production rate can also be doubled. This will be referred to hereafter as the "modified Xue's design." The estimated cost of the machine based on the modified Xue's

\footnotetext{
${ }^{*}$ Numerals in [ ] represent corresponding items in REFERENCES on page 18.
} 
design is $\$ 500,000$. The cost of the truck-mounted smaller system, including the rotary press, the truck (freightliner and flat bed), and the auxiliary equipment (such as a hammermill and a vibratory feeder), was estimated to be $\$ 228,723$ by Mao [1]. A modified design is proposed in Appendix 1 to enhance the log production rate by four times. The machine cost based on the modified Mao's design is estimated as $\$ 400,000$. The coal log production costs for both types of plants are evaluated and discussed in detail in Appendix A.

\section{(b) Fuel Transportation Cost $\left(\mathrm{C}_{\mathrm{ft}}\right)$}

Fuel transportation cost in $\$ / T$ (dollars per ton) generally increases with transportation distance, and decreases with the throughput (i.e., the tonnage transported per year). Therefore, fuel transportation cost should be studied as a function of distance and throughput. In a previous research project of the Capsule Pipeline Research Center (CPRC), coal transportation costs have been assessed for various modes including rail, truck, slurry pipeline and coal log pipeline $[3,4]$. The same methodology can be used for analyzing the cost of transporting biomass by various modes. As in the case of the coal log pipeline technology [5], the cost of transporting biomass by any existing commercial carrier (transportation mode) such as truck, rail and barge will be based on the actual charges paid to the carrier. For transportation by pipeline, since there is no commercial pipelines that exist today to transport biomass waste material, a special pipeline must be designed for each case to enable a detailed life-cycle cost analysis of the pipeline system including not only all the costs but a reasonable profit, such as a $15 \%$ inflation-adjusted return. The same cost model used for assessing the coal transportation cost by coal log pipeline will be used herein to determine the biomass transportation cost by pipeline. Details are given in Appendix B.

\section{(c) Power Plant Handling Cost $\left(\mathrm{C}_{\mathrm{ph}}\right)$}

Upon reaching the power plant by trucks or other transportation means, the biomass logs will be crushed immediately to an appropriate size for combustion and then stored for up to 24 hours in a silo before fed into the boiler. Therefore, the power plant handling cost of the biomass logs includes crushing and storage. It can be analyzed in a way similar to the analysis of the fuel manufacturing cost.

It should be realized that the power plant handling cost is not a part of the delivered fuel cost which is the price paid on delivery. Nevertheless, it is a part of the cost of the power 
plant operation and hence should be separately determined. It should also be realized that when using biomass fuel for co-firing with coal, the amount of coal needed at the power plant is reduced and hence there is a saving or reduction in the cost of coal handling at the plant. Therefore, the net cost of biomass logs to power plant operation is the cost of handling biomass at the plant, minus the saving or reduction in the cost of handling coal at the plant. However, to be conservative, in this study the saving produced from reduced handling of coal at power plant is ignored.

\section{COST MODEL}

The cost model used herein for determining the fuel manufacturing cost, $\mathbf{C}_{\mathrm{fm}}$, the fuel transportation cost, $\mathbf{C}_{\mathrm{ft}}$, and the power plant handling cost, $\mathbf{C}_{\mathrm{ph}}$, are similar to that used for analyzing the cost of coal log pipeline given in the 1995 model [3], and published by Liu et al [4]. It is described briefly as follows:

The cost model is based on a life-cycle cost analysis performed over the estimated economic life of the system, $\mathrm{N}$ years. The net-cash-flow approach is used which considers all the revenues (incomes) of a project as positive cash flow, and all costs (expenditures) as negative cash flow. During the life cycle (economic life) of the system, each cash flow is treated as a discrete payment (outlay of cash). Costs paid at the beginning of the project are the initial costs, and those paid subsequently are treated as annual outlays (annual costs). For simplicity, it is assumed that all the capital costs (for constructing the plant and purchasing the equipment needed for the plant) are encumbered at the beginning of the project. So, the capital cost and initial cost are treated as the same thing. All annual costs (expenses) are assumed to be paid at the end of each year--the end-of-year convention.

The unit price, $\mathbf{U}$ (i.e., the price charged to customers for manufacturing, transporting or power-plant handling each ton of biomass in $\mathbf{\$} / \mathbf{T}$ ) is calculated based on the need to generate an above-inflation rate of return, $r$. To achieve this return rate, the after-tax cash flow equations for each year are first developed, treating the unit price as a variable with respect to time (years). These equations include the following:

The after-tax cash flow (ATCF) $)_{\mathbf{n}}$ for any year $\mathbf{n}(\mathbf{n}=1,2,3 \ldots N)$ is:

$$
\mathrm{ATCF}_{\mathrm{n}}=\mathrm{BTCF}_{\mathrm{n}}-\mathrm{T}_{\mathrm{n}}
$$


where $\mathbf{B T C F}_{\mathbf{n}}$ is the before-tax cash flow for year $\mathbf{n}$, and $\mathbf{T}_{\mathbf{n}}$ is the corporate income tax that must be paid during year $\mathrm{n}$.

The quantity $\mathbf{B T C F} \mathbf{F}_{\mathbf{n}}$ is determined from:

$$
\mathrm{BTCF}_{\mathrm{n}}=\mathrm{R}_{\mathrm{n}}-\mathrm{C}_{\mathrm{n}}
$$

where $\mathbf{R}_{\mathbf{n}}$ is the revenue for year $n$, and $\mathbf{C}_{\mathbf{n}}$ is the cost for year $\mathbf{n}$.

The tax, $\mathbf{T}_{\mathbf{n}}$, in Eq. 2 is calculated from

$$
\mathrm{T}_{\mathrm{n}}=\left(\mathrm{BTCF}_{\mathrm{n}}-\mathrm{d}_{\mathrm{n}}\right) \mathrm{t}
$$

where $\mathbf{d}_{\mathbf{n}}$ is the depreciation which must be determined from the tax code, and $\mathbf{t}$ is the rate of corporate income tax, assumed to be $37 \%$ in this analysis. For simplicity, a "straight-line" or uniform depreciation over 20 years is used. Therefore,

$$
\mathrm{d}_{\mathrm{n}}=\mathrm{d}=\frac{\mathrm{C}_{\mathrm{c}}}{\mathrm{N}_{\mathrm{d}}}=\frac{\mathrm{C}_{\mathrm{c}}}{20}
$$

where $C_{c}$ is the capital cost, and $N_{d}$ is the years of depreciation. The value of $N_{d}$ must conform to government tax code. Note that when $\mathrm{N}_{d}$ (say, 20 years) is less than $\mathrm{N}$ (say, 30 years), Eq. 5 is valid only for the first $N_{d}$ years. Thereafter, there will be no more depreciation and $d_{n}=0$ (zero) for the remaining years of the project's economic life.

Combining Eqs. 2, 3, and 4 yields

$$
\operatorname{ATCF}_{\mathrm{n}}=(1-\mathrm{t})\left(\mathrm{R}_{\mathrm{n}}-\mathrm{C}_{\mathrm{n}}\right)+\mathrm{td}_{\mathrm{n}}
$$

The present value of $\mathrm{ATCF}_{\mathbf{n}}$ is denoted as $\mathbf{A T C F}_{\mathrm{np}}$. It can be calculated from

$$
\operatorname{ATCF}_{n p}=\frac{\operatorname{ATCF}_{n}}{(1+\delta)^{n}}=\frac{(1-t)\left(R_{n}-C_{n}\right)+t_{n}}{(1+\delta)^{n}}
$$

The quantity $\delta$ in Eq. 7 is the inflation-adjusted discount rate which should be calculated from

$$
\delta=r+I+r I
$$

in which $\mathbf{r}$ is the above-inflation return rate, and $\mathbf{I}$ is the inflation rate.

The revenue $\mathbf{R}_{\mathbf{n}}$ in Eqs. 6 and 7 is to be determined for each year in such a manner that the sum of the present value of $\mathrm{ATCF}_{\mathrm{n}}$ over the $\mathrm{N}$ years (from $\mathrm{n}=0$ to $n=N$ ) is zero, namely,

$$
\sum_{n=0}^{N} \mathrm{ATCF}_{\mathrm{np}}=0
$$


where $\mathrm{n}=0,1,2,3, \ldots \mathrm{N}$. Note that year 0 refers to the beginning of the project when the capital cost $C_{c}$ is incurred, which constitutes a negative cash flow. Equation 9 can be rewritten as

$$
\left[\sum_{n=1}^{N} \frac{(1-t)\left(R_{n}-C_{n}\right)+t d_{n}}{(1+\delta)^{n}}\right]-C_{c}=0
$$

The revenue is assumed to be $R_{1}$ for the first year, and it escalates at the rate of $\mathbf{e}_{\mathrm{r}}$--the revenue escalation rate. Therefore,

$$
\begin{aligned}
R_{n}= & \left(1+e_{r}\right) R_{n-1}=\left(1+e_{r}\right)^{2} R_{n-2} \\
& =\left(1+e_{r}\right)^{3} R_{n-3}=\ldots \ldots \ldots \\
& =\left(1+e_{r}\right)^{n-1} R_{1} \quad(n=1,2,3, \ldots N)
\end{aligned}
$$

Assuming that the quantity of fuel (biomass logs) produced or transported each year is $\mathbf{Q}$ (T/yr), the revenue generated each year, $\mathbf{R}_{\mathbf{n}}$, becomes

$$
\mathrm{R}_{\mathrm{n}}=\mathrm{QU}_{\mathrm{n}}
$$

where $U_{n}$ is the price charged to the customer, during year $n$, for manufacturing and/or transporting unit weight of the biomass logs, hereafter referred to simply as the "unit price."

Substituting $\mathrm{R}_{1}=\mathrm{QU}_{1}$ (from Eq. 12) into Eq. 11 yields:

$$
R_{n}=\left(1+e_{r}\right)^{n-1} U_{1} Q
$$

Equation 13 can now be substituted into Eq. 10 to yield

$$
\left\{\sum_{n=1}^{N} \frac{(1-t)\left[\left(1+e_{r}\right)^{n-1} U_{1} Q-C_{n}\right]+t_{n}}{(1+\delta)^{n}}\right\}-C_{c}=0
$$

Realizing that both $\mathrm{Q}$ and $\mathrm{U}_{1}$ in Eq. 14 are constant and do not vary with $\mathrm{n}$, they can be factored out of the equation to yield

$$
U_{1}=\frac{\left[\sum_{n=1}^{N} \frac{(1-t) C_{n}-t_{n}}{(1+\delta)^{n}}\right]+C_{c}}{Q \sum_{n=1}^{N} \frac{(1-t)\left(1+e_{r}\right)^{n-1}}{(1+\delta)^{n}}}
$$

Equation 15 can be reduced to

$$
\mathrm{U}_{1}=\frac{\mathrm{C}_{\mathrm{a}}}{\mathrm{Q}}
$$


and

$$
C_{a}=\frac{\left[\sum_{n=1}^{N} \frac{(1-t) C_{n}-t d_{n}}{(1+\delta)^{n}}\right]+C_{c}}{\sum_{n=1}^{N} \frac{(1-t)\left(1+e_{r}\right)^{n-1}}{(1+\delta)^{n}}}
$$

where $\mathrm{C}_{\mathrm{a}}$ is the present value of the averaged annual cost, including both initial (capital) cost and annual (variable) costs. For simplicity, $\mathrm{C}_{\mathrm{a}}$ will be referred to in this report as the "annualized total cost (ATC)."

The annual cost $C_{n}$ in the foregoing equations is to be determined from

$$
\mathrm{C}_{\mathrm{n}}=\left(1+\mathrm{e}_{\mathrm{c}}\right)^{\mathrm{n}-1} \mathrm{C}_{1} \quad(\mathrm{n}=1,2,3, \ldots \mathrm{N})
$$

where $C_{1}$ is the annual cost for the first year, and $e_{c}$ is cost escalation rate which is assumed to be the same as the general inflation rate I.

The unit price for the first year, $U_{1}$, can be obtained from Eq. 16 and 17. Then, the price charged to the customer for producing and/or transporting each ton of biomass logs for each of the subsequent years can be obtained from

$$
\mathrm{U}_{\mathrm{n}}=\left(1+\mathrm{e}_{\mathrm{r}}\right)^{\mathrm{n}-1} \mathrm{U}_{1}
$$

Since the present values refer to that of year zero $(n=0)$, both the annual cost of the first year, $C_{1}$, and the unit price for the first year, $U_{1}$, can be expressed in their present values, $C_{0}$ and $\mathrm{U}_{\mathrm{o}}$ respectively, as follows:

$$
\begin{aligned}
& \mathrm{C}_{1}=\mathrm{C}_{\mathrm{o}}\left(1+\mathrm{e}_{\mathrm{c}}\right) \quad(\mathrm{n}=1,2,3, \ldots \mathrm{N}) \\
& \text { and } \mathrm{U}_{1}=\mathrm{U}_{\mathrm{o}}\left(1+\mathrm{e}_{\mathrm{r}}\right) \quad(\mathrm{n}=1,2,3, \ldots \mathrm{N})
\end{aligned}
$$

Substituting Eqs. 20 and 21 into Eqs. 16-19 yields

$$
\begin{gathered}
U_{o}=\frac{C_{a}^{\prime}}{Q} \\
C_{a}^{\prime}=\frac{\left[\sum_{n=1}^{N} \frac{(1-t) C_{n}-t d_{n}}{(1+\delta)^{n}}\right]+C_{c}}{\sum_{n=1}^{N} \frac{(1-t)\left(1+e_{r}\right)^{n}}{(1+\delta)^{n}}} \\
C_{n}=\left(1+e_{c}\right)^{n} C_{o} \\
U_{n}=\left(1+e_{r}\right)^{n} U_{o} \\
\quad(n=1,2,3, \ldots N)
\end{gathered}
$$


The present value of the first-year annual cost, $C_{0}$, is determined from the present annual cost of various items including energy, fuel, salaries/wages, property tax, insurance, and other operations/maintenance costs, namely,

$$
\mathrm{C}_{\mathrm{o}}=\mathrm{C}_{\mathrm{e}}+\mathrm{C}_{\mathrm{f}}+\mathrm{C}_{\mathrm{s}}+\mathrm{C}_{\mathrm{p}}+\mathrm{C}_{\mathrm{i}}+\mathrm{C}_{\mathrm{o} / \mathrm{m}}
$$

where $C_{e}$ is the energy cost, $C_{f}$ is the fuel cost, $C_{s}$ is the cost of salary and wages, $C_{p}$ is the property tax cost, $C_{i}$ is insurance cost; and $C_{o / m}$ is other operation/maintenance costs-all firstyear costs based on current values. Note that corporate income tax is not included here since it has already been included before by using $t$ in previous equations.

The property tax, $C_{p}$, and the insurance cost, $C_{i}$, for the present year are calculated from

$$
\begin{aligned}
C_{p} & =e_{p} C_{c} \\
\text { and } \quad C_{i} & =e_{i} C_{c}
\end{aligned}
$$

where $e_{p}$ and $e_{i}$ are respectively the property tax rate and the insurance rate.

For simplicity, it is assumed that the total annual cost for each year is escalated at the rate of $e_{c}$. Therefore, the total annual cost for year $n$ is

$$
\begin{aligned}
& C_{n}=C_{n-1}\left(1+e_{c}\right)=C_{n-2}\left(1+e_{c}\right)^{2}=\ldots \\
& =C_{o}\left(1+e_{c}\right)^{n}
\end{aligned}
$$

The procedure for calculating the unit price $U_{0}$ is as follows:

1. Determine $C_{o}$ from Eq. 26 and $C_{c}$ from the capital need. Both $C_{o}$ and $C_{c}$ are based on current market price.

2. The values of $N, N_{d}, t, I, e_{c}$ and $e_{r}$ are specified based on reasonable assumptions.

3. The desired or required above-inflation return rate $r$ is also specified, and the discount rate is calculated from Eq. 8.

4. $C_{n}$ and $d_{n}$ for each year are determined respectively from Eq. 29 and Eq. 5.

5. Equation 23 can then be used to calculate $C_{a}^{\prime}$, and Eq. 22 can be used to calculate $U_{0}$.

6. Once $U_{0}$ is determined, the unit price for any year $n$ can be determined from Eq. 25 , and the revenue for each year, $R_{n}$, can be determined from Eq. 13 .

A computer program can be written based on the aforementioned procedure. The program can be written to print not only the value of $U_{o}$, but also values of $C_{n}, R_{n}$ and $U_{n}$ for each year in a tabular form. All the assumptions and input values should also be listed. The value of $U_{0}$ obtained can then be compared with current price of manufacturing or transporting biofuel by other contemporary technologies. 


\section{COST ASSUMPTIONS AND SCENARIOS}

Due to the great variability of the cost of compacting and transporting biomass materials under different conditions, different cost scenarios will be evaluated. The common assumptions used for all the scenarios are described first. Additional assumptions different for different scenarios will be specified in the discussion of each scenario.

\section{Common Assumptions}

Common assumptions used for all scenarios, unless otherwise specified, are as follows:

(1) The general inflation rate, $I$, is $3 \%$.

(2) The return rate, $r$, is $15 \%$.

(3) The economic life of the project, $\mathrm{N}$, is $20 \mathrm{yrs}$.

(4) Depreciation of capital is flat (constant) over 20 years $\left(\mathrm{N}_{\mathrm{d}}=20\right)$.

(5) The corporate income tax rate, $t$, is $37 \%$

(6) The discount rate, $\delta$, calculated from Eq. 8, is 0.1845.

(7) Present costs are based on Year 2000 values.

(8) All the cost items are inflated according to the same general inflation rate, I, of 3\%.

(9) The revenue escalation rate, $e_{r}$, is the same as the general inflation rate, I which is $3 \%$.

(10) The property tax rate is equal to $2 \%$ of the total capital cost.

(11) The annual insurance cost is $0.5 \%$ of the total capital.

(12) The equity is 1.0. This means that all the money invested on the project (the capital cost) comes from the owner; no money is borrowed. Otherwise, interest rate would also enter the calculation.

(13) The cost figures are based on those discussed in Appendix A.

(14) No binder or heating of biomass materials is required.

(15) Peak compaction pressure is $15,000 \mathrm{psi}$, and compaction time is 3 seconds.

(16) The large fixed-location biomass log manufacturing machine can produce two 5.4-inchdiameter logs per second; the smaller portable machine can produce four 2.0 -inchdiameter logs per second.

(17) The specific gravity of the biomass logs is 1.0 , which means that the logs have the same density as water. This refers to the real or wet density of the logs--the density with moisture included.

(18) All the biomass fuels need protection from rain. 
(19) The biomass waste materials at the source are combustible and already separated from the non-combustible solid waste materials. No cost is included for separation of solid wastes into combustible and non-combustible parts.

\section{$\underline{\text { Scenarios }}$}

The following three scenarios on biomass production will be analyzed first:

Scenario 1: Compacting the biomass waste materials at the source of a large city. The assumptions used in Appendix $A$ are valid. There is no cost for the raw material $\left(C_{r m}=0\right)$. Find the fuel production cost $\mathrm{C}_{\mathrm{fp}}$ in terms of unit price, $\mathrm{U}_{\mathrm{o}}$, for this case in $\$ /$ ton.

Scenario 2: Same as Scenario 1 except that $C_{r m}$ is negative $(-\$ 15 /$ ton $)$. This means that a revenue of $\$ 15 /$ ton is generated from collecting the raw material. This revenue is in addition to that generated from the sale of the fuel to power plants. Assuming that the biomass fuel (logs) can be sold at $\$ 10$ per ton, what is the rate of return $\mathrm{r}$ for this case?

Scenario 3: Compacting sawdust at various sawmills. The truck-mounted mobile machine is used. There is no cost for the raw materials $\left(C_{r m}=0\right)$. The machine works 300 days a year at different plants. Find the fuel production cost $C_{f p}$ for this case in terms of unit price, $U_{o}$, in $\$ /$ ton.

Scenario 4: Same as Scenario 1 except that the study is conducted at five levels of throughput or plant capacity: $675,000,540,000,405,000,270,000$, and 135,000 . The result shows the increases in log production cost at facilities that handle smaller amounts of biomass than at the large plant assumed in Scenario 1.

Scenario 5: Same as Scenario 1 except that the capital cost of biomass log production is varied by $\pm 25 \%$. The result shows the sensitivity of the unit production cost of biomass logs to the variation of the capital cost.

Scenario 6: Same as Scenario 1 except that the annual (operations/maintenance) cost is varied by $\pm 25 \%$. The result shows the sensitivity of the unit production cost of biomass logs to the variation of the annual cost.

Scenario 7: Same as Scenario 1 except that the availability of the plant operation was studied at three levels: $100 \%, 90 \%$ and $80 \%$. The result shows the sensitivity of the unit production cost of biomass logs to the reduction in availability. 


\section{RESULTS}

The capital cost and the operations/maintenance costs for both a fixed-location plant and a truck-mounted mobile plant are determined in Appendix A. A simple Visual Basic Program was used to compute the results of all scenarios and cases, using the same economic model discussed in Sec. 3. COST MODEL, and using assumptions listed in Sec. 4. COST ASSUMPTIONS AND SCENARIOS. The Visual Basic program is listed in Appendix D.

Using the program in Appendix D for Scenario 1, which is the fixed-location plant to produce 5.4-inch-diameter logs without cost for the raw material, the unit production cost $U_{0}$ for a 675,000 tons/yr plant was found to be $\$ 5.47$. This means that the biomass logs can be produced at $\$ 5.47$ per ton which will still earn the producer a $15 \%$ above-inflation rate of return. So, if the general inflation rate is $3 \%$, the return will be $18 \%$. Two appropriate questions may be asked at this point. The first is: "Are power plants willing to pay $\$ 5.47$ per ton for the biomass log fuel?" This depends on how much additional cost will be encumbered for transporting this fuel to the power plant. If the distance is short and transportation cost is only a few dollars, the power plant manager may want to use this fuel since the delivered price will be less than the price of delivered coal even on per-BTU basis. In contrast, if the transportation distance is long and the transportation cost is high (say, over $\$ 10$ a ton), the power plant may find it not cost-effective to use this fuel. This shows the importance of the transportation cost in determining whether the biomass log fuel will be used or not in a given situation.

The second pertinent question is whether the unit price of $\$ 5.47$ is competitive with biomass fuel on the market produced by using pelletizers. From literature survey, the current price for pre-delivered biomass fuel pellets is much higher than that found here. For instance, a cost study of a pelletizing facility for densification of paper and cardboard waste at the City of Columbia, Missouri, conducted by the Black \& Veatch Company in 1996 [6] showed that the unit cost for a 21 -tons-per-day facility (7,350 tons/yr.) is $\$ 25$ per ton, and for a 66 -tons-per-day facility $(23,100$ tons/yr.) is $\$ 10$ per ton. Comparing these prices with the calculated pre-delivered price for the biomass logs shows that the biomass logs are very competitive in price. The main reason for the much lower price for the biomass $\log$ fuel analyzed here than the price of commercial biomass pellets is the economy of size of the products (a 5.4-inch-diameter log weighs about onethousand times that of a pellet), and economy of the scale of the plant (more than half a million tons a year at the waste processing plant of a large municipal). 
Scenario 2 allows or enjoys a $\$ 15 /$ ton income (revenue) received from the owner of the waste material who is willing to pay this fee to get rid of the waste and to avoid the transportation and tipping fees. The result shows that if the fuel is sold at $\$ 10$ per ton (the pre-delivered price), the biolog plant can reap a huge profit--a return rate of $132 \%$ which is enormous!

The result for Scenario 3 shows that the production cost of biomass logs by the mobile plant is approximately $\$ 79$ per ton. This cost is much higher than that for the fixed-location plants at large municipalities (Scenario 1). This is due to the much smaller tonnage of biomass raw materials available at each source, the use of a smaller machine, and the need for transporting the machine from place to place. In today's economy, it is highly questionable that such a mobile plant can be economical. From Sec. A.2 of Appendix A, it is clear that the highest cost component of the truck-mounted mobile plant is the capital cost associated with having a shelter to store the compacted biomass logs for 24 hours at each of the ten sites served by the mobile plant. The total cost for the ten shelters is $\$ 2.55$ million which is more than six times the cost of the mobile plant itself. To reduce cost, it is possible to store the logs in trailers as soon as the logs are compacted, and then have the trailers hauled away within 24 hours. Whether this will produce a net saving or not will be investigated during the next quarter, and will be reported in the final report as an additional scenario. Further analysis will also be performed during the next quarter to determine whether using a number of small compactors (for 2-inch-diameter logs) at fixed locations is more cost-effective than using the truck-mounted mobile unit.

The result of Scenario 4 shows that the plant size has a strong impact on the unit cost of biomass log production-the smaller the plant size, the higher the unit cost of production. For instance, as shown in Table A.1, the unit cost of production is $\$ 5.47$ for a plant that processes 675,000 tons of biomass per year, and $\$ 8.16$ if the plant processes only 135,000 tons/yr.

The result of Scenario 5 is given in Fig. A.4. It shows that a $25 \%$ increase (decrease) in capital cost causes a $10 \%$ increase (decrease) in the unit cost of biomass log production.

The result of Scenario 6 (Fig. A.5) shows that a $25 \%$ increase (decrease) in the annual (operations/maintenance) cost causes a $15 \%$ increase (decrease) in the unit cost of biomass production. This shows that the annual cost has even a stronger impact than does the capital cost on the unit production cost of biomass logs.

Finally, the result of Scenario 7 shows that by decreasing the plant availability (i.e., the percent of time that the plant is operational) from $100 \%$ to $90 \%$ and $80 \%$, the unit production 
cost for the large plant of 675,000 tons/yr. is increased from $\$ 5.47$ to $\$ 5.92$ and $\$ 6.49$ respectively.

For biomass transportation, information has been gathered in Appendix B for the cost of transporting biomass by truck, train and barge. It can be seen from Table B.10 that transportation by train and barge are always more economical than by truck. However, in most situations, there is no railroad or waterway linking the biomass source to the power plant, and hence truck wins by default.

A life-cycle cost analysis was performed in Appendix B to determine the cost of transporting biomass logs by using pneumatic capsule pipeline (PCP). The result is listed in Table B.5 which compares the unit transportation cost in $\$ / T$ for PCP of different transport distances ranging from 5 miles to 100 miles. The study was conducted for the throughput of a large plant $-675,000$ tons/yr. Comparison of the result of PCP costs for this case with the freight costs for truck in Table B.11 shows that PCP does not appear to be competitive in cost with trucks, except for distances less than 5 miles, or in special situations where trucks are not allowed due to environmental and safety concerns. Research is currently underway at CPRC to improve the PCP technology in order to make it more cost-effective.

An analysis was also conducted in Sec. B.5 of Appendix B to determine the transport of solids (including biomass logs) by hydraulic capsule pipeline (HCP), using water as the fluid. Metallic cylindrical containers were used as the capsules to carry the solids, and the capsules are pumped through the pipe by using linear induction motors (LIMs). Dual pipelines are used-one line to transport loaded capsules, and the other to return unloaded empty capsules to the pipeline intake. The result of such an analysis is shown in Table B.9. It shows that the unit transportation cost by HCP is a function of both the freight throughput which in turn determines pipe diameter and the transportation distance. Generally, the larger the throughput is, the lower the unit cost becomes. Also, the longer the transportation distance is, the higher becomes the unit transportation cost. Note that the minimum throughput in Table B.9 is $2.0 \mathrm{MT} / \mathrm{yr}$. which corresponds to a 12-inch-diameter pipe. Extrapolating the values in Table B.9 to $0.675 \mathrm{MT} / \mathrm{yr}$. yields the following approximate values of the unit transportation costs for biomass logs transported by HCP: $8,9,12,15,22,29$, and $36 \$$ ton, respectively for distances of $5,10,20,30$, 50, 75 and 100 miles. Comparison of these unit cost values with PCP shows that they are 
generally lower than that of PCP especially for long distances. However, comparing them with truck shows that they are generally higher than those for trucks except at very large throughputs.

The foregoing results show that for transporting biomass, both HCP and PCP cannot compete economically with trucks. Two main reasons account for their non-competitiveness. The first is that for biomass the maximum tonnage to be transported is less than $1 \mathrm{MT} / \mathrm{yr}$. It requires small pipes (pipe diameter less than $1 \mathrm{ft}$.) which are not economically competitive. Pipelines are more competitive for larger throughputs using larger pipes-see for instance the unit cost listed in Table B.11 for HCP at large throughputs. The second reason is that both HCP and PCP require a double pipeline so that the capsules, after having unloaded their cargoes, can be returned by a separate pipeline. This greatly increases the cost of pipeline and the cost of capsules.

Another type of capsule pipeline investigated for its possibility to transport solids is CLP (coal log pipeline). As can be seen from Table B.11, CLP is far more economical than HCP and PCP, and is more economical than truck. This is due to the reason that the materials to be transported by CLP, such as coal, is compacted into logs which constitute the capsules. There is no need for containers (capsules) and no need for a second pipeline to transport the empty capsules back, thereby greatly reducing costs. Unfortunately, biomass logs cannot be transported like coal logs, flyash logs, or pet-coke logs, because biomass logs soak water and disintegrate in pipeline. It is possible that biomass logs can be manufactured into linked-sausages with a protective plastic skin which can be combusted with the logs. If this is feasible technically, then the need for a return pipeline is eliminated, and the log transportation cost can be greatly reduced. This possibility should be investigated in the future in a separate research project.

Power plant handling of biomass, including both crushing and storage costs, is analyzed in Appendix $\mathrm{C}$ for different throughputs. The results listed in table C.1 show that the power plant handling cost is approximately 53 cents per ton of logs. Comparing this cost with the unit cost of biomass production and transportation shows that the former is an order of magnitude smaller than the latter, and hence it plays a minor role in determining the cost effectiveness of biomass fuel. This means that the cost effectiveness of biomass fuel can be determined mainly from the unit cost of production plus the unit cost of transportation, namely, the delivered cost.

Table 1 is a summary of biomass utilization cost which is the sum of the unit costs of biomass production, transportation (by truck), and handling at power plants. It can be seen that 
the biomass utilization cost using trucks increases with increased transportation distance, and decreases with increased throughput. For instance, for throughput of 675,000 tons/yr. and distance of 30 miles, the cost is $\$ 13.8$ per ton, and for throughput of 135,000 tons/yr. and the same distance, the cost is $\$ 16.5$ per ton. For throughput of 675,000 and distance of 100 miles, the cost is $\$ 25.8$.

It is expected that power plant managers will be willing to pay between $\$ 10$ and $\$ 20$ for each ton of biomass logs. Based on Table 1, it can be seen that biomass logs are economical for transportation distances less than 50 miles, marginally economical for distances between 50 and 100 miles, and uneconomical for distances over 100 miles.

Table 1. Biomass log fuel (BLF) utilization unit cost: Summary of results for different throughputs and transportation distances. (Note: The numbers listed in the table, other than the distances listed in the heading, are unit costs in \$/ton. Transportation by truck is assumed.)

\begin{tabular}{|c|c|c|c|c|c|c|c|}
\hline \multirow{2}{*}{$\begin{array}{c}\text { Throughput } \\
\text { or Plant Capacity } \\
\text { Q (ton/yr.) }\end{array}$} & \multicolumn{7}{|c|}{ Transportation Distance (miles) } \\
\hline & 5 & 10 & 20 & 30 & 50 & 75 & 100 \\
\hline 675,000 & 9.6 & 10.4 & 12.1 & 13.8 & 17.2 & 21.5 & 25.8 \\
\hline 540,000 & 9.7 & 10.5 & 12.2 & 13.9 & 17.3 & 21.6 & 25.9 \\
\hline 405,000 & 9.8 & 10.6 & 12.3 & 14.0 & 17.4 & 21.7 & 26.0 \\
\hline 270,000 & 10.6 & 11.4 & 13.1 & 14.8 & 18.2 & 22.5 & 26.8 \\
\hline 135,000 & 12.3 & 13.1 & 14.8 & 16.5 & 19.9 & 24.2 & 28.5 \\
\hline
\end{tabular}

\section{CONCLUSIONS}

Based on the foregoing results, it can be concluded that when biomass waste materials exist in large quantity at a given site, such as the waste disposal site or a waste transfer station of a large municipality, the materials can be economically compacted into logs for power plant use as fuel to co-fire with coal provided that the transportation distance is not too high--say, less than 100 miles. The production cost (pre-delivered price) for large plants (of capacity in the neighborhood of 675,000 tons/yr.) is of the order of $\$ 6$ per ton. This is based on the assumption that the raw materials (biomass waste) can be obtained free-of-charge from the source. This cost will increase if the raw material is not free, or when the plant capacity is small. Note that the capacity of 675,000 tons/yr. corresponds to the quantity of biomass generated in a city such as St. Louis, Missouri, which has a population of one million, approximately. 
In cases where the owner of the biomass raw material does not have a market for the material and must bring the waste to the disposal site and pay a tipping fee, the economics of the biomass logs will be very attractive. If the waste generator or owner is willing to pay the log producer a $\$ 15 /$ ton fee for getting rid of the waste for the former, the return or profit rate for the latter will be very attractive--over $100 \%$ !

The foregoing analysis is based on the assumption that the biomass raw materials at the source (municipal solid waste disposal site or transfer station) are already collected and separated from the non-combustible materials such as cans, bottles, and metals. If log production cost must include collection cost and separation cost, then the log production cost will be much higher than determined herein, and the price of the fuel produced will be too expensive for power plants. This means to encourage the use of municipal waste for power plant fuel, not only must cities continue to collect waste and charge the collection cost to household or waste generators, the city should also separate the waste, or more economically, collect the waste that is already separated, and provide the fuel producer with the separated waste materials either free of charge or with a subsidy. The subsidy is justified due to the reduction of waste at the landfill.

This study also shows that a truck-mounted portable biomass log production plant can be used to compact wastes such as sawdust generated at industrial plants. The log production cost (undelivered unit price) in this case is very high (about $\$ 79$ per ton), which makes it highly unlikely to be economical in today's market. The main reason that the unit production price of the mobile plant is so much higher than that of the fixed-location plant is the scale of the machine and scale of production. While the fixed plant using ten large machines produces 675,000 tons of biomass logs per year, the mobile plant using only one small machine can produce only 11,760 tons/yr which is 57 times smaller than the production rate of the large fixed plant. This shows the importance of the economy of scale. The unit cost for log production by the portable system may be reduced significantly by reducing or eliminating the need for log storage at the plant, which is costly.

Finally, barge is the most economic way to transport biomass logs, followed by train and then truck. In most cases, truck will be used because there is no navigable waterways or railroads linking the biomass production plant to the power plant. For distances less than about 5 miles, or in special situations where trucks are not allowed due to environmental and safety concerns, PCP or HCP will be a good alternative due to their safety and environmental friendliness. Research is 
also underway to improve both HCP and PCP in order to increase their economic attractiveness for transporting biomass logs and other freight.

\section{REFERENCES}

1. Mao, S. F., Research and Design of a Portable Log Fabrication System, M.S. Thesis (draft), Department of Mechanical \& Aerospace Engineering, January 2000.

2. Xue, K., Research and Design of 5.4-Inch Diameter Mold Rotary Press for Coal Log and Biomass Compaction, M.S. Thesis, Mechanical \& Aerospace Engineering, University of Missouri-Columbia, 1999, 101 pages.

3. Liu, H. Noble, J., Wu, J. P. and Zuniga, R., "Economics of Coal Log Pipeline for Transporting Coal," Transportation Research-A, Vol. 32, No. 5, 1999, pp. 377-391

4. Liu, H., Noble, J., Zuniga, R. and Wu, J. P., Economic Analysis of Coal Log Pipeline Transportation of Coal, Capsule Pipeline Research Center, University of Missouri-Columbia, CPRC Report No. 95-1, July 1995.

5. Liu, H. and Marrero, T. R., "Coal Log Pipeline Technology: An Overview," Powder Technology, Vol. 94, 1997, pp. 217-222.

6. Black \& Veatch (1997). Site Evaluation and Feasibility Studies for a Solid Waste Materials Recovery Facility, Vol. 1, prepared for the City of Columbia, Missouri.

7. Kosugi, S., "A Capsule Pipeline System for Limestone Transportation," Proc. Of the 7th Int. Sym. on Freight Pipelines, Wollongong, Australia, Institution of Engineers, Barton, Australia, pp. 13-17.

8. Biomass Residue Supply Curves for the United States (Update), prepared by Antares Group, Inc., Landover, MD for United States Department of Energy's Biomass Power Program and the National Renewable Energy Laboratory (NREL), June 1999.

9. Noon, C. E., Daly, M. J., Graham, R. L. and Zahn, F. B., "Transportation and Site Location Analysis for Regional Integrated Biomass Assessment," Proc. Of Bioenergy '96, Nashville, Tennessee, Sept. 15-20, 1996, 6 pages.

10. Hacker, K. and Malone, C., USDA Grain Transportation Report, Transportation and Marketing, Agricultural Marketing Service, United States Department of Agriculture (USDA), 8 pages.

11. Brown, R.A.S., "Capsule Pipeline Research at the Alberta Research Council, 1958-1978, Journal of Pipelines, Vol. 6, No. 1, 1987, pp. 75-82.

12. ASCE Task Committee on Freight Pipelines, "Freight Pipelines: Current Status and Anticipated Future Use," Journal of Transportation Engineering, Vol. 124, No. 4, 1998, pp. 300-310.

13. Wu, J.P., Economic Feasibility of Using Hydraulic Capsule Pipelines to Transport Farm Products of the Midwestern States of the United States, M.S. Thesis, Department of Civil Engineering, University of Missouri-Columbia, 1989, 118 pages. 


\section{APPENDIX A. BIOMASS LOG PRODUCTION COSTS}

The production of biomass logs involves size reduction of the biomass raw material (feedstock), drying the feedstock if needed, storage of the dried feedstock, compaction of the dry feedstock into logs, and storage of logs before transportation to power plants. The whole process is shown in Fig. A.1.

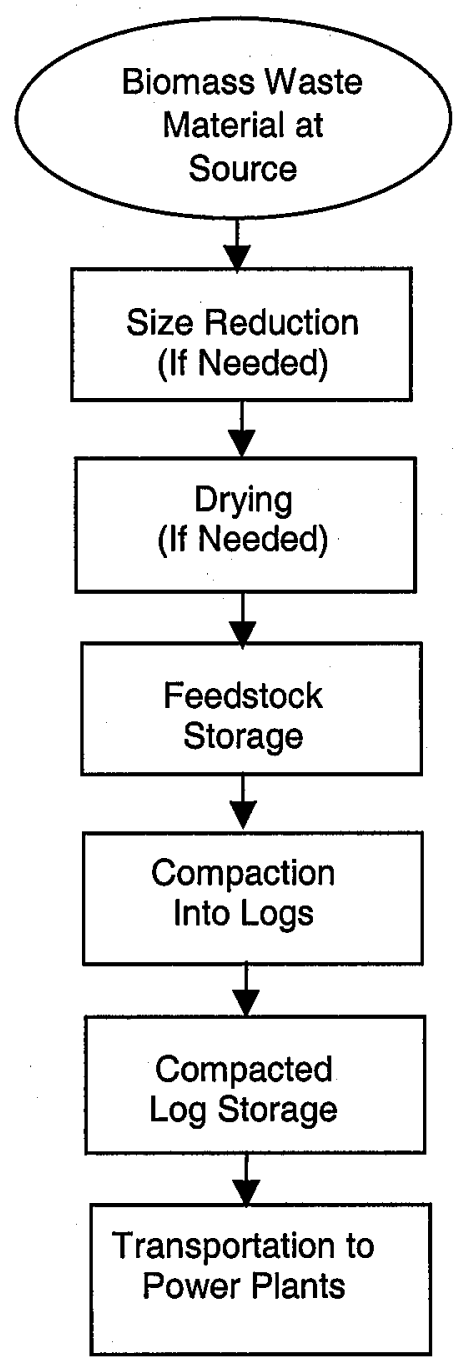

Figure A.1. Process flowchart for biomass log fuel (BLF) production

The details of biomass log production costs are derived and determined here based on two types of rotary press log compactor--a truck-mounted mobile system that can be transported from one source or site of biomass waste to another, and a larger press system to be used at a fixed location. They are separately evaluated as follows: 


\section{A.1. Fixed-Location System}

The fixed-location rotary press is a relatively large rotary press that produces 5.4-inchdiameter biomass logs at the rate of two logs per second. Assuming that the log length is the same as the log diameter and the specific gravity of the logs is 1.0 (unity), the volume of each $\log$ is $0.0716 \mathrm{ft}^{3}$, and the weight of each log is $4.47 \mathrm{lbs}$. The production rate of this machine is 16.1 tons/hr, or 386 tons/day in a continuous (around-the-clock) operation. Assuming that the plant operates 350 days a year, the annual capacity or throughput will be 135,000 tons. For a large city that uses five such machines at a given location, the amount of biomass waste material processed in a year will be 675,000 tons. Two spare machines will be included. The entire system, shown in Fig. A.2., involves the following: (1) transporting the collected biomass to the production plant by truck which dumps the material into the crusher (usually hammer mills); (2) if the material is wet, bringing it into the drying chamber to be dried; (3) storing the dried feedstock in a shelter; (4) compacting the dried material into logs by using rotary presses; (5) storing the logs in a storage shelter until the logs are picked up by trucks.

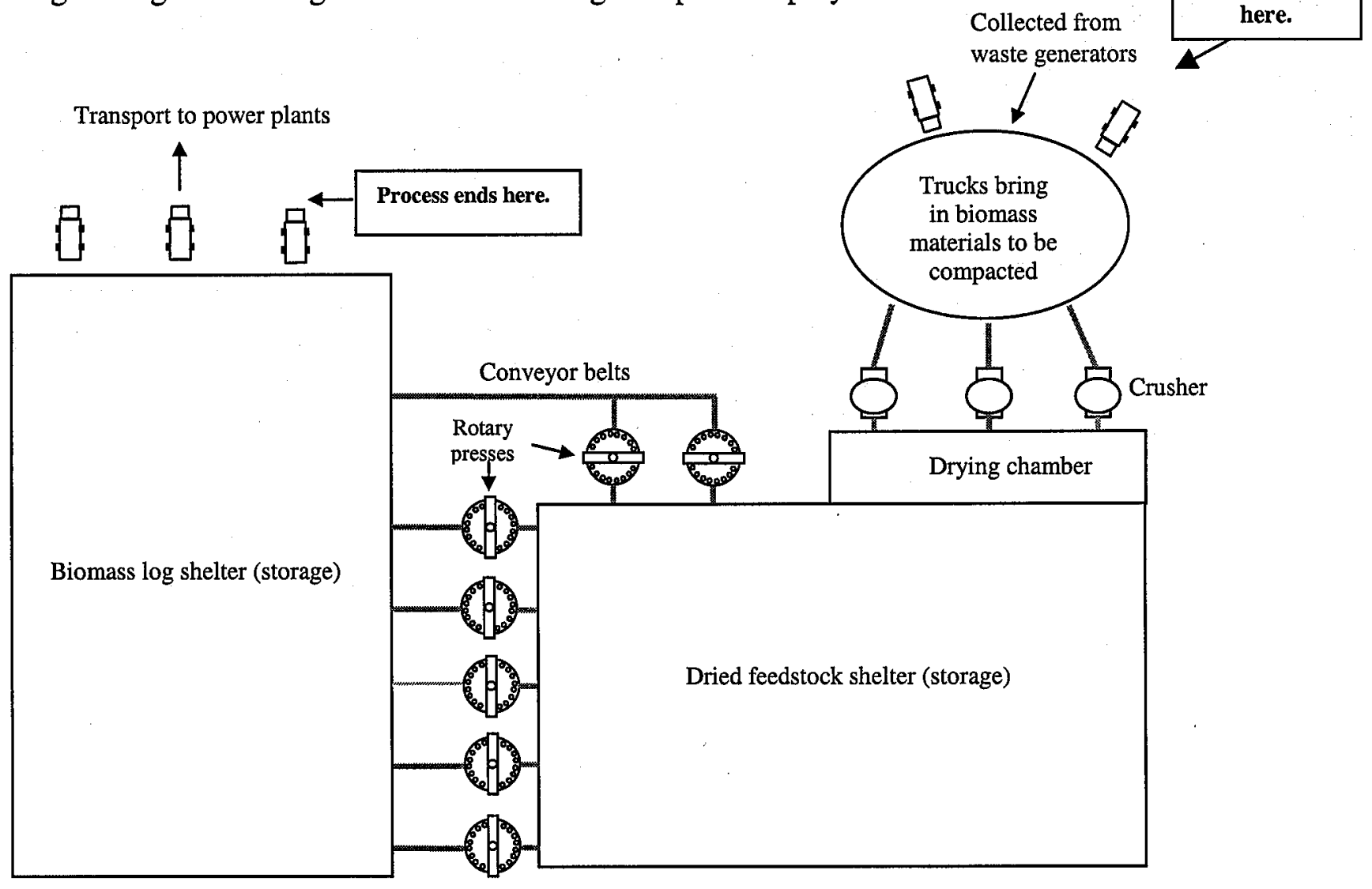

Fig. A.2. Fixed-location biomass log fuel (BLF) production plant general layout. 
The capital costs and the operation/maintenance cost of the fixed-location system are evaluated separately as follows:

\section{A.1.1. Capital Cost}

\section{Compaction Machine Cost $\left(\mathbf{C}_{\mathrm{cm}}\right)$}

Assuming that each of such machine (rotary press) costs $\$ 500,000$, and that two extra machines are needed as backup or spare in order to be able to have five machines operating 350 days a year, the capital cost for the rotary presses of the fixed-location system is $\$ 500,000 \times 7=$ $\$ 3,500,000=\$ 3.5$ million.

\section{Building Cost $\left(\mathbf{C}_{\text {bu }}\right)$}

The building to house the seven rotary presses and the auxiliary equipment is expected to be $50 \mathrm{ft}$ (width) x $70 \mathrm{ft}$ (length) x $30 \mathrm{ft}$ (height). Assuming that the building costs $\$ 100$ per square foot of the floor plan, the cost of the building is $\$ 100 \times 50 \times 70=\$ 350,000$.

\section{Material Drying Cost $\left(\mathbf{C}_{\mathrm{md}}\right)$}

Drying the wet material is done by passing warm dry air through the feedstock piled up in a specially designed large drying chamber. As shown in Fig. A.3, warm dry air is blown into the air chamber beneath the grate that holds the biomass. The air rises through the 10 -ft-layer of biomass materials to remove the moisture of the biomass. Drying can be accomplished rapidly in such a fluidized-bed system.. Then, the dried material is pushed out by an automatic moving wall to make room for the next batch to be dried. A facility is designed to handle 675,000 tons of material per year, which is equivalent to 1,929 tons /day, or 80.4 tons/hr. The cost of this facility is estimated to be $\$ 480,000$.

\section{Size Reduction Cost $\left(\mathbf{C}_{s r}\right)$}

For certain biomass waste material, such as sawdust, no size reduction is required. Therefore, $\mathrm{C}_{\mathrm{sr}}$ is zero. On the other hand, materials such as waste paper, tree trimmings and municipal solid waste require size reduction before they can be compacted in molds.

The equipment needed for size reduction is different for different types of biomass. For instance, while shredders are needed for paper, mulchers are needed for producing mulches from tree trimmings. As listed in Appendix E, a new "wood-waste recycler" which is a machine for waste-wood size reduction, Model HC 2400, has a capacity of 45 tons/hr, and costs 
approximately $\$ 241,000$. Therefore, for a plant that must process 675,000 tons of biomass material a year (in 350 days of around-the-clock continuous operation), three such machines will be needed-two operating and one spare. The total cost for the machines will be $\$ 723,000$.

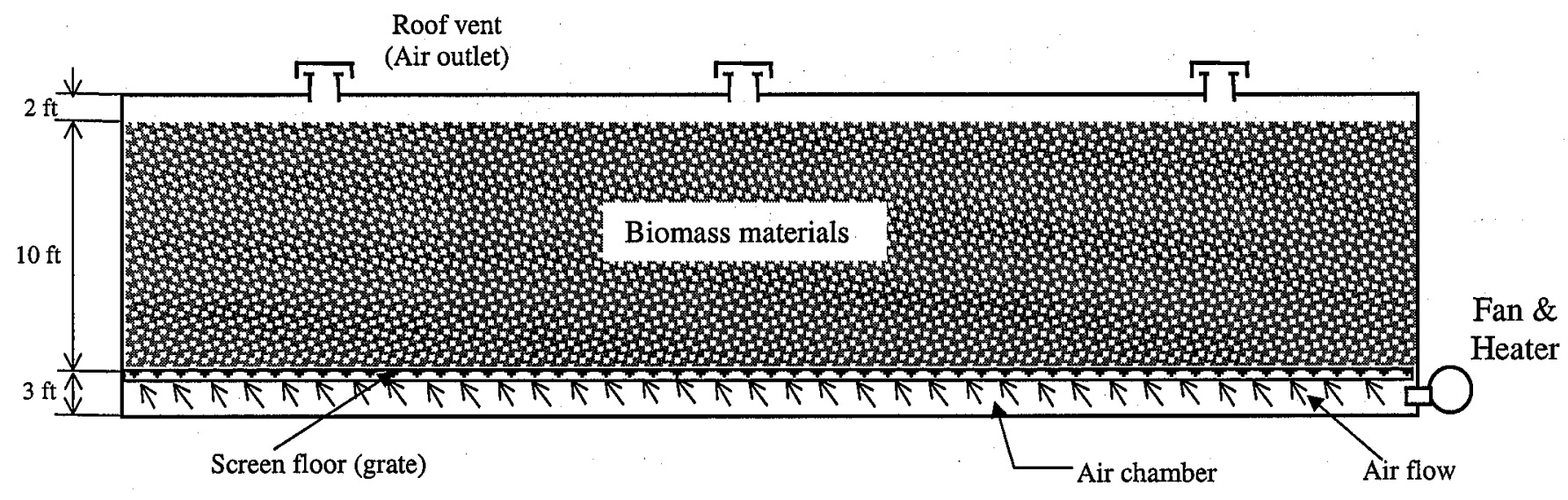

(a) Vertical profile

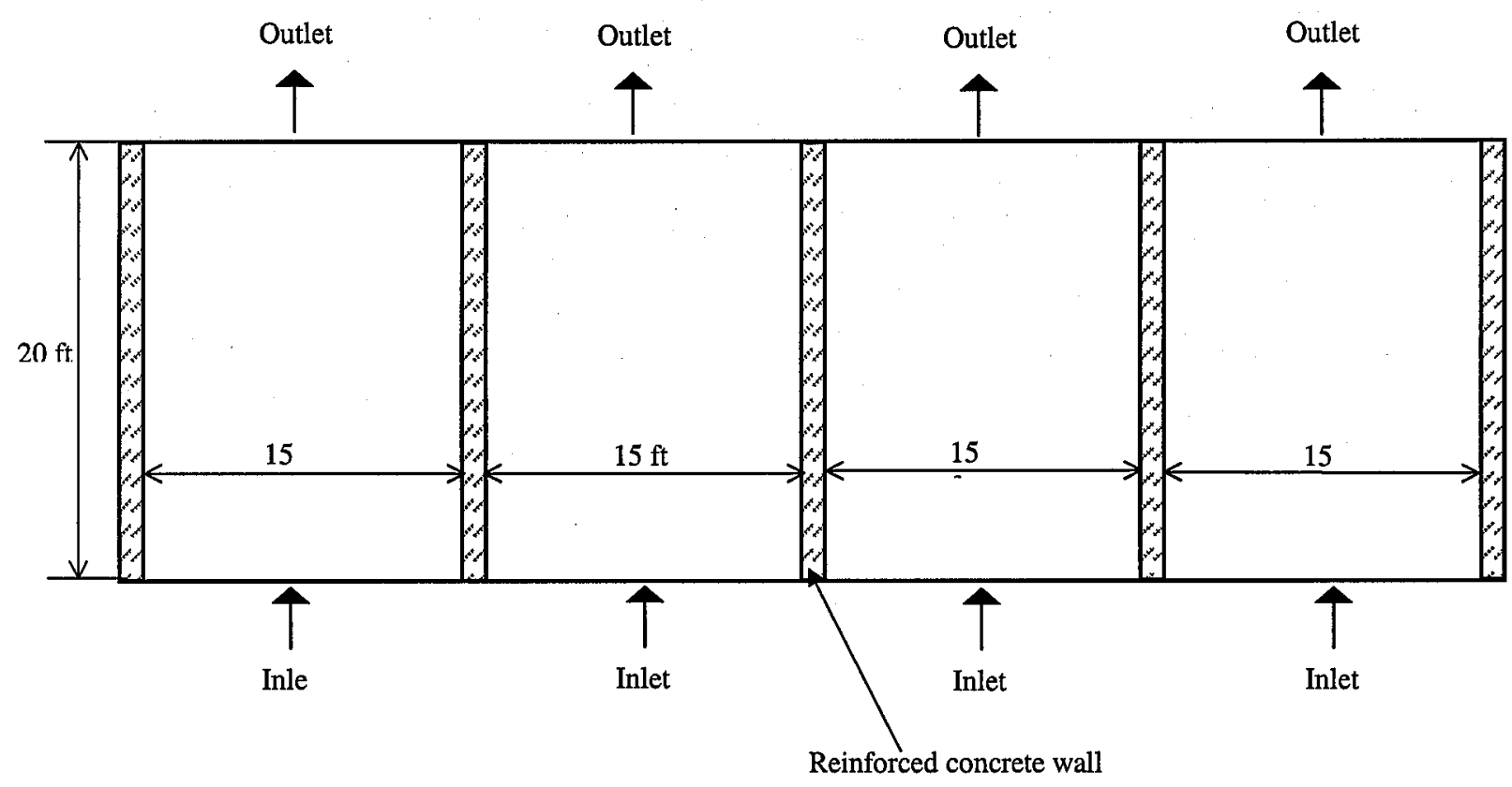

(b) Plan view

Figure A.3. Fluidized-bed air drying chamber for biomass raw material. 


\section{Material Storage Cost $\left(\mathrm{C}_{\mathrm{ms}}\right)$}

Dried biomass raw material is to be stored in a shelter (shed) so that it will not be wetted by rain. The shelter should have a capacity to store enough material for 24 hours of continuous operation of the biomass log production plant. This means a total weight of 1,930 tons of biomass raw material must be stored at the plant site. If the raw material has a bulk specific gravity of 0.22 , and if the material is piled up $10 \mathrm{ft}$ high at the storage, the storage area will be $28,100 \mathrm{ft}^{2}$ which will occupy an area of about 0.65 acre. This can be done by using a rectangular building the size of $140 \mathrm{ft}$ (width) $\times 200 \mathrm{ft}$ (length) $\times 15 \mathrm{ft}$ (height). If the construction of the shelter is $\$ 30$ per square foot, the total capital cost for the storage shed will be approximately $\$ 843,000$. Note that land acquisition cost is not included herein because all city solid waste disposal sites already have large areas for storage of waste materials. It is not an extra cost for biomass log production. Even if it were, a 0.65 -acre land would not add a significant amount to the $\$ 843,000$.

\section{$\underline{\text { Log Storage Cost }\left(\mathrm{C}_{\mathrm{ls}}\right)}$}

The compacted logs may need to be stored at the site for up to three days before they are transported by truck or another means to a power plant. This requires the storage of 5,794 tons of logs on site. Assuming that the bulk specific weight of a pile of logs is $40 \mathrm{lbs} / \mathrm{ft}^{3}$, storing 5,794 tons of logs requires a storage volume of $290,000 \mathrm{ft}^{3}$. Assuming that the compacted logs are stored in a $10 \mathrm{ft}$ layer in a shelter, the storage area required will be $29,000 \mathrm{ft}^{2}$ or 0.7 acre. This will take a shelter of the size of $200 \mathrm{ft}$ (length) x $145 \mathrm{ft}$ (width) x $15 \mathrm{ft}$ (height). At $\$ 30$ per square foot, the cost of the shelter will be approximately $\$ 869,000$.

\section{Substation Cost $\left(\mathbf{C}_{\text {ss }}\right)$}

The substation is the transformer facility needed for providing the power for the biomass log production plant. Based on the information provided in [4], the cost of a substation can be estimated from:

$$
\mathrm{C}_{\mathrm{ss}}=0.67 \mathrm{P}^{0.6}
$$

where $C_{s s}$ is the substation installed cost in thousand dollars, and $P$ is the total power needed for the plant in kw. The value of $\mathrm{P}$, as determined in the next section (A.12. Annual Cost), is 1,034 kw. From Eq. A.1, the cost of the substation for the biomass log production plant is approximately $\$ 43,000$. 


\section{Other Equipment Cost $\left(\mathbf{C}_{0 e}\right)$}

Other equipment needed for processing the biomass material at the biomass log production plant include conveyer belts or alternative conveying equipment, two skid loaders (Bob Cats), automatic control equipment, and other miscellaneous equipment. The conveying equipment is estimated to be $\$ 300,000$, the two skid loaders cost $\$ 80,000$, the automatic control equipment costs $\$ 100,000$, and other miscellaneous equipment cost $\$ 40,000$. So, the total other equipment cost is $\mathrm{C}_{\mathrm{oe}}=\$ 520,000$.

\section{Total Capital Cost}

The total capital cost for a fixed-location biomass log production plant that produces 675,000 tons of biomass logs per year is:

$$
\begin{aligned}
C_{c} & =C_{c m}+C_{b u}+C_{m d}+C_{s r}+C_{m s}+C_{l s}+C_{s s}+C_{o e} \\
& =3,500+350+480+723+843+869+43+520 \\
& =7,328 \text { (unit is in thousands of dollars). }
\end{aligned}
$$

This shows that total capital cost for this plant is approximately $\$ 7.3$ million.

\section{A.1.2. Annual Cost}

The annual cost for the fixed-location system includes the following components:

\section{Electricity $\operatorname{Cost}\left(\mathbf{C}_{2}\right)$}

The electrical power needed to operate a fixed-location biomass production system includes that for plant illumination $\mathrm{P}_{\mathrm{pi}}$, for operating the compaction machines $\mathrm{P}_{\mathrm{co}}$, for materials drying $P_{m d}$, and for operating other miscellaneous equipment $P_{\mathrm{eq}}$. No electric power is included for size reduction because machines for that use diesel fuel instead of electricity. The fuel cost will be assessed separately.

For plant illumination, the power needed is estimated to be $10 \mathrm{kw}$.

The greatest amount of power consumed is for compaction. It is know that to compact a 5.4-inch-diameter, 5.4-inch-length biomass log at peak pressure of 15,000 psi requires a maximum force of $3.44 \times 10^{5} \mathrm{lbs}$, and a compaction work of $51,500 \mathrm{ft}-\mathrm{lb}$.

For a machine that produces two logs per second, the power required to supply the energy needed for compaction is $103,000 \mathrm{ft}-\mathrm{lb} / \mathrm{sec}$ or $187 \mathrm{Hp}$. With five machines operating simultaneously in the plant, the power needed is $937 \mathrm{Hp}$. Assuming that the efficiency of compaction is only $80 \%$, this requires a total electrical power of $1,170 \mathrm{Hp}$ or $874 \mathrm{kw}$. 
Assume that other miscellaneous equipment at the plant requires $100 \mathrm{kw}$. Therefore, the total electrical power needed to run the plant is estimated to be:

$$
\begin{aligned}
P & =P_{p i}+P_{c o}+P_{e q}+P_{m d} \\
& =10+874+100+50 \\
& =1,034 \mathrm{kw}
\end{aligned}
$$

The foregoing calculation shows that the total electrical power required to run the fixed-location plant is $1,034 \mathrm{kw}$ or approximately one MW.

Assuming that the cost of electricity is 6 cents per kwh as in Missouri, the annual cost for electricity will be $C_{e}=\$ 521,000$. It is assumed that this will increase each year at the same rate as the general inflation rate.

\section{Fuel Cost $\left(\mathbf{C}_{f}\right)$}

Fuel cost includes that for heating the building by using natural gas, and for running the two skid loaders by using gasoline. The former is estimated to cost $\$ 10,000$ per year, and the latter is estimated to cost $\$ 200$ per day or $\$ 70,000$ per year. In addition, diesel fuel is used for running the biomass size reduction machine. Based on the information provided by the manufacturer of Model HC-2400 (see Appendix 4), each such machine uses 14 gallons of diesel per hour. At $\$ 1.50$ per gallon, continuous use of two such machines 24 hours a day and 350 days a year costs $\$ 352,800$. Therefore, the total fuel cost, $\mathrm{C}_{\mathrm{f}}$, is estimated to be $\$ 432,800 / \mathrm{yr}$. This is the fuel cost for the first year. The fuel cost is escalated at the same annual rate as the general inflation rate.

\section{Water Cost $\left(\mathbf{C}_{\mathrm{w}}\right)$}

Water is needed not only to flush toilets and wash plant equipment, but also to increase the moisture of biomass materials that are overly dry. It is assumed that the daily consumption of water is $10,000 \mathrm{ft}^{3}$. At 50 cents per $100 \mathrm{ft}^{3}$, it cost $\$ 50$ per day or $\$ 18,000$ per year.

\section{Salary \& Wages $\left(\mathrm{C}_{\mathrm{sw}}\right)$}

Assume that the plant requires one supervisor at annual salary (including fringe benefits) of $\$ 60,000$. It also requires a crew of 12 workers to operate and maintain the plant around the clock at an annual salary (including fringe benefits) of $\$ 50,000$. The total salary for operating such a plant per year is then approximately $\$ 660,000$. 


\section{Parts and Supply $\mathrm{C}_{\mathrm{ps}}$ )}

Parts for repair/replacement and supply for miscellaneous items are estimated to be $\$ 200,000$ per year per plant.

\section{Property Tax and Insurance Cost $\left(\mathrm{C}_{\mathrm{i} i}\right)$}

The property tax rate is $\mathbf{t}_{\mathbf{p}}$, and the insurance rate is $\mathbf{i}$. Both are based on the capital cost $\mathrm{C}_{\mathrm{c}}$, namely,

$$
\mathrm{C}_{\mathrm{ti}}=\mathrm{t}_{\mathrm{p}} \mathrm{C}_{\mathrm{c}}+\mathrm{iC}_{\mathrm{c}}=\left(\mathrm{t}_{\mathrm{p}}+\mathrm{t}_{\mathrm{i}}\right) \mathrm{C}_{\mathrm{c}}
$$

In this study, it is assumed that $t_{p}=0.02$, and $i=0.005$. Therefore, from Eq. A.4, the combined cost for property tax and insurance is $C_{t i}=\$ 7,328,000 \times 0.025=\$ 183,000$.

\section{Total Annual Cost $\left(\mathrm{C}_{\mathrm{a}}\right)$}

Based on the foregoing estimates, the total annual cost to operate the plant is expected to be

$$
\begin{aligned}
& C_{a}=C_{e}+C_{f}+C_{w}+C_{s w}+C_{p s}+C_{t i} \\
& =521+433+18+660+200+183 \\
& =2,015 \text { (in thousand dollars) }
\end{aligned}
$$

Based on the foregoing determination of the Capital and Annual Costs, and using the cost model and assumptions described in Sections 3 and 4, the unit production cost for the 675,000tons/yr. plant is computed to be $\$ 5.47 /$ ton. The capital and annual costs at different throughputs or plant sizes are estimated and included in Table A.1 (a) and (b), from which the unit costs at various throughputs are determined, listed in Table A.1 (c), and plotted in Figs. A.4 and A.5. It can be seen from the table and the two figures that the unit cost of biomass log production increases as the plant capacity decreases. For the large plant that produces 675,000 tons of logs per year, the unit cost of production is only $\$ 5.47$, whereas for a smaller plant that produces 135,000 tons of biomass per year, the unit cost is $\$ 8.16$. This shows the economy of scale. Note that the calculated results are for an inflation-adjusted, after-tax return of $15 \%$ which is a good investment. For higher return rates of $20 \%, 25 \%$ and $30 \%$, the production costs were also determined and included in Table A.1 (c). 
Table A.1. Biomass log production cost for different throughputs

(a) Itemized capital cost $\left(\times 10^{3}\right.$ dollars)

\begin{tabular}{|c|c|c|c|c|c|c|c|c|c|c|}
\hline $\mathrm{Q}$ (tons/yr) & $\mathrm{N}_{\mathrm{cp}}$ & $\mathrm{C}_{\mathrm{cm}}$ & $\mathrm{C}_{\mathrm{bu}}$ & $\mathrm{C}_{\mathrm{md}}$ & $\mathrm{C}_{\mathrm{sr}}$ & $\mathrm{C}_{\mathrm{ms}}$ & $\mathrm{C}_{\mathrm{ls}}$ & $\mathrm{C}_{\mathrm{ss}}$ & $\mathrm{C}_{\mathrm{o}}$ & Total \\
\hline 675,000 & 7 & 3,500 & 350 & 480 & 723 & 843 & 869 & 43 & 520 & 7,328 \\
\hline 540,000 & 5 & 2,500 & 250 & 384 & 578 & 674 & 695 & 38 & 416 & 5,536 \\
\hline 405,000 & 4 & 2,000 & 200 & 288 & 434 & 506 & 521 & 32 & 312 & 4,293 \\
\hline 270,000 & 3 & 1,500 & 150 & 192 & 289 & 337 & 348 & 25 & 208 & 3,049 \\
\hline 135,000 & 2 & 1,000 & 100 & 96 & 145 & 169 & 174 & 16 & 104 & 1,803 \\
\hline
\end{tabular}

(b) Itemized annual cost $\left(\times 10^{3}\right.$ dollars)

\begin{tabular}{|c|c|c|c|c|c|c|c|}
\hline $\mathrm{Q}$ (tons/yr) & $\mathrm{C}_{e}$ & $\mathrm{C}_{\mathrm{f}}$ & $\mathrm{C}_{\mathrm{w}}$ & $\mathrm{C}_{\mathrm{sw}}$ & $\mathrm{C}_{\mathrm{ps}}$ & $\mathrm{C}_{\mathrm{ti}}$ & Total \\
\hline 675,000 & 521 & 433 & 18 & 660 & 200 & 183 & 2,015 \\
\hline 540,000 & 417 & 346 & 14 & 660 & 160 & 138 & 1,736 \\
\hline 405,000 & 313 & 260 & 11 & 510 & 120 & 107 & 1,321 \\
\hline 270,000 & 208 & 173 & 7 & 510 & 80 & 76 & 1,055 \\
\hline 135,000 & 104 & 87 & 4 & 410 & 40 & 45 & 689 \\
\hline
\end{tabular}

(c) Unit production cost

\begin{tabular}{|c|c|c|c|c|c|c|}
\hline \multirow{2}{*}{$\begin{array}{c}\text { Throughput Q } \\
\text { (tons/yr) }\end{array}$} & \multirow{2}{*}{$\begin{array}{c}\text { Total capital cost } \\
\left(\times 10^{3} \text { dollars }\right)\end{array}$} & \multirow{2}{*}{$\begin{array}{c}\text { Total Annual cost } \\
\left(\times 10^{3} \text { dollars }\right)\end{array}$} & \multicolumn{4}{|c|}{ Unit production cost for different } \\
\cline { 5 - 7 } & & & $r=15 \%$ & $r=20 \%$ & $r=25 \%$ & $r=30 \%$ \\
\hline 675,000 & 7,328 & 2,015 & 5.47 & 6.25 & 7.06 & 7.90 \\
\hline 540,000 & 5,536 & 1,736 & 5.56 & 6.30 & 7.06 & 7.85 \\
\hline 405,000 & 4,293 & 1,321 & 5.69 & 6.45 & 7.25 & 8.06 \\
\hline 270,000 & 3,049 & 1,055 & 6.49 & 7.30 & 8.15 & 9.02 \\
\hline 135,000 & 1,803 & 689 & 8.16 & 9.12 & 10.12 & 11.15 \\
\hline
\end{tabular}

Q - Throughput

$\mathrm{N}_{c p}$ - Number of compact machines. 7 includes 2 backups; 2 through 5 include 1 backup

$\mathrm{C}_{\mathrm{cm}}$ - Compaction machine cost ( $\$ 500,000$ per machine)

$\mathrm{C}_{\mathrm{bu}}$ - Building cost, proportional to number of compactors

$\mathrm{C}_{\mathrm{md}}$ - Material drying cost, proportional to throughput

$\mathrm{C}_{\mathrm{sr}}$ - Size reduction cost, proportional to throughput

$\mathrm{C}_{\mathrm{ms}}$ - Material storage cost, proportional to throughput

$\mathrm{C}_{\mathrm{ls}}$ - Log storage cost, proportional to throughput

$\mathrm{C}_{s s}$ - Substation cost, calculated from $C_{s s}=0.67 P^{0.6}$, where $\mathrm{P}$ is power needed

$\mathrm{C}_{0 \theta}$ - Other equipment cost, proportional to throughput

$\mathrm{C}_{\theta}$ - Electricity cost, proportional to throughput

$\mathrm{C}_{\mathrm{f}}-$ Fuel cost, proportional to throughput

$\mathrm{C}_{\mathrm{w}}$ - Water cost, proportional to throughput

$\mathrm{C}_{\mathrm{ws}}$ - Salary, 12 workers for the first two throughputs, 9 for the third and fourth, and

6 for the last

$\mathrm{C}_{\mathrm{ps}}$ - Parts and supply, proportional to throughput

$\mathrm{C}_{\mathrm{ti}}$ - Property tax and insurance cost, 0.025 times total capital cost

In Figures A.4 and A.5, the points on both sides of the curves mark the results of a sensitivity analysis with $25 \%$ variation of capital or annual cost, respectively for Figs. A.4 and A.5. It can be seen from Fig. A.4 that an increase or decrease of the capital cost by $25 \%$ causes the unit cost to increase or decrease by $10 \%$, approximately. And, an increase or decrease of the 
operations and maintenance cost (i.e., annual cost) causes the unit cost to increase or decrease by $15 \%$ approximately. Finally, from Fig. A.6, it can be seen that as the return rate increases, the unit cost increases proportionately.

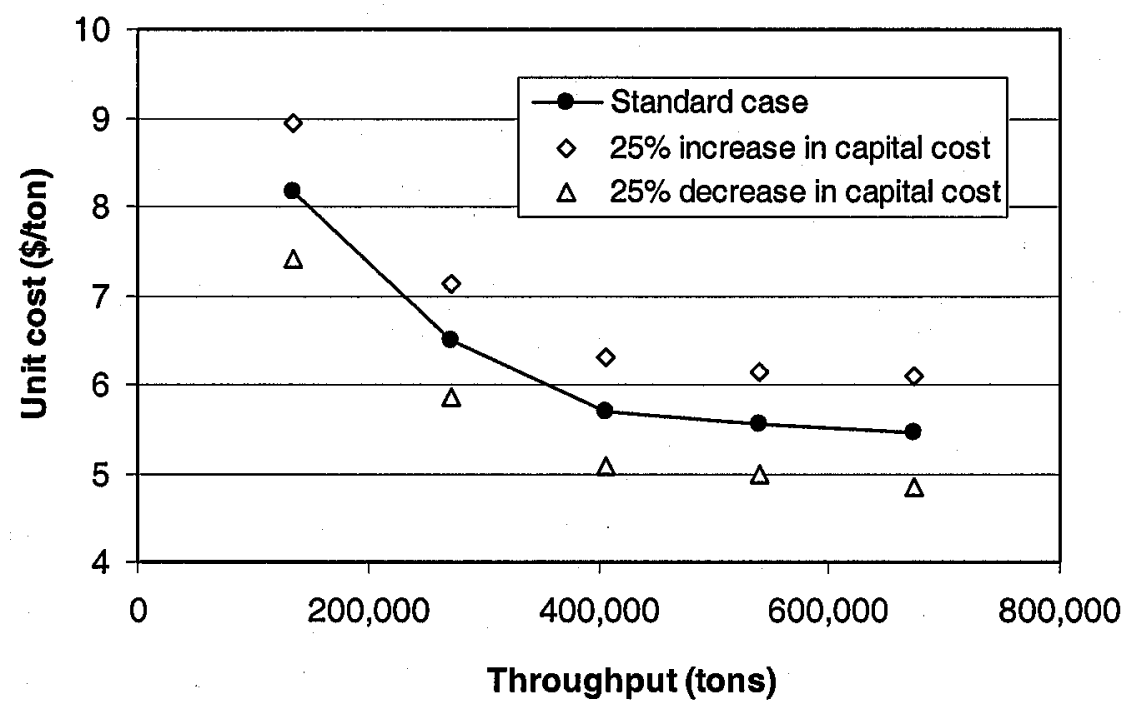

Figure A.4. Variation of unit production cost of biomass log fuel (BLF) with throughput, and the effect of capital-cost changes on the production cost

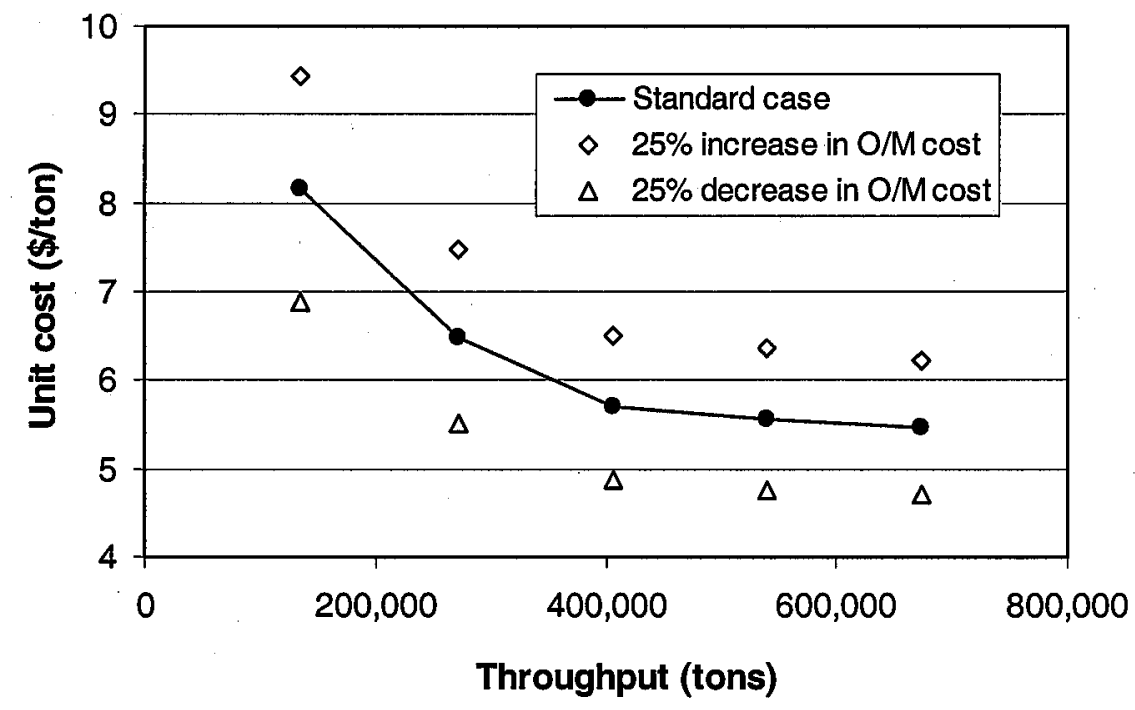

Figure A.5. Variation of unit production cost of biomass log fuel (BLF) with throughput, and the effect of operation and maintenance $(\mathrm{O} / \mathrm{M})$ cost changes on the production cost 


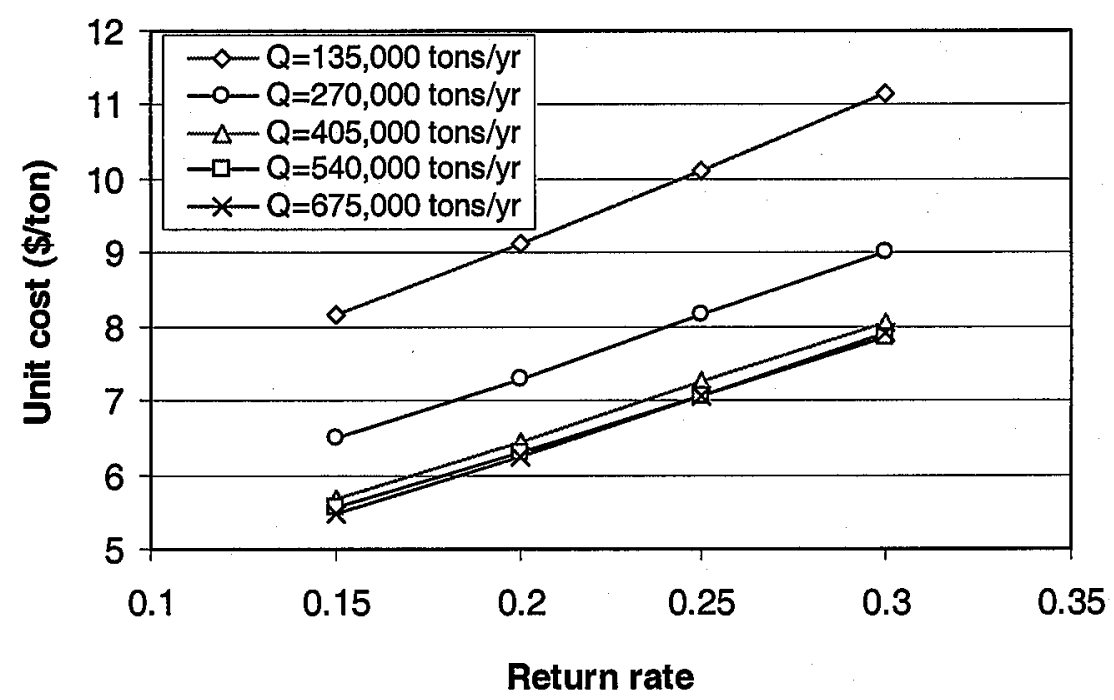

Figure A.6. Variation of unit production cost of BLF with after-tax return rate for different throughputs

\section{A.2. Portable (Truck-Mounted) System}

The portable (truck-mounted) biomass log production plant produces 2-inch-diameter logs at the rate of four logs per second. Assuming that the log length is also 2 inches, the volume of each $\log$ is $0.00364 \mathrm{ft}^{3}$. With the specific gravity of each log being 1.0 , the weight of each log is $0.227 \mathrm{lb}$. With 4 logs per second, the system can produce logs at the rate of $1.63 \mathrm{tons} / \mathrm{hr}$, or 39.2 tons/day in a 24-hour-continuous operation. Assume that the plant is operational only 300 days per year. In the other 65 days of each year, the plant is either being repaired, maintained, or on the road (being transported from one source to another). Then, the annual production rate of this system is 11,760 tons/yr.

Note that this portable system is needed for materials such as sawdust which must be collected from a number of sawmills. The annual production rate of sawdust at each sawmill is assumed to be much less than 11,760 tons. Otherwise, a fixed-location system should be used. The capital cost and the annual (operation/maintenance) cost of the portable biomass log production system are estimated separately as follows:

\section{A.2.1. Capital Cost}

\section{Portable System Cost $\left(\mathrm{C}_{\mathrm{ps}}\right)$}

A portable system to compact 1.9-inch-diameter biomass logs was designed by Mao [1]. The system was initially designed to produce 1 log per second, and the cost, including the compactor (rotary press), the truck (freightliner with flat-bed) and the processing equipment 
(hammermill, screen, feeder, etc.), is $\$ 228,723$. The system can be modified to produce 4 logs per second if: (1) a larger motor is used so that the angular speed of the rotary press can be doubled, and (2) two concentric rows of molds are used so that the number of molds can be doubled. The capacity of the processing equipment of the modified machine must also be increased four times so that the equipment can handle four times the increased throughput. It is estimated that the modified Mao's system for producing 2-inch-diameter logs, including the truck, will cost $\$ 400,000$.

\section{Shelter Cost $\left(\mathbf{C}_{\mathrm{sh}}\right)$}

A shelter is needed at each site of the source (such as a sawmill) to store the biomass materials needed for compaction, and to provide sheltering from rain and snow for the portable (truck-mounted) plant. Assume that the portable plant derives its raw materials from ten different sites. This means the plant is working 30 days per year at each site, at the rate of 39.2 ton/day. A shelter is needed at each site to store the biomass raw material for one day or 39.2 tons. Assuming that the bulk specific gravity of the raw material (sawdust) is 0.22 , the storage volume is $5,711 \mathrm{ft}^{3}$. The sheltering area for the compacted material (logs) is calculated as follows:

Assume that the logs need to be stored for up to two days at the source before they are delivered to the power plant. This means a total of 78 tons must be stored. At bulk weight of 40 $\mathrm{lbs} / \mathrm{ft}^{3}$, the logs occupy a volume of $3,920 \mathrm{ft}^{3}$. If the logs are piled up $5 \mathrm{ft}$ high, the needed log storage area is $784 \mathrm{ft}^{2}$. The area needed to shelter the truck and processing equipment is estimated to be $2,000 \mathrm{ft}^{2}$.

From the foregoing, the total shelter area is $5,711+784+2,000=8,495 \mathrm{ft}^{2}$. This requires a combined shelter of $85 \mathrm{ft}$ (width) $\times 100 \mathrm{ft}$ (length) $\times 20 \mathrm{ft}$ (height) $=8,500 \mathrm{ft}^{2}$. At the rate of $\$ 30$ per square foot, the cost of the shelter at each site is $\$ 255,000$. For ten sites, it is $\$ 2.55$ million.

\section{Additional Equipment Cost ( $\mathbf{C}_{\underline{a}}$ )}

The truck-mounted portable system includes not only the truck and a rotary press compactor, but also a power source and some processing equipment. Even so, it is still necessary to have some additional equipment at each plant, such as a skid loader. However, since the need for such additional equipment at each source is infrequent for the portable plant, the equipment can be rented or shared at the source. Based on this assumption, the cost for additional equipment is estimated to be $\$ 20,000$ for each site or $\$ 200,000$ for the ten sites. 


\section{Total Capital Cost}

The total capital cost for a portable (truck-mounted) biomass log production plant that can produce 11,760 tons of biomass logs per year is:

$$
\begin{aligned}
& C_{c}=C_{p s}+C_{s n}+C_{a e} \\
& =400+2,550+200 \\
& =3,150 \text { (in thousand dollars) }
\end{aligned}
$$

\section{A.2.2. Annual Cost}

The annual cost for the portable system includes the following components:

\section{Electricity $\operatorname{Cost}\left(\mathbf{C}_{\mathrm{e}}\right)$}

The electrical power needed to operate the truck-mounted portable biomass production system includes that for biomass raw materials size reduction $P_{s r}$, for plant illumination $P_{p i}$, for operating the compaction machine $\mathrm{P}_{\mathrm{co}}$, and for operating other miscellaneous equipment $\mathrm{P}_{\mathrm{eq}}$. They are separately estimated as follows:

For sawdust, no size reduction is required and hence $P_{s r}$ is zero. For waste paper, it is assumed to be $1.5 \mathrm{kw}$ for each ton of material per hour. Since the plant processes $1.63 \mathrm{tons} / \mathrm{hr}$, the needed size reduction for waste paper is estimated to be $2.45 \mathrm{kw}$.

For plant illumination, the power needed at each site is $2 \mathrm{kw}$. Since only one site will be operational at any time, the total needed for ten sites is still $2 \mathrm{kw}$.

The power required to compact the biomass logs is proportional to the annual production rate which is 11,760 tons/yr for this case. Using the same approach used for estimating the power needed for the fixed-location plant, the power required for operating the compactor of the truckmounted mobile plant at anytime during its 300 days/yr operation is $18 \mathrm{kw}$.

For other miscellaneous needed electrical equipment, $20 \mathrm{kw}$ is assumed.

Based on the foregoing estimates, the total power required to operate the mobile plant is, approximately,

$$
\begin{aligned}
\mathrm{P} & =\mathrm{P}_{\mathrm{sr}}+\mathrm{P}_{\mathrm{pi}}+\mathrm{P}_{\mathrm{co}}+\mathrm{P}_{\mathrm{eq}} \\
& =0+2+18+20=40 \mathrm{kw} \text { (for sawdust) } \\
& =2.5+2+18+20=43 \mathrm{kw} \text { (for paper) }
\end{aligned}
$$

Assuming that the plant operates 300 days/yr, and the electricity cost 6 cents per kwh, the annual cost for electricity is $C_{e}=\$ 17,300$ for producing sawdust logs and $\$ 18,600$ for producing paper logs. 


\section{Fuel Cost $\left(\mathbf{C}_{f}\right)$}

The fuel cost includes that for heating the plant (truck), for driving the truck from one site to another, and for driving the skid loader. Assuming that a total of 8,000 gallons of diesel or gasoline is used, and the fuel cost is $\$ 1.50$ per gallon, the total fuel cost is $\$ 12,000$.

\section{Water Cost $\left(\mathbf{C}_{W}\right)$}

Assuming that $1,000 \mathrm{ft}^{3}$ of water is consumed per day, at 50 cents per $100 \mathrm{ft}^{3}$ it cost $\$ 5$ per day, or $\$ 1,500$ in 300 days of operation each year.

\section{$\underline{\text { Salary \& Wages }\left(\mathbf{C}_{\text {sw }}\right)}$}

Assume that the plant requires an operator who is the same as the truck driver, and an assistant. The annual salary, including fringe benefits, is $\$ 50,000$ for the operator, and $\$ 40,000$ for the assistant. The total salary will be $\$ 90,000$ per year.

\section{Maintenance $\left(\mathbf{C}_{\mathbf{m}}\right)$}

The maintenance cost is assumed to be $\$ 10,000$ per year.

\section{Property Tax and Insurance Cost $\left(\mathbf{C}_{t i}\right)$}

The property tax and insurance, determined from Eq. A.4, is $C_{t i}=\$ 3,150,000 \times 0.025=$ $\$ 78,750$.

\section{Total Annual Cost $\left(\mathrm{C}_{\mathrm{a}}\right)$}

Based on the foregoing estimates, the total annual cost to operate the truck-mounted mobile unit is

$$
\begin{aligned}
C_{a} & =C_{e}+C_{f}+C_{w}+C_{s w}+C_{m}+C_{t i} \\
& =17+12+1.5+90+10+79 \\
& =\$ 210 \text { (in thousand dollars) }
\end{aligned}
$$

\section{A.3. Results}

Using the information developed in this Appendix, and using the cost model discussed in Section 3, a computer program was written to compute the unit production price of biomass logs, in $\$ /$ ton, and to print the result for all the three scenarios.

It was found that for the fixed-location large plant that produces 675,000 tons of 5.4-inchdiameter biomass logs per year, the unit cost is $\$ 5.47$ which is very attractive or promising.

If the logs can be sold for $\$ 10 /$ ton (f.o.b.) and a $\$ 15$ tipping fee saving is accredited to the plant, the project can earn an enormous profit (after tax return) of 132\%! 
On the other hand, for the truck-mounted portable system that produces only 11,760 tons of 2-inch-diameter biomass logs per year, the unit cost is as high as $\$ 79 /$ ton. This shows the importance of economy of scale. 


\section{APPENDIX B. TRANSPORTATION COST ANALYSIS}

The transportation cost analysis will be done for truck, train, barge and pipeline. It should be realized that in over $90 \%$ of cases, truck will be the only practical means for transporting biomass logs. However, on limited occasions, a railroad or a waterway may exist linking the biomass waste source or site to the power plant where the logs are burned. On such occasion, rail or barge may provide a better (more cost-effective) alternative to truck. Finally, for biomass logs produced at very large fixed-location plants, pipeline transport may be a possibility. Two types of pipeline are considered herein for transporting biomass waste logs. They are pneumatic capsule pipeline (PCP) which is an existing technology used commercially in Japan [7]--see Fig. B.1, and hydraulic capsule pipeline (HCP) which is a new technology that has been studied extensively in the last nine years at Capsule Pipeline Research Center (CPRC), University of Missouri-Columbia-see Fig. B.2. The coal log pipeline (CLP) technology is more economical than HCP and PCP, but it is not considered here because it is not applicable to biomass logs which swell and disintegrate in water.

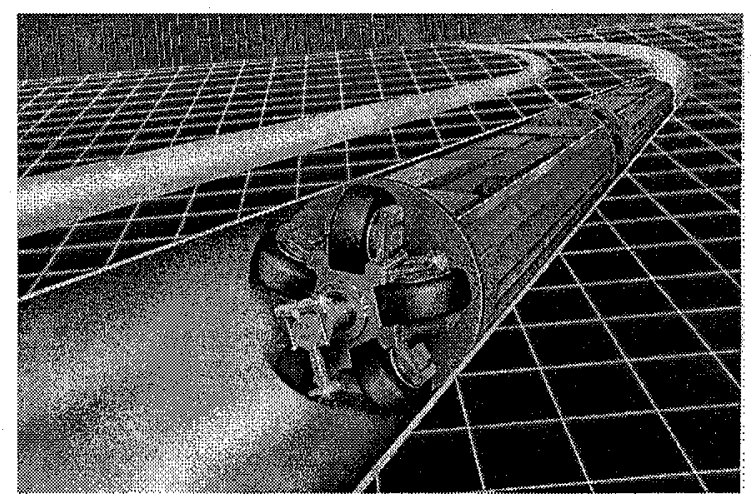

Figure B.1: Pneumatic Capsule Pipeline (PCP) used in Japan by the Sumitomo Metal Industries, Ltd.

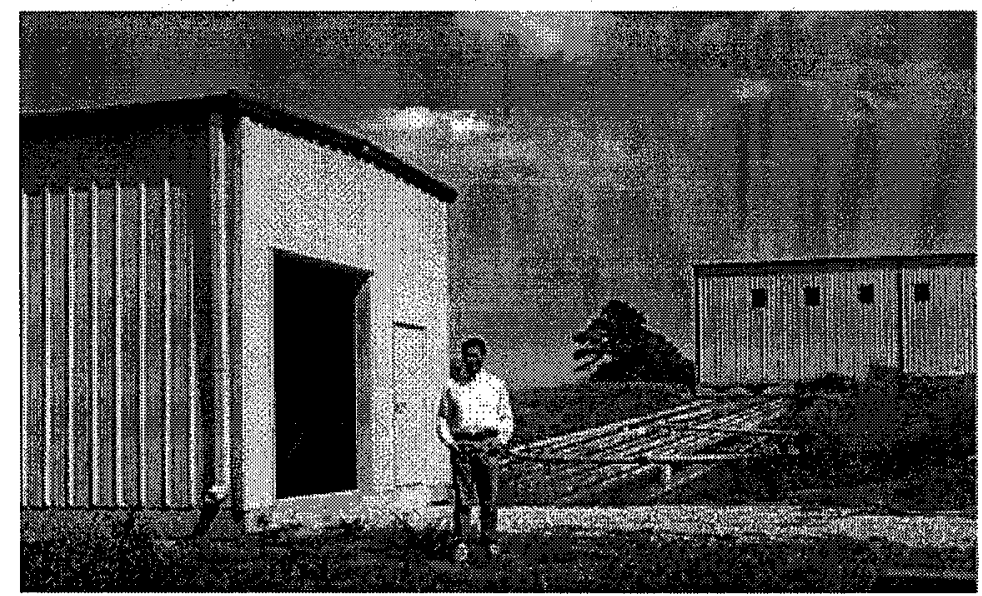

Figure B.2: HCP Pilot Plant under construction at University of Missouri-Columbia 
In what follows, an analysis is provided to determine the cost of transporting biomass by truck, railroad, barge and pipeline (PCP and HCP).

\section{B.1. Trucking Cost}

\section{B.1.1. Introduction}

Trucking cost data specific to biomass is sparse. Searches for trucking costs for other similar materials such as coal or grain did not turn up much information that was recent or pertinent. Consultants that were contacted suggested that truck rates for biomass would be highly site specific. In the past, truck rate data for Missouri was available from the Division of Transportation of the Missouri Department of Economic Development. However, with deregulation in the mid-1990s, the department no longer regulates or reports the rates of truck freight.

However, literature search uncovered two important relevant studies. The first is a report on biomass supply issued by the Antares Group [8], and the other is a Tennessee study on biomass transportation and site location, published in the Proceedings of BIOENERGY '96 [9]. They are separately discussed next.

\section{B.1.2. Antares Group Report [8]}

A national study was conducted for DOE last summer (June 1999) by the Antares Group, a consulting firm that helps industry and government introduce emerging technologies into the power, transportation, industrial and commercial sectors, including renewable and fossil energy resources. This study included estimates of trucking costs for transporting biomass by state.

For each state, the study developed an average city rate and a low city rate. It recommends the use of the average or higher rates for biomass waste materials such as municipal solid waste materials which are generated in primarily urban areas. The low rate is intended for biomass waste such as sawdust and forest residues most likely to be generated in rural areas.

The study calculated the state rates by first establishing a U.S. local transportation rate. It was calculated using data from the Statistical Abstract of the United States (1997). The total outlays for local transportation, $\$ 122$ billion, was divided by the total miles logged, 506 billion, to arrive at a U.S. average local freight rate per ton mile of $\$ 0.2411$.

State truck rates were calculated using state transportation cost indices also from the Statistical Abstract of the United States (1997). To obtain the state average city cost and the state 
low city cost, the U.S. average was multiplied by the state index number. Table B.1 contains the average and low indices for each state. For example, for Missouri the cost associated with transporting biomass in the rural areas is the product of Missouri's low average city rate of 0.836 times the U.S. average rate of $\$ 0.2411 /$ ton-mile, or $\$ 0.2016 /$ ton-mile. For municipal solid waste the rate would be $\$ 0.2266 /$ ton-mile ( $=0.94 \times 0.2411 \$ /$ ton-mile).

For example, to transport 100 tons of sawdust 65 miles in Missouri would cost $\$ 1,310$ $(\$ 0.2016 \times 100 \times 65)$. The estimated cost of moving 100 tons of waste paper 15 miles in Missouri would be $\$ 340$ ( $\$ 0.2266 \times 100 \times 15)$.

To verify the validity of the approach to estimate the truck transportation costs for biomass, the study checked the estimates with trucking companies serving biomass power plants. It was found that the estimated rates were comparable to rates the truckers quoted.

The foregoing quoted result must be kept in perspective. First, the study was conducted in 1999 prior to the recent sharp rise in diesel fuel price. Since truck rates depend strongly on the price of diesel, they increase as diesel price increases. Secondly, Table B.1 lists a single rate for each state; it does not reflect the variation of transportation cost within the state due to the variation of local topography, road conditions and traffic conditions. Neither does it reflect the effect of distance on rates. For instance, for short distances such as a few miles, the rates must be higher to properly account for the handling (loading/unloading) cost which is the same regardless of distance. This can be seen from the study to be discussed next.

\section{B.1.3. Tennessee Study [9]}

According to this Tennessee study, the transportation cost of biomass (bales of switch grass) can be broken down into three components: (a) hauling-distance cost, (b) hauling-time cost, and (c) loading/unloading cost. The total transportation cost is the sum of the three.

The study found that the expected national average for hauling-distance cost is 5 cents $/ \mathrm{km} / \mathrm{dry}$ tonne which is equivalent to 7.32 cents/TM-T stands for American ton or short ton (2,000 lbs), and $\mathrm{M}$ stands for mile. For a one-way distance of $\mathrm{L}$ miles, the hauling-distance cost is

$$
\mathrm{C}_{\mathrm{hd}}=0.0732 \mathrm{~L}
$$

where $L$ is in miles, and $C_{h d}$ is in $\$ / d r y$ ton. 
Table B.1. State Local Transportation Indices [8]

\begin{tabular}{|c|c|c|c|c|c|c|c|}
\hline $\begin{array}{c}\text { State } \\
\text { Name } \\
\text { Abbrev. }\end{array}$ & State Name (Full) & Low & Average & $\begin{array}{c}\text { State } \\
\text { Name } \\
\text { Abbrev }\end{array}$ & State Name (Full) & Low & Average \\
\hline AL & ALABAMA & 92.4 & 99.5 & MT & MONTANA & 113.1 & 113.1 \\
\hline AK & ALASKA & 110.4 & 110.4 & NE & NEBRASKA & 99.7 & 100.5 \\
\hline$\overline{A Z}$ & ARIZONA & 96.8 & 106.7 & NV & NEVADA & 98.6 & 108.9 \\
\hline AR & ARKANSAS & 90.6 & 95.9 & $\mathrm{NH}$ & NEW HAMPSHIRE & 103.4 & 111.4 \\
\hline $\mathrm{CA}$ & CALIFORNIA & 107.1 & 113.9 & $\overline{N J}$ & NEW JERSEY & 117.9 & 117.9 \\
\hline $\mathrm{CO}$ & COLORADO & 90.2 & 101.2 & NM & NEW MEXICO & 95.7 & 106.1 \\
\hline CT & CONNECTICUT & 103.6 & 111.5 & NY & NEW YORK & 105.6 & 112.5 \\
\hline $\mathrm{DE}$ & DELAWARE & 99.1 & 99.3 & NC & NORTH CAROLINA & 113.1 & 113.1 \\
\hline $\mathrm{FL}$ & FLORIDA & 95.7 & 99.8 & ND & NORTH DAKOTA & 91.4 & 97.0 \\
\hline $\mathrm{GA}$ & GEORGIA & 85.8 & 94.2 & $\overline{\mathrm{OH}}$ & $\mathrm{OHIO}$ & 88.0 & 100.5 \\
\hline $\mathrm{HI}$ & HAWAII & 145.2 & 145.2 & OK & OKLAHOMA & 83.5 & 90.4 \\
\hline ID & IDAHO & 96.6 & 96.6 & OR & OREGON & 103.2 & 107.2 \\
\hline $\mathrm{IL}$ & ILLINOIS & 91.7 & 101.2 & PA & PENNSYLVANIA & 93.5 & 104.3 \\
\hline IN & INDIANA & 89.9 & 96.8 & $\mathrm{RI}$ & RHODE ISLAND & 101.5 & 110.4 \\
\hline $\mathrm{IA}$ & IOWA & 93.2 & 97.3 & $\mathrm{SC}$ & SOUTH CAROLINA & 86.6 & 96.2 \\
\hline $\mathrm{KS}$ & KANSAS & 91.2 & 93.1 & SD & SOUTHDAKOTA & 96.0 & 98.1 \\
\hline $\mathrm{KY}$ & KENTUCKY & 89.9 & 97.4 & TN & TENNESSEE & 85.8 & 94.3 \\
\hline$L A$ & LOUISIANA & 95.6 & 99.5 & $T X$ & TEXAS & 90.8 & 101.3 \\
\hline $\mathrm{ME}$ & MAINE & 103.4 & 111.4 & UT & UTAH & 94.9 & 98.0 \\
\hline $\mathrm{MD}$ & MARYLAND & 95.5 & 104.8 & VT & VERMONT & 101.6 & 108.5 \\
\hline $\mathrm{MA}$ & MASSACHUSETTS & 101.5 & 110.4 & VA & VIRGINIA & 88.8 & 102.9 \\
\hline $\mathrm{MI}$ & MICHIGAN & 95.6 & 98.7 & WA & WASHINGTON & 90.7 & 104.1 \\
\hline $\mathrm{MN}$ & MINNESOTA & 91.4 & 104.2 & WI & WISCONSIN & 89.6 & 97.7 \\
\hline $\mathrm{MS}$ & MISSISSIPPI & 88.3 & 88.3 & WV & WEST VIRGINIA & 95.5 & 106.8 \\
\hline $\mathrm{MO}$ & MISSOURI & 83.6 & 94.0 & WY & WYOMING & 95.2 & 96.5 \\
\hline
\end{tabular}

For the hauling-time cost, the average is $\$ 4.00 / \mathrm{hr} / \mathrm{dry}$ tonne ${ }^{*}$ which is equivalent to $\$ 3.64 / \mathrm{hr} /$ ton. If the average truck speed is $\mathrm{V} \mathrm{mph}$, and the distance is $\mathrm{L}$, the hauling time-cost is

$$
\mathrm{C}_{\mathrm{ht}}=3.64 \mathrm{~h}=3.64 \frac{\mathrm{L}}{\mathrm{V}}
$$

Where $h$ is one-way driving time in hours, and $C_{h t}$ is $\$ /$ dry ton.

\footnotetext{
" The word "tonne" stands for metric tonne which is $1,000 \mathrm{~kg}$ or approximately $2,200 \mathrm{lbs}$.
} 
For the loading/unloading cost, the average rate found was approximately $\$ 3.00 /$ dry tonne which is equivalent to $\$ 2.73 /$ dry ton. For a one-way distance of $L$, this yields

$$
\mathrm{C}_{\mathrm{lu}}=2.73 \text { (\$/dry ton) }
$$

Combination of the three cost components yields

$$
\begin{aligned}
& C_{t}=0.0732 L+3.64 \frac{L}{V}+2.73 \\
& =\left(0.0732+\frac{3.64}{V}\right) L+2.73
\end{aligned}
$$

where $C_{t}$ is total transportation cost of biomass fuel by truck $\$ / T$ (dollars per dry ton) for any transportation distance $\mathrm{L}$ in miles, and $\mathrm{V}$ is in mph. Note that the Tennessee study is based on one-way transportation distance, assuming that the truck is empty on the return trip.

\begin{tabular}{|c|c|c|c|c|}
\hline \multirow{3}{*}{$\begin{array}{c}\text { Transportation } \\
\text { Distance, } \\
L \\
\text { (Miles) }\end{array}$} & \multicolumn{2}{|c|}{$\begin{array}{c}\text { Unit Transportation Cost; } \\
\mathrm{C}_{t} \\
(\$ / \mathrm{dry} \text { ton })\end{array}$} & \multicolumn{2}{|c|}{$\begin{array}{c}\text { Unit-Distance Transportation Cost } \\
C_{t} / L \\
(\$ / \text { mile } / \text { dry ton })\end{array}$} \\
\hline & $V=50 \mathrm{mph}$ & $V=30 \mathrm{mph}$ & $V=50 \mathrm{mph}$ & $V^{\prime}=30 \mathrm{mph}$ \\
\hline & (Class-I Road) & (Class-II \& -III Road) & (Class I Road) & (Class-II \& -III Road) \\
\hline 0 & 2.73 & 2.73 & $\infty$ & $\infty$ \\
\hline 10 & 4.19 & 4.68 & 0.419 & 0.468 \\
\hline 20 & 5.65 & 6.62 & 0.283 & 0.331 \\
\hline 30 & 7.11 & 8.57 & 0.237 & 0.286 \\
\hline 40 & 8.57 & 10.51 & 0.214 & 0.263 \\
\hline 50 & 10.03 & 12.46 & 0.201 & 0.249 \\
\hline 60 & 11.49 & 14.40 & 0.192 & 0.240 \\
\hline 70 & 12.95 & 16.35 & 0.185 & 0.234 \\
\hline 80 & 14.41 & 18.29 & 0.180 & 0.229 \\
\hline 90 & 15.87 & 20.24 & 0.176 & 0.225 \\
\hline 100 & 17.33 & 22.18 & 0.173 & 0.222 \\
\hline
\end{tabular}

Table B.2. Unit Transportation Price $C_{t}$ by Truck as a Function of Distance $L$, and Transportation Speed V, Calculated from Eq. (B.1.4)

Based on $\mathrm{V}=50 \mathrm{mph}$ for Class-I roads, and $\mathrm{V}=30 \mathrm{mph}$ for Class-II and Class-III roads, the values of $\mathrm{C}_{\mathrm{t}}$ (\$/ton) for different distances ranging from 0 to 100 miles are calculated here and listed in Table B.2. The corresponding values of the unit-distance transportation $\cos t, \mathrm{C}_{\mathrm{t}} / \mathrm{L}$ ( $\$ /$ mile/ton), are also listed. It can be seen that the latter $\left(C_{t} / L\right)$ increases rapidly when the distance is short. For instance, at large distances (say $\mathrm{L}=100$ miles), $\mathrm{C}_{\mathrm{t}} / \mathrm{L}$ is of the order of $\$ 0.17$ to $0.22 /$ ton $/$ mile, whereas at small distances (say, $\mathrm{L}=10$ miles), $\mathrm{C}_{\mathrm{t}} / \mathrm{L}$ increases to $\$ 0.42$ to $0.47 /$ ton $/ \mathrm{mile}$. The value of $\mathrm{C}_{\mathfrak{l}} / \mathrm{L}$ at $\mathrm{L}=0$ is $\infty$ (infinity).

Comparison of the results based on the Tennessee study and the Antares study shows that they are about the same for relatively large distances. For instance, at 50 and 100 miles, the 
Antares study estimates the cost of transporting municipal solid waste, $C_{t}$, based national average to be respectively $\$ 12.06$ and $\$ 24.11$. This compares with $\$ 12.46$ and $\$ 22.18$ based on the Tennessee study for the average truck speed of $30 \mathrm{mph}$, which corresponds to urban condition.

\section{B.2. Rail Transport Cost}

The CPRC researcher in charge of collecting truck, rail and barge transportation cost data was unable to find any biomass transportation cost data attributable to train and barge transports. Therefore, rates for hauling grain by rail and barge are used as surrogates. They should be approximately the same as for compacted biomass.

The U.S. Department of Agriculture publishes grain transportation costs weekly [10]. Results in the January 11, 2000 report are tabulated in Table B.3. The rates listed in the table are based on unit trains, each of which is comprised of 110 rail cars, with each car carrying approximately 110 tons of grain. The cost will be higher if the train is not unit train. It can be seen from the table that the rates for unit train range from 1.35 to 2.27 cents/TM. The perdistance rates (i.e., unit-distance transportation costs) are valid only for long hauls. As in the case of truck, for short distances the per-distance rates are higher. Assuming that the rates listed in Table B.3 are applicable to biomass, and assuming that the loading/unloading cost for biomass is the same as for truck given in the Tennessee report [9], then $\$ 2.73$ must be added to the transportation cost for each ton of the biomass loaded on a unit train regardless of transportation distance. This means that the following equation holds approximately for densified biomass materials transported by unit train:

$$
\begin{aligned}
& \mathrm{C}_{\mathrm{t}}(\mathrm{Low})=0.0135 \mathrm{~L}+2.73 \\
& \mathrm{C}_{\mathrm{t}}(\text { High })=0.0227 \mathrm{~L}+2.73
\end{aligned}
$$

where $C_{t}$ is in $\$ / T$, and $L$ is in miles. The two above equations predict the lower and the higher bounds of $\mathrm{C}_{\mathrm{t}}$ by unit train. The price charged by railroads for transporting biomass by unit train is expected to be within such a range. 


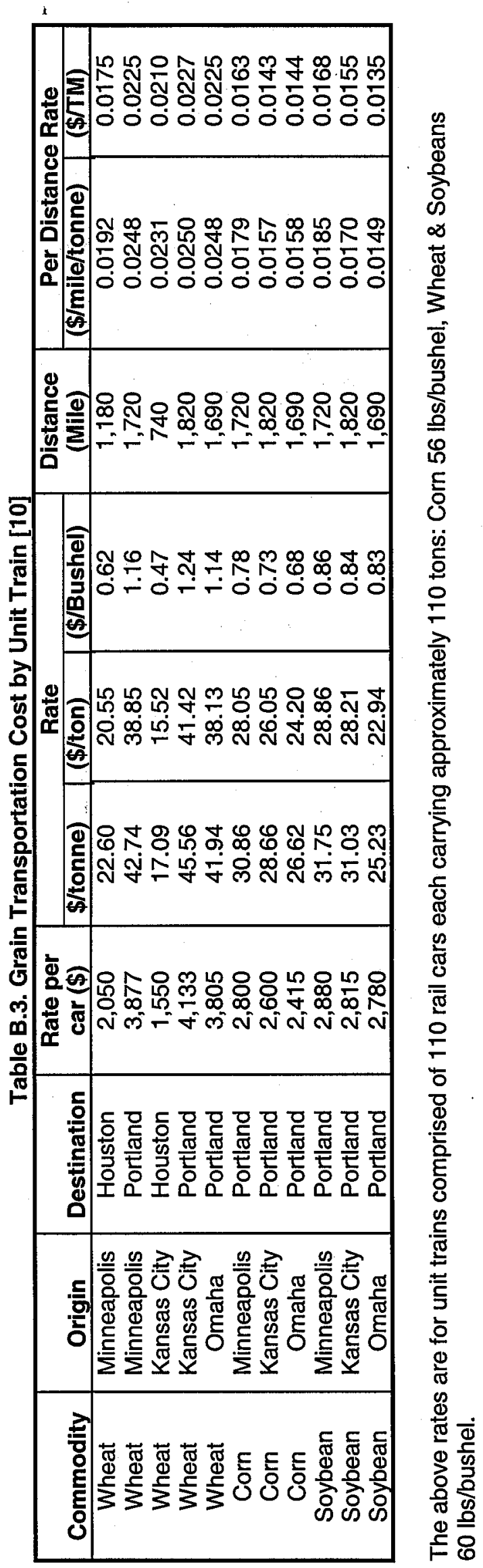




\section{B.3. Barge Transport Cost}

Based on the January 11, 2000 report of the U.S. Department of Agriculture [10], some of the barge rates are listed in Table B.4. As can be seen from the table, the barge rate for long distances (above 410 miles) is between 0.71 and $0.90 \mathrm{cent} / \mathrm{TM}$. This is generally much lower than the rates charged by railroads for unit-train haul.

Adding a $\$ 2.73$ per ton for loading/unloading, and assuming that the cost for transporting biomass by barge is the same as for transporting grain by barge, the expected price for transporting biomass by barge in large quantity is expected to be

$$
\begin{aligned}
& \mathrm{C}_{\mathrm{t}}(\text { Low })=0.0071 \mathrm{~L}+2.73 \\
& \mathrm{C}_{\mathrm{t}}(\text { High })=0.0090 \mathrm{~L}+2.73
\end{aligned}
$$

where $C_{t}$ is in $\$ /$ ton, and $L$ is in miles. The two above equations give the lower and higher bounds of $\mathrm{C}_{\mathrm{t}}$.

Table B.4. Grain Transportation Costs by Barge [10]

\begin{tabular}{|l|l|c|c|c|}
\hline \multicolumn{1}{|c|}{ Origin } & \multicolumn{1}{|c|}{ Destination } & Rate per Ton (\$) & $\begin{array}{c}\text { Distance } \\
\text { (Miles) }\end{array}$ & $\begin{array}{c}\text { Rate } \\
\text { (\$/TM) }\end{array}$ \\
\hline Minneapolis & New Orleans & 12.07 & 1,350 & 0.0089 \\
\hline Cincinnati & New Orleans & 5.91 & 810 & 0.0073 \\
\hline St. Louis & New Orleans & 4.95 & 700 & 0.0071 \\
\hline Memphis & New Orleans & 3.67 & 410 & 0.0090 \\
\hline
\end{tabular}

Note: (1) Barge capacity is 1,500 Tons.

(2) Barge traffic is seasonal. These rates were spot rates for March 1999. March rates were used because it was the first rate available for Minneapolis.

\section{B.4. PCP Transport Cost}

Pneumatic capsule pipeline (PCP) uses wheeled capsules to carry cargo moving through a pipeline. The capsules are propelled by the air moving through the pipeline driven by blowers or fans. The costs for transporting biomass by PCP analyzed here are based on data supplied by the Sumitomo Metal Industries, Ltd., which operates, manufactures and sells commercial PCP systems with air driven by blowers [7]. For this study, a special PCP was designed and analyzed for transporting 676,000 tons/yr of densified biomass (logs) having a bulk specific weight of 40 $\mathrm{lb} / \mathrm{ft}^{3}$. The pipeline diameter chosen is 26 inches. Each capsule weighs $880 \mathrm{lbs}$, and each carries $440 \mathrm{lbs}$ of biomass logs. The system was designed for seven different lengths: $5,10,20,30,50$, 75 and 100 miles. This enables the determination of unit transportation cost as a function of distance or pipeline length. The total capital cost, and the variable (annual) costs including power, personnel, and maintenance, are all listed in Table B.5. 
From the data supplied in Table B.5, and the additional assumption of $\mathrm{N}=30, \mathrm{~N}_{\mathrm{d}}=20, \mathrm{e}_{\mathrm{c}}, \mathrm{e}_{\mathrm{r}}$ and $\mathrm{I}$ are all equal to $3 \%, \mathrm{e}_{\mathrm{p}}=2 \%, \mathrm{e}_{\mathrm{i}}=0.5 \%, \mathrm{t}=37 \%$, and $\mathrm{r}=15 \%$, the present prices for unit transportation, $\mathrm{U}_{0}$, for the seven distances were calculated using the model discussed in Section 3. The results are listed in the last column of Table B.5.

Table B.5 PCP Transportation Analysis

\begin{tabular}{|c|c|c|c|c|}
\hline $\begin{array}{c}\text { Transportation } \\
\text { Distance } \\
\text { (Miles) }\end{array}$ & $\begin{array}{c}\text { Capital } \\
\text { Cost (M\$) }\end{array}$ & $\begin{array}{c}\text { O/M } \\
\text { Cost (M\$) }\end{array}$ & $\begin{array}{c}\text { Annual Property Tax } \\
\text { \& Insurance } \\
\text { (M\$) }\end{array}$ & $\begin{array}{c}\text { Unit Freight } \\
\text { Transportation } \\
\text { Price (\$/T) }\end{array}$ \\
\hline 5 & 16.05 & 0.559 & 0.401 & 7.16 \\
\hline 10 & 24.73 & 0.744 & 0.618 & 10.86 \\
\hline 20 & 45.82 & 1.241 & 1.146 & 19.92 \\
\hline 30 & 66.96 & 1.694 & 1.674 & 28.93 \\
\hline 50 & 109.23 & 2.780 & 2.731 & 47.21 \\
\hline 75 & 163.95 & 4.094 & 4.099 & 70.75 \\
\hline 100 & 214.93 & 5.269 & 5.373 & 92.61 \\
\hline
\end{tabular}

\section{B.5 HCP Transport Cost}

Hydraulic capsule pipeline (HCP) uses unwheeled capsules to carry cargoes moving through a water-filled pipeline. The water moving through the pipe provides buoyancy and the lift needed for suspending (levitating) the capsules in the pipe, and provides the thrust to transport the capsules through the pipe. HCP is a new technology studied initially in Canada at the Alberta Research Council in the 1960s and 1970s [11]. Then the interest spread around the world, as demonstrated by research conducted in many nations. The technology was studied extensively at the University of Missouri-Columbia (UMC), in the last two decades. In 1991, the National Science Foundation (NSF) awarded a research center to UMC-the Capsule Pipeline Research Center (CPRC)-to develop HCP, PCP, and CLP (Coal Log Pipeline) [12].

The economics of HCP for transporting coal and grain has been established through previous studies $[3,13]$. In these previous studies, it was found that due to the need of containers to protect the cargoes transported by $\mathrm{HCP}$ in a water-filled pipe, and the need for a separate pipeline to return empty capsules, rigid-container-type HCP can be economical only if the freight throughput and pipe diameter are large (over $1 \mathrm{MT} / \mathrm{yr}$. using pipes larger than 1 foot in diameter) and when the distance is long (over 20 miles) [13]: Since the quantity of biomass that needs to be transported in each case is generally much less than the quantity of coal and grain that needs to be transported, it is quite questionable that HCP can compete with truck, train or barge for transporting biomass. Nonetheless, a preliminary assessment has been conducted herein to 
determine the economic feasibility of using HCP to transport biomass. The study was done in the same manner as for PCP, using similar assumptions and the same rate of return-15\%.

Table B.6 lists the assumptions and parameters used for the HCP study; Table B.7 lists the capital cost of the system and how the total capital cost for each distance was determined; Table B. 8 lists the annual (operation/maintenance/insurance/tax) cost of the system and how the total annual cost for each distance was determined; and finally, Table B.9 shows the unit freight transportation costs calculated for various throughputs and transportation distances.

Table B.6 Transportation of Municipal Solid Waste by HCP: Design Considerations $\left(V_{c}=6 \mathrm{ft} / \mathrm{s}, S_{c}=1.02, \alpha=0.90, \beta=60 \%, n_{0}=360, \gamma_{\max }=200 \mathrm{psi}\right.$, using LIM pumps

\begin{tabular}{|c|c|c|c|c|c|}
\hline \multirow{2}{*}{ Item } & \multicolumn{5}{|c|}{ Pipe Diameter } \\
\hline & $1 \mathrm{ft}$ & $1.5 \mathrm{ft}$ & $2 \mathrm{ft}$ & $2.5 \mathrm{ft}$ & $3 \mathrm{ft}$ \\
\hline Water Throughput (cfs) & 0.94 & 2.1 & 3.7 & 5.8 & 8.4 \\
\hline Freight Throughput (MT/yr.) & 2.0 & 4.5 & 8.0 & 12.5 & 18.0 \\
\hline Pressure Gradient (psi/mile) & 22 & 16.1 & 1.2 & 11.5 & 10.6 \\
\hline Distance between pumping stations (miles) & 9.0 & 12.4 & 15.2 & 17.4 & 19.0 \\
\hline Number of pumping stations in 100 miles & 11 & 8 & 7 & 6 & 5 \\
\hline Installed power (kw/station) & 248 & 562 & 1,013 & 1,738 & 2,305 \\
\hline Power for pumping ( $\mathrm{kw} / 100$ miles) & 2,890 & 4,800 & 6,940 & 9,420 & 12,500 \\
\hline
\end{tabular}

Table B.7 Capital Cost of Components of LIM-Driven HCP for Transporting Municipal Solid Waste

\begin{tabular}{|c|c|c|c|c|c|c|}
\hline \multirow{2}{*}{\multicolumn{2}{|c|}{ Component }} & \multicolumn{5}{|c|}{ Pipe Diameter } \\
\hline & & $1 \mathrm{ft}$ & $1.5 \mathrm{ft}$ & $2 \mathrm{ft}$ & $2.5 \mathrm{ft}$ & $3 \mathrm{ft}$ \\
\hline \multicolumn{2}{|c|}{ Inlet/Outlet Facilities, $\mathrm{C}_{1}(\$ \mathrm{M})$} & 15 & 21 & 26 & 31 & 36 \\
\hline \multirow{2}{*}{$\begin{array}{l}\text { Pipe Cost, } \mathrm{C}_{2} \\
\text { (\$M/100 miles) }\end{array}$} & Single line & 28 & 43 & 59 & 76 & 94 \\
\hline & Dual line & 45 & 69 & 94 & 122 & 150 \\
\hline \multicolumn{2}{|c|}{ Capsule Cost, $\mathrm{C}_{3}(\$ \mathrm{M} / 100$ miles) } & 112 & 172 & 236 & 304 & 376 \\
\hline \multirow{2}{*}{$\begin{array}{l}\text { LIM Pump Cost } C_{4} \\
\text { (\$M/100 miles) }\end{array}$} & Single Line & 2.9 & 4.8 & 6.9 & 9.4 & 12.5 \\
\hline & Dual Line & 5.8 & 9.6 & 13 & 19 & 25 \\
\hline
\end{tabular}

Note: 1) Total Capital Cost $=C_{1}+\frac{L}{100}\left(C_{2}+C_{3}+C_{4}\right)$, where $L$ is the pipeline length in miles.

2) LIM stands for "linear induction motor" which is a special electromagnetic capsule pump for HCP and PCP. 
Table B.8 Annual Cost of Transporting Municipal Solid Waste by a LIM-Driven HCP

\begin{tabular}{|c|c|c|c|c|c|c|}
\hline \multirow{2}{*}{\multicolumn{2}{|c|}{ Cost Item }} & \multicolumn{5}{|c|}{ Pipe Dlameter } \\
\hline & & $1 \mathrm{ft}$ & $1.5 \mathrm{ft}$ & $2 \mathrm{ft}$ & $2.5 \mathrm{ft}$ & $3 \mathrm{ft}$ \\
\hline \multicolumn{2}{|c|}{ Encapsulation Cost, $\mathrm{C}_{1}^{\prime}$ (\$M/yr.) } & 6 & 12 & 20 & 28 & 36 \\
\hline \multicolumn{2}{|c|}{ Salary $\mathrm{C}_{2}^{\prime}(\$ M / y r)}$. & 0.5 & 0.6 & 0.7 & 0.8 & 0.9 \\
\hline \multirow{2}{*}{$\begin{array}{l}\text { Power, } \mathrm{C}_{3}^{\prime} \\
(\$ \mathrm{M} / \mathrm{yr} . / 100 \text { miles })\end{array}$} & Single Line & 1.5 & 2.5 & 3.6 & 4.9 & 6.5 \\
\hline & Dual LIne & 3.0 & 5.0 & 7.2 & 9.8 & 13 \\
\hline
\end{tabular}

Table B.9 Unit Freight Transportation Cost by Double-Line HCP Using LIM Pumps

\begin{tabular}{|c|c|c|c|c|c|}
\hline \multirow{2}{*}{$\begin{array}{c}\text { Transport } \\
\text { Distance } \\
\text { (Miles) }\end{array}$} & \multicolumn{5}{|c|}{ Freight Throughput (MT/yr.) } \\
\cline { 2 - 6 } & $\mathbf{2 . 0}$ & $\mathbf{4 . 5}$ & $\mathbf{8 0}$ & $\mathbf{1 2 . 5}$ & $\mathbf{1 8 . 0}$ \\
\cline { 2 - 6 } & $\mathbf{5}$ & $\mathbf{1 . 5}$ & $\mathbf{2}$ & $\mathbf{2 . 5}$ & $\mathbf{3}$ \\
\hline 5 & 6.2 & 4.7 & 4.0 & 3.4 & 3.0 \\
\hline 10 & 7.2 & 5.4 & 4.5 & 3.9 & 3.4 \\
\hline 20 & 9.3 & 6.9 & 5.6 & 4.8 & 4.2 \\
\hline 30 & 11.5 & 8.3 & 6.8 & 5.7 & 5.0 \\
\hline 50 & 15.7 & 11.3 & 9.0 & 7.6 & 6.6 \\
\hline 75 & 21.1 & 14.9 & 11.9 & 10.0 & 8.7 \\
\hline 100 & 26.4 & 18.6 & 14.7 & 12.4 & 10.7 \\
\hline
\end{tabular}

(Note: The numbers in the table, other than the boldfaced column headings, are unit freight transportation costs in $\$ / T$-dollars per ton)

\section{B.6 Comparison Between Modes}

Based on the foregoing analyses of various modes, a comparison can be made between different modes for the unit cost (price) of transporting biomass logs. First, the three conventional freight transport modes-truck, train and barge-will be compared and co-listed in Table B.10.

It can be seen from Table B.10 that there is little difference in the unit cost when the transportation distance is very short-below 5 miles. At such short distances, the transportation cost is mainly for loading and unloading at the terminals, which are about the same for different modes. However, as the distance becomes long (say, 100 miles), barge is definitely by far the most economical way to transport biomass logs, provided that a navigable waterway exists between the source of the biomass and the destination of the logs. Second to barge is train, provided that a railroad links the biomass source to the biomass log fuel (BLF) destination. When barge and railroad do not exist between the source and the destination, truck will be the only mode available in most cases. 
Table B.10. Comparison of Unit Transportation Cost (Price) for Biomass Logs Transported by Truck, Train and Barge

\begin{tabular}{|c|c|c|c|}
\hline \multirow{2}{*}{$\begin{array}{c}\text { Transportation } \\
\text { distance, } L \\
\text { (miles) }\end{array}$} & \multicolumn{3}{|c|}{ Unit transportation price, $\mathbf{U}_{\mathbf{0}}(\mathbf{\$} / \mathbf{T})$} \\
\cline { 2 - 4 } & Truck & Unit train & Barge \\
\hline 0 & 2.73 & 2.73 & 2.73 \\
\hline 5 & $3.46-3.70$ & $2.82-2.84$ & $2.77-2.78$ \\
\hline 10 & $4.19-4.68$ & $2.87-2.96$ & $2.80-2.82$ \\
\hline 20 & $5.65-6.62$ & $3.00-3.18$ & $2.87-2.91$ \\
\hline 30 & $7.11-8.57$ & $3.14-3.41$ & $2.94-3.00$ \\
\hline 50 & $10.03-12.46$ & $3.41-3.87$ & $3.09-3.18$ \\
\hline 75 & $13.68-17.32$ & $3.74-4.43$ & $3.26-3.41$ \\
\hline 100 & $17.33-22.18$ & $4.08-5.00$ & $3.44-3.63$ \\
\hline 200 & $31.9-41.6$ & $5.43-7.27$ & $4.15-4.53$ \\
\hline 500 & $75.7-100$ & $9.48-14.08$ & $6.28-7.23$ \\
\hline 1,000 & $149-197$ & $16.23-25.43$ & $9.83-11.73$ \\
\hline
\end{tabular}

From the foregoing analyses and from Table B.11, both HCP and PCP systems that require dual pipeline to return empty capsules are not cost-effective as compared to truck, train or barge, except for the cases of very large systems that can transport more than $1 \mathrm{MT} / \mathrm{yr}$. In spite of that, because HCP and PCP are environmentally more friendly and much safer than truck, they may still be preferred in places where truck is not welcome or allowed. The relatively high unit price for PCP is most likely due to its high capital cost stemming from use of large diameter pipe-approximately $\$ 3$ million per mile, and the low throughput, due to low linefill rate. The cost-effectiveness of the system can be much improved if the throughput is drastically increased, as by using linear induction motor (LIM) instead of blowers to drive the system. This is beyond the scope of this investigation, and is being pursued in a separate study at CPRC sponsored by the Sumitomo Metal Industries, Ltd. 
Table B.11. Comparison of Unit Freight Transportation Cost for Hauling Solid Waste by Truck, PCP, HCP and CLP MT/yr.)

\begin{tabular}{|c|c|c|c|c|c|c|c|}
\hline \multirow{2}{*}{$\begin{array}{c}\text { Transport } \\
\text { Distance } \\
\text { (miles) }\end{array}$} & \multirow{2}{*}{$\begin{array}{l}\text { Truck } \\
\text { (\$iton) }\end{array}$} & \multirow{2}{*}{$\begin{array}{l}\text { PCP* } \\
\text { (\$/ton) }\end{array}$} & \multicolumn{5}{|c|}{$\begin{array}{c}\text { HCP (\$/ton) } \\
\text { Pipe Diameter (ft) }\end{array}$} \\
\hline & & & 1 & 1.5 & 2 & 2.5 & 3 \\
\hline & & & \multicolumn{5}{|c|}{ Throughput (MT/yr) } \\
\hline & & & 2.0 & 4.5 & 8.0 & 12.5 & 18.0 \\
\hline 5 & 3.6 & 7.2 & 6.2 & 4.7 & 4.0 & 3.4 & 3.0 \\
\hline 10 & 4.4 & 10.9 & 7.2 & 5.4 & 4.5 & 3.9 & 3.4 \\
\hline 20 & 6.1 & 19.9 & 9.3 & 6.9 & 5.6 & 4.8 & 4.2 \\
\hline 30 & 7.8 & 28.9 & 11.5 & 8.3 & 6.8 & 5.7 & 5.0 \\
\hline 50 & 11.2 & 47.2 & 15.7 & 11.3 & 9.0 & 7.6 & 6.6 \\
\hline 75 & 15.5 & 70.8 & 21.1 & 14.9 & 11.9 & 10.0 & 8.7 \\
\hline 100 & 19.8 & 92.6 & 26.4 & 18.6 & 14.7 & 12.4 & 10.7 \\
\hline
\end{tabular}

"The cost for PCP was calculated for a system that transports only 0.68 MT/yr (million tons per year). Larger throughput will be more economical. 


\section{APPENDIX C. BIOMASS HANDLING COST AT POWER PLANTS}

The cost for handling biomass at power plants, including both crushing and storage, depends not only on throughput but also on the transportation method-whether the logs are shipped to the plant by truck, train or pipeline. Since truck is the most common method of transportation, the cost analyzed here will be based on truck delivered biomass logs. For a typical plant, the biomass logs will be delivered by trucks to the crushers. The crushed logs are then stored in a large silo prior to combustion. The costs for crushing and storage are first assessed separately, and then combined to determine the unit cost of handling biomass logs at power plants, in $\$ /$ ton.

\section{C.1. Log Crushing Cost at Power Plant}

For simplicity, it is assumed that the cost of crushing biomass logs at a power plant is the same as that of crushing coal logs of the same quantity under similar conditions. This assumption is conservative, and convenient because it allows us to use the coal log crushing cost figures reported in "Economic Analysis of Coal Log Pipeline Transportation of Coal," CPRC Report No. 95-1, University of Missouri-Columbia, 1995 [4].

Based on the information given in the aforementioned CPRC report, and adjusted for an average annual inflation rate of $3 \%$ between 1995 and 2,000, the capital cost for the crushing facility can be estimated from

$$
\mathrm{C}_{\mathrm{cr}}=\mathrm{C}_{\mathrm{o}}\left(95+0.0192 \mathrm{Q}^{1.315}\right)
$$

Where $\mathrm{C}_{\mathrm{cr}}$ is the crusher facility cost in thousand dollars; $\mathrm{Q}$ is the throughput of biomass logs in tons/hour; and $\mathrm{C}_{0}$ is 2.32 for $\mathrm{Q}$ less than 735 tons per hour.

From Eq. (C.1), the capital cost for crushing biomass logs in the 675,000 tons/yr (81 tons $/ \mathrm{hr}$ ) plant is $\$ 235,000$. Multiplying this figure by 1.5 to cover installation yields $\$ 353,000$.

The annual (operation/maintenance) cost for the crusher depends on the electrical power used which in turn can be estimated from:

$$
\mathrm{P}_{\mathrm{cr}}=11.6+0.29 \mathrm{Q}^{0.934}
$$

where $\mathrm{Q}$ is the throughput in tons $/ \mathrm{hr}$; and $\mathrm{P}_{\mathrm{cr}}$ is the electric power used in $\mathrm{kw}$. For the 81 tons $/ \mathrm{hr}$ case, $P_{c r}=292 \mathrm{kw}$. At 6 cents per kwh rate, the cost per hour is $\$ 1.75$ per hour, or $\$ 14,700$ per year.

Assuming that 3 persons are needed to watch the operations of the crusher and related operations at the power plant, and each is paid $\$ 50,000$ (including fringe benefits), the salary cost is $\$ 150,000$ per year. 
Adding the salary cost to the power cost yields an annual cost of $\$ 170,000$. Including other miscellaneous operational costs, the total annual cost for crushing the BLF at power plants is estimated at $\$ 200,000$ per year.

\section{C.2. Log Storage Facility Cost at Power Plant}

Because biomass is to be burned at a coal-fired power plant, and because the plant can operate either without biomass or with any amount of biomass up to $20 \%$ of the total fuel, the amount of biomass fuel used at any given time may vary from 0 to $20 \%$ without significant impact on the power plant operation. This flexibility makes it unnecessary to store a large amount of biomass logs at the plant, which saves storage cost. In this analysis, it is assumed that a one-day (24-hour) storage of biomass in a large silo is needed, and the logs can be delivered to the silo from the truck via a conveyor belt.

Because the throughput of this large biomass log production plant is 675,000 tons per year or 1,930 tons per day ( 24 hours), at the bulk specific weight of $40 \mathrm{lbs} / \mathrm{ft}^{3}$, the logs made in one day occupy a volume of $97,000 \mathrm{ft}^{3}$ approximately. This volume of logs can be contained in three large silos designed by the A.O. Smith Engineered Storage Products Company, with each silo having the storage capacity of $35,000 \mathrm{ft}^{3}$-see quotes in Appendix $\mathrm{E}$. The quoted price for three of such silos, including freight and erection, is $\$ 98,900 \times 3=\$ 296,700$ or approximately $\$ 300,000$. Adding another $\$ 50,000$ for conveyor belts yields $\$ 350,000$. This will be used as the cost of the storage facility (silo) at the power plant. This cost is conservative because if one uses a single large silo instead of three silos, the cost will be somewhat reduced.

\section{C.3. Unit Cost for BLF Handling at Power Plant}

Combining the capital cost and annual cost listed in C.1 (for crushing) and C.2 (for storage), and assuming that they decrease linearly with size, the unit cost for biomass handling at a power plant is calculated at different throughputs and listed in Table C.1. It can be seen from Table C.1 that the unit cost of log handling at power plant, including both crushing (size reduction) and storage in silos is approximately $0.53 /$ ton, over a wide range of throughputs. This shows that the unit cost for keeping biomass logs at power plants is much smaller than the cost of log production and trucking.

Table C.1 Capital cost, Annual Cost, and Unit Cost of Biomass Handling at Power Plant

\begin{tabular}{|c|c|c|c|}
\hline $\begin{array}{c}\text { Throughput Q } \\
\text { (tons/yr) }\end{array}$ & $\begin{array}{c}\text { Total Capital } \\
\text { Cost }(\mathbf{\$ 1 , 0 0 0 )}\end{array}$ & $\begin{array}{c}\text { Total Annual Cost } \\
\mathbf{( \$ 1 , 0 0 0 / y r )}\end{array}$ & $\begin{array}{c}\text { Unit Cost } \\
\text { (\$/ton) }\end{array}$ \\
\hline 675,000 & 703 & 200 & 0.53 \\
\hline 540,000 & 562 & 160 & 0.53 \\
\hline 405,000 & 422 & 120 & 0.53 \\
\hline 270,000 & 281 & 80 & 0.53 \\
\hline 135,000 & 141 & 40 & 0.54 \\
\hline
\end{tabular}




\section{APPENDIX D. COMPUTER PROGRAMS}

The same computer program attached here was used to compute the unit costs of biomass log production at the source, transportation of logs to power plants, and handling of logs at the plant. 
Visual Basic Program for Computation of the Unit Cost for Biomass Log Production, Transportation, and Handling at Power Plant

(Revised April 20, 2000)
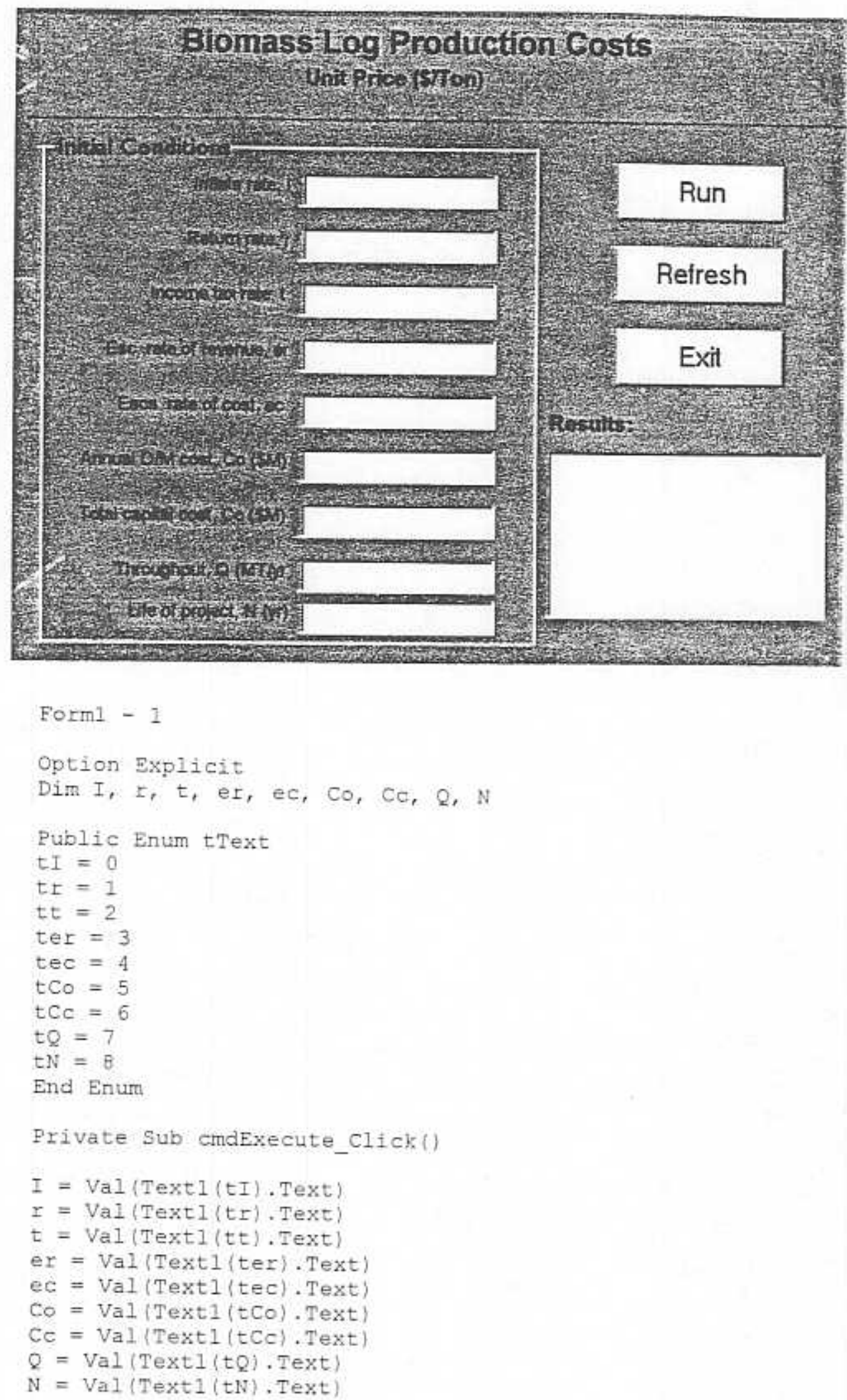


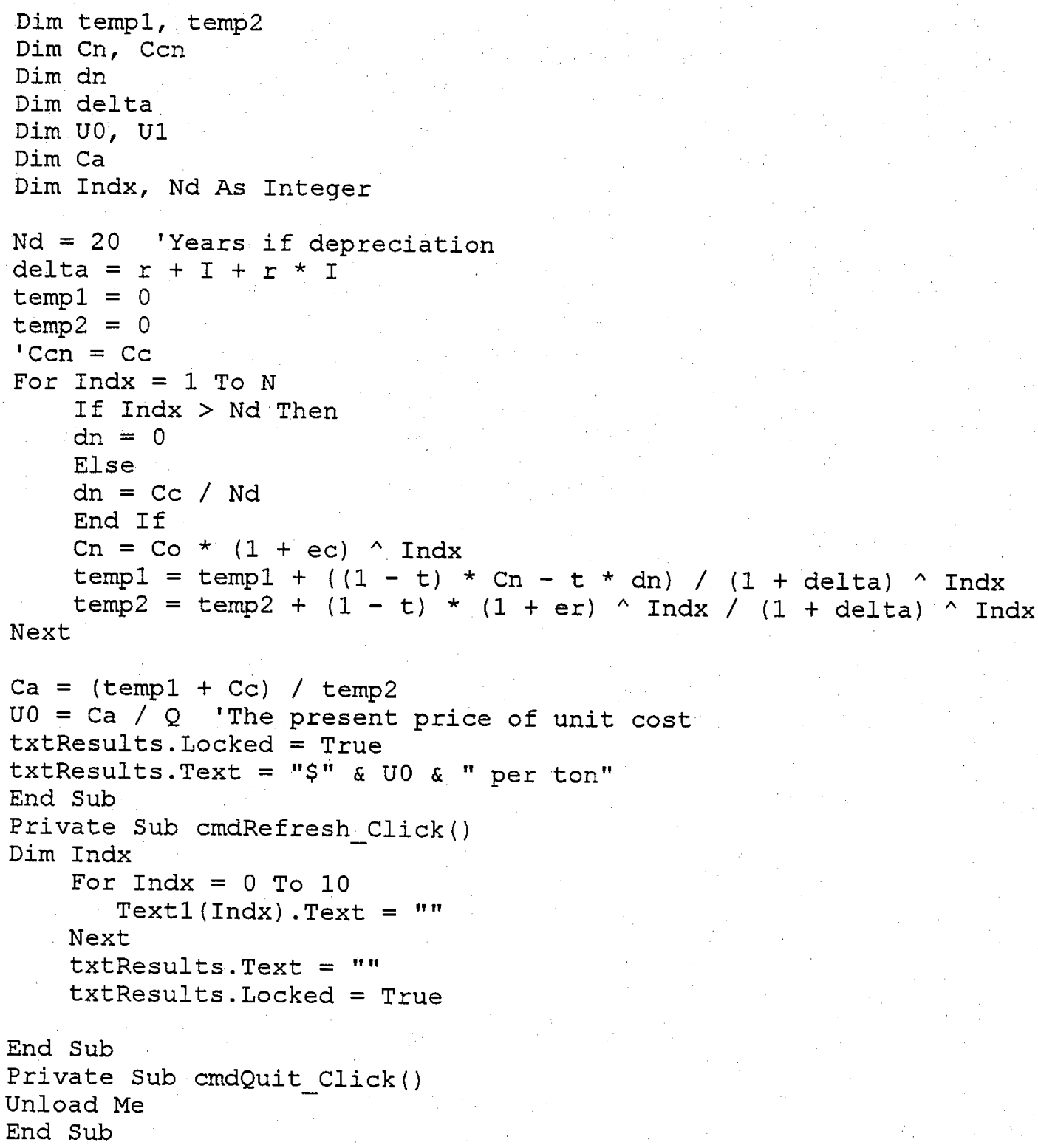

End Sub

Private sub cmdQuit_Click()

Unload Me

End sub 


\section{APPENDIX E. COST DATA}

This appendix lists all the collected information that has been or can be used in cost analysis for biomass fuel production and transportation costs. They are listed in a somewhat arbitrary manner. 


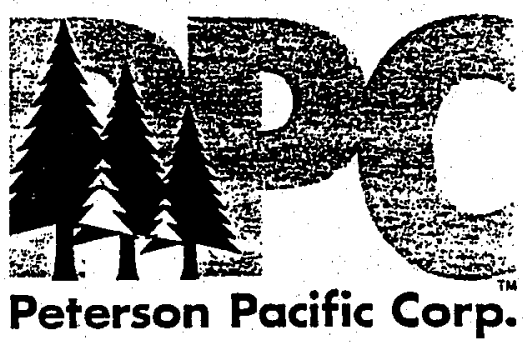

January 11,2000

University of Missouri

Attn: Bill Burkett

Engineering Bldg East 2421

Columbia MO 65211

\section{SUBJECT: PETERSON PACIFIC WOOD WASTE RECYCLERS \& TROMMEL SCREEN}

Thank you for your interest in the Peterson Pacific product line.

Our newest recycler, the Model HC5400, is a mid-sized grinder that handles high volume applications and is easy to feed and operate. The larger Model HC7400 has exceeded our expectations in production and capacity. Organic material processors will find it is particularly suited for processing greenwaste, land clearing debris, and construction debris. The Model HC2400 horizontal feed recycler features a $330-460$ hp engine, and continuous horizontal feed. Primarily designed for medium duty and production of green waste and scrap wood. Production rates up to 45 tons per hour have been observed for this $40,000 \mathrm{lb}$. machine.

Introduced recently, the Model TS 725 Mobile Trommel Screen classifies material into either two or three seperate size grades. With this heavy-duty portable machine, we offer a wide range of conveyors and screen opening sizes. The 12 cubic yard hopper and 60 inch wide "load-sensing" feed conveyor yields up to 300 cubic yards of material per hour. This machine is designed for use by recycling yards, contractors, landfills, municipalities, and other organic material processors.

Peterson Pacific manufactures equipment exclusively for timber and waste processing. The primary models delimb, debark and chip small whole trees for pulp chips. We have approximately 350 machines in service of the several models manufactured in our factory.

Other products in production at our factory are:

- Model 4800-DH multiple log delimber-debarker

- Model DDC-5000 complete delimber-debarker-chipper, one-person operation

Please review the specifications enclosed to determine if this equipment applies to your operation. The "Costs of Owning \& Operating" sheets will give you an approximate price for each machine, F.O.B. Eugene, Oregon. For , answers to your questions, please call me at (541)953-7538.

Sincerely,<smiles>[AlH2]</smiles>

Joe Jacobson SE/SC Sales Manager Enctusures: General Brochure w/6 each recycler specs, O\&O all recyclers, "Horizontal Recycler" tape 
PETERSON PACIFIC CORP.

29408 Airport Road

Eugene, OR 97402

(541) $689-6520 \cdot(541) 689-0804$

MODEL HC.2400A

WOOD WASTE RECYCLER

(CAT 460hp Engine)

ESTIMATED OWNING \& OPERATING COSTS

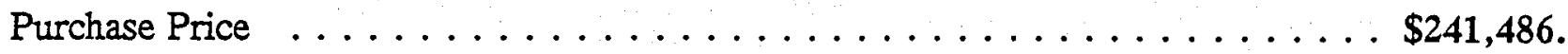

FIXED

COSTS/HR
Depreciation 5 yr. - 10,000 hours @

$90 \% \mathrm{PP}=\$ 217,337 \div 10,000$

Interest $=@ 9.5 \%$ APR $\$ 217,337 .-5 \mathrm{yr}$.

Insurance $=\$ 2460 / \mathrm{yr} \div 2000$ hours

TOTAL FIXED COST
$\$ 21.73 / \mathrm{hr}$

$6.57 / \mathrm{hr}$

$1.23 / \mathrm{hr}$

$\$ 29.53 / \mathrm{hr}$

VARIABLE

Fuel, Oil, Lubes, Filters, etc

Bits

$\$ 12.00 / \mathrm{hr}$

Grates

$2.62 / \mathrm{hr}$

Anvil

$2.56 / \mathrm{hr}$

Misc. rebuild

$1.34 / \mathrm{hr}$

TOTAL VARIABLE COSTS*

$\$ 21.89 / \mathrm{hr}$

*Variable costs figured at 30 tons or 150 cubic yards per hour outfeed.

TOTAL ESTIMATED FIXED \& VARIABLE COSTS PER HOUR

$\$ 51.42 / \mathrm{hr}$

NOTE: All Prices US Funds. All costs are for estimating purposes only and no guarantees are made or implied by Peterson Pacific Corp. 


\section{PETERSON PACIFIC CORP. \\ 29408 Airport Road \\ Eugene, OR 97402 \\ (541) $689-6520$ • (541) 689-0804}

\section{MODEL HC 5400 \\ WOOD WASTE RECYCLER \\ (with 800hp engine option)}

\section{. ESTIMATED OWNING \& OPERATING COSTS}

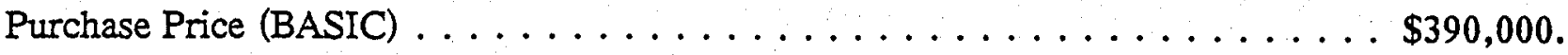

FIXED

COSTS/HR
Depreciation 5 yr. - 10,000 hours @

$90 \% \mathrm{PP}=\$ 351,000 \div 10,000$

Interest $=@ 9 \%$ APR $\$ 351,000-5 \mathrm{yr}$.

Insurance $=\$ 2460 / \mathrm{yr} \div 2000$ hours

TOTAL FIXED COST
$\$ 35.10 / \mathrm{hr}$

$10.02 / \mathrm{hr}$

$1.23 / \mathrm{hr}$

$\$ 46.35 / \mathrm{hr}$
VARIABLE COSTS/HR
Fuel (24 gallons/hr@ @ $\$ 1.00$ per gallon)

Oil, Lubes, Filters, etc.

Bits (28 bits per 100 hours)

Grates

Anvil

TOTAL VARIABLE COSTS
$\$ 24.00 / \mathrm{hr}$

$3.77 / \mathrm{hr}$

$5.21 / \mathrm{hr}$

$2.69 / \mathrm{hr}$

$1.38 / \mathrm{hr}$

$\$ 37.05 / \mathrm{hr}$

TOTAL ESTIMATED FIXED \& VARIABLE COSTS PER HOUR

$\$ 83.40 / \mathrm{hr}$

NOTE: All Prices US Funds. All costs are for estimating purposes only and no guarantees are made or implied by Peterson Pacific Corp. 
PETERSON PACIFIC CORP.

29408 Airport Road

Eugene, OR 97402

(541) $689-6520$ • (541) 689-0804

MODEL HC 7400

WOOD WASTE RECYCLER

\section{ESTIMATED OWNING \& OPERATING COSTS}

Purchase Price

FIXED

COSTS "

VARIABLE COSTS
Depreciation 5 yr. - 10,000 hours @

$90 \% \mathrm{PP}=\$ 422,100 \div 10,000$

Interest $=@ 9.5 \%$ APR $\$ 422,100-5$ yr.

Insurance $=\$ 10,000 / \mathrm{yr} \div 2000$ hours

TOTAL FIXED COST =

Fuel 24 GPH@\$1.25

Oil, lubes, filters, etc.

Cutting Bits - 27 bits per 100 hours

Grates - Varies 250 - $500 \mathrm{hrs} / \mathrm{set}$

Anvil

MAJOR ENGINE REBUILD (VARIES)

MISCELLANEOUS REBUILD

$\$ 11,250 \times 5$ yrs $=\$ 56,250 \div 10,000 \mathrm{hrs}=$ TOTAL VARIABLE COST
$\$ 495,000$.

$\$ 44.55 / \mathrm{hr}$

$13.47 / \mathrm{hr}$

$5.00 / \mathrm{hr}$

$\$ 63.02 / \mathrm{hr}$

$\$ 30.00 / \mathrm{hr}$

$5.25 / \mathrm{hr}$

$7.43 / \mathrm{hr}$

$6.00 / \mathrm{hr}$

$.72 / \mathrm{hr}$

$\underline{5.63 / \mathrm{hr}}$

$\$ 55.03 / \mathrm{hr}$

TOTAL ESTIMATED FIXED \& VARIABLE COSTS PER HOUR

$\$ 118.05 / \mathrm{hr}$

NOTE: All Prices US Funds.

NOTE: All costs are for estimating purposes only and no guarantees are made or implied by Peterson Pacific Corp.

Wpdocs199currentldomesticl1299increaselo\&olo\&07400.495 


\section{Engine/Drive System}

Cummins Model MIIC, 350 hp engine, or

Caterpillar Model 3406, 460 hp engine

Fuel tank capacity: 194 U.S. gallons (734 liters)

Heavy-duty clutch

Rotary screen radiator guard, Cummins

Hydraulic reversing fan with waffle screen, Caterpillar

\section{Feed System}

Speed sensing, automatic reversing feed system

Powered compression roller:

Feed throat: $60 \mathrm{in} .(152 \mathrm{~cm})$ wide $\times 34.5 \mathrm{in} .(88 \mathrm{~cm})$ high

Feed chain: WD-110 wide series, welded steel

Loading height: 93 in. $(236 \mathrm{~cm})$

\section{Hammer Mill Hog}

24 fixed hammers with replaceable tips

\section{Trailer/Frame}

Machine weight: approx. 41,000 lbs. $(18,611 \mathrm{~kg})$, Cummins approx. 45,500 lbs. $(20,654 \mathrm{~kg})$, Caterpillar

Overall travel length: $43 \mathrm{ft.} 1 \mathrm{in.}$ ( 13.13 meters)

Travel width: $8 \mathrm{ft} .6 \mathrm{in.}$ ( 2.59 meters), Cummins

$8 \mathrm{ft} .8$ in. (2.64 meters); Caterpillar

Travel height: $13 \mathrm{ft}$. (3.96 meters), Cummins

$13 \mathrm{ft} .4$ in. (4.06 meters), Caterpillar

Double channel frame

Hopper dimensions: $5 \mathrm{ft}$. wide $\times 17 \mathrm{ft}$. long $(1.52 \mathrm{~m} \times 5.18 \mathrm{~m}$ )

Suspension: Dual axle

Tire size: 255/70R 22.5

\section{Output Production*}

Caterpillar Engine

Green waste: up to $220 \mathrm{cu}$. yds./63 U.S. tons,

( $165 \mathrm{cu} . \mathrm{m} / 57$ metric tons) per hour

Scrap dry wood: up to 262 cu. yds./31 U.S. tons,

(200 cu. $\mathrm{m} / 28$ metric tons) per hour

Cummins Engine

Green waste: up to 165 cu. yds./43 U.S. tons,

(126 cu. $\mathrm{m} / 39$ metric tons) per hour

Scrap dry wood: 197 cu. yds./23 U.S. tons,

(151 cu. $\mathrm{m} / 21$ metric tons) per hour

* actual output may vary due to moisture content, material density, material size, support equipment, and grate size.

\section{Hydraulic System}

Tank capacity: 55 U.S. gallons (208 liters)

Pump: vane and variable displacement pumps

Filter system: Ten micron return filter plus ten

micron breather

Hydraulic cooler, Caterpillar

\section{Safety Mechanisms}

Three emergency shutdown buttons

High heat automatic engine shutdown

Low oil pressure automatic engine shutdown

Non-crushable material release/shutdown system

Break-away anvil/grate system

\section{Options}

Multi-function radio remote control

Feed reverse/stop/forward

Compression roller raise/lower and forward/reverse

Emergency stop

Magnetic head pulley

Radial stacking conveyor

Wide variety of grate configurations available

Specifications subject to change without notice

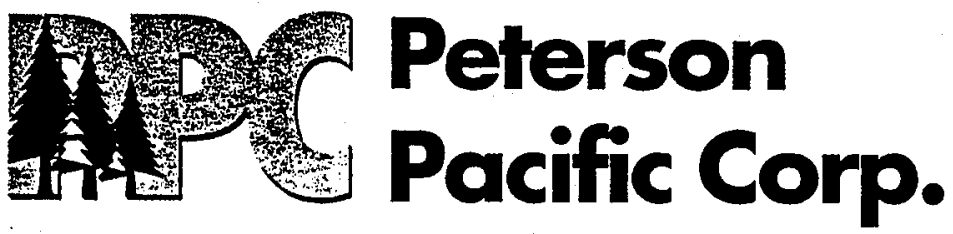

Find out more about the entire Peterson Pacific Corp. producc line at: 


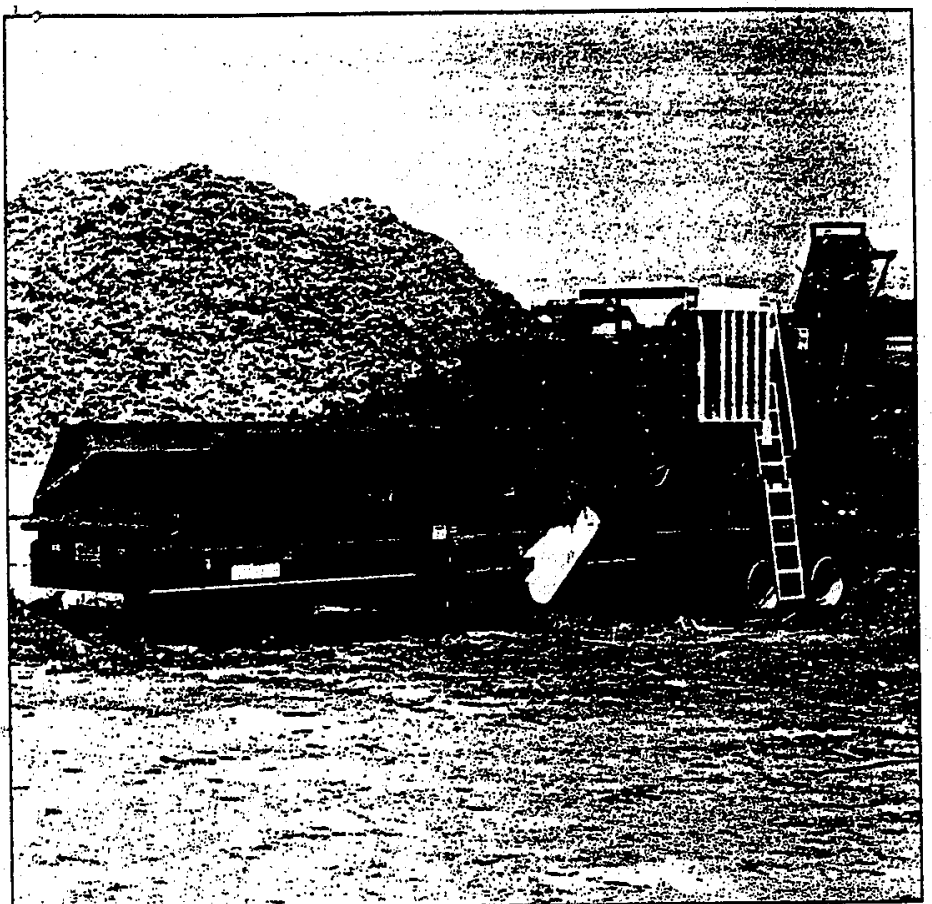

The HC 2400-A complements our family of

Portable Waste Recyclers. With a continuous chain conveyor feed and compression roller to crush material prior to grinding, the $\mathrm{HC} 2400-\mathrm{A}$ excels at processing brushy, bulky materials that bridge or clog up conventional grinders. Our unique rotor design allows the HC 2400-A to process more material per horsepower than any other grinder on the market. Compact and efficient, the $\mathrm{HC} 2400-\mathrm{A}$ can be moved without the need for special permits.
The

HC 2400-A

Portable Heavy

Duty Waste

Recycler

is ideal for

waste wood

processing!

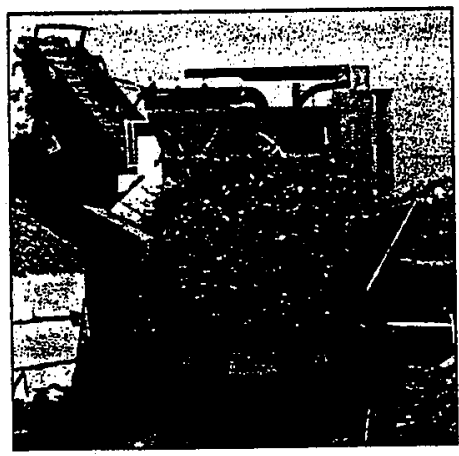

The HC 2400-A transforms mountains of green waste into a pile of organic gold!

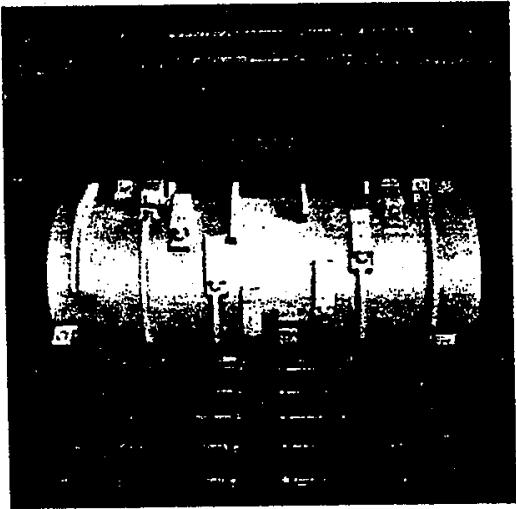

The heavy duty rotor is continuously fed by a chain conveyor.
Highly portable and able to process a wide range of material, the HC 2400-A Portable Heavy Duty Waste Recycler is able to transform problems into solutions!

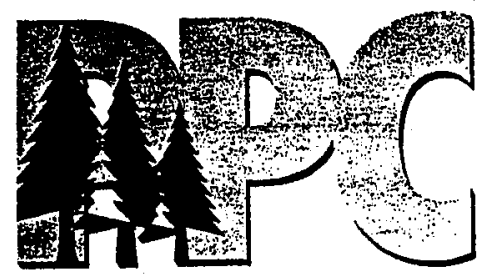

When you want the best, there's really only one choice...

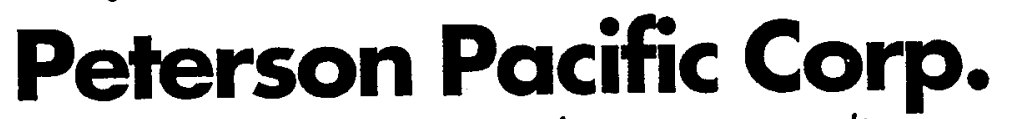
Leading the way... with waste recycling 


\section{Engine/Drive System}

Caterpillar ${ }^{8}$ Model 3408,575 hp engine, or

Caterpillar ${ }^{3}$ Model 3412,800 hp engine

Fuel tank capacity: 200 U.S. gallons (757 liters), $575 \mathrm{hp}$

300 U.S. gallons (1,136 liters), $800 \mathrm{hp}$

Hydraulic drive auto-purge radiator fan

Heavy-duty straddle bearing clutch

\section{Grinder Assembly}

Rotor diameter: $41 \frac{1}{2}$ in. $(105.4 \mathrm{~cm})$

Rotor width: $631 / 8$ in. (160.3 cm)

28 fixed hammers, with two-sided replaceable cutting bits

Wide variety of grate sizes and configurations available

\section{Feed System}

Hopper loading height: $9 \mathrm{ft} .31 / 4$ in. $(2.83 \mathrm{~m})$

Feed throat: $60 \mathrm{in} .(152.4 \mathrm{~cm})$ wide $x 40 \mathrm{in} .(101.6 \mathrm{~cm})$ high

Hydraulically driven, variable speed drag chain feed

conveyor, 60 in. $(1.52 \mathrm{~m})$ wide

Heavy-duty compression roller, automatically adjusts to

material height

\section{Safety Mechanisms}

Two emergency shutdown buttons

High-heat automatic engine shutdown

Low oil pressure automatic engine shurdown

Single shear pin breakaway anvil system with automatic

shutdown

\section{Hydraulic System}

Tank capacity: 150 U.S. gallons (568 liters)

Vane and variable displacement pumps

Filter system: Ten micron retum filtration plus ten

micron breather

Specifications subject to change without notice

\section{Output Capacity*}

$575 \mathrm{hp}$ engine:

Green waste: up to 300 cubic yards or 95 tons

(229 cubic meters or 86 metric tons) per hour

Construction/demolition debris: up to 325 cubic yards or 60 tons

( 248 cubic meters or 54 metric tons) per hour

800 hp engine:

Green waste: up to 350 cubic yards or 97 tons

(268 cubic meters or 88 metric tons) per hour

Construction/demolition debris: up to 500 cubic yards or 75 tons

( 382 cubic meters or 68 metric tons) per hour

* actual output may vary due to moisture content, material density, material size, support equipment, and grate size.

\section{Trailer/Frame}

Machine weight: approx. 69,000 lbs. (31,320 kg), $575 \mathrm{hp}$. approx. $74,750 \mathrm{lbs} .(33,930 \mathrm{~kg}), 800 \mathrm{hp}$

Overall length: $41 \mathrm{ft} .8$ in. (12.7 meters)

Width, North America: $10 \mathrm{fr}$. (3.0 meters)

Travel height, North America: 13 ft. $1 \frac{1}{2}$ in. (4.0 meters)

Hopper dimensions: $5 \mathrm{ft}$. wide $\mathrm{x} 15 \mathrm{ft} .7 \mathrm{in}$. long

$(1.52 \mathrm{~m} \times 4.75 \mathrm{~m})$

\section{Conveyors}

Discharge height: $14 \mathrm{ft} .6$ in. $(4.42 \mathrm{~m})$

Conveyor width:

Primary conveyor: $571 / 2$ in. $(146.0 \mathrm{~cm})$

Secondary conveyor: $36 \mathrm{in} .(91.4 \mathrm{~cm})$

\section{Options}

Radio remote control

Auxiliary air compressor

Magnetic head pulley

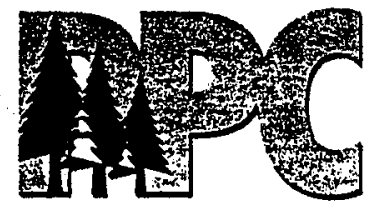

\section{Peterson}



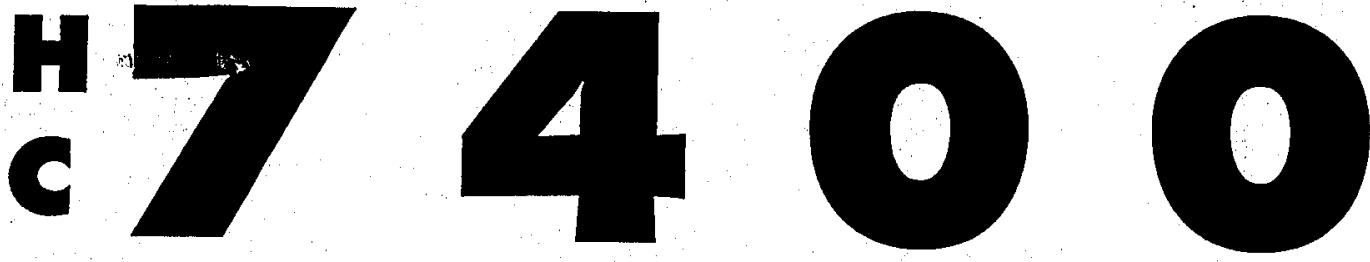

Portable

\section{SPECIFICATIONS}

\section{Engine/Drive System}

Caterpillar ${ }^{B}$ Model 3412,800 hp engine

Fuel tank capacity: 300 U.S. gallons (1,136 liters)

Hydraulic drive auto-purge radiator fan

Heavy-duty straddle bearing clutch

\section{Grinder Assembly}

Rotor shaft: $71 / 2$ in. diameter $(19.1 \mathrm{~cm})$

Rotor diameter: $49 \frac{1}{1} / 2$ in. $(125.7 \mathrm{~cm})$

Rotor width: $723 / 4$ in. $(184.8 \mathrm{~cm}$ )

27 fixed hammers, with two-sided replaceable cutting bits

Wide variety of grate sizes and configurations available

\section{Feed System}

Hopper loading height: $9 \mathrm{ft.} 61 / 2$ in. $(2.9 \mathrm{~m})$

Hydraulically driven, variable speed drag chain feed

conveyor, 72 in. $(1.8 \mathrm{~m})$ wide

Heavy-duty compression roller, automatically adjusts to material height

\section{Safety Mechanisms}

Two emergency shutdown buttons

High-heat automatic engine shutdown

Low oil pressure automatic engine shutdown

Non-crushable material release system with automatic

shurdown

\section{Hydraulic System}

Tank capacity: 150 U.S. gallons (568 liters)

Vane and variable displacement pumps

Filter system: Ten micron return filtration plus ten micron breather
Output Capacity

Green waste: up to 450 cubic yards or 125 tons (334 cubic meters or 113 metric tons) per hour

Stumps, land clearing debris: up to 240 cubic yards or 52 tons (184 cubic meters or 47 metric tons) per hour

Construction/demolition debris: up to 540 cubic yards or 70 tons ( 413 cubic merers or 64 metric tons) per hour

* actual output may vary due moisture content, material density, material size, support equipment, and grate size.

\section{Trailer/Frame}

Machine weight: approx. $88,000 \mathrm{lbs} .(39,945 \mathrm{~kg})$

Overall length: $43 \mathrm{ft}$. (13.1 meters)

Width, North America: 10 ft. 2 in.

Export: 3.0 meters

Travel height, North America: 13 ft. 6 in.

Export: 4.0 meters

Hopper dimensions: $6 \mathrm{ft}$. wide $\times 16 \mathrm{ft} .10 \mathrm{in}$. long $(1.8 \mathrm{~m} \times 5.1 \mathrm{~m})$

\section{Conveyors}

Discharge height, North America: $14 \mathrm{ft} .3^{1 / 2}$ in.

Export: 4.39 meters

Conveyor width:

Primary conveyor: 67 in. $(170.2 \mathrm{~cm})$

Secondary conveyor: 48 in. $(121.9 \mathrm{~cm})$

Conveyor speed: approx. $600 \mathrm{ft} . / \mathrm{min} .(183 \mathrm{~m} / \mathrm{min}$.)

\section{Options}

Caterpillar ${ }^{\circledR}$ Model 3412, $990 \mathrm{hp}$ engine

Radio remote control

Auxiliary air compressor

Magnetic head pulley

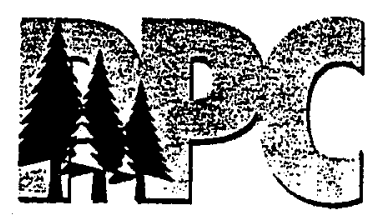

Peterson Pacific Corp.

Leading the way... with waste recycling
Find out more about the entire Peterson Pacific Corp. product line at: 
The HC 7400

Portable Heary

Duty Waste

Recycler is the

solution for

high-capacity

grinding

applications!

The Peterson Pacific HC 7400 Recycler handles the toughest waste problems with ease.

The HC 7400 features: $\checkmark$ Improved design heary duty hammer mill requires less horsepower and yields longer bit life $\checkmark$ Safest portable grinder in the world! $\checkmark$ Continuous horizontal chain feed conveyor $\checkmark$ Convenient feed height $\boldsymbol{V}$ Single shear pin breakaway anvil $\sim$ Easy access to rotor and grates $\checkmark$ Wide variety of grate sizes and configurations available $\boldsymbol{\sim}$ Variable feed speed $\boldsymbol{\sim}$ Load sensitive feed control $\boldsymbol{V}$ Low operating cost

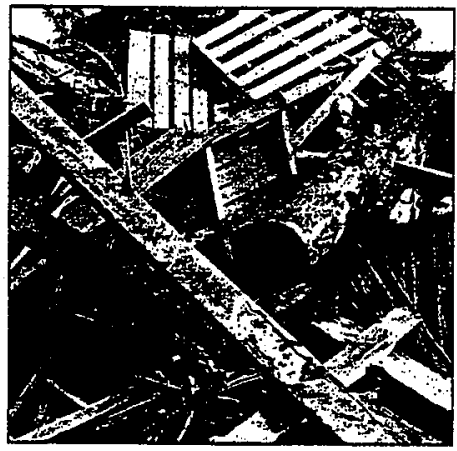

The HC 7400 easily handles demolition debris, pallees, green waste, building debris, even logs.

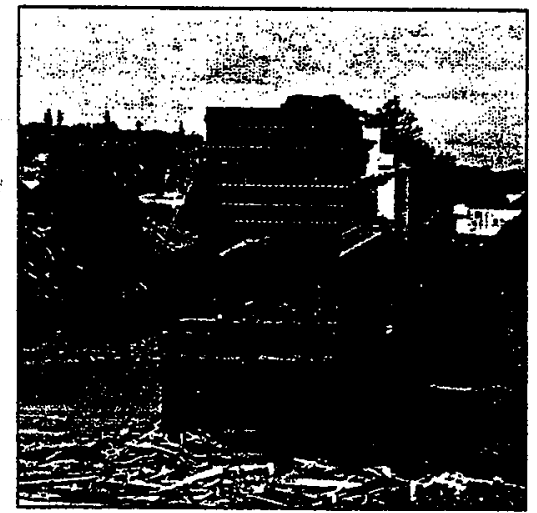

The heavy duty hammer mill is continuously fed by a chain conveyor.
We are confident that the $\mathrm{HC} 7400$ will outperform every machine in its horsepower. class. Perhaps there should be a new class? The HC 7400 Portable Heavy Duty Waste Recycler is able to transform recycling problems into solutions!

When you want the best, there's really only one choice...

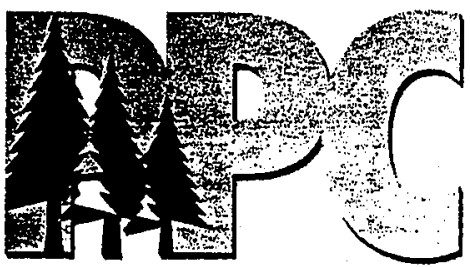

